\title{
Handlungsfelder von Internet Governance
}

\subsection{Internet Governance als Handeln}

Aus sozialwissenschaftlicher Sicht lässt sich Internet Governance allgemein als strategisches, formelles oder informelles Handeln zur Erreichung bestimmter Ziele übersetzen. Theoretisch lassen sich diverse Handlungstypen und strukturelle Kontexte dafür unterscheiden. Denn Handeln generiert neue soziale Situationen, reagiert auf Defizite und Probleme, verstetigt und routinisiert ständige, alltägliche Anforderungen, erweckt Erwartungen, konstituiert Deutungen, kann aber auch weitere Probleme schaffen und soziale Situationen evozieren oder auch eskalieren (Schimank 2000). Die dabei verfolgten Ziele können erklärter oder versteckter Art sein; sie können sich aus der kodifizierten Organisationsfunktion, aus anfallenden, konkreten Interessensdefinitionen der Organisationsmitglieder selbst oder Gruppen/Fraktionen von ihnen ergeben oder sich instrumentell und latent durchsetzen, indem die Organisation als Faktor oder Katalysator verwendet wird.

Wiederum können sich Handlungen und Ziele auf das Internet als Ganzes oder auf relevante, für die jeweiligen Interessen wichtige Segmente richten. Handlungen unter dem Rubrum Internet Governance sind nicht unbedingt materieller Form, vielmehr eher sozialer und kommunikativ-symbolischer Qualität, wie es dem Gegenstand entspricht. Selbstverständlich lassen sich unter den Handlungsfeldern solche, die eher technischer Art - wie etwa die Domainvergabe -, eher rechtlicher Natur - wie Datenschutz und Urheberrecht -, eher sozialer - wie digital divide - oder eher wirtschaftlicher Fasson - wie E-Commerce sind, identifizieren Aber bei jedem dieser Handlungsfelder bewirkt die universelle Funktionalität des Internets, dass ihre Bearbeitung und Steuerung jeweils in andere der angestammten Handlungssegmente hineinreichen, so dass Abgrenzungen und Zuordnungen schwerfallen oder unangemessen sind. Daher 
empfiehlt es sich, die relevanten Handlungsfelder jeweils als Ganzes und interdisziplinär zu erarbeiten und darzustellen, wiewohl dabei immer wieder Kompetenzgrenzen der Autoren tangiert werden.

Quer zu den konkreten thematischen Handlungsfeldern lassen sich funktionale und zielgerichtete Dimensionen ansetzen, wie sie schon zu Beginn des 5. Kapitels angesprochen worden sind. Denken ließe sich zunächst wiederum im technischen Sinne an die Optimierung und Weiterentwicklung des Internets als globale Kommunikationsinfrastruktur, wie auch teilweise das Thema der Netzneutralität verstanden wird. Unter dem Postulat „Information und Kommunikation für alle“, wozu sich UNO und UNESO verpflichtet sehen, müssen die Voraussetzungen für die optimale Implementation und Nutzung des Internets geklärt und verbessert werden. Diese sind vorderhand technischer Art - freilich im Hinblick auf die gesamte kommunikative Infrastruktur, angefangen von Elektrizität und Netzdichte bzw. -verteilung -, sodann entscheiden finanzielle Ressourcen über den Grad und den Komfort der Internetversorgung, wobei hier auch indirekte Finanzierungen über Werbung, Subventionen und Sponsoring beträchtliche Anteile haben, und endlich kommt es auf persönliche Kompetenzen des einzelnen Users und/oder der Usergruppen an. Hiermit beschäftigen sich mittlerweile weit verbreitete Maßnahmen der so genannten Internet oder Digital Literacy für alle pädagogischen Bereiche - vom Kindergarten über die Schule bis hin zur Erwachsenen- und beruflichen Bildung (Deutscher Bundestag 2011a). Schließlich lassen sich Folgen und (mögliche) Wirkungen der Internetinhalte und -nutzung beurteilen und steuern. Manche Wirkungen gilt es unter bestimmten normativen Prämissen zu verhindern; dazu zählen zum einen etwa Täuschung, Irreführung und Betrug bei geschäftlichen, kommerziellen Aktionen, Kontrollverlust über persönliche Daten beim Datenschutz, der Verlust geistiger Eigentumsrechte und die Gefährdung von Kindern und Jugendlichen durch ungeeignete Inhalte. Oder es werden zum anderen die Folgen geahndet und bestraft, wie sie bei Straftaten oder Verstößen gegen den Daten- und Jugendschutz anfallen. Solche Ahndungen können von Gesetzen und Abkommen formalrechtlich fixiert sein, oder sie ergeben sich aus wechselseitigen Vereinbarungen und freiwilligen Selbstverpflichtungen der Akteure und Beteiligten.

Sicherlich sind Relevanz und Regelungsbedarf der verschiedenen Handlungsfelder von einer Vielzahl interner wie externer Faktoren abhängig, die jeweils im Einzelnen spezifiziert und gewichtet werden müssen. Ohne Frage ändern sie sich auch immer wieder; je schneller und gründlicher die Entwicklung voranschreitet, umso häufiger und nachhaltiger. Neue Konstellationen können auftreten und andere Steuerungs- und Regelungsnotwendigkeiten hervorrufen. Daher kann es sich bei der Darstellung dieser Handlungsfelder jeweils nur um mehr oder weniger anhaltende Momentaufnahmen handeln, wobei einige Aufgaben und Maßnahmen 
mit dem Internet fast systembedingt verknüpft sind (wie etwa Domainvergabe und Netzneutralität), andere sich unter den jeweiligen rechtlichen und politischen Konditionen unterschiedlich konstituieren (wie etwa Datenschutz, Urheberrecht, Zensur, Jugendmedienschutz) und es auch welche gibt, die stellvertretend für die auf der Welt bestehende System- und Regimekonkurrenz ausgetragen werden (wie Zensur, Überwachung, Internetkriminalität und -krieg). Solche Entwicklungen werden sicherlich angesichts der Allgegenwart und rasanten Weiterentwicklung des Internets andauern und womöglich eskalieren. Insofern ist Internet Governance keine befristete, aber auch keine zu spezialisierende und klar zuordenbare Aufgaben vieler Akteure.

Neben den bereits genannten, als „grundsätzlich“ eingestuften „drei Schichten der Internet Governance", nämlich die physische Infrastruktur, der Code und die Inhalte (Donges und Puppis 2010, 93ff.), die für die gesamte Steuerungs- und Regelungsaufgabe des Internets gewiss nicht erschöpfend sind, finden sich etliche andere Vorschläge oder auch nur pragmatische Ansätze. Die Enquete-Kommission Internet und digitale Gesellschaft des Deutschen Bundestags (2011) hat anfangs sechs, an die üblichen Ressorts angelehnten „Betätigungsfelder“ aufgeführt, die aus der Sicht der Verantwortung des Parlaments zu bearbeiten seien, nämlich „Kultur und Medien“, „Wirtschaft und Umwelt“, „Bildung und Forschung“, „Verbraucherschutz“, „Recht und Innen“ sowie "Gesellschaft und Demokratie“. Daraus bildeten die Mitglieder der Enquete-Kommission in ihrer ersten regulären Sitzung am 17. Mai 2010 zwölf Projektgruppen, von denen allerdings nur vier unverzüglich die Arbeit aufnahmen und auch ein Jahr später Zwischenberichte vorlegte: Diese sind:

- Netzneutralität

- Datenschutz, Persönlichkeitsrechte

- Urheberrecht

- Medienkompetenz (Ebd., 3).

Die anderen Themen, nämlich „Bildung und Forschung“, „Demokratie und Staat“, „Internationales und Internet Governance“, „Interoperabilität, Standards, Freie Software“, „Kultur, Medien, Öffentlichkeit“, „Verbraucherschutz“, „Wirtschaft, Arbeit, Green IT“ sowie „Zugang, Struktur und Sicherheit im Netz“ wurden später angepackt und sind auch mit mehr oder weniger vollständigen Berichten bearbeitet worden (http://www.bundestag.de/internetenquete/). Ohne Frage sind in diesen Dokumenten fast alle Aspekte und Dimensionen des Internets und der Internet Governance repräsentiert.

Bei einer qualitativen Befragung von so genannten, "prominenten“ NetzAktivisten (Wendelin und Löblich 2013, 63) im Jahr 2010 stellten sich folgende Handlungsfelder als besonders dringlich und politisch relevant heraus: 
(1) „Privatsphäre und Datenschutz“ - vorrangig die Verteidigung und Bewahrung von Bürgerrechten im Internet, und zwar primär gegen Polizeibehörden und andere staatliche Vertreter gerichtet;

(2) "freier Zugang zu Informationen" - vor allem die Erkämpfung freier Kommunikations- und Informationsflüsse ohne jegliche Einschränkung durch staatliche Maßnahmen; Protest richtet sich insbesondere gegen Gesetzesinitiativen, die das Sperren von Webseiten vorsehen;

(3) "offene Standards und freie Software" - also die Ablehnung von antiquiertem Urheberrecht und unzeitgemäßen Abkommen (ACTA), die dessen Status quo sichern wollen, sowie der Verfolgung und Bestrafung von Software-Piraterie; hingegen das Eintreten für Creative-Commons-Lizenzen und freie Software;

(4) "Gleichberechtigung von Frauen“ im und über das Netz sowie außerhalb des Netzes - d. h. das Eintreten für weibliche Perspektiven auf die Internetpolitik sowie - allgemein - für den Schutz der Privatsphäre und für den freien Zugang zu Informationen (Ebd., 67f.).

Offensichtlich sind die meisten Ziele und Handlungsrichtungen noch eher der ,klassischen' Netzpolitik geschuldet und noch nicht auf der Höhe der Zeit. Erneut zeigt es sich, wie rasch sich Themen und Handlungsbedarfe im Internet ändern, verfallen oder neu aufkommen, aber auch wie sich gewisse Konstanten des politischen und sozialen Handelns durchziehen, weil sie großenteils nicht nur internetspezifisch sind, sondern für alle Verteilungsprobleme der Gesellschaft gleichermaßen relevant sind. Diese Einschränkungen und Bedingtheiten gelten selbstverständlich für die nun darzustellenden Handlungsfelder.

\subsection{Konzepte und Maßnahmen für Netzneutralität}

Seit Mitte der 1990er Jahre in den USA, in Europa etwa seit der Jahrtausendwende zirkuliert in den Fachdiskussionen der zunächst kaum evidente Begriff der Netzneutralität und hat inzwischen vielfältige Bedeutungen erfahren. Für die einen - um einmal die Extreme zu ermessen - handelt es sich um eine bare Selbstverständlichkeit, allenfalls um einen technischen Parameter; für die anderen um eine normative Größe, mittlerweile sogar um eine prinzipielle Kampfparole, mit der um die weltweite Freiheit des Internets gerungen wird. Mit dem seither gewachsenen wirtschaftlichen Potential des Internets rücken vor allem ökonomische Interessen in den Vordergrund. Dadurch sind die Regelungsstrategien auf den verschiedenen politischen Ebenen - von den UN über die EU bis hin zu 
den Nationalstaaten oder gar bis zu einzelnen Konzernen, Netzbetreibern und Providern -, die sich allesamt unter der pauschalen Überschrift der Internet Governance rubrizieren lassen, sehr unterschiedlich, wenig transparent und kaum vergleichbar (Libertus und Wiesner 2011).

\subsubsection{Netzneutralität als technische Herausforderung}

Seit das Internet mit dem World Wide Web (Gillies und Cailliau 2002) in wenigen Jahren (ab den 1990er Jahren, seit 2003 als Web 2.0) zum globalen Werbe- und Alltagsmedium mutiert ist und ebenso immer mehr Nutzer anzieht - wie die folgende Grafik illustriert - (Abb.6.1), gerieten die verfügbaren Speicher- und Übertragungskapazitäten immer wieder auf den Prüfstand. Dies geschah und geschieht umso mehr, als die inzwischen verbreiteten Daten durch Visualisierung, gar Multimedialisierung und Dynamisierung - etwa durch Übertragung von Videofilmen bei YouTube, bei Video on Demand oder vernetztes Fernsehen zumal in HD- oder gar 3D-Qualität - ständig umfänglicher und komplexer werden, so dass sie die Netze überlasten, gar blockieren

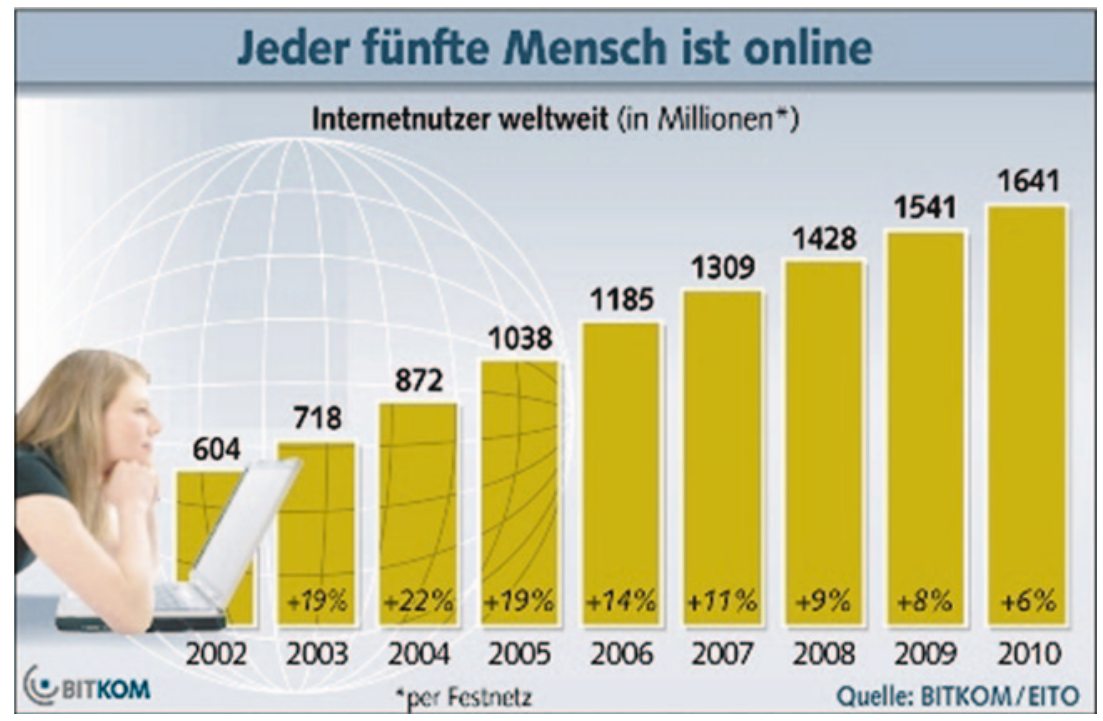

Abb.6.1 @ Internetnutzer weltweit http://www.bitkom.org/files/images/BITKOM_INTE RNETNUTZER_Dload.jpg 
und Daten nicht mehr effizient übertragen werden können. Aus solch technischer Sicht heißt mithin Netzneutralität: Das Internet muss ständig so viel Speicher- und Übertragungskapazität bereithalten, dass alle Daten, unabhängig wie umfangreich sie sind, in welchen medialen Modi sie konfiguriert und in welche Pakete sie gepackt sind, gleich schnell, gut und effizient gespeichert und übertragen werden. Damit soll - in der Konsequenz - jedem Internet-Nutzer die gleichen Zugangs- und Übertragsmöglichkeiten zur Verfügung gestellt werden. Diese Anforderungen sollen ebenso für die anhaltende Verbreitung des Netzes sowie für die besagten neuen, umfangreicheren Angebotsmodalitäten gelten, so dass unaufhörlich Grenzen der Netzkapazität erreicht und überwunden werden müssen.

Trotz des üblichen Sprachgebrauchs gilt zu bedenken, dass das Internet kein einheitliches Netz ist, sondern ein Netzwerk von einer Vielzahl untereinander verbundener Netze. In ihnen erfolgt die Übermittlung von Daten entweder in der direkten Übergabe zwischen Netzen (Peering) oder durch den Transport über Drittnetze (Transit). Dabei nehmen Datenpakete jeweils ihre eigenen Wege, die von Routern in den einzelnen Netzen je nach Auslastung bestimmt werden. So reagiert ,das' Internet auf entstehende Engpässe und nutzt für den Datentransport die jeweils effizienten Routen. Diese dezentrale Struktur des Internets lässt keine zentrale Planung für die Weiterentwicklung der Netzstruktur zur Bewältigung von Datenmengen zu; vielmehr muss der Ausbau jeweils bei den Netzkomponenten - etwa Kabel, Router oder Übergabepunkte - erfolgen, die an bestimmte Beanspruchungsgrenzen stoßen. Auftretende Ausfälle von Netzelementen sind nicht planbar, plötzliche Störungen können immer wieder auftreten.

Allenfalls grob lässt sich das Wachstum von Datenmengen antizipieren; allerdings verändern sich Spitzenbelastungen durch die expandierende Indienstnahme der Netzwerke in weiteren Ländern rund um den Globus, durch steigende Nutzerzahlen sowie durch zunehmende Datenkomplexe. Der Visual Networking Index von Cisco geht von einer jährlichen Wachstumsrate des globalen IP-Verkehrs von 34 Prozent aus. Für die Mobilnetze wird sogar eine Steigerung von 108 Prozent angenommen (Deutscher Bundestag 2012,6) (Tab. 6.1).

Andere Prognosen erwarten sogar eine Verdoppelung des Datenverkehrs alle eineinhalb Jahre, wobei insbesondere der mobile Datenverkehr wächst und zusätzliche Kapazitäten verlangt. Gemessen werden die Netzqualität (Quality of Service) und die Erfordernisse an das Netzwerkmanagement sowohl aus der Sicht der User als auch - von ingenieurstechnischer Warte aus - für alle Verkehrssteuerungsmaßnahmen, welche die Qualität der Datenübertragung für die Endnutzer verbessern sollen. Dafür existieren folgende Parameter: 
Tab. 6.1 Prognose zum Datenvolumen des Internet-Traffics von 2011 bis 2016 nach Segment (in Petabytes je Monat)

\begin{tabular}{lccc}
\hline & File-sharing & Web/E-mail & Internet-gaming \\
\hline 2011 & 5.967 & 3.909 & 67 \\
\hline $2012^{*}$ & 7.337 & 5.497 & 91 \\
\hline $2013^{*}$ & 9.093 & 7.512 & 123 \\
\hline $2014^{*}$ & 11.524 & 10.272 & 164 \\
\hline $2015^{*}$ & 14.658 & 13.716 & 235 \\
\hline $2016^{*}$ & 18.698 & 18.233 & 440 \\
\hline
\end{tabular}

Datenvolumen in Petabytes je Monat

Weltweit; Cisco Systems; 2011 und 2012 (Quelle Cisco Systems)

(c) Statista 2012

- „Latenzzeit: die Verzögerung der Ende-zu-Ende-Übertragung,

- Jitter: die Abweichung der Latenzzeit von ihrem Mittelwert,

- Paketverluste: die Wahrscheinlichkeit, dass einzelne IP-Pakete bei der Übertragung verloren gehen (oder - bei Echtzeitdiensten - ihr Ziel zu spät erreichen),

- Durchsatz: die pro Zeiteinheit im Mittel übertragene Datenmenge,

- Bandbreite: die Datentransportgeschwindigkeit innerhalb des Teilstücks einer Verbindung.

Quality of Service kann [mithin] als ,[...] Zusicherung von Grenzwerten [... $]^{c}$ dieser fünf Eigenschaften [...] für eine komplexe Verbindung zwischen zwei Endpunkten [...] definiert werden" (Deutscher Bundestag 2012, 5).

Um diese Ziele zu erreichen, muss einerseits eine bestimmte Bandbreite zur Verfügung stehen und dürfen andererseits potentielle Engpässe nicht zu Zeitverzögerungen beim Transport führen. Diese haben allerdings für die verschiedenen Datenpakete bzw. die Anwendungen und Dienste unterschiedlich starke Auswirkungen. So bedeuten sie für Internet-Sprachtelefonie (Voice-over-IP [VoIP]), für Online-Spiele und Video-Übertragungen erhebliche Qualitätseinbußen, während Streaming-Dienste bereits heute so viel Pufferpotentiale haben, um Unterbrechungen oder Verzögerungen im Datenfluss zu kompensieren. Bei einer E-Mail bleiben sie sogar unbemerkt. Deshalb sind vielfach Forderungen laut geworden, den Datenverkehr zu differenzieren und Datenpakete unterschiedlich zu behandeln - insoweit als bestimmte, auch unterschiedliche zu bezahlende Datenpakete bevorrechtigt (priorisiert) sind bzw. für ihre Transportqualitäten und -termine zu bezahlende Garantien gewährt werden. 
Solche Forderungen widersprechen selbstverständlich dem allgemeinen Gebot der Netzneutralität, und ihre Realisierung ist auch nur dann erforderlich, wenn tatsächlich Kapazitätsengpässe bzw. -ausfälle auftreten und der weitere Ausbau der Netzwerke weltweit wie auch regional und lokal nicht vorankommt. Allerdings gilt es ebenso zu berücksichtigen, dass die Leistungsfähigkeit und Effizienz der Netze durch technische Innovationen und durch Kostensenkung fortwährend ansteigen. Mit der expandierenden Verbreitung von über Glasfaser übertragbarer Bandbreite und deren zusätzlicher Kapazitätserhöhung durch optimierte Steuerung und höhere Datenkompression steigen sowohl die Leistungsfähigkeit der Netzwerktechnik, wie mit ihr eine laufende Kostendegression beim Aufbau, Betrieb und auch bei der Aufrüstung der Kapazität einhergeht, die die erforderlichen Investitionen mindern. Auch die Art der Datendistribution dürfte sich künftig fortlaufend verändern, so dass voraussichtlich nur einige Netzbereiche erhöhte Datenmengen zu bewältigen haben werden. Aus technischer Sicht lassen sich unterscheiden:

- der unmittelbare Zugang der User zum Internet (Access- und Anschlussnetz),

- die Zusammenführung der Verkehre verschiedener Nutzer im Access-Netz,

- und das eigentliche Rückgrat des Internets (Backbone-Netz), über das die Daten zwischen Absender und Empfänger in verschiedenen Netzen geleitet werden (vgl. Deutscher Bundestag 2012, 7).

Da das Internet ein so genanntes „Pull-Medium“ ist, kommen potentielle Engpasssituationen nur durch bestimmte Nachfragesituationen, also bei einem zeitgleichen massenhaften Zugriff auf bestimmte Inhalte - etwa bei LiveÜbertragungen von Bewegtbildern -, zustande. Daher könnten sich die größten Engpässe im Zugang der Endkunden zu den Netzen ergeben: im Festnetz infolge der Flatrate-Abrechnungsmodelle, die keine Anreize mehr zu einer effizienten, zeitbezogenen Nachfrage nahelegen, und vor allem im Mobilfunkbereich durch die noch enorm zunehmenden internetfähigen mobilen Endgeräte und den voraussichtlich starken Anstieg der Anwendungsoptionen. Hier könnte es zur Rivalität verschiedener Nutzer bei simultaner Nutzung kommen (Ebd., 9).

Daher kommen auf die einzelnen Länder und Netzbetreiber erhebliche Investitionskosten in den nächsten Jahren zu, um den Aufbau von Breitbandund Hochgeschwindigkeitsnetzen in Glasfaser und für die Kapazitätserweiterung von derzeit $100 \mathrm{MBit} / \mathrm{s}$ bei den Heimanschlüssen auf $400 \mathrm{GBit} / \mathrm{s}$ pro Kanal oder gar mehr zu bewerkstelligen. Solche Erweiterungen sind sowohl für mobile Netznutzungen zumal bei zunehmend individualisierten Diensten wie Social Media, für Technologiemixe von Mobilfunk, TV-Kabel und Festnetz sowie für künftige Clouding-Dienste erforderlich. In Deutschland lassen sich Versorgungsgrad dem 
Breitbandatlas der Bundesregierung (www.zukunft-breitband.de) entnehmen: 2011 waren, so das Bundesministerium für Wirtschaft und Technologie, 51 Prozent der Haushalte mit Anschlüssen von $50 \mathrm{MBit} / \mathrm{s}$ versorgt. Bis 2014 soll der Anteil auf 75 Prozent und bis 2018 auf 100 Prozent ansteigen, so das Ziel der Bundesregierung (www.heise/newsticker vom 12. September 2012). Wer dafür die anhaltenden Kosten trägt, ist nicht nur hierzulande umstritten. Für die EU schätzt man die Kosten auf 200 bis 300 Milliarden $€$. Bis 2013 will die EU für alle Bürger eine Basisversorgung mit schnellen Internet-Zugängen sicherstellen, bis 2020 soll auch die Qualität der Versorgung verbessert werden.

Konkret richten sich Ansprüche zur Kostenbeteiligung der Netzbetreiber an die großen Inhalteanbieter wie Google, YouTube, Facebook sowie an Onlineverkäufer wie E-Bay und Amazon, deren Verbreitung- und Datenvolumina ständig wachsen. Kommen zusätzliche Optionen wie das Cloud Computing - bei dem Hardwareund Softwarefunktionen ganz oder teilweise auf Server von Diensteanbietern überall auf der Welt ausgelagert werden - sowie Internettelefonie mit Video (VoIP) hinzu, verstärken sich die Kapazitätsanforderungen weiter. Zudem streben zusätzliche Betreiber ins Netz, da mit ihm künftig bislang noch anderweitig vermittelte Dienste - wie intelligente Stromzähler, vernetzte Haushaltsgeräte, Alarmanlagen und Gesundheitsdienste mit individualisierter Echtzeitmessung - abgewickelt werden sollen. Dafür sucht man nach neuen, speziellen Bezahlmodellen, die bislang noch nicht hinreichend entwickelt und kalkuliert sind. Sie werden unausweichlich weitere Dimensionen von Netzneutralität zeitigen, hieß es auf dem Jahreskongress der Deutschen Breitbandinitiative 2012 (Ebd.).

Technisch möglich werden solche Geschäftsmodelle, seit die Daten und ihre Pakete im Internet nicht mehr unterschiedslos akzeptiert werden müssen, sondern mit der so genannten Deep Packet Inspection (auch Complete Packet Inspection oder Information eXtraction [IX] genannt) überwacht und gefiltert sowie ihre Quellen und Inhalte in Echtzeit identifiziert werden können. Dabei werden gleichzeitig der Datenteil und der Headerteil der Datenpakete auf bestimmte Merkmale wie Protokollverletzungen, Computerviren, Spam und weitere unerwünschte Inhalte untersucht. Auch lassen sich damit Datenströme regulieren. Allgemeines Ziel ist es, Daten nach Inhalten zu priorisieren, umzuleiten, zu verlangsamen oder gänzlich zu blockieren. Mit Deep Packet Inspection sind mithin datenschutzrechtliche Vorbehalte berührt.

Seit das Internet mehr und mehr ökonomisch-kommerzielle Dimensionen annimmt und vielfältig genutzte Komponenten für Geschäftspraktiken vorhält, sind mit diesen technischen Aspekten unweigerlich wirtschaftliche Kalküle verbunden: Ob unzählige Dienste (Apps), Datenbanken und Plattformen, Online-Medien und -Werbung, Unternehmenskommunikation, Vertriebswege für Videos und andere audiovisuelle Dokumente, E-Mail- und Twitterkontakte, Nachrichtendissemination, 
Konsum-Interaktionen und anderes mehr - für alle erweist sich das Internet als unentbehrliches Verbindungs- und Vermittlungsmedium, das unweigerlich (wie alle anderen Transfermittel) seinen Preis hat und nicht mehr unentgeltlich bereitgestellt werden soll. Für die Netzbetreiber müssen sich Investitionen in den Netzausbau und Preise für die Dienste bei möglichst optimaler Ausnutzung der jeweils vorhandenen Infrastruktur betriebswirtschaftlich rechnen.

Solche Konzepte und Maßnahmen werden unter den Begriff des Netzwerkmanagement gefasst. Darunter wird ,jede Form der Ungleichbehandlung von Datenpaketen in Netzen auf Internet Protocoll (IP)-Basis“ verstanden, „unabhängig von ihrem Zweck und den dafür eingesetzten Techniken und Kriterien. Grundsätzlich ermöglichen Netzwerkmanagementtechniken den Netzbetreibern, den Datentransport je nach Verkehrslage und ökonomischem Bedürfnis zu steuern" - so die Definition der Enquete-Kommission Internet und digitale Gesellschaft des Deutschen Bundestages (2012, 12). Netzwerkmanagement betrifft vor allem Fragen des Leistungsmanagements, um die so genannte Quality of Service (QoS) zu verbessern. Es werde heute schon „innerhalb der das Internet in seiner Gesamtheit bildenden Einzelnetze“ betrieben, künftig soll mit ihm auch „über die Netzgrenzen hinweg eine differenzierte Behandlung von Datenpaketen“ üblich werden. Dafür sind technische Investitionen, aber auch normative Regelungen mindestens größtmögliche Transparenz - nötig (Ebd., 12). Kritische Verbraucher halten Netzwerkmanagement großenteils für fragwürdig und wollen es allenfalls bei maximaler Transparenz des Eingriffs im Falle einer temporären, nicht selbst verursachten Überlastung des Netzwerks zulassen. Diese Transparenz müsste sich ergeben, wenn eindeutig geklärt ist, welche Leistungsparameter bei der Buchung eines Internetanschlusses zu erwarten und welche Nutzungseinschränkungen mit dem jeweiligen Vertrag verbunden sind: etwa Bandbreitendrosselungen oder fehlende Berechtigung zum so genannten Tethering, das ist die Verbindung eines Smartphones mit einem PC oder Personal Digital Assistent (PDA).

\subsubsection{Netzneutralität unter normativ-publizistischen Prämissen}

Mit dem Internet und seiner rasanten Verbreitung verbanden sich euphorische Erwartungen auf freie Kommunikation von jedem/r, auf uneingeschränkte Meinungs- und Informationsfreiheit und auf unbegrenzten Zugang für alle zu sämtlichen Inhalten und auf weltweite Kommunikation. Ein neues Zeitalter von direkter Demokratie und freier Rede auf dem Markplatz (wie auf der athenischen Agora), nunmehr im Netz, sah 1994 etwa der damalige US-Vizepräsident Al Gore 
heraufziehen; andere schwärmten von der virtuellen Gemeinschaft der User, und bis heute begeistern sich viele engagagierte Netizens (Net + Citizens) an solchen Visionen, verteidigen sie gegen jegliche politische, juristische und/oder ökonomische Indienstnahme. Dies wird auch als „inhaltliche Netzneutralität“ bezeichnet (Deutscher Bundestag 2012, 31):

„Das neutrale Netz gewährleistet, dass zum einen jeder Inhaltsanbieter die Option hat, eine eigene Dienste-Plattform aufbauen und betreiben zu können, um seine Inhalte in geeigneter und selbstbestimmter Form zu publizieren, und zum anderen jeder interessierte Internetnutzer auf die Inhalte zugreifen und sie nutzen kann" (Ebd.).

Dass die Beteiligten am Netz ganz unterschiedliche Voraussetzungen mitbringen und ebenso divergierende Potentiale für seine Nutzung haben - an einem Extrem milliardenschwere, multinationale Medien- und Informationskonzerne, die ihre Inhalte durch viele Kanäle schicken, mehrfach verwerten und via Werbung und Entgelte multiple Geschäftsmodelle praktizieren, am anderen Extrem der individuelle, private Nutzer, der telefonieren, mailen, recherchieren und kommunizieren will -, interessierte die pauschale Verfechtung allgemeiner Netzneutralität anfangs kaum und mutet aber als politisch naiv an. Denn mächtige, finanzstarke Anbieter haben längst integrierte Plattformen wie die sozialen Netze entwickelt - Prototyp: Facebook -, die sämtliche Funktionen und Dienste anbieten, so dass durchschnittliche User kaum mehr wechseln. Außerdem sind die Chancen im Netz, aufgefunden zu werden, unterschiedlich verteilt. Hier kommen die Suchmaschinen - allen voran der Marktführer Google - ins Spiel; mit ihren Suchalgorithmen entscheiden sie über die Platzierung der Treffer und steuern damit die Aufmerksamkeit der Nutzer. Denn Inhalte, die nicht gefunden werden, sind praktisch nicht existent, in jedem Fall diskriminiert.

Im Einzelnen lassen sich exemplarisch folgende Konzepte und Maßnahmen identifizieren:

In den USA wurde erstmals über Netzneutralität verhandelt anlässlich der Novellierung des US-amerikanischen Telecommunications Act von 1996, was allerdings an der Blockade im Kongress scheiterte (Libertus und Wiesner 2011, 81). 2005 veröffentlichte die US-Regulierungsbehörde für Telekommunikation (Federal Communications Commission, [FCC]) ein so genanntes Internet Policy Statement, indem vier Prinzipien für Netzneutralität formuliert sind. Sie sind zu Leitlinien für viele Diskussionen und Bestrebungen geworden. Danach sollen die Endnutzer berechtigt sein bzw. erwarten können,

- „nach ihrer Wahl Zugang zu legalen Inhalten zu erhalten;

- alle Dienste und Applikationen ihrer Wahl zu nutzen (unter Berücksichtigung der Erfordernisse der Strafverfolgung); 
- alle legalen Endgeräte ihrer Wahl an das Netz anschließen und nutzen zu können, soweit nicht das Netzwerk geschädigt wird;

- Netze-, Dienste-, Service- und Internetanbieter in einem Wettbewerbsverhältnis vorzufinden“"(Ebd.).

Im Oktober 2009 eröffnete die FCC ein neues Verfahren (Notice of Public Rulemaking), um den bestehenden FCC-Regeln zur Sicherung der Netzneutralität zwei weitere hinzuzufügen, nämlich

- ein Verbot der Diskriminierung von Verkehrsströmen und bestimmten Internetdiensten bzw. -anwendungen sowie

- die Transparenz des Netzmanagements zu erreichen (Ebd.).

Allerdings wurden drei Ausnahmen von dem Diskriminierungsverbot eingeräumt, nämlich

- bei Überlastung des Netzes soll es das Recht geben, den Netznutzer daran zu hindern, seine Interessen zu Lasten anderer Nutzer durchzusetzen;

- für den weiteren Netzausbau kann es von Vorteil sein, wenn die Betreiber ihre Netze nach Quality-of-Service-Aspekten betreiben;

- das Transparenzgebot soll Breitbandanbieter verpflichten, ihre Netzwerkmanagementpraktiken zu veröffentlichen (Ebd.).

Außerdem sieht der American Recovery and Reinvestment Act für die Förderung des Breitbandes Mittel in Höhe von 7,2 Mrd. US-Dollar vor; dafür sollen sich die Unternehmen als Gegenleistung für die staatlichen Unterstützungen die Prinzipien der Netzneutralität zu Eigen machen. Zwar haben zwischenzeitlich gerichtliche Urteile, die auf Betreiben von Netzanbietern gefällt wurden, einzelne Maßnahmen der FCC abgeschafft, aber insgesamt werden besagte Prinzipien weitgehend anerkannt, wie auch neuerliche Vorstöße im Kongress zur Netzneutralität belegen. Sie sollen verhindern, dass Betreiber für besonders schnelle Internetverbindungen (Premium Services) Sonderzahlungen von Kunden verlangen dürfen.

Am 9. August 2010 haben Google und der größte Anbieter für Festnetz und Mobilfunk in den USA, Verizon, gemeinsam einen Vorschlag zur Netzneutralität vorgelegt, dessen Kernpunkte sind:

- „Diskriminierungsverbot: In drahtgebundenen Netzen sollen die Anbieter von Breitbandzugängen Inhalte oder Anwendungen ohne Unterscheidung hinsichtlich der verwendeten Protokolle, der Diensttypen oder nach Herkunft und Ziel durchleiten. 
- Transparenzgebot: Die Kunden sollen über ein ,vernünftiges Netzwerkmanagement', etwa zur Gewährleistung einer speziellen Servicequalität oder zur Verhinderung von Staus in den Netzen, detailliert informiert werden.

- Ausnahme: Die Regeln sollen mit Ausnahme der Transparenzverpflichtung nicht für mobiles Breitband gelten (d. h. die Technologieneutralität wird hier aufgegeben).

- Anbietern von Breitbandzugängen, die die oben genannten Kriterien erfüllen, soll es möglich sein, darüber hinaus ,zusätzliche Onlinedienste` anzubieten“ (Ebd., S. 82).

Diese Vorschläge wurden von Kritikern als "Verrat“ an den Prinzipien der Netzneutralität gebrandmarkt, da zumal der letzte Punkt schon den Plan eines künftigen Zweiklassen-Internets, nämlich die Trennung in eine Grundversorgung oder -bandbreite, die nach dem Best-Effort-Prinzip gestaltet wird, und in so genannte Managed Services wie Internet-TV je nach Marktlage und Preispolitik, erkennen lässt. Die ökonomischen Verwertungsinteressen mit beträchtlicher Marktmacht oder auch von regional beherrschenden Netzbetreibern werden voraussichtlich Techniken erfinden und Mittel aufbieten, um ihre verschiedenen Dienst- oder Inhaltsklassen zu priorisieren - sofern sie daran nicht durch gesetzliche Regelungen oder Vereinbarungen gehindert werden. Bereits heute setzen große Onlinegamesund Inhalteanbieter wie Facebook und Google bei der Übertragung von zeitkritischen audiovisuellen Datenströmen auf dezentral organisierte und an Endkunden gelegene Serverfamilien, die so genannten Content-Delivery-Networks (CDN). Sie sind allerdings sehr kostenintensiv und daher nur von solchen Mega-Playern zu finanzieren; andere haben das Nachsehen (Deutscher Bundestag 2012, 26).

Im Dezember 2010 verabschiedete die FCC ihr 194 Seiten umfassendes Rahmenwerk zur Netzneutralität. Es sieht unter anderem eine Verpflichtung für Netzbetreiber vor, die Verbreitung „rechtmäßiger“ Inhalte, Anwendungen und Dienste in ihren Leitungen sowie den Anschluss von Endgeräten nicht zu behindern. Eine „unangemessene Unterscheidung" zwischen Datenpaketen beim Transfer legitimen Netzverkehrs wird untersagt. Spezielle Breitband-Zusatzdienste etwa in den Bereichen E-Health oder Internet-TV sollen zunächst von der Regulierung ausgenommen und im Gegenzug genau beobachtet werden. Die Grundprinzipien gelten auch nur eingeschränkt für den Mobilfunk. Während die Neutralitätsregeln für das Festnetz strenger ausfielen, ließ die Behörde beim mobilen Internet die Zügel lockerer. So wird den Mobilfunk-Betreibern zwar untersagt, Online-Video-Services oder VoIP-Telefonie komplett zu sperren, unterschiedliche Geschwindigkeiten bei der Zustellung von Datenpaketen sind aber weiterhin erlaubt. Ausdrücklich dürfen aber Voice-Apps von Konkurrenten nicht blockiert werden. Die 
Regulierungsbehörde setzt zudem auf Transparenz: Sollten Zugangsanbieter Techniken fürs Netzwerkmanagement etwa zur Gewährleistung einer speziellen Servicequalität einsetzen, müssten sie ihre Kunden genau darüber in Kenntnis setzen. Gegen diese staatlichen Auflagen hatten die beiden Netzbetreiber Verizon und MetroPCS geklagt. Allerdings wies ein US-Berufungsgericht in Washington die Eingabe im April 2011 aus formalen Gründen zurück.

Anfang September 2011 unterzeichnete eine Leitungsbehörde im Weißen Haus, das Office of Management and Budget (OMB), die Prinzipien der Federal Communications Commission (FCC) zur Festschreibung der Netzneutralität. Das OMB ist unter anderem für die abschließende Prüfung von Gesetzen und Behördenanordnungen zuständig und erfüllt in diesem Zusammenhang ähnliche Aufgaben wie hierzulande das Bundespräsidialamt. Die formelle Ausfertigung der Regeln zur Sicherung des offenen Internets sowie ihre Veröffentlichung im USBundesregister (Federal Register) erfolgten am 25. Juli 2012 für die Dauer von drei Jahren (http://www.gpo.gov/fdsys/pkg/FR-2012-07-25/html/2012-18181.htm).

Wie in ihrem Konsultationsdokument vom Juni 2001 erneut bekräftigt wurde, setzt die Europäische Kommission bei ihrer Politik für Netzneutralität vor allem auf einen funktionierenden Wettbewerb zwischen den verschiedenen Angeboten am Markt und auf größtmögliche Transparenz der Anbieter. Allerdings wurden in dem 2009 überarbeiteten EU-Telekompaket von 2002 der Grundsatz der Netznetzneutralität nicht ausdrücklich verankert und nur begrenzte Regelungen im Telekommunikationsrecht - etwa der freie Umgang mit Internet-Informationen und die ungehinderte Nutzung von Anwendungen und Diensten - fixiert. Sie haben das Ziel, den Endkunden hinreichende Informationen bereitzustellen, damit sie Auswahlentscheidungen nach ihren Präferenzen möglichst fundiert und ungehindert treffen können. Vorrangig bleibt insgesamt, den Mechanismen des Marktes Geltung zu verschaffen und regulatorische Eingriffe nur dann vorzunehmen, wenn durch marktbeherrschende Stellungen der Qualitätswettbewerb gestört wird und das bestehende Telekommunikationsrecht sowie das allgemeine Wettbewerbsrecht ausgehöhlt werden. Um den Wettbewerb zu fördern und zu erhalten, sollen hinreichende Übertragungs- und Dienstqualitäten als technische Voraussetzungen vorgehalten werden. Solange sie gegeben sind bzw. immer wieder hergestellt werden, sind regulatorische Maßnahmen zur aktiven Sicherung von Netzneutralität oder gar Diskriminierungsverbote, wie es die FCC-Richtlinien vorsehen, aus Sicht der EU-Kommission nicht erforderlich.

Allerdings will die EU-Kommission die Entwicklung weiterhin verfolgen und holte 2010 dazu Vorschläge und Anregungen von insgesamt 318 Anbietern ein, wie künftig der offene und neutrale Charakter des Internets gewahrt und seine Weiterentwicklung gefördert werden kann. Mehrheitlich wurde dafür plädiert, 
erst einmal die Umsetzung der EU-Richtlinien in nationale Regelungen abzuwarten. Außerdem wurde einvernehmlich ein Traffic-Management gefordert, um den Netzbetrieb gesichert und effektiv zu gestalten. Software-Systeme für die Deep Package Inspection, mit der die Provider in einzelne Datenpakete Einblick nehmen und ihre Qualität analysieren können, wurden als problematisch eingestuft.

Seither hat die EU-Kommission die Diskussion über Netzneutralität in Europa etwa durch die Empfehlung zu Next Generation Access Networks fortgeführt und etwa die präzise Klärung der Begriffe Quality-of-Service oder Transparenz vorangetrieben. Auch einen Zusammenhang mit der europäischen Frequenzpolitik wurde postuliert: Mit ihr sollen die Mobilfunknetze - vor allem durch die Zuweisung von Frequenzen an den Mobilfunk - mehr Kapazitäten bekommen und damit den Bedarf für explizite Regulierungen mindern (Libertus und Wiesner 2011, 83f.).

Zusätzlich setzte die Kommission 2010 eine neue Instanz an, die zwischen den nationalen Regulierungsbehörden untereinander und mit der Europäischen Kommission Beratungen bereitstellen, Regelungen und deren Fortschritte koordinieren, Initiativen voranbringen und Positionen entwickeln soll: das Gremium Europäischer Regulierungsstellen für elektronische Kommunikation (GEREK, engl. BEREC). Die Behörde besteht aus Vertretern der 27 nationalen Regulierungsbehörden und ist bei der EU-Kommission angesiedelt, was einige wichtige Staaten bis zuletzt verhindern wollten. Vor allem Deutschland und Spanien wollten GEREK nur den Status eines „privaten Vereins“ zubilligen.

Im Juli 2012 schlug die EU-Kommission erneut einschlägige Empfehlungen zur Netzneutralität vor, die im kommenden Jahr zum Abschluss einer mehrjährigen Sondierungsphase vorliegen sollen. Mit weiteren Konsultationen will Brüssel dafür erneut Meinungen von Internetprovidern, Inhalte- und Diensteanbietern, Geräteherstellern, Investoren, Behörden, Verbrauchern und Verbänden einholen. Im Mittelpunkt sollen abermals Transparenz, Anbieterwechsel und Netzwerkmanagement stehen.

Auch auf nationaler Ebene, in den europäischen Ländern wurde und wird über Netzneutralität diskutiert und über Maßnahmen zu ihrer Sicherung nachgedacht. Mehrheitlich wird auf die Kräfte des Marktes vertraut, die mittels öffentlicher und privater Investitionen in den Netzausbau und die Kapazitätserweiterung unterstützt werden (sollen). In eher staatswirtschaftlich orientierten Ländern werden vielfach Leitlinien statuiert und an die Internet-Beteiligten appelliert, sich daran freiwillig $\mathrm{zu}$ halten. Allenfalls bei gravierender Verletzung werden Sanktionen angedroht (deren Realisierung angesichts des internationalen Operierens der mächtigen Provider und Informationskonzerne ohnehin schwierig ist). Konkrete Aktivitäten sind jeweils von der politischen Grundhaltung der Regierungen und Administrationen bestimmt. 
So kündigte etwa die britische Regulierungsbehörde Ofcom im März 2010 an, das Thema Netzneutralität einer regulatorischen Überprüfung unterziehen zu wollen. Im Juni legte sie ein Diskussionspapier zur Praxis des Internet Traffic Management vor, in dem sie Netzneutralität wie folgt definierte: „Net neutrality is a concept based on the internet being a level playing field for internet traffic. There are several definitions, but all share a concern that traffic management by network operators and ISPs could lead to discrimination between different traffic carried over the moment" (zit. nach Libertus und Wiesner 2011, 84). Entgegen solcher Vorgaben bekundete die neue konservative Regierung unter David Cameron Mitte November 2010, sie wolle ein „Internet der zwei Geschwindigkeiten“ durch Internet-ServiceProvider zulassen, falls Inhalteanbieter, darunter auch Rundfunkunternehmen, bereit sind, für eine schnelle und bessere Durchleitung zu zahlen.

Auch in Frankreich hat die dortige Regulierungsbehörde für elektronische Kommunikation und Post (Arcep) ein öffentliches Konsultationsverfahren zur Netzneutralität durchgeführt und zudem Fragen aufgeworfen, die weit über die sonst geführten Debatten hinausreichen: so etwa zu exklusiven Inhalteverträgen, exklusiven Verträgen zwischen Netzwerkanbietern und Endgeräteherstellen (wie beim iPhone), zu der dominierenden Rolle von Suchmaschinen oder zu Herausforderungen des hybriden Fernsehens als proprietäre Systeme etc. In den „zehn Geboten“ der Behörde zur Netzneutralität vom September 2010 werden sie allerdings kaum berücksichtigt und wiederum nur die Prinzipien der Transparenz und der Nichtdiskriminierung betont. Auch die zuvor vielfach apostrophierte Netzpiraterie bleibt unbeachtet. Insgesamt plädiert man auch in Frankreich für einen funktionierenden Wettbewerb als beste Voraussetzung für die Sicherung der Netzneutralität. Die Umsetzung der Regularien des revidierten EU-Telekompakets in nationale Regeln wird als ausreichend erachtet.

Als eines der wenigen Länder haben die Niederlande verbindliche, gesetzliche Regelungen zur Netzneutralität beschlossen. Am 9. Mai 2012 stimmte das Parlament dem Gesetz zur Sicherung der Netzneutralität zu. Es legt fest, dass Netzanbieter den Datenverkehr ihrer Nutzer nicht beeinflussen dürfen, es sei denn, das Netzmanagement erfolgt im Interesse des Nutzers.

In Deutschland kam die Debatte über Netzneutralität nur schleppend in Gang und blieb bis heute weitgehend ein Thema für Internet-Insider. Allenfalls Detailaspekte tauchten in politischen Debatten auf - etwa bei Beschwerden wegen der Sperrung von Skype in den Mobilfunknetzen oder wegen des langsamen Netzausbaus in ländlichen Gebieten. In die am 10. Mai 2012 in Kraft getretene Novelle des Telekommunikationsgesetzes (TKG) sind sie insoweit aufgenommen, als dass in die allgemeinen Zielsetzungen (TKG $₫ 2$ ) zum einen die Bundesnetzagentur die 
„Möglichkeit“ der Endnutzer fördern soll, „Informationen abzurufen und zu verbreiten oder Anwendungen und Dienste ihrer Wahl zu nutzen“. Zum andern sollen „die Sicherstellung eines chancengleichen Wettbewerbs und die Förderung nachhaltig wettbewerbsorientierter Märkte der Telekommunikation im Bereich der Telekommunikationsdienste und -netze sowie der zugehörigen Einrichtungen und Dienste, auch in der Fläche“ angestrebt und zudem "gewährleistet" werden, „dass es im Bereich der Telekommunikation, einschließlich der Bereitstellung von Inhalten, keine Wettbewerbsverzerrungen oder -beschränkungen gibt" (TKG $\$ 2$, Abs. 1 und 2). Das sind recht vage, unverbindliche Regelungen.

Der Terminus „Netzneutralität“ taucht nur als Überschrift - ohne weitere Definition - in dem zusätzlichen, wohl nachträglich eingefügten $\$ 41$ a auf. Darin wird die Bundesregierung „ermächtigt, in einer Rechtsverordnung mit Zustimmung des Bundestages und des Bundesrates gegenüber Unternehmen, die Telekommunikationsnetze betreiben, die grundsätzlichen Anforderungen an eine diskriminierungsfreie Datenübermittlung und den diskriminierungsfreien Zugang zu Inhalten und Anwendungen festzulegen, um eine willkürliche Verschlechterung in den Netzen zu verhindern" (TKG $₫ 41 \mathrm{a}$, Abs. 1). Ebenso kennzeichnen diese Formulierungen den niedrigsten Regulierungsbedarf, da sich schon aus technischer Sicht "grundsätzliche Anforderungen" kaum pauschal aufstellen und schon gar nicht messen lassen.

Auch die seit Mai 2010 arbeitende Enquetekommission Internet und digitale Gesellschaft des Deutschen Bundestages, die ihren knappen Abschlussbericht samt Empfehlungen verspätet im Januar 2013 vorlegte, konnte sich offensichtlich nicht zu einem Vorschlag gesetzlicher Regelungen durchringen. Im einschlägigen Zwischenbericht vom Februar 2012 (Deutscher Bundestag 2012) findet sich immerhin noch die allgemeine Zusicherung (Ebd. 33f.):

„Die mögliche gesetzgeberische Behandlung des Themenfeldes Netzneutralität muss absehbare technische Entwicklungen, den signifikant steigenden Bedarf an Bandbreite, die Sicherheit der Netze und die Erwartungen der Nutzer ebenso berücksichtigen wie notwendige Maßnahmen zum Erhalt von Meinungsfreiheit und Vielfalt. Um dabei die notwendige Innovationsoffenheit und ökonomische Spielräume gewährleisten zu können, ist die Festlegung allgemeiner Prinzipien empfehlenswert. Diese grundsätzlich technologieunabhängigen Prinzipien sollten sich beziehen auf:

- Transparenz,

- Diskriminierungsfreiheit,

- den freien Zugang zu Inhalten und Empfängern (Any-to-Any) im Rahmen gesetzlicher Grenzen, 
- die Förderung des Wettbewerbs auf Ebene der Netze, im Dienstemarkt und bei den Inhalteanbietern sowie dem damit verbundenen Schutz vor dem Ausnutzen einer marktbeherrschenden Stellung,

- die Gewährleistung und dynamische Fortentwicklung des Best Effort-Internets sowie die Sicherung von Mindeststandards,

- den Einsatz sachlich gerechtfertigter Netzwerkmanagementmaßnahmen,

- Möglichkeiten zur Einführung von Dienste- beziehungsweise Qualitätsklassen neben Best Effort,

- die Wahrung der Vielfalt von Inhalten und damit insbesondere verbunden auch von nicht kommerziellen Inhalten,

- Ausschluss der Inhaltekontrolle durch Netzbetreiber“ (Ebd., 33f.).

Zur praktischen, aber letztlich unverbindlichen Umsetzung schlägt die EnqueteKommission "Selbstverpflichtungen" der Netzbetreiber vor: Sie sollen zum einen gewährleisten, dass jeder Nutzer von Telekommunikationsdiensten im Rahmen der gesetzlichen Grenzen grundsätzlich Zugang zu jedem Inhalt und jeder Anwendung im Internet hat. Zugleich soll jeder Anbieter grundsätzlich jedem Empfänger Inhalte im Internet anbieten können, es sei denn, solche Angebote wünscht der Empfänger aufgrund individueller vertraglicher Abreden nicht. Zum anderen sollen ebenfalls in Selbstverpflichtungen Einsatz und Umfang von Verkehrs- und Netzmanagement wegen seiner besonderen Bedeutung für die Öffentlichkeit festgehalten werden. Solche Bekundungen sollen den prinzipiell chancengleichen Wettbewerb (dessen Kriterien und Grenzen freilich nicht definiert und effizient gemacht worden sind) flankieren (Ebd., 43).

Emphatisch wird am Ende betont, dass ein „freies und offenes Internet $[\ldots]$ von unschätzbarem, kulturellem, gesellschaftlichem, politischem und wirtschaftlichem Wert" ist; es sei Vorbedingung von Meinungsvielfalt, Pluralismus und demokratischer Öffentlichkeit einerseits, für dynamische Entwicklung, wirtschaftliche Prosperität und kreativ-kommunikative Entfaltung andererseits. Es müsse frei von Diskriminierungen, fair, transparent und bezahlbar für alle sein. Antrieb und Garantie dafür ist die Netzneutralität, für deren Sicherung es eines rechtlichen Rahmens auf nationaler und internationaler Ebene bedarf. Sein Fokus müsse die neutrale und bestmögliche Übertragung von Datenpaketen im Internet sein. Weiterer Ausbau sei nötig, damit jeglicher Anreiz für Access-Provider entfalle, eine Verknappung der Übertragungskapazitäten herbeizuführen (Ebd., 45). Bleibt zu hoffen, dass sich Gesetzgeber und Akteure finden, die über die schönen Worte hinaus Regelungen treffen und Maßnahmen realisieren, um sie Realität werden zu lassen. 


\subsection{Domain Names}

\subsubsection{Entwicklungen und Ziele}

Das Domain Name System (DNS) ist eine der Kernressourcen des Internets; es ist eine Datenbank, welche die kaum einprägsamen numerischen Internetadressen realen Namen (Domain Name, Domain Adresse) zuordnet, die sich leichter erinnern lassen. Das DNS leistet also in erster Linie Übersetzungsarbeit (Gernroth 2008). Es ist hierarchisch strukturiert, besteht aus einer unbenannten Wurzel (= root), von der sämtliche Operationen ausgehen, den Ästen (Top Level Domains, TLD) und Zweigen (Second Level Domains). Top Level Domains gliedern sich in Länderkennungen (z. B. .de) und generische TLD (wie .com, .edu., .gov, .net, org). Second-Level-Domains untergliedern die TLDs (z. B. uni-hamburg).

Vor der Gründung der Internet Corporation for Assigned Numbers and Names (ICANN) wurde das DNS von der unabhängigen Internet Assigned Numbers Authority (IANA) koordiniert, einer Selbstverwaltungsagentur, die von der US-Regierung finanziert und von Prof. Jan Postel von der University of South California geführt wurde. Diese eigentümliche, recht privat anmutende Konstruktion machte nur so lange Sinn, wie der Zugang zu Computern und die Nachfrage nach Domainnamen vergleichsweise gering blieben. IANA hatte in erster Linie dafür zu sorgen, dass Domainnamen nicht doppelt vergeben wurden und wie die vergebenen Namen in ein zentrales Register eingespeist wurden (das sogenannte root directory). Zudem wies diese Agentur die Länderkodizes zu, eine Privatgesellschaft (die Networks Solution Inc., NSI) verwaltete die zunächst auf fünf begrenzte Generic Top-Level Domains. Der Zugriff auf die Domainnamen erfolgte zunächst nach dem Prinzip „first come, first served“ und war kostenfrei. Besitzansprüche waren explizit ausgeschlossen, Domainnamen galten als öffentliches Gut (Hofmann 2005).

Diese einfache Konstruktion sollte sich allerdings mit der wachsenden Attraktivität des Netzes bald ändern. NSI begann Gebühren für die Registrierung $\mathrm{zu}$ erheben - eine Maßnahme, die bei den an kostenfreien Zugang gewöhnten Nutzern wenig populär war, zumal NSI ja über eine Monopolstellung gebot (Mathiason 2009). Die Registrierungskosten waren und sind allerdings nicht besonders hoch, da die Registrierungsagenturen nicht profitorientiert arbeiten. Die Verbreitung des World Wide Web und die zunehmende wirtschaftliche Bedeutung der Domainnamen führten aber schon bald zu Konflikten über Markenschutzrechte bei der Namensvergabe, die mit der Gründung der ICANN 
vorläufig beigelegt wurden (Pickard 2007; Mathiason 2009). Denn ICANN wurde 1988 auf Initiative der US-Regierung mit der Aufsicht und Kontrolle der Root Server, der Internetadressen und der Top-Level Domains (TLD) betraut.

Die eigentlichen operativen Funktionen werden durch regionale Internetregistrare (RIR) wahrgenommen; das sind private, nicht gewinnorientierte Mitgliederorganisationen. Mitglieder sind dort Internet Service-Providers, Organisationen mit privaten Internet-Netzwerken und ähnliches. Die RIR haben ähnliche, aber doch etwas unterschiedliche Geschäftsmodelle und finanzieren sich nur aus den Registrierungsgebühren; sie haben sich der Oberaufsicht durch ICANN 2003 mit der Bildung der Number Resource Organization weitgehend entzogen. Noch selbständiger sind die Registrare der Country Code-TLDs (ccTLDs, also etwa .us oder .de). Diese operieren ähnlich den nationalen Telekom-Gesellschaften in vielen Teilen der Welt (vor allem in Asien) gleichsam als Monopolisten und stehen häufig unter starkem staatlichem Einfluss. Daher werden sie auch genutzt, um den Zugang der Bevölkerung zum Internet zu kontrollieren. Etliche nationale Registrare haben keine vertragliche Bindung zu ICANN, daher können sie von dieser Organisation auch nicht diszipliniert werden (Mueller 2010).

Umstritten sind bei der Verwaltung der Domainnamen nach wie vor folgende Punkte:

- Erstens sind zehn der weltweit dreizehn operierenden Root Server in den USA beheimatet. Diese verwalten eine Datenbank der Domainnamen und IP-Adressen der jeweiligen TLDs; ihr Registrierungsprozess ist nicht standardisiert. Ein ebenfalls in den USA angesiedelter "Masterserver“ aktualisiert täglich die komplette Datenbank, auf die nur ICANN und das US-Handelsministerium Zugriff haben (Gernroth 2008). Diese doch sehr einseitige Verteilung der Root Server und der staatliche Einfluss der USA haben zu begreiflichem Missbehagen nicht nur der Regierungen ärmerer Staaten geführt.

- Zweitens werden TLDs nur in lateinischer Schrift verwaltet - eine Tatsache, die vor allem von Ländern mit anderer Schriftsprache als wenig nutzerfreundlich kritisiert wurde und wird (O Siochrú 2004).

- Drittens wird die wenig transparente, „undemokratische“ Verwaltung von ICANN bemängelt; dies vor allem deshalb, weil sie nicht nur rein technische Entscheidungen zu treffen hat, z. B. über Ansprüche auf Markennamen im Netz (Pickard 2007).

- Viertens kollidiert der freie Zugriff auf Domainnamen mit dem Markenschutz, da identische oder ähnliche, auch missbräuchlich gewählte Namen zunehmend mit diesem Schutz kollidieren. 


\subsubsection{Technische Probleme}

Weniger konfliktreich sind die technischen Probleme, die sich bei der Verwaltung der Domainnamen ergeben. Die Sicherheit der Nutzung ist durch sogenannte DNS-Angriffe gefährdet; das sind Umleitungen von Nutzeranfragen auf einen anderen Rechner, um an persönliche Passwörter oder Kreditkartennummern zu gelangen. Um dies zu unterbinden, hat ICANN 2010 ein neues Verfahren präsentiert. Es soll verhindern, dass der Datenverkehr zwischen Netznutzer und Webserver manipuliert werden kann. Dazu wird der Adresse des Webservers ein virtueller, geheimer und verschlüsselter Ausweis hinzugefügt, durch den sich Webserver und Empfänger gegenseitig ausweisen. Das neue System befindet sich noch in flächendeckender Ausbreitung.

Ein potentielles Problem stellt auch die Routensicherheit im Datenverkehr dar. Die Kommunikation im Internet hängt ja nicht nur von der Fähigkeit ab, einzelne IP-Adressen, sondern auch solche zwischen den Computern korrekt zu identifizieren. Diese Aufgaben bewerkstelligen die Internet Service Providers bislang durch Absprachen auf der Basis des sogenannten Border Gateway Protocol. Die Verletzbarkeit dieses Datenverkehrs wurde auf dramatische Weise im Jahr 2008 deutlich, als YouTube für fast eine Stunde aus dem Internet verschwand, weil die pakistanische Zensurbehörde den Zugang von YouTube unterband, fälschlicherweise aber die Verbindungen zu YouTube weltweit blockierte. Ein technischer Behelf für dieses Problem wurde zwar mittlerweile entwickelt; er setzt aber voraus, dass der Datenverkehr von einer übergeordneten Agentur kontrolliert und für zulässig befunden wird. Diese Entscheidung ist aber eine im Wesentlichen hoheitliche Aufgabe, die kaum einer privat organisierten Institution überlassen bleiben kann.

\subsubsection{Risiken und Missbrauch}

Domainnamen lassen sich allerdings auch anders missbrauchen: Cybersquatting bezeichnet die Registrierung eines Domainnamen in der Absicht, durch die Umleitung des Datenverkehrs eines markenrechtlich geschützten Anbieters Gewinne zu machen, oder es ist der Versuch, einem Markenschutzhalter durch Besetzung eines Domainnamens Zahlungen abzupressen. Ähnlich bezeichnet Typosquatting die bewusste, geringfügige Änderung eines Domainnamens (etwa durch Hinzufügung eines Buchstabens), um Teile des Datenverkehrs an den rechtmäßigen Nutzer abzuschöpfen. Damit hängt auch die missbräuchliche Hortung von Domainnamen zusammen, die sich mit etablierten Markennamen 
überschneiden oder diesen sehr ähnlich sind, und zwar zu dem Zweck, den Inhabern dieser Markennamen Zahlungen abzupressen. Markennamen sollen bewirken, dass Konsumenten die Hersteller von Produkten korrekt identifizieren können. Die Rechte daraus gelten für unbegrenzte Zeit.

Markennamen sind natürlich vor allem bei E-Commerce, beim elektronischen Handel, von großer Bedeutung, da sich Konsumenten hier stark auf die Reputation des Anbieters verlassen (müssen). Große Firmen halten für die Vielzahl ihrer Produktionsstätten, Dienste und Produkte bis zu 500 Domainnamen, die gegen möglichen Missbrauch auf Millionen von Servern geschützt werden müssen. Die Verletzung von Markenschutzrechten bei der Verwendung von Domainnamen war und ist tatsächlich immer noch ein verbreitetes Phänomen. Nach einer Quelle sollen 70 Prozent der Domainnamen, die man mit bestimmten Marken in Verbindung bringen könnte, nicht von den Inhabern der Markenrechte selbst registriert worden sein (WIPO o.J.). Angesichts dieser Entwicklungen hatte die US-Regierung schon 1998 gefordert, dass die World Intellectual Property Organization (WIPO) mit der Streitschlichtung bei Konflikten mit dem Markenschutz im Internet betraut werden sollte. Deren Mitgliedsländer haben, basierend auf den Konsultationen der WIPO, im September 2001 eine Empfehlung zum Schutz der Markennamen im Internet beschlossen, welche den Rahmen für nationale Ausführungsgesetze abgeben soll (WIPO 2002). Nach dieser Empfehlung sind die Halter von Domainnamen so lange frei von rechtlicher Verantwortung, solange sie nicht über die Existenz konfligierender Namenrechte informiert worden sind. Markenrechte im Internet sollen so weit wie möglich auf das Territorium beschränkt bleiben, in dem sie ausgeübt werden. Sehr bekannte Markennamen genießen zusätzlichen Schutz gegen Reproduktion, Imitation oder bei Übersetzung.

Im Jahr 1999 wurde von ICANN die Einführung eines Streitschlichtungsmechanismus beschlossen, welcher den Inhabern von Markennamen erlaubt, ohne Rückgriff auf nationale Gerichte den Missbrauch von Markennamen im Internet beizulegen und zwar durch das einschlägige Organ der WIPO (Arbitration and Mediation Centre). Dieses behandelt Fälle, bei denen der Domainname identisch mit einem Markennahmen ist oder diesem stark ähnelt, der Besitzer des Domainnamen kein legitimes Recht auf ihn hat und diesen böswillig nutzt. Bis 2011 hat dieses Zentrum schon rund 35.000 Fälle geschlichtet, damit die Gerichte erheblich entlastet (WIPO 2010, 2011). Diese Übereinkunft regelt freilich nicht alle Probleme. Staaten, welche die Empfehlung nicht gezeichnet haben, bleiben ebenso außen vor wie die Namen internationaler Organisationen, pharmazeutischer Substanzen, von Herkunftsbezeichnungen und Personen. Zusätzliche Probleme ergeben sich bei der Einführung neuer TLDs. Dazu kommt, dass etwa viele Klagen missbräuchlich angestrengt werden und Anmeldungen von Domainnamen durch 
Strohmänner bzw. -firmen erfolgen. Diese vertraglichen Lücken zu stopfen (etwa durch das Prinzip, den Verlierer eines Verfahrens zu belasten), würde aber das informelle Schlichtungsverfahren wieder schwerfälliger machen. Die WIPO ist sich auch nicht sicher, dass eine Vertragsänderung innerhalb der ICANN, in der sie wenig Einfluss hat, erfolgversprechend wäre (WIPO 2011).

\subsubsection{Kapazitätsprobleme und der neue Standard}

Das hauptsächliche Problem der Internetadressen ist aber immer noch, dass sie zur Neige gehen. Das bis unlängst einzig verwendete Programm der Verwaltung von Domainnamen $(\mathrm{IPv} 4=$ Internet Protocol Version 4) ist ein nahezu 30 Jahre alter Standard, der dem immer noch stark wachsenden Bedarf an Adressen zunehmend weniger gewachsen ist. IPv4-Adressen werden üblicherweise als vier Zahlen zwischen 1 und 255 angezeigt (etwa: 174.17.253.1), woraus sich ein Maximum an 4,3 Milliarden Adressen ergibt, die für die experimentelle Phase des Internets für mehr als ausreichend gehalten wurden. Die rasche Verbreitung und steigende kommerzielle Nutzung des Netzes, auch die nicht optimale Vergabe der Adressen ließen diese Hoffnung aber relativ schnell zur Illusion werden; schon im September 2005 schätzte eine Untersuchung des Unternehmens Cisco Systems (Hain 2005), dass der verfügbare Namensraum in vier bis fünf Jahren erschöpft sein würde. Die OECD präzisierte 2008 diese Prognose und setzte das Ende auf 2011 an (OECD 2008). Präzise zu Beginn dieses Jahres war es dann tatsächlich so weit: Die IANA vergab am 3. Februar 2011 die letzten 80 Millionen Adressen. Die schnelle Erschöpfung war auch bedingt durch die zunehmende Zahl internetfähiger Mobiltelefone, vor allem aber durch die rapide Wachstumsrate aller Empfangsgeräte von 26 Prozent jährlich seit dem Jahr 2000 und der Registrierung von Domainnamen um 22,1 Prozent pro Jahr (OECD 2011). Der weitaus größte Teil der IPv4-Adressen wird von den OECD-Staaten beansprucht (65 Prozent), davon allein fast zwei Drittel durch die USA, gefolgt von Südkorea, Deutschland und Großbritannien.

Angesichts des rapide steigenden Bedarfs an Domainnamen wurde bereits zwischen 1993 und 1998 an einem neuen Standard (IP6v) gearbeitet, der einen um ein Vielfaches erhöhten, praktisch unbegrenzten Raum für neue Domainnamen, höhere Qualität (vor allem für tragbare Internetgeräte) und besseren Datenschutz bietet. Er wurde 1999 eingeführt. IPv6-Adressen sind wesentlich länger (Beispiel: 2012:0ab7:1200:7b2f:1731:8442), erlauben daher die Vergabe einer astronomischen Zahl von Adressen, die ausreichend sein müsste, um den Bedarf der nächsten Generationen zu decken. Der neue Standard soll auch den Datentransfer 
leichter und sicherer machen, und mit ihm können Datenpakete gleichzeitig an viele Adressaten in einem Vorgang versendet werden.

Er ist freilich nicht rückwärtig kompatibel mit IPv4, der Übergang vom alten zum neuen System bedarf überdies einer Vielzahl zusätzlicher IPv4-Adressen, um alte in neue Domainnamen zu übersetzen. Dieser Sachverhalt und die nicht unbeträchtlichen Übergangskosten von einem zum anderen Standard bedingen eine bislang nur zögerliche Übernahme von IPv6s. Anfang 2011 vermochten erst 8,3 Prozent der Netze Datenverkehr in IP6v zu bewerkstelligen (OECD 2011), der aktuelle Verkehr mit diesen Adressen belief sich auf einen noch deutlich geringeren Anteil. Nicht überraschenderweise wurden neue IPv6-Adressen weitaus am häufigsten in den USA, Deutschland, Japan und Großbritannien registriert (Ebd.).

Die Übergangskosten entstehen erstens daraus, dass die Betriebssysteme dem neuen Standard angepasst werden müssen. Dies ist mittlerweile bei den gängigen Programmen (Windows, Mac) geschehen. Ähnliches gilt für die nötige Software: Nahezu alle Programmiersprachen, DNS-Server und Router sind mittlerweile IPv6-kompatibel. Bei der Anpassung innerhalb eines Server-Verbundes (Intranet) hapert es aber noch erheblich (OECD 2008). Die Umstellung und die Installierung von Dual-Track-Systemen (die beide Standards nutzen können) ist aber so teuer (und wird daher staatlicherseits in den USA, Japan und Südkorea unterstützt), dass man ohne Vorhersicht weiter von einer weltweit äußerst ungleichen Verteilung der Domainnamen auch im neuen Standard ausgehen muss.

\subsubsection{Künftige Entwicklungen von Domain Governance}

Rückblickend lässt sich konstatieren, dass das Geschäftsmodell der Verteilung von IPv4-Adressen nicht besonders nachhaltig war: Bis vor kurzem wurden ungenutzte Domainnamen kostenfrei verteilt, wenn ein "gerechtfertigtes Bedürfnis" nach der Zuteilung nachgewiesen werden konnte. Man hätte wohl besser die Adressen nach Prioritäten und Gewicht der Nutzer verteilen sollen, nicht genutzte Domainnamen zurückfordern und zu großzügige Ausgaben von Adressen zurückstutzen müssen. Mit dem traditionellen, vorwiegend technischen und politikfreien Geschäftsmodell der Registrare war dies aber kaum möglich. Immerhin ermöglichten europäische und nordamerikanische Registrierungsagenturen 2008 bzw. 2009, dass Nutzer die Domainnamen nicht ausgeschöpfter Adressen an Interessenten verkauften, die zusätzlichen Bedarf anmeldeten. Die Rückforderung nicht genutzter Adressen durch die Registrare machte aber keine Fortschritte (Mueller 2010). Es bleibt abzuwarten, ob bei der Nutzung des neuen Standards diese Defizite vermieden werden. 
Das oben angesprochene Problem der TLDs ausschließlich in lateinischer Schrift ist vor allem für große Entwicklungsländer mit anderer Schrift, aber auch für einige europäische Länder mit Minderheitssprachen ein Ärgernis (MacSitigh 2010). Daher fühlte sich selbst der Europarat bemüßigt, ein mehrsprachiges Internet zu fordern. Die UNESCO stellte sich an die Spitze solcher Forderungen und verband sie mit dem Anspruch, die „digitale Spaltung“ zu verringern. Dieses Problem wurde im Herbst 2009 weitgehend beigelegt, denn zu diesem Zeitpunkt führte ICANN internationalisierte Domainnamen (IDN) mit nicht-lateinischen (arabischen, koreanischen, japanischen etc.) Schriftzeichen ein und begann entsprechende IDNs zu registrieren.

Es gab immer wieder Anläufe, die Macht von ICANN und der angeschlossenen Registrare über die Vergabe von Domainnamen zu beschränken, bislang allerdings ohne nachhaltigen Erfolg. So operierte von 2002 bis 2008 das Open Root Server Network als Alternative zu ICANN. Dieses Netzwerk war keiner politischen Einflussnahme ausgesetzt, aber mangels geringem Interesse der Nutzer wurde es eingestellt. Bei der Firma Unified Root lassen sich seit 2005 DomainEndungen registrieren, die nicht auf den TLDs von ICANN basieren und parallel zu den TLDs genutzt werden können; das Unternehmen verlangt aber einen speziellen Browser. Ähnliche Vorkehrungen sieht die kostenfreie Teilnahme am Open Source Projekt OpenNIC vor - ein Zusammenschluss freiwillig arbeitender Experten mit unbeschränkter Möglichkeit zur Teilnahme. All diese Alternativen stellen wegen mäßiger Verbreitung und der Notwendigkeit zur Installierung spezieller Software die Hegemonie von ICANN nicht in Frage.

Eine wirkliche Herausforderung für die Unabhängigkeit derjenigen Institutionen, welche die sogenannten kritischen Internet-Ressourcen verwalten, stellt allerdings das Bestreben nicht weniger Nationalstaaten dar, die Verwaltung dieser Ressourcen an sich zu reißen oder zumindest zu kontrollieren - Bestrebungen, die seit dem ersten Weltinformationsgipfel (WSIS) nicht abgerissen sind. Verwunderlich sind sie nicht. Denn es fällt Regierungen immer schwer, einer transnationalen, nichtstaatlich organisierten Verwaltung wirtschaftlich immer wichtiger werdender Internet-Ressourcen zuzugestehen, sofern Vorstellungen nationaler Souveränität und Rechenschaftspflicht gegenüber den eigenen Bürgern in Betracht gezogen werden. Der nicht sehr überzeugende Kunstgriff (namentlich bei WSIS I), technische Aspekte der Internet-Verwaltung von solchen öffentlicher Belange zu trennen, ist wie die bisher gemachten Ausführungen zeigen sollen - nicht sehr überzeugend.

Solche Delegationen widerstreben vor allem Regierungen, deren Volkswirtschaften nicht an der Spitze des technologischen Fortschrittes stehen und wenig prosperieren. Sie verfügen auch nicht - anders als die USA - über die entscheidende Infrastruktur der Internet-Governance, sondern müssen die Kontrolle über 
die Namensvergabe oder die Festlegung der Routen für den Datenverkehr globalen oder regionalen Agenturen überlassen. Dieser Nachteil ist nicht nur der chinesischen Regierung ein Dorn im Auge, welche die erste Initiative zur stärkeren nationalen Kontrolle der Vergabe von Domainnamen startete (Mueller 2006). Es ist auch das Anliegen praktisch aller Entwicklungsländer und - erstaunlicherweise - neuerdings auch der EU und ihrer Mitgliedsstaaten. Der ursprüngliche chinesische Vorschlag zielte darauf ab, nationalen Regierungen eine konkurrierende Kompetenz bei der Vergabe von Domainnamen einzuräumen. Die regionalen Registrare und einige westliche Regierungen reagierten mit Entrüstung, die Registrare wohl hauptsächlich deshalb, um ihr Monopol zu schützen. Die EUKommission begründete das Bestreben um stärkeren Zugriff der Regierungen auf die kritischen Internetressourcen mit der wachsenden Bedeutung des Internets für die Gesellschaft insgesamt, mit der notwendigen Sicherheit des Datenverkehrs, der begrenzten Rechenschaftspflicht von ICANN und der Registrare sowie mit der notwendigen Berücksichtigung der Belange öffentlicher (und nicht nur privater oder privatwirtschaftlicher) Interessen (Kommission der Europäischen Gemeinschaften 2009). Dieser Vorstoß der EU unterscheidet sich verbal nur wenig von der Position mehr oder eher weniger demokratischer Regime andernorts.

Diese durch unterschiedliche Interessen bedingten Konflikte schleppen sich schon seit dem ersten Weltinformationsgipfel 2003 in Genf dahin, an der Substanz der Argumentation der unterschiedlichen Parteien hat sich wenig geändert. Vorläufig letzter Akt dieses Dramas war die Weltkonferenz zur Internationalen Telekommunikation (Dezember 2012) in Dubai, bei der es um die Überarbeitung der Internationalen Telekommunikations-Regulierungen von 1988 gehen sollte. Die Regierungen autoritär oder halbdemokratisch organisierten Staaten machten dort wieder die üblichen Vorschläge, um insbesondere die staatliche Souveränität gegenüber Einmischungen in die inneren Angelegenheiten im Netz zu stärken und die politische Macht der ITU (in der die nichtwestlichen Staaten die Mehrheit haben) zu steigern. Sie sollte die Kompetenz für die Vergabe von Domainnamen und die für die Regulierung von Online-Inhalten bekommen. Die iranische und die russische Regierung schlugen zusätzlich vor, den Internet-Verkehr an nationalen Grenzen zu messen und vom Urheber bezahlen zu lassen (Meister 2012). Gegen diese Vorschläge setzten sich westliche Regierungen erneut scharf zur Wehr (Motto: autoritäre Staaten würden mit Hilfe einer obskuren UN-Organisation das Internet steuern und die Informationsfreiheit drastisch beschneiden wollen). Nach hitziger Diskussion auf dieser Konferenz blieb ein harmloser Kompromiss übrig, der alle kontroversen Punkte ausklammert (ITU 2012). 


\subsection{Staatliche Kontrolle und Überwachung}

\subsection{1 "Big Brother is watching you“}

„Auf jedem Treppenabsatz starrte dem Lichtschacht gegenüber das Plakat mit dem riesigen Gesicht von der Wand. Es war eines jener Bilder, die einem mit dem Blick überallhin zu folgen scheinen. DER GROSSE BRUDER SIEHT DICH, lautete die Textzeile darunter. In der Wohnung verlas eine sonore Stimme eine Zahlenstatistik, bei der es irgendwie um die Roheisenproduktion ging. Die Stimme kam aus einer länglich-rechteckigen Metallplatte, die wie ein blinder Spiegel in der Wand zur Rechten eingelassen war [...]. Man konnte das Gerät (den sogenannten Teleschirm) zwar leiser stellen, aber ganz ausschalten ließ er sich nicht [...]. Winston kehrte dem Bildschirm weiter den Rücken zu. Es war sicherer so; obgleich, wie er sehr wohl wußte, selbst ein Rücken verräterisch sein konnte. Einen Kilometer entfernt türmte sich das Ministerium für Wahrheit, seine Arbeitsstätte, weiß und gewaltig über die rußige Landschaft auf" (Orwell, 1984, 7ff.).

So lauten einige der Eingangssätze in dem wohl berühmtesten Science-FictionRoman über Überwachung und Kontrolle, verfasst 1948 von dem britischen Schriftsteller Eric Arthur Blair (Pseudonym: George Orwell, 1903-1950). Mit schon beängstigender Präzision zeichnete er für 1984 Manipulation und psychische Zerstörung des Menschen durch perfekte Überwachung und brutale Einschüchterung in einem totalitären Staat, dessen perfide Kontrollmechanismen und Repressionen bis heute im kollektiven Bewusstsein nachwirken. Noch nicht gänzlich konnte sich der Autor die Technologien ausmalen, die man braucht, um Überwachungsdokumente zu sammeln, zu registrieren, auszuwerten, um immense Datenmengen zu transportieren, zu speichern und zu kategorisieren, also Computer und digitale Netze. Doch Ahnungen davon kursierten bereits; sie sind dann sinnigerweise in den 1980er und 1990er Jahren verfügbar geworden und geben dem Roman bis heute eine bislang einmalige Aktualität, Plausibilität und Realitätsnähe.

\subsection{2 Überwachte Lebenswelten}

Umfassende Videoüberwachung des öffentlichen Raums, also von U-Bahnen, Park- und Kaufhäusern, in öffentlichen Parks und gefährdeten Straßen, die Bewegungsgewohnheiten und -profile von Personen rekonstruierbar machen, 
die routinemäßige Erstellung von Bewegungsprofilen, Gendatenbanken (genetischer Fingerabdruck), biometrische Datenbanken, Gesichtskennungen durch Muster-Codierungen und ihre Zuordnung zu Personaldateien, elektronisch lesund auswertbare Kredit- und Gesundheitskarten, Identitätsausweise und Pässe, Kunden-, Mitgliedskarten für Unternehmen und Vereinen sowie RFID-Chips, also: Identifizierung mit Hilfe elektromagnetischer Wellen in Geldscheinen für Registrierkassen, computergestützte Überwachung von Telefongesprächen („Abhören“), Langzeit-Speicherung von Telekommunikationsdaten inklusive des Aufenthaltsorts bei Mobiltelefon-Nutzern, inhaltliche Kontrollen des InternetDatenverkehrs, unbemerktes elektronisches Eindringen von staatlichen Stellen (Verfassungsschutz, Geheimdienste) in private Computer („Online-Durchsuchung“), Nachverfolgung des elektronischen Zahlungsverkehrs mit EC- und Kreditkarten, umfassende Beobachtungen von Banküberweisungen - all dies und noch einiges mehr sind Methoden und Techniken, die IT-gerüstete Staaten und Instanzen heute schon (und künftig noch intensiver) praktizieren (können) und kollektive Befürchtungen, wenn nicht Alpträume der totalen Überwachung und Kontrolle hervorrufen (Krotz 2009, 18f.). Aber auch private Unternehmen und Dienstleistungen sind oft daran beteiligt, entweder in eigener Regie, beauftragt oder auch in Kooperation mit staatlichen Institutionen. Meist nur vordergründig und oberflächlich sind sie gesetzlich legalisiert und werden unabhängig selbst vom gesetzlichen Datenschutz kontrolliert. Vieles passiert im Geheimen und Zwielichtigen, wie die jährlichen Berichte der Datenschutzbeauftragten und anderer Kontrollgremien (etwa Ausschüsse der Parlamente) immer wieder belegen. Daher laufen gesetzliche Regelungen und exekutive Kontrollen oft genug den Überwachungspraktiken hinterher, sofern überhaupt ein politischer Willen vorhanden ist, sie zu regulieren. Schalten sich gar kriminelle Akteure dazwischen - etwa wenn amtliche Daten von privaten Hackern und Vermarktern gestohlen und weiterverkauft werden, was letztlich nie ganz zu vermeiden ist -, werden die Datenüberwachung und ihre Anwendung bzw. Verwertung vollends undurchsichtig und für alle bedrohlich.

In autoritären Staaten wird starke, geheime oder auch absichtlich demonstrative Überwachung eingesetzt, um Bürger von nicht genehmen Verhaltensweisen oder in diesem Regime inkriminierten Straftaten abzuhalten. Dazu dienen natürlich heute die verbreitete Videoüberwachung und Datenauswertung in allen öffentlichen Bereichen. Oft genug werden in repressiven Regimen (z. B. China, Nordkorea, Arabische Staaten, Iran, Russland) als ,staatsfeindlich' eingeschätzte Personen ,präventiv' festgenommen und weggesperrt, um sich anbahnende Proteste zu ersticken und ihre Akteure einzuschüchtern, aber auch um bei internationalen Veranstaltungen das öffentliche Erscheinungsbild zu beeinflussen. 


\subsubsection{Zur Theorie der sozialen Kontrolle}

Aus wissenschaftlicher Sicht ist der Terminus der sozialen Kontrolle der umfassendste für diesen Handlungsbereich. Er wurde von den amerikanischen Soziologen Edward Alsworth Ross mit einem Aufsatz im American Journal of Sociology als Social Control in die sozialwissenschaftliche Diskussion eingeführt (Ross 1986). Gemeint ist damit die absichtliche Lenkung des Individuums durch eine größere soziale Gruppe, allgemeiner noch: die willentliche Herrschaft der Gesellschaft über das Individuum. Eine neuere Definition fasst unter dem Begriff „jene Prozesse und Mechanismen, mit deren Hilfe eine Gesellschaft versucht, ihre Mitglieder zu Verhaltensweisen zu bringen, die im Rahmen dieser Gesellschaft positiv bewertet werden" (Fuchs-Heinritz u. a. 2007; Menzel und Wehrheim 2010).

Unterschieden werden vor allem zwei Formen der sozialen Kontrolle: zum einen die äußere Kontrolle, also die durch negative und positive Sanktionen erreichte Steuerung durch übergeordnete Gruppierungen bzw. durch die gesamte soziale Umwelt; zum anderen die innere Kontrolle, also die Verinnerlichung von sozialen Normen, insbesondere durch Sozialisationsprozesse, in das Persönlichkeitssystem oder Gewissen, so dass die aufgezwungenen Normen und Verhaltensweisen als ,natürlich ' - gewissermaßen als zweites Ich - erachtet werden. Sie reichen dann über die Lenkung des offenen Verhaltens hinaus in individuelle Gedanken und Gefühle hinein. Ausgeübt werden kann die soziale Kontrolle durch sanktionsbewehrte Normen, aber auch durch konkrete Strukturen und Handlungsprozesse sozialer Gruppierungen und Institutionen (wie Familie, Schulen, Kirchen, Vereine, Institutionen der Justiz und Sozialarbeit). Ihre Mittel reichen von sozialer Kommunikation (Anerkennung, Ermutigung, Überzeugung, Kritik, Anweisung) über Sanktionen (Benachteiligungen, Strafen) bis hin zur sozialen Isolation. Ihr Ziel ist die Erzeugung von Verhaltenskonformität gemäß den Normen der Mehrheit. All diese Prozesse und Praktiken erfolgen inzwischen nicht mehr nur im direkten, sozialen Kontakt, sondern auch im medialen. Und je mehr die digitalen Strukturen persönliche Adressierungen - etwa durch soziale Netzwerke - erreichen (Peiser 2012), umso eher können sie indirekt-medial ausgeübt werden.

Besonders strikt und effektiv werden Kontrolle und Überwachung in totalen Institutionen - heute wohl auch in ähnlich engmaschigen Netzwerken - ausgeübt. Ihre analytische Konzeption ist von dem amerikanischen Soziologen Irving Goffman (1973) skizziert worden, der französische Soziologie Michel Foucault (2007) hat das der Disziplinierung von der informellen Sozialisation bis hin zur repressiven Bestrafung beigesteuert. Beide Ansätze weisen darauf hin, dass neben direkter, offener Disziplinierung und Repression vor allem langfristig informelle Disponierungen wirken können, um normgerechtes Verhalten und auch Denken 
zu erzeugen. Dies kann durch Isolation von anderen sowie durch die allmähliche Unterdrückung der eigenen Identität erreicht werden: „Diskulturation“, nennt Goffman diese Maßnahme; sie besteht darin, „dass jemand gewisse, im weiteren Bereich der Gesellschaft erforderliche Gewohnheiten verliert oder sie nicht erwerben kann"(Goffman 1973, 24, 198).

\subsubsection{Praktiken staatlicher Überwachung}

Ähnlich verschafft sich die moderne Überwachung über jeden Bürger zu jedem Zeitpunkt tendenziell alle relevanten Informationen, über Aufenthaltsorte, über Gewohnheiten, Vorlieben und Handlungen, über Interaktions- und Kommunikationspartner, über Inhalte und Stile der Kommunikation. Je nach Gefährdungslage, die meist von Geheimdiensten nach ihren undurchsichtigen Kriterien definiert wird, werden die Mechanismen der Überwachung verschärft. Private Unternehmen wie Kaufhäuser, Banken, Arztpraxen und Krankenhäuser verfügen wiederum über einschlägige Daten und daraus gewonnene Gewohnheitsmuster. Solange sie noch nicht miteinander abgeglichen und zentral vernetzt sind, mag sich der einzelne noch in gewisser Sicherheit wiegen. Der Orwellsche Überwachungsapparat funktioniert aber dann perfekt, wenn all diese Daten und Netze verbunden sind und zentralisiert werden - unter welcher obersten Steuerungsagentur auch immer (Singelnstein und Stolle 2008).

In der deutschen Öffentlichkeit wurde diese Problematik vehement anlässlich der 1981 beabsichtigten Volkszählung diskutiert (Bull 2011). Infolge ungeklärter Finanzierung konnte das erforderliche Gesetz erst 1982 verabschiedet und der Zähltermin erst für 1983 anberaumt werden. Dagegen erhoben sich zahlreiche Boykottaufrufe kritischer sozialer Gruppen und Parteien. Beim Bundesverfassungsgericht (BVG) in Karlsruhe erwirkten sie einen höchstrichterlichen Einspruch, der in dem historisch bedeutsamen Volkszählungsurteil vom 15. Dezember 1983 gipfelte. In ihm wurde nämlich das Grundrecht auf informationelle Selbstbestimmung formuliert, das sich aus der Menschenwürde des Art. 1 GG und dem Recht auf freie Entfaltung der Persönlichkeit nach Art. 2 Abs. 1 GG ableitet. Daher musste die Befragung teilweise neu konzipiert werden, indem personenbezogene Angaben von den Fragebögen getrennt und die Fragebögen selbst überarbeitet wurden, um so die Anonymität der Befragten besser zu gewährleisten: „Mit dem Recht auf informationelle Selbstbestimmung wären eine Gesellschaftsordnung und eine diese ermöglichende Rechtsordnung nicht vereinbar, in der Bürger nicht mehr wissen können, wer was wann und bei welcher Gelegenheit über sie weiß“, definierte das BVG die Grenzen 
staatlicher Schnüffelei und Kontrolle (Ebd.). Auch Art. 8 Abs. 1 der Europäischen Menschenrechtskonvention unterstützt nach Ansicht des Europäischen Parlamentes das Recht auf informationelle Selbstbestimmung: „Jede Person hat das Recht auf Achtung ihres Privat- und Familienlebens, ihrer Wohnung und ihrer Korrespondenz" (EMRK Art. 8 Abs. 1) (Holtz-Bacha 2011, 63ff.).

$\mathrm{Zu}$ massiven Gegenbewegungen und Verschärfungen der Überwachung kam es nach den Terroranschlägen in den USA vom 11. September 2001. Weltweit wurde der Kampf gegen terroristische Bedrohungen ausgerufen, einschlägige Gesetze eingeführt oder bestehende verschärft und vor allem geheime, digitale Methoden des Aufspürens aggressiver Pläne und Personen entwickelt. Weltweit sollen inzwischen schätzungsweise 15 Millionen Überwachsungskameras im Einsatz sein (Behrens 2013).

Seit 2008 wurde etwa in der Europäischen Union die so genannte Vorratsdatenspeicherung eingeführt, aber auch immer wieder durch nationale Einsprüche in Frage gestellt. Eine neue Qualität soll etwa das bis 2013 laufende Forschungsprojekt INDECT bringen; denn mit ihm sollen Prävention als vorsorgende Datensammlung und simultane Überwachung der Planung von Straftaten vermengt werden. Dabei sollen sämtliche bestehende Überwachungstechnologien auf der Basis der automatisierten Auswertung und Verknüpfung von Bildern von Überwachungskameras des öffentlichen Raums mit einer großen Zahl weiterer Datenquellen wie etwa Daten aus sozialen Netzwerken und der Telekommunikationsüberwachung zu einem universellen Überwachungsinstrument gebündelt werden, um so eine verbrechensvorbeugende Polizeiarbeit zu ermöglichen. Die Überwachung würde nahezu total sein; entsprechend scharf wird das Vorhaben kritisiert.

Auch in anderen europäischen Staaten nehmen Überwachungsmaßnahmen zu: So sind in Österreich nach gerichtlicher Genehmigung Rasterfahndung und Lauschangriff erlaubt. Österreichische Reisepässe enthalten bereits Mikrochips, auf denen biometrische Daten sowie Fingerabdrücke gespeichert sind. Ebenso darf die Polizei ab 2008 ohne richterliche Kontrolle auf IP-Adressen und Standortdaten von Handys zugreifen.

In Frankreich erging ein Dekret, wonach seit Juli 2008 Daten potenzieller Gewalttäter ab 13 Jahren vom Inlandsgeheimdienst in einer Datenbank zentral erfasst werden dürfen. Selbst wenn Personen keine Straftat begangen haben, dürfen ihre Daten gesammelt werden. Die Speicherungen umfassen Angaben zu Adressen, Familienstand, Steuer, Vorstrafen, zur Anmeldung des Autos, zum Bekanntenkreis, zu Körper- und Wesensmerkmalen, zu Fotos und in Ausnahmefällen auch zur ethnischen Abstammung, zur Gesundheit und zum Geschlechtsleben. Auch dürfen Daten von Personen gespeichert werden, die ein politisches, gewerkschaftliches oder wirtschaftliches Mandat bekleiden oder 
vorhaben, eine bedeutende Rolle im öffentlichen Leben zu spielen. Unter das Dekret fallen ebenso Individuen wie Gruppen, die möglicherweise die öffentliche Ordnung stören könnten.

Am verbreitetsten und lückenlosesten wird die Überwachung wohl in Großbritannien seit Beginn dieses Jahrtausends praktiziert: Das Mutterland der Demokratie verwandelt sich seither in den rabiatesten Überwachungsstaat der westlichen Welt. 1984 installierte die Londoner Polizei erstmals 145 Kameras eines „integrierten Verkehrskontrollsystems“ zur Beobachtung von Demonstrationen und Unruhen; die aufgenommenen Bilder werden in der Zentrale am New Scotland Yard Broadway zusammengeführt. Es dauerte weitere sechzehn Jahre, bis der Überwachungsstaat zum Regierungsprinzip erhoben wurde. Im Jahre 2000 verabschiedete das Parlament den Regulation of Investigatory Powers Act (RIPA), der in Teil 2 offene und versteckte Überwachungsmethoden regelt. In Provinzstädten wie Edinburgh und Manchester wird jeder Bürger durchschnittlich an die hundertmal am Tag gefilmt, und 300 Kameras verfolgen jeden Londoner beim Einkauf und auf dem Weg zur Arbeit. Dafür sorgt CCTV; es ist das Kürzel für closed circuit television, eine durch ein geschlossenes Kabelnetz verbundene Videoanlage. CCTVs werden von der Polizei, von Behörden und Kommunen, von privaten Firmen und öffentlichen Diensten betrieben. Landesweit wird die Zahl der Kameras, die auf britische Bürger gerichtet sind, auf 4,2 Millionen geschätzt. Von ihnen dürfte inzwischen jeder/jede durchschnittlich 300mal am Tag erfasst werden (Behrens 2013). Kein anderes Land der Welt kann da auch nur annähernd mithalten.

Die 1997 ins Amt gekommene New-Labour-Regierung etablierte zudem die größte und technologisch ausgefeilteste genetische Datenbank der Welt. Die Polizei darf von jeder festgenommenen Person auch bei nur geringfügigen Vergehen DNA-Proben nehmen. Und wer einmal in der Datei ist, hat so gut wie keine Chance, je wieder daraus entfernt zu werden. Die Regierung rechtfertigt diese Praxis damit, dass unter Verdacht Geratene, auch wenn sie diesmal unschuldig sind, „,in Zukunft ein Verbrechen begehen könnten“. Mittlerweile enthält die Datei 1,5 Millionen Proben. Bis 2008 sollen 4,25 Millionen Briten genetisch erfasst sein, über sechs Prozent der Bevölkerung.

In einer Analyse der Bürgerrechtsgruppe Privacy International landete Großbritannien als Staat, in dem Verletzungen der Privatsphäre „endemischen" Charakter haben, neben Russland, China, Malaysia und Singapur in der Spitzengruppe von 37 Ländern. Deutschland und Kanada schützen die Privatsphäre der Studie zufolge am wirkungsvollsten. Solche Beanstandungen finden in Großbritannien - unabhängig von der jeweiligen Regierung - offenbar kaum Gehör. Seit 2012 wird die schon umfassende Beobachtung des gesamten Internet-, Telefon- und E-Mail-Verkehrs durch den Geheimdienst weiter perfektioniert. Den 
Berichten zufolge sieht ein Entwurf vor, dass Provider entsprechende Hardware zu installieren hätten, die der britischen Geheimdienst-Behörde GCHG (Grand Challenges in Global Health) eine plattformübergreifende Beobachtung individueller Kommunikation erlaubt. Zeitpunkt, Position der Teilnehmer und Dauer, aber nicht Inhalte der Kommunikation sollen dabei langfristig gespeichert werden und in Echtzeit verfolgbar sein. Diese Überwachung soll im Gegensatz zur bestehenden Gesetzgebung dann ohne richterliche Erlaubnis möglich sein.

Bislang müssen Überwachsungsvideos von realen Personen angesehen und ausgewertet werden - was bei der Überfülle der Daten immer weniger gelingt. Daher wird an möglichst intelligenten Systemen gearbeitet, die primär verdächtige Situationen, Handlungen, Personen und Objekte automatisch erkennen und auswerten können: Aisight der US-Firma BRS gilt derzeit als modernster, vielversprechender Prototyp. Anders als bei festen Kennungs-Algorithmen, die bestimmte Muster wie „liegende Person“, Menschenansammlung, Aggression“ oder allgemein „auffälliges Verhalten“ registrieren, ist die amerikanische Version als selbstlernend konstruiert und kann, ähnlich einem neuronalen Netz, Erfahrungen sammeln und lernen, was in welcher Situation als normal gilt und was nicht - etwa welchen Sektor Passanten nicht betreten oder welche Tür sie nicht öffnen sollten. Ein riesiger Investitionsmarkt ist dieser Technologie bereits avanciert. Aber Datenschützer monieren ebenso, dass künftig eine Maschine darüber entscheidet, ob ein Mensch und sein Verhalten verdachtswürdig ist oder nicht (Behrens 2013).

Soziale Kontrolle und Überwachung zumal von Seiten des Staates ist keine weiche, unauffällige und folgenlose Governance-Praxis; sie rechnet mithin zum expliziten staatlichen Gewaltapparat, sei sie offen angewendet und gesetzlich legalisiert, sei sie geheim und mehr oder weniger im Zwielicht geheimdienstlicher Aktivitäten. Mit der Expansion des transnationalen Terrorismus haben die Praktiken sicherlich zugenommen und sich verschärft - so dass sie zunehmend dem Transparenzund offenen Kontrollgebot der Demokratie widersprechen. Oft genug kollidieren Maximen der möglichst hohen Effizienz und Effektivität mit Postulaten für rechtsstaatliches und - das heißt immer auch - transparentes, gesetzlich legalisiertes und exekutiv kontrolliertes Handeln. Diese Entwicklung ist besonders mächtig, wenn der Staat solche Überwachungsaufgaben an private Unternehmen delegiert, wie dies nicht nur bei direkten Sicherheitsaufgaben geschieht, sondern auch bei Computer- und Netzüberwachungen. Vollends unüberschaubar werden die Praktiken, wenn private Dritte - etwa Unternehmen (bei Betriebsspionage), Kaufhäuser (contra Ladendiebstahl), Banken (bei kriminellen Geschäften), Krankenkassen (zur Beaufsichtigung von Simulanten) - Überwachungen und Kontrollen mittels digitaler Datensicherung selbst in die Hand nehmen. Ihre internen Datenspeicher und Intranetze sind Tresore für willkürliches, 
interessengeleitetes Handeln. Gänzlich beherrschen lässt sich dieses Wirken sicherlich nicht mehr - nicht zuletzt deshalb, weil die digitalen Technologien des Überwachsens, Datensammelns, -auswertens und -verwendens permanent tätige, höchst wirksame Apparaturen bereitstellen, die nur noch von Experten oder künftig auch von Automaten betätigt werden können und der geheimen Willkür unterliegen.

\subsection{Zensur und Informationsbehinderung}

\subsubsection{Zensur als Informationskontrolle}

Allgemein lässt sich Zensur als Informationskontrolle jedweder Art bezeichnen; damit wird das Amt oder die Amtstätigkeit des Zensors benannt, eines hohen Beamter der Römischen Republik, zu dessen Aufgaben die Durchführung der Volksund Vermögensschätzungen [census], die Besetzung des Senats und die Aufsicht über die Sitten der Römer gehörten. Zensur im engeren publizistischen Sinn meint die Verhinderung bestimmter, vermeintlich nicht förderlicher Informationen von Seiten einer Obrigkeit, früher auch von Kirche und Papst, im modernen Staat durch staatliche Behörden, Justiz oder Polizei (Breuer 1990; Plachta 2006).

Moderne Zensur setzt Öffentlichkeit voraus, die weitgehend durch Medien konstituiert wird (Habermas 1990; Hohendahl 2000; Wendelin 2011), und sie bedarf eines kundigen, politisch selbstbewussten Publikums, das seine Informations- und Meinungsfreiheit einfordert und/oder wahrnimmt. Zensur liegt im Interesse von Staat oder staatsähnlichen Gebilden in autoritären Regimen und wird von ihnen möglichst vor Publikwerden der Information ausgeführt. In diesem konkreten Sinn meint Zensur also staatliche Vorzensur, Informationsboykott vor der Publikation. Einer der Wesensbestandteile moderner Demokratie ist das Menschen- oder Grundrecht auf freie Information und Meinung, auf Presse- und Medienfreiheit, weshalb sich Zensur verbietet: „Eine Zensur findet nicht statt“, heißt es daher im zuständigen Artikel (5.1 GG) des Grundgesetzes der Bundesrepublik Deutschland. Auch die Europäische Union und die Vereinten Nationen bekennen sich zu diesem Menschenrecht.

Weiter gefasst, meint Zensur jede Informationsbehinderung: etwa wenn Medien und Verlage auf wirtschaftliche Interessen Rücksicht nehmen und Informationen unterdrücken oder manipulieren, da sie von jenen über die Werbefinanzierung weitgehend abhängig sind, oder wenn von Medienproduktionen und Redaktionen bestimmte Rücksichtnahmen oder Sichtweisen aus eigenem oder ideologischpolitischem Interesse praktiziert werden. Dann spricht man von (informeller) 
Selbstzensur, in materialer Anschaulichkeit auch von der "Schere im Kopf“. Systemische Dimensionen hat Nachrichtenkontrolle bzw. -gestaltung in Regimen, die aus politischen Restriktionen, ideologischen, religiösen, kulturellen und ethischen Prämissen oder auch aus wertbezogenen, oft genug latenten Perspektiven vorgenommen werden. So hatte der frühere Sowjetblock eine massive Nachrichtenrepression, und heute reproduzieren sich diese Mechanismen - wenn auch weniger stark - in Russland. Islamische Staaten bekennen sich sogar zu ihrer praktizierten, religiös verbrämten, oft auch autoritär-politisch intendierten Nachrichtenauswahl und -unterdrückung. China rühmt sich eines landesweiten Zensursystems um der Regimestabilität willen.

Aber selbst westliche Demokratien üben in ihren etablierten Medien Nachrichtenselektion aus: Sie ist einerseits zwangsläufig, da die ständig wachsende Flut von Informationen sortiert und gewichtet werden muss (Schulz 1976; Staab 1990). Erfolgt sie indes stets und vorwiegend mit bestimmter Gewichtung, etwa hinsichtlich bestimmter Regionen, Länder, Regime, Gruppierungen oder auch Themen, lassen sich deutliche, absichtliche oder systemisch inkorporierte Filter vermuten, durch die Nachrichten unterdrückt, verzerrt oder frisiert werden. Diese Aussonderungen oder auch nur Akzentuierungen praktizieren schon bei der Nachrichtenproduktion die führenden Nachrichtenagenturen (Reuters, AP, AFP), denen oft westliche Voreingenommenheit vorgeworfen wird (Steinweg 1994; Wilke 1993, 2000). In der modernen Nachrichtenforschung werden dafür so genannte Nachrichtenfaktoren identifiziert, die den Wert einer Nachricht und damit die Wahrscheinlichkeit ihrer Verbreitung, Platzierung und Relevanz bestimmen sowie Parameter für die Interpretation von Wirklichkeit und für die Prioritäten und Werte gesellschaftlicher Systeme erkennen lassen (Schulz 1976; Eilders 1997; Ruhrmann u. a. 2003). Web-Plattformen wie „mediawatch.com/org“ (www.nichtmit-uns.de) decken die Selektionen bzw. die „unterdrückten Nachrichten“ auf.

\subsubsection{Zur Geschichte der Zensur}

Die Geschichte der modernen Zensur ist zum einen an die Erfindung des mechanischen Drucks von Johannes Gutenberg seit Mitte des 15. Jahrhunderts sowie an die für damalige Verhältnisse rasche Verbreitung von Druckereien und Druckwerken (Flugblätter, Hefte, Breviere) geknüpft, die Martin Luther schon recht professionell für die Diffusion seiner Reformideen nutzte. Zum anderen hatte sich der Römische Bischofssitz allmählich als zentrale Leitungsinstanz der katholischen Kirche etabliert und suchte mit der exekutiven Unterstützung weltlicher katholischer Mächte (Habsburg, Spanien) die bald ihrem Monopol 
entrinnende, sich unkontrolliert verbreitende Flut nicht sanktionierter Druckwerke zu verhindern (Breuer 1990). Auf Konzilen und in päpstlichen Bullen wurde die kirchliche Zensur schon 20 Jahre nach Gutenbergs Erfindung beschlossen. Ausgeführt wurde sie durch die katholischen Fakultäten der Universitäten, in Deutschland etwa von der in Frankfurt. Ihnen mussten alle Neuerscheinungen, die meist auf Messen anfangs von den Druckern selbst verkauft wurden, zur Billigung vorgelegt werden; die zugelassenen Drucke wurden in Listen eingetragen, die anderen gerieten auf den so genannten Index.

Traurige Berühmtheit, nicht zuletzt wegen seiner langen Laufzeit, errang der Index Librorum Prohibitorum (Verzeichnis der verbotenen Bücher, kurz auch Index Romanus genannt) - ein Verzeichnis der nicht genehmen Bücher der römischen Inquisition. Erstmals erschien es 1559, seine letzte amtliche Ausgabe datiert von 1948 mit Nachträgen bis 1962, und es nannte zuletzt 6000 Bücher. Erst 1965 wurde dieser Index nach dem Zweiten Vatikanischen Konzil abgeschafft. Für einen gläubigen Katholiken war der "Index“ verbindlich; die Lektüre der dort gelisteten Bücher galt als schwere Sünde, für manche drohte die Exkommunikation. Allerdings funktionierte er als Nachzensur; oft dauerte es bis zu zwei Jahre zwischen der Erstpublikation eines Werkes und dem Beginn des Zensurverfahrens. Da die Kirche aber nicht über weltliche Sanktionsmittel verfügte, konnte sie das vollständige Verschwinden der indizierten Werke nicht durchsetzen, mit der anhaltenden Säkularisierung seit dem 20. Jahrhundert immer weniger.

Auch die weltlichen Mächte in verschiedenen Ländern führten nationale Indizes ein, die je nach politisch-ideologischer Ausrichtung der Obrigkeit Bücher und Druckwerke sanktionierten. Im Heiligen Römischen Reich Deutscher Nation war der Reichshofrat für die Kontrolle des Schrifttums zuständig. Ihm unterstand die Kaiserliche Bücherkommission in Frankfurt am Main. Die einzelnen Fürstentümer und Länder exekutierten ihre eigenen Kontrollen, zu Zeiten der religiösen Auseinandersetzungen - etwa im und nach dem Dreißigjährigen Krieg vornehmlich entsprechend dem Bekenntnis des Herrscherhauses: Allmählich traten der Schutz des feudalen Regimes und seiner Repräsentanten sowie moralische und Verhaltensnormen zur Aufrechterhaltung der bestehenden Ordnung in den Vordergrund. Außer den katholischen Staaten im Süden machte sich das protestantische Preußen mit Dekreten seiner Herrscher für Zensurmaßnahmen stark.

Strenge Zensurgesetze erließ 1803 Napoleon in den eroberten Reichsgebieten sowie in den assoziierten Staaten Baden, Bayern und Rheinland; sie waren vor allem politisch ausgerichtet. Ab 1809 wurde in jedem Ort mit Buchdruckereien oder Buchhandlungen ein Zensor eingesetzt. Auf dem Wiener Kongress 1815 wurde die Pressefreiheit in die Deutsche Bundesakte aufgenommen, aber nur in wenigen Staaten ansatzweise praktiziert. Mit den Karlsbader Beschlüssen 1819 wurde 
eine strenge, für den Deutschen Bund einheitliche Zensur eingeführt. Sie sah eine präventive Zensur für alle Publikationen mit weniger als 20 Druckbogen und eine nachträgliche, repressive Zensur für alle darüber hinausgehenden Publikationen vor. Spitzel und Polizei überwachten die Vorgaben. Autoren und Verlage übten sich daher in der gezielten Kalkulation von Umfängen ihrer Druckwerke.

Die Freiheitsbewegungen in Deutschland wie in den Nachbarländern in den 1830er Jahren beantworten die Regenten mit der Verschärfung der Zensurbestimmungen; sie ließen sich indes nur noch bis zu den Aufständen Ende der 1840er Jahre aufrechterhalten. Die erste Parlamentarische (National-) Versammlung in der Frankfurter Paulskirche 1848/49 forderte Pressefreiheit und schrieb sie in die Verfassung von 1851. Erstmals in einem gültigen Gesetz wurde sie 1874 im Reichspressegesetz des Deutschen Reiches fixiert. Aber die so genannten Sozialistengesetze unter Bismarcks Reichskanzlerschaft schränkte sie primär für alle linken Presseprodukte wieder ein. Auch danach gab es immer wieder Einschränkungen, besonders dann für das neue Medium Film.

Während des Ersten Weltkriegs war seit 1915 das Kriegspresseamt für die militärisch relevante Zensur zuständig. Erstmals in der Verfassung verankert wurde die Presse- und Meinungsfreiheit in der Weimarer Reichsverfassung von 1918. Allerdings erlaubte das am 21. Juli 1922 verabschiedete Republikschutzgesetz drastische Eingriffe in die Presse- und Versammlungsfreiheit. Am 18. Dezember 1926 verabschiedete der Reichstag zudem das Gesetz zur Bewahrung der Jugend vor Schund- und Schmutzschriften - erklärtermaßen eine Jugendschutzmaßnahme, die aber auch als allgemeine Zensur wirkte.

Mit der Machtübernahme der Nationalsozialisten wurde die Presse- und Meinungsfreiheit praktisch abgeschafft und die politische Vor-Zensur durch Parteiinstanzen eingeführt: Nach der Bücherverbrennung in vielen Städten wurden ab dem 31. Mai 1933 jüdische und politisch missliebige Autoren und Verleger rigoros verfolgt. Das Schriftleitergesetz vom Oktober 1933 definierte den Journalismus als eine vom Staat geregelte Aufgabe. Das Reichskulturgesetz vom September 1934 vervollständigte die Gleichschaltung der Medien. Ab 1935 stellte die Reichsschrifttumskammer schwarze Listen unerwünschter Bücher zusammen, die nicht mehr im Buchhandel verbreitet werden durften.

Nach dem Ende des Zweiten Weltkriegs 1945 wurden in allen deutschen Besatzungszonen eine Lizenzierungspflicht vor allem für Presseprodukte und die so genannten Altverleger eingeführt sowie eine Liste der auszusondernden Literatur erstellt, die aus der NS-Zeit stammte. In den westlichen Besatzungszonen wurde die Lizenzpflicht mit der Verabschiedung des Grundgesetzes 1949 aufgehoben, in der SBZ (Sowjetisch Besetzte Zone), später in der DDR wurde sie als Druckgenehmigungsverfahren von Partei und Staat bis zu 
ihrem Ende 1989 mehr oder weniger konsequent weitergeführt, obwohl die DDRVerfassung von 1949 und ihre zwei weiteren Versionen von 1968 und 1974 in ihrem Artikel 27 formal Meinungs- und Pressefreiheit vorsahen. Im Grundgesetz ist Medien- und Meinungsfreiheit im Art. 5 als unverrückbares Menschen- und Grundrecht gesichert. Absatz 2 formuliert drei Einschränkungen hinsichtlich der "Vorschriften allgemeiner Gesetze“ - worunter vor allem strafrechtliche Vorschriften rechnen -, des „Schutzes der Jugend“ und des „Rechtes der persönlichen Ehre". Sie wie der so genannte Kunstvorbehalt (Art. 5 Abs. 3) waren und sind immer wieder Gegenstand juristischer Auslegungen und Entscheidungen, die für Kritiker wiederholt an die Grenzen informeller Zensur heranreichen.

Im Laufe der bundesdeutsche Geschichte sind auch immer mal wieder Verstöße unternommen worden, die Presse- und Medienfreiheit einzuschränken oder für bestimmte Produkte auszusetzen: Meist geschahen sie unter dem Vorwand politisch-ideologischer Indoktrination etwa in Zeiten des Kalten Krieges (wie bei der Überprüfung von Spielfilmen aus Osteuropa seit 1953), politisch-militärischer Sicherheit (wie etwa bei der SPIEGEL-Affäre 1962), zur angeblichen Aufrechterhaltung der sittlich-moralischen Ordnung anlässlich von freizügigen Filmen (wie etwa bei Die Sünderin mit Hildegard Knef 1951) sowie gegen aktuelle Gefahrenabwehr und mutmaßliche Rechtsverstöße (zumal im Kontext aufwühlender TerrorismusVerfolgung), wo Presse-Privilegien wie Information- und Quellenschutz unter der Maßgabe der Strafvereitelung missachtet werden. Die 1985 gegründete internationale (Nichtregierungs) Organisation Reporter ohne Grenzen (ROG) - die deutsche Sektion existiert seit 1994 in Berlin -, die jährlich ein Ranking der weltweiten Medien- und Pressefreiheit publiziert, platzierte die Bundesrepublik Deutschland 2012 zusammen mit Jamaika und Zypern auf Platz 16. Finnland, Norwegen, Estland, die Niederlande, Österreich, Island, Luxemburg, Schweiz, Dänemark, Schweden und Irland sind in dieser Reihenfolge als europäische Länder vorweg rangiert. Als Begründung wurde angeführt, dass exekutive Behörden trotz der Wachsamkeit des Bundesverfassungsgerichts über die Medienfreiheit immer wieder journalistisches Material zu beschlagnahmen, undichte Stellen in staatlichen Apparaten ("Whistleblower") zu ermitteln, das Recht auf Zugang zu den Akten öffentlicher Stellen zu behindern suchen sowie Informanten von Journalisten nicht sorgfältig und aktiv genug schützen.

Vor gänzlich neuen Herausforderungen stellt das Internet potentielle Zensurbestrebungen - besonders deutlich, wenn sie mit traditionellen Boykottmitteln bewerkstelligt werden (Zelger 1999; Scholz 2004; Koreng 2010). Denn das Internet bemisst sich nicht nach nationalen Grenzen, Rechtsmitteln und Strafverfolgungen. Seine Einschränkungen rufen sofort den ,OnlineSchwarm' von Kritikern und Helfern hervor, so dass selbst geringfügige Maßnahmen nicht geheim, nicht einmal unkommentiert bleiben: 2002 versuchte 
beispielweise der von der SPD in Düsseldorf gestellte Regierungspräsident, Jürgen Büssow, mehreren Internetprovidern in Nordrhein-Westfalen den Zugang zu verschiedenen Seiten auf ausländischen Servern, die rechtsextremistische und nationalsozialistische Inhalte transportierten, sowie den Zugang zur amerikanischen Gore-Seite rotten.com zu sperren. Er handelte sich erheblichen Online-Protest ein. Im April 2009 legte die damalige Familienministerin Ursula von der Leyen einen Gesetzentwurf zur Bekämpfung der Kinderpornografie in Kommunikationsnetzen vor. Er sah vor, alle Provider in Deutschland zu verpflichten, vom Bundeskriminalamt inkriminierte Seiten mit strafbaren Angeboten $\mathrm{zu}$ sperren. Auch dieser Vorstoß musste bald zurückgenommen werden. Denn erstmals wurde online eine Petition eingebracht, bei der sich über 134.000 Personen gegen eine Sperrung von Internetseiten aussprachen. Im April 2011 entschied die Bundesregierung, das bereits beschlossene, aber nie zur Anwendung gelangte Gesetz wieder aufheben zu lassen; am 1. Dezember 2011 wurde es von einer breiten Mehrheit im Bundestag endgültig kassiert.

\subsubsection{Zensur im Internet}

\subsubsection{Weltweite Entwicklungen}

Auch für das Internet bestehen mithin Bestrebungen von Staaten und Gruppierungen, Publikation und Verbreitung bestimmter Inhalte $\mathrm{zu}$ kontrollieren, zu unterdrücken oder im eigenen Sinn zu steuern. Im Fokus sind dabei vorrangig die öffentlichen Dimensionen des Internets, seine privaten fallen eher unter Bewachung und Strafverfolgung. Zensuriert werden demnach politische, wirtschaftliche, ideologische, aber auch religiöse und erotische Inhalte, je nach den normativen Vorgaben des zensurierenden Regimes. Vielfach werden gesetzliche, aber auch willkürliche Richtlinien angewendet, die auch schon bei den traditionellen Massenmedien praktiziert wurden. Insofern ähneln sich auch die Staaten darin, wie sie Presse- bzw. Medienfreiheit und die Freiheit des Internets garantieren bzw. unterdrücken.

Bei einer Auflistung der „Feinde des Internets 2011“, erstellt von der Organisation Reporter ohne Grenzen (ROG) (http://Propz.de/wp-content/uploads/2011/02/internetzensur-weltweis.jpg), fällt auf, dass auch Staaten, die gemeinhin als Garanten der Medienfreiheit gelten oder sich so feiern lassen wie etwa die europäischen, nur das Prädikat „etwas Zensur" erhalten haben. Die Kriterien dafür sind allerdings in den zugehörigen Berichten nicht hinreichend offengelegt und begründet worden womöglich ein Grund, weshalb ab 2012 nur noch zwischen "Internet-Feinden“ und "Staaten unter Beobachtung" unterschieden wird. Unter den letzteren sind 
solche verzeichnet, die im laufenden Jahr Maßnahmen gegen das Internet, meist gegen bestimmte Teile oder Betreiber wie Hosts ergriffen haben und die nun in ihrem weiteren, womöglich internetfeindlichen Tun beobachtet werden sollen.

Über sie heißt es im Pressebericht von ROG: „Jedem dritten Internetnutzer weltweit bleibt der Zugang zu einem freien Netz verwehrt. In zehn Staaten ist die Überwachung des Internets und die Verfolgung von Bloggern und Internetnutzern so stark, dass sie den Titel ,Feinde des Internets' verdienen. Das EU-Mitglied Frankreich und die Staaten Libyen und Venezuela stehen in diesem Jahr erstmals ,Unter Beobachtung' “

Auf der Liste der „Feinde des Internets" stehen wie in den beiden Vorjahren Birma, China, Kuba, Iran, Nordkorea, Saudi Arabien, Syrien, Turkmenistan, Usbekistan und Vietnam. Diese Staaten zensieren das Internet durch massive Filterungen und Sperrungen von Websites, verfolgen kritische Internetnutzer systematisch und instrumentalisieren das Netz für propagandistische Zwecke. Auch weil Internetnutzer in Ländern wie China, Iran und Saudi Arabien zunehmend Programme zur Umgehung von Zensur nutzen, haben viele autoritäre Staaten in den vergangenen Jahren über das Blockieren und Filtern hinausgehende Methoden der Online-Überwachung entwickelt: Staatliche Mitarbeiter oder eine eigens geschaffene Cyberpolizei kontrollieren Inhalte im Netz oder infiltrieren soziale Netzwerkseiten. Blogger werden dafür bezahlt, Kommentare auf gut besuchten Websites zu platzieren. Websites werden durch Cyberattacken oder Spyware lahmgelegt. Mit neuen Gesetzen versuchen die Regierungen Internetnutzer zu zwingen, ihre Anonymität aufzugeben. In Ländern wie Birma war mehrfach zu beobachten, dass die Geschwindigkeiten der Internetverbindungen so stark gedrosselt wurden, dass eine Nutzung des Mediums für die Bevölkerung kaum mehr möglich war. Die Störungen gehen in einigen Ländern bis hin zur Abschaltung des Internets und sind häufig begleitet von Unterbrechungen des Mobilfunks.

16 Staaten stellt ROG in seinem Bericht „Unter Beobachtung“. Es handelt sich um Länder, die beunruhigende Zensurmaßnahmen ergriffen haben, die leicht missbraucht werden könnten. In Frankreich stimmte die Nationalversammlung in zweiter Lesung im Februar 2011 dem Online-Gesetzespaket ,Loppsi 2' (Loi d'orientation et de programmation pour la performance de la sécurité intérieure) zu. Das Innenministerium kann jetzt unter anderem ohne gerichtliche Anordnung Provider anweisen, die Webseiten ihrer Kunden nach pädophilen Inhalten zu filtern. Die Schlüsselwörter hierfür sucht eine Regierungsbehörde ohne Kontrolle durch ein „Gericht aus“ (ROG 2012).

Die Open Net Initiative (ONI), die sich aus Gruppen von Forschern der Universitäten von Toronto, Oxford, Cambridge und der Harvard Law School zusammensetzt, beobachtet eine weltweite Zunahme der Zensur im Internet. Die von der 
US-Regierung finanzierte Organisation Freedom House kommt im März 2009 in ihrer 15 Länder umfassenden Studie Freedom on the Net zu dem Ergebnis, dass in allen untersuchten Ländern Internetinhalte reguliert oder zensiert werden. Mit Ausnahme Großbritanniens sei das Internet allerdings noch insgesamt weniger reguliert als die Presse. Einige Regierungen beschäftigen nach Angaben der Organisation auch sogenannte "Cyberclaqueure“ zur Manipulation von Inhalten in OnlineDiskussionen. Bei vielen Nutzern stellt sie einen „staatsbürgerlichen Aktivismus“ fest, um vermehrt Gegenmaßnahmen zu entwickeln. Allerdings werde ihrer Ansicht nach mit dem Fortschreiten der technischen Entwicklung auch die Zensur in autoritären wie demokratischen Staaten weiter zunehmen. Als bedenklich wird die zunehmende Auslagerung der Zensurmaßnahmen an private Internetdiensteanbieter eingeschätzt.

Generell sind Normen und gesetzliche Regelungen in den Staaten auf der Welt oft nicht kompatibel. Regierungen und staatliche Organe können zwar durch Abschalten von Webseiten, die in ihrem Rechtsbereich liegen, auch Bürger anderer Staaten von diesen Informationen abhalten, jedoch können sie nicht verhindern, dass die Bürger sich Zugang zu illegalen Informationen verschaffen, die im Ausland liegen. Während beispielsweise in den USA erotische und sexuelle Darstellungen relativ schnell geahndet werden, hingegen rassistische und sogar faschistische Aussagen weitgehend toleriert sind und unter die Meinungsfreiheit fallen, sind in Deutschland infolge seiner Geschichte die Verherrlichung der NS-Kriegsverbrechen oder auch die Leugnung des Holocaust verboten. Entsprechend Gesinnte können sich indes ungehindert von den US-Servern bedienen.

In Dubai, auf dem Weltgipfel der Internationalen Fernmeldeunion (ITU), starteten im Dezember 2012 autoritäre Staaten wie China und Russland zusammen mit einigen Schwellenländern einen neuen Vorstoß, um der ITU mehr Rechte bei der Verwaltung des Internets zu übertragen und gemeinsame Regeln für CyberSicherheit zu beschließen. Bislang war die ITU, anfangs zuständig für die globalen Funkfrequenzen und Tarife für Ferngespräche, an der Internet-Entwicklung und -Administration kaum beteiligt. In Zeiten, in der Skype-Chats zunehmend Ferngespräche ersetzen, ist die ITU auf der Suche nach neuen Aufgaben. Entsprechend haben die westlichen Länder ihre Mitgliedsbeiträge in den vergangenen Jahren deutlich reduziert; die Schwellenländer die ihren hingegen massiv erhöht, so dass deren Einfluss gestiegen ist. Mittels der ITU soll die Rolle der Nationalstaaten im Internet gestärkt und das Internet international kontrolliert werden, fordert nicht nur Russlands Präsident Wladimir Putin. So können die Zuteilung und Kontrollen von IP-Adressen sowie der Kauf von Domains, die bislang von der Nichtregierungsorganisation ICANN mit Sitz in den USA vorgenommen wird, an die ITU übertragen werden. Im Einzelnen sollen folgende Bereiche nach dem Vorschlag der „Regulierer“ in einem neuen ITU-Vertrag fixiert werden: 
- Die ITU-Regularien sollen auch Internet-Infrastruktur und Internet-Dienste umfassen. In den Definitionen führt das Dokument als Begriff „nationale Internet-Segmente" ein - also jene Teile der Netzinfrastruktur, die im Hoheitsbereich bestimmter Nationalstaaten liegen.

- Die Nationalstaaten sollen das Netz technisch regulieren. Alle ITUMitgliedstaaten sollen "gleiche Rechte" zur Regulierung von Adress- und Namensräumen haben - dieser Passus dürfte darauf zielen, die Position der Internet-Adressverwaltung ICANN zu schwächen.

- Über technische Details hinausgehende Internet-Regulierungen und die Kontrolle über die „nationalen Internet-Segmente“ soll den Nationalstaaten obliegen - ein Hinweis auf das Grundrecht auf Meinungs- und Informationsfreiheit fehlt. Der Begriff „public policy on matters of Internet governance" wird nicht weiter ausgeführt und könnte in dieser Breite womöglich auch die Filterung bestimmter Inhalte umfassen (SPIEGEL-Online vom 9. Dezember 2012).

Die westlichen Staaten, voran die USA und Deutschland, wollen eine stärkere Internetregulierung durch die ITU und damit durch die Nationalstaaten um jeden Preis verhindern. Sie wollen die zuletzt vereinbarten, sehr allgemein und unverbindlich gehaltenen Regeln namens International Telecommunications Regulations (ITR) von 1988 beibehalten und setzten sich auf dem Weltgipfel 2012 noch einmal durch (SPIEGEL-Online vom 3. Dez. 2012).

\subsubsection{Zensur-Tendenzen in Europa}

Die EU-Richtlinie 2000/31/EG vom 8. Juni 2000 zum E-Commerce macht Provider für den Inhalt der Webseiten verantwortlich, die sie hosten, und verlangt von ihnen, diese zu blockieren, wenn sie Kenntnis von ihrem illegalen Charakter erhalten. Nach Ansicht der Organisation Reporter ohne Grenzen schafft diese Vorgabe eine Art privates Rechtssystem, in dem die Provider und ihre Techniker das Richteramt ausüben. Das Europäische Parlament und der Rat der Europäischen Union haben 2003 der Weiterführung eines Aktionsplans zur sicheren Nutzung des Internets zugestimmt. Es soll stärker gegen illegale und schädliche Inhalte vorgegangen werden.

Weitgehende Übereinstimmung besteht in Europa - inzwischen auch darüber hinaus - beim Verbot kinderpornografischer Seiten bzw. Bilder und der Verfolgung seiner Urheber und Nutznießer: In der Europäischen Union werden mit Unterstützung von Europol die Web-Seiten mit dem Child Sexual Abuse Anti Distribution Filter (CSAADF) des CIRCAMP-Projekts, einer Domain Name System-Blockadeliste (DNS), gesperrt. So soll verhindert werden, dass Bilder und Filme missbrauchter Kinder weiterhin im Internet kursieren und sie dadurch erneut zu Opfern werden. Im März 2010 wurde der CSAADF in Dänemark, 
Finnland, Italien, Neuseeland, Norwegen, Schweden und der Schweiz eingesetzt. Das Vereinigte Königreich von Großbritannien sperrt diese Internetseiten mit dem Contentfiltersystem Cleanfeed.

Auf der 38. Europäischen Regionalkonferenz der IKPO-Interpol Ende Mai 2009 wurde empfohlen, eine globale „Sperrliste“ von Internet-Adressen zu erstellen, die auf Zulieferungen aller Interpol-Mitgliedsstaaten basiert. Damit soll auf internationaler Ebene ein deutliches Zeichen für den Kampf gegen Kinderpornografie im Internet gesetzt und zugleich dem Umstand Rechnung getragen, dass das Internet weltweit eine zentrale Rolle bei der Verbreitung von Kinderpornografie einnimmt. 2009 in Singapur wurden diese Empfehlungen bekräftigt.

Im April 2011 startete auf europäischer Ebene das Projekt Clean IT. Es beruht auf dem Konzept der Partnerschaft zwischen europäischen Sicherheitsbehörden und verschiedenen IT-Unternehmen. Dabei sollen Vorgaben für die IT-Industrie entwickelt werden, die die Unternehmenspartner freiwillig einhalten. So soll die „terroristische Nutzung des Internets eingeschränkt“ und die „illegale Nutzung des Internets bekämpft" werden. Letztlich wird eine flächendeckenden Kontrolle der Netzinhalte angestrebt, zunächst auf europäischer, später womöglich auch auf globaler Ebene.

\subsubsection{Zensurmaßnahmen in einzelnen Staaten}

Afghanistan: In Afghanistan werden seit Juni 2010 Facebook, YouTube, Twitter, G-Mail und Webseiten, die die Themen Alkohol, Dating/soziale Netzwerke, Glücksspiel und Pornographie beinhalten, gesperrt.

Australien: Die australische Regierung beabsichtigte 2008 mit dem Plan for CyberSafety den Zugang zu Websites, die auf einer von der Regierung vorgegebenen, nicht öffentlichen Sperrliste stehen, für alle Internetzugänge sperren zu lassen. Dagegen reichten über 120.000 Personen eine Internetpetition ein. Im Mai 2009 wurde von der Telekommunikations-Regulierungsbehörde Australian Communications and Media Authority (ACMA) bei einer Anhörung vor dem Senat Estimates Committee im australischen Parlament bekanntgegeben, dass die australische Sperrliste 977 Einträge enthielt, davon bezogen sich 32 Prozent auf Kindesmisshandlungen oder sexuellem Kindesmissbrauch. Die ACMA führte seither Gespräche mit der Internet Watch Foundation in Großbritannien und korrespondierenden Stellen in den USA über einen Austausch der Sperrlisten und erwägt Optionen für mehr Transparenz und Verantwortlichkeit beim Führen der Negativliste.

China: Die chinesische Regierung zensiert das Internet mit einem Mix aus Zensur-Technik (wie Filter), Ausspähung und Einschüchterung der Anwender und Forderungen an ausländische Internet-Unternehmen. „China ist weltweit 
das größte Gefängnis für Cyber-Dissidenten mit derzeit 62 Menschen in Haft für Online-Veröffentlichungen“, so der Bericht von Reporter ohne Grenzen 2011. So sind neben pornographischen Seiten die Auftritte religiöser und politischer Gruppierungen, die die chinesische Regierung als schädlich ansieht, sowie renommierte Nachrichtendienste gesperrt. Dies galt zeitweise für die BBC und ab dem 18. Oktober 2005 für Wikipedia; beide sind inzwischen wieder zugänglich. Wikipedia hatte sich geweigert, politische Einträge für eine chinesische Version zu blockieren. Sehr beliebte Seiten wie YouTube, Twitter und Facebook sind gesperrt. Microsoft, Yahoo und Google zensieren dagegen die Inhalte gemäß den Wünschen der chinesischen Regierung; inzwischen bietet Google keine Suche mehr in China an. Die Seite www.google.cn verweist auf die Google-Suche in Hongkong. In Absprache mit den chinesischen Behörden werden für die chinesische Öffentlichkeit brisante Seiten zu Themen wie Tibet oder Taiwan nicht angezeigt.

Kuba: Internetzugang ist für die heimische Bevölkerung nur mit Einschränkung möglich. Mittlerweile können aber Kubaner Touristenhotels regulär nutzen, müssen hierfür allerdings in Devisen bezahlen. Diese Hotels verfügen überwiegend über einen langsamen Internetzugang, welcher gegen Bezahlung eines Tickets ohne jede weitere Kontrolle zugänglich ist. Die dabei aktiven Sperren betreffen systemkritische Internetseiten primär aus den USA (z. B. von Exilkubanern). Darüber hinaus braucht man eine Spezialgenehmigung für einen privaten Internetzugang, welcher nur sehr restriktiv erteilt wird. Verbreitet sind allerdings private Internetzugänge über das drahtgebundene Telefonnetz ohne Genehmigung, welche aber mit hohen Telefonkosten verbunden sind. Eine massive Erhöhung der Datenübertragungsraten und Reduzierung der Preise steht nun unmittelbar durch ein Internet-Seekabel aus Venezuela bevor.

Indien: Das Land hat eine extrem wachsende Reichweite für das Internet. Ende 2011 waren es ungefähr 100 Millionen Netizens. Insbesondere nehmen mobile Internet-Applikationen $\mathrm{zu}$, da ihr Preis kontinuierlich sinkt. Die nationale Sicherheitspolitik schränkt indes die Meinungsfreiheit und die Privatheit der Internetuser zunehmend ein, weshalb das Land bei ROG „unter Beobachtung“ steht. Seit den Bombenanschlägen in Mumbai 2008 hat die Regierung die Onlineüberwachung verschärft. Außerdem wird die Überwachung des Webs erweitert. Auch Google wurde von den indischen Behörden 2010 mehrfach aufgefordert, kritische politische Inhalte, vor allem in Videos, die auf YouTube und in einigen Blogs zu sehen waren, zu unterdrücken. In schätzungsweise mehr als einem Fünftel der 282 Fälle folgte Google der Order (ROG 11. März 2012).

Iran: Das Informationsministerium erklärte, dass es derzeit Hunderttausende von Webseiten blockiert, und zwar sowohl Sex- als auch Nachrichtenseiten. Eine 
unbekannte Anzahl von Bloggern wurde von Herbst 2004 bis Sommer 2005 verhaftet. Seit 2006 wird das Internet verstärkt zensiert (SPIEGEL-Online vom 23. Juli 2006). Eine Zentralstelle für Filtering, die im Sommer 2006 ihre Arbeit aufgenommen habe, bekämpft alle unerwünschten Seiten; sie werden nach bestimmten Schlüsselwörtern blockiert. Außerdem suchen die Mitarbeiter der Zentralstelle im Web gezielt nach Inhalten, die sie zensieren können. Im Zuge der Proteste im Jahre 2009 wurde die Internet-Zensur nochmals verschärft.

Türkei: Seit 2007 können lokale Strafgerichte des Landes Websites wegen pädophiler oder pornografischer Inhalte, Verherrlichung von Drogen, aber auch wegen Beleidigungen des Staatsgründers Atatürk blockieren. Mehrfach wurde wochenlang so die Videowebsite YouTube gesperrt, aber auch Indymedia, Google Groups und der Blog-Anbieter Wordpress waren von der Zensur betroffen.

USA: Die USA, die bei der Garantie der allgemeinen Pressefreiheit nur auf Platz 47 rangieren, sind explizit nicht wegen staatlicher Einschränkungen nominiert. Dennoch sind immer wieder Initiativen zu vermelden, die in diese Richtung weisen. So veröffentlichte das Project for the New American Century, dessen Mitglieder sich in der Regierung Bush wiederfanden, im September 2001 ein Dokument, in welchem dem Internet eine große Bedeutung in der modernen Kriegsführung und Informationspolitik und -beschaffung beigemessen wird. Ferner wird seit 2011 über ein Gesetzesvorhaben diskutiert (Stop Online Piracy Act, kurz SOPA), mit dem Google, Ebay, Facebook (mithin quasi alle sozialen Netzwerke), Bezahldienste wie Paypal, Visa und viele andere Seiten mit Kontrollen und Repressionen zu rechnen hätten. Vorderhand soll das Gesetz gegen InternetPiraterie vorgehen, aber es würde gleichzeitig viele große Seiten einschränken. Denn beim leisesten Verdacht, dass eine Verletzung eines Urheberrechts oder Markenzeichens besteht, könnte der Internetanbieter gezwungen werden, diese Websites zu sperren. Außerdem soll jeder Seitenbetreiber für seine Angebote haftbar gemacht werden.

\subsubsection{Informelle Zensurmaßnahmen}

Neben der staatlichen, meist offenen Zensur werden wiederholt weltweit rechtlich oder völkerrechtlich fragliche Praktiken und Vorhaben bekannt, die die Meinungsfreiheit im Web bedrohen oder beschränken:

So leisten große Internetanbieter nach Angaben von Menschenrechtsorganisationen Beihilfe zur Zensur in Ländern mit eingeschränkter Meinungsfreiheit. In Myanmar liefert nach Angaben von Reporter ohne Grenzen das US-Unternehmen Fortinet die Technologie zur Blockierung von oppositionellen Webseiten. 
US-Internetunternehmen wie Yahoo, Cisco Systems, Microsoft und Google werden von Reporter ohne Grenzen und Amnesty International beschuldigt, mit chinesischen Zensurbehörden zusammenzuarbeiten. Auch in anderen Staaten hat sich Google schon einmal bereitgefunden, politisch und ideologisch heikle Suchergebnisse aus "Rechtsgründen“ nicht anzuzeigen, ohne dass die User von diesen Maßnahmen erfahren. Im Februar 2004 blockierte auch der Internetdienstanbieter Freenet.de Webseiten, die sich kritisch zu dem Unternehmen äußerten: Nutzer seines Dienstes, die versuchten, die unternehmenskritischen Seiten aufzurufen, wurden auf andere Webseiten umgelenkt. Technisch wurde dies durch einen transparenten Proxy realisiert. Im September 2007 sperrte der deutsche Internetprovider Arcor seinen Kunden den Zugriff auf einige ausländische Internetpräsenzen mit pornografischem Inhalt; als Begründung wurde angeführt, diese Seiten hätten nach deutschem Recht kein ausreichendes Altersverifikationssystem. Am 17. April 2009 schlossen fünf deutsche Internetprovider (Deutsche Telekom, Kabel Deutschland, O2, Arcor und Alice) freiwillige Verträge mit der Bundesregierung ab, um Internetseiten mit Dokumentationen missbrauchter Kinder zu blockieren. Die Verträge sehen vor, dass das Bundeskriminalamt (BKA) täglich aktualisierte, geheime und verschlüsselte Sperrlisten von Webseiten mit problematischen Inhalten an die Provider übermittelt.

Ähnlich einem latenten, weltweiten, oft auch am Rande der Legalität verlaufenden Guerillakampf engagieren sich viele Online-Aktivisten, die sich auch als „Cyberpunks“ verstehen (Assange u. a. 2013), gegen aus ihrer Sicht verheerende, geheime Machenschaften, mit denen "neototalitäre“ Staaten, Geheimdienste, aber auch IT-Weltkonzerne wie Google und Facebook totale Überwachung und Kontrolle, Datenspeicherung und -missbrauch, Finanztransaktionen, Unterdrückung, Spionage und virtuelle Kriegsführung gegen die ohnmächtige Weltbevölkerung betreiben. Ihnen gelten ihre ebenso geheimen, mitunter riskanten Aktionen gegen die so genannte unkontrollierte „Kryptografie“. Gegen sie rufen sie zur „digitalen Revolution“ auf, um ein "freies, offenes und universelles Internet" (Ebd., 161) zu erreichen. Bekanntester Pionier ist der in Australien geborene (Mit-)Begründer von WikiLeads, Julian Assange, der seit Sommer 2012 in der ecuadorischen Botschaft in London im politischen Asyl lebt. Die seit 2006 von teilweise unbestimmten Initiatoren eingerichtete Plattform dient der anonymen Enthüllung von geheim gehaltenen Dokumenten und Aktivitäten, um sie der Weltöffentlichkeit publik zu machen und so Kontrolle und Widerstand zu ermöglichen. WikiLeaks firmiert mithin als gänzliches Gegenkonzept gegen jede Zensur und für totale Informationsfreiheit.

Seit Herbst 2009 hatte WikiLeaks sich zu einer zentralen Sammelstelle mit 1,2 Millionen Dokumenten entwickelt. China, Israel, Nordkorea, Russland, Simbabwe und Thailand sperrten den Zugang zu WikiLeaks zumindest zeitweise. 
Die USA wähnen sich nach der Publikation von Militärdokumenten durch den seither inhaftierten GI Bradley Manning angegriffen. Seit September 2010 können keine Unterlagen mehr hochgeladen werden, im Oktober 2011 wurde auch die Veröffentlichung von Dokumenten vorübergehend ausgesetzt. Finanzielle Spenden zur Weiterführung des Projektes werden blockiert (Ebd.).

\subsubsection{Zur Wirkung von Zensurmaßnahmen}

Infolge seiner unbegrenzten Reichweite und der nimmermüden Aktivität seiner engagierten User, die auf jegliche Einschränkung des Inhalte-Angebots und der Meinungsfreiheit allergisch - wenn auch nicht immer angemessen und gerechtfertigt - reagieren, sind Wirkungen von Zensurmaßnahmen fragwürdig. Denn Zensur bedeutet im Internet zwangsläufig Identifikation und Bekanntwerden auch inkriminierter Inhalte. Sie werden dann umgehend von den Zensurkritikern auf anderen Webseiten außerhalb des Zugriffsbereichs des Zensors gespiegelt und zugänglich gemacht, so dass der Zensor zuerst einmal das Gegenteil seiner Absicht erreicht. Er fördert damit die Publikation dessen, was er unterbinden will.

Technische Zugangssperren zu einzelnen Webpräsenzen bzw. IP-Adressen, z. B. durch Content-Filter, sind ferner problematisch, weil dadurch auch der Zugriff auf zusätzliche Inhalte, Websites und E-Mail-Adressen behindert oder gar unterbunden wird. Will man hingegen die Zugangssperre ausschließlich auf die vom Zensor beanstandeten Inhalte fokussieren, ist eine solche Maßnahme technisch aufwändig, kostenintensiv und mit Leistungseinbußen verbunden. Außerdem kann jede Codierung von findigen Hackern überlistet werden; total ist eine solche Sperrung im Netz nie. Bei Sperrungen durch den Internetanbieter sind - je nach technischer Umsetzung der Zugriffssperre - die originären Inhalte meist problemlos weiter abrufbar. Denn oft genug befinden sich die Provider im Ausland. Einige Dienste wie das Tor-Netzwerk und Anonymizer, die zum Schutz der Anonymität im Internet entwickelt wurden, fungieren sogar wie ProxyServer als Überwindung der Zugriffssperren. Eine weitere Möglichkeit, durch Manipulation von DNS-Servern gesperrte Seiten zu erreichen, besteht darin, sie nicht mehr über den Domainnamen, sondern direkt über die entsprechenden IPAdressen im Browser aufzurufen. Oft genug ist es praktisch gar nicht nötig, den Anwender zu umgehen, weil viele von ihnen regelmäßig ihre Domain-Namen ändern und diese Umbenennung auch den potentiellen Usern durch Newsletter mitteilen. Dann ist die Blockierung komplett ausgehebelt.

Ebenso muss ins Kalkül einbezogen werden, wie die jeweilige Bevölkerung auf Zensur und/oder Blockierung von Webseiten reagiert, wie die Medien zusammen 
mit der jeweiligen Öffentlichkeit das Thema aufbereiten und aufbauschen - je nach der Tradition und der Brisanz gefährdeter Meinungs- und Medienfreiheit - und damit politische Bewegungen pro oder contra auslösen. Dafür gab es in den vergangenen Jahren etliche Beispiele, z. B. 2012 die gänzlich unterschiedliche Rezeption und Interpretation des dänischen, auf YouTube verbreiteten Videos Innocence of Muslims, das in westlichen (christlichen) Ländern als wenn auch drastische Satire akzeptiert oder auch goutiert wurde, während es in islamischen Ländern als unerträgliche Beileidung des Propheten Mohammed wahrgenommen wurde und heftige Protestaktionen auslöste.

\subsection{Urheberrecht und Copyright}

\subsubsection{Zur Entstehung und Verbreitung von Urheberrechten und Copyright}

Der Anspruch auf die individuelle Nutzung und Verwertung geistigen Eigentums, ja diese Vorstellung selbst, ist neueren Datums. Es geht nicht wie andere Teile unserer Rechtsdogmatik auf das römische Zivilrecht zurück. Die Antike kannte nämlich kein Urheberrecht. Im Mittelalter fand die Wissensproduktion fast ausschließlich in den Klöstern statt, wo die alten Schriften aufbewahrt, kopiert und kommentiert wurden. Erst im späten Mittelalter versahen die Kommentatoren ihre Arbeiten mit ihrem Namen, machten sich gewissermaßen als ,Urheber ${ }^{\prime}$ kenntlich. Mit der Entstehung der Universitäten verlagerte sich die Wissensproduktion in die profanen Studierstuben. Lehrmaterialien wurden dort gegen Bargeld kopiert und gehandelt. Die Erfindung des Buchdrucks Mitte des 15. Jahrhunderts veränderte die Bedingungen für die massenhafte Fertigung von Kopien grundlegend; umfangreiche Schriftstücke konnten allmählich zu bezahlbaren Preisen hergestellt werden. Schnell tauchte auf den neuen Märkten die unliebsame Konkurrenz von Nachdrucke auf, die gerade erst erschienene Bücher billiger nachdruckten und damit die Gewinne der ursprünglichen Drucker drastisch zu senken drohten. Als Lösung dieses Problems erhielten diese ab etwa 1475 sogenannte ,Druckerprivilegien', d. h. das ausschließliche Recht zum Druck einer bestimmten Schrift für üblicherweise zwei Jahre. Dieses Recht musste aber auch ausgeübt werden - sonst verfiel es, und es galt nur in jenem meist kleinen Land, in dem es zugeteilt worden war (Gehring 2007). Die Zuteilung verlangte überdies die Unterwerfung unter die staatliche Zensur. Belohnt und gefördert wurde also weniger die individuelle Kreativität, sondern die lokale Wertschöpfung oder das politische Wohlverhalten (Hofmann und Katzenbach 2006). 
Mit der Vermehrung der Druckereien entwickelte sich bald ein reger Buchhandel vor allem auf Messen (etwa in Frankfurt und Leipzig), wo Druckwerke getauscht und erworben wurden. Rechtlich erwarb der Drucker damals nach allgemeiner Auffassung die alleinigen Verwertungs- und Eigentumsrechte. In Deutschland dauerte es wegen der Reformation und Glaubensspaltung sowie der deutschen Kleinstaaterei lange, bis sich ein spezielles Urheberrecht durchsetzte. Schneller ging es andernorts: Als Geburtsstunde des individuellen Urhebers gilt ein englisches Gesetz (Statute of Anne) aus dem Jahre 1709/10, das den Schöpfern geistiger Werke ein zeitlich begrenztes Recht auf Kopie und damit Verwertung ihrer Werke zugestand. Ziel dieses Gesetzes war es aber in erster Linie nicht, die Autoren zu begünstigen, sondern - wie es hieß „das Lernen zu fördern“. Die Vereinigten Staaten von Amerika orientierten sich gleich nach ihrer Unabhängigkeit am britischen Vorbild. Ihre Verfassung von 1790 enthielt eine sogenannte ,Copyright-Klausel', die den amerikanischen Kongress ermächtigte, Autoren und Erfindern für begrenzte Zeit das exklusive Recht an ihren Werken und Erfindungen zuzusichern, um - wie in England - „den Fortschritt in der Wissenschaft und den nützlichen Künsten zu fördern" (Gehring 2007). Etwas anders waren die französischen Regelungen aus der Revolutionszeit (1791-1793): Auch sie sahen ein ausschließliches Verwertungsrecht der Urheber vor, begriffen geistige Werke aber als Ausdruck der Person der Urheber, von denen sie nie getrennt werden können.

Somit entstanden im späten 18. Jahrhundert zwei etwas unterschiedliche Urheberrechtskonzeptionen: Während das angloamerikanische Modell (,Copyright') das öffentliche Interesse an Wissensproduktion und -verbreitung in den Vordergrund stellte, setzte das französische Recht (später kopiert von den meisten kontinentaleuropäischen Staaten) den Schöpfer und seine Persönlichkeitsrechte ins Zentrum (Deterding und Otto 2008). Das Copyright schützt in erster Linie die wirtschaftlichen Interessen der Verleger vor Verlusten durch billigere Nachdrucke, es erlaubt die vollständige Übertragung der Rechte vom Autor auf den Verleger und die ,angemessene Verwendung' geschützter Werke für Bildungszwecke oder ähnliches. Auf das Urheberrecht kann jedoch nicht verzichtet werden, der Urheber kann nur Nutzungsrechte einräumen. Teile eines Werkes dürfen unter Hinweis auf den Autor zitiert werden, Vervielfältigungen sind in festgelegtem Umfang erlaubt (,Privatkopie'). Die Schutzdauer ist in beiden Ansätzen etwa gleich (bis 70 Jahre nach Tod des Autors).

Eine Übersicht stellt die beiden Rechtstypen so einander gegenüber (Abb. 6.2).

In Deutschland erließ zuerst Baden ein Urheberrecht nach französischem Vorbild, Preußen folgte 1837, erst nach der Reichsgründung wurde 1871 ein für das ganze Deutsche Reich einheitliches „Gesetz betreffend das Urheberrecht an Werken der bildenden Künste" verabschiedet. Kurz nach der Wende zum 20. Jahrhundert folgten Gesetze zum Schutz musikalischer Werke, der Fotografie und der bildenden Künste. Diese Gesetze haben im Kern bis heute Bestand (Gehring 2007). 


\section{- Urheberrecht und Copyright}

Vergleich zweier ungleicher Brüder

\begin{tabular}{|c|c|c|}
\hline Urheberrecht & Tradition & Copyright \\
\hline $\begin{array}{l}\text { Schützt die geistigen und wirtschaftlichen } \\
\text { Interessen des Autors; Werk ist untrenn- } \\
\text { barer Teil der Autorenperson }\end{array}$ & Ansatz & $\begin{array}{l}\text { Schützt die wirtschaftlichen Interessen } \\
\text { der Verleger; soll öffentliches Wohl durch } \\
\text { wirtschaftlichen Anreiz fördern }\end{array}$ \\
\hline $\begin{array}{l}\text { Verzicht auf Urheberrecht ist unmöglich; } \\
\text { Recht geht durch Tod des Autors auf } \\
\text { Erben über; Urheber kann nur Nutzungs- } \\
\text { rechte einräumen }\end{array}$ & Übertragbarkeit & $\begin{array}{l}\text { Verzicht auf Copyright ist möglich (Werk } \\
\text { fällt dann in Public Domain); kann vom } \\
\text { Autor vollständig übertragen und vom } \\
\text { Empfänger weiterübertragen werden }\end{array}$ \\
\hline $\begin{array}{l}\text { Zitate: Teile eines Werks dürfen unter } \\
\text { Hinweis auf Autor und Beachtung } \\
\text { weiterer Regelungen verwendet werden } \\
\text { Privatkopie: Vervielfältigung für private } \\
\text { Zwecke ist in festgelegtem Umfang } \\
\text { erlaubt } \\
\text { Bildung \& Forschung: Werk kann ohne } \\
\text { Zustimmung des Autors einem abgrenz- } \\
\text { baren Personenkreis für Forschung und } \\
\text { Bildung zugänglich gemacht werden }\end{array}$ & Beschränkungen & $\begin{array}{l}\text { Fair use (USA): "angemessene Verwen- } \\
\text { dung" geschützter Werke (für Bildung, } \\
\text { als Anregung neuer Werke) ist ohne } \\
\text { Zustimmung des Rechteinhabers erlaubt } \\
\text { First sale doctrine (USA): Einmal im } \\
\text { Warenverkehr befindliche Werke können } \\
\text { ohne Zustimmung weiterverkauft werden } \\
\text { Fair dealing (Commonwealth): } \\
\text { erlaubt Erstellung weniger Kopien ohne } \\
\text { Zustimmung für privates Studium, } \\
\text { Rezensionen, Kritik, Berichterstattung }\end{array}$ \\
\hline $\begin{array}{l}\text { Deutschland \& Frankreich: } \quad 70 \text { Jahre } \\
\text { nach Tod des Autors }\end{array}$ & Schutzdauer & $\begin{array}{l}\text { USA: } 70 / 95 \text { Jahre nach Tod des Autors } \\
\text { GB: } 70 \text { Jahre nach Tod des Autors }\end{array}$ \\
\hline $\begin{array}{l}\text { U.a. Deutschland, Frankreich, Schweiz, } \\
\text { Österreich, Niederlande, teilw. EU-Recht }\end{array}$ & Verbreitung & $\begin{array}{l}\text { U.a. USA, Großbritannien, Common- } \\
\text { wealth }\end{array}$ \\
\hline
\end{tabular}

Beim Schutz geistiger Schöpfungen gibt es

weltweit zwei Rechtstraditionen, die sich in

vielen Punkten unterscheiden: das konti-

nentaleuropäische Urheberrecht bzw. droit

d'auteur, und das angloamerikanische des

Copyright.

(cc) $3 \mathrm{BY}-\mathrm{NG}-\mathrm{ND}$ bpl:

Abb.6.2 (c) http://www.bpb.de/gesellschaft/medien/urheberrecht/63355/urheberrecht-undcopyright

Mit diesen und mit späteren Gesetzen wurde der Grundsatz der privaten Eigentumsrechte auf die Welt der Literatur, Musik und der bildenden Kunst übertragen. Später kamen Schutzrechte für werkbezogene Handlungen hinzu, also für Übersetzungen, Inszenierungen und Archivierungen, neuerdings auch für die Entwicklung von Computerprogrammen und die Schaffung von Datenbanken. Diese Regelungen ergingen allerdings ausschließlich im nationalen Rahmen. Werke waren zunächst nur in jenem Land geschützt, in dem sein Urheber Staatsbürgerrechte hatte oder das Werk zuerst veröffentlicht wurde. Für das Werk galt daher auch das entsprechende nationale Recht. 
Mit zunehmender Verbreitung der Werke über nationale Grenzen hinweg wurden internationale Regelungen unumgänglich: Im frühen 20. Jahrhundert erfolgten diese mit der Ratifizierung der Berner und Pariser Konventionen, freilich zunächst nur im Kreise der westlichen Staaten. Diese und weitere internationale Verträge werden seit 1974 von einer neu gegründeten Sonderorganisation der Vereinten Nationen, der World Intellectual Property Organization (WIPO) mit Sitz in Paris, betreut. Im Rahmen dieser Organisation wurden zwei Zusatzverträge zur Berner Übereinkunft erarbeitet, welche diese an die Bedingungen der neuen Medien anpasste: Der WIPO Copyright Treaty über Literatur, Software und Datenbanken und der WIPO Performance and Phonogram Treaty, der Musik, Tonträger und Aufführungen schützt. Zuletzt wurde das Urheberrecht im grenzüberschreitenden Handel durch das 1994 vereinbarte Agreement on Trade-related Aspects of Intellectual Property Rights (kurz: TRIPS-Abkommen) im Rahmen der neu gegründeten Welthandelsorganisation (World Trade Organization [WTO]) geschützt.

\subsubsection{Kontroversen um Urheberrecht und Copyright}

Das Urheberrecht bzw. das Copyright ist Teil des Rechts am geistigen Eigentum, zu dem auch das Patentrecht, das Marken- und Gebrauchsmusterrecht gehören. Gemeinsames Merkmal dieser Rechte ist, dass dem jeweiligen Inhaber (ob Urheber oder Verwerter) gesetzlich die ausschließliche Befugnis zugestanden wird, das Werk, die Erfindung oder die Marke zu nutzen und Dritte von der unentgeltlichen Nutzung auszuschließen (Hofmann 2006 und Dreyer u.a. 2013). Natürlich werden dadurch die Zugangsmöglichkeiten der Allgemeinheit zum Wissen verringert, monopolähnliche Vorrechte geschaffen und der freie Wettbewerb behindert. Andererseits heben die Befürworter strikter Urheberrechte hervor, dass Produkte geistigen Schaffens den Charakter öffentlicher Güter haben. Ihre Nutzung durch zusätzliche Interessenten setzt ihren Wert nicht herab, und ohne gesetzliche Regelung kann nur schwer jemand von ihrer Nutzung ausgeschlossen werden. Deshalb besteht in einem marktwirtschaftlichen System nur geringer Anreiz, kreativ tätig zu werden (Troy und Werle 2012). Angemessene und faire Urheberrechte werden diese Anreize schaffen und damit den gesellschaftlichen Wohlstand mehren. Allerdings verlangen diese Rechte einen einigermaßen gerechten Ausgleich zwischen den Interessen der Öffentlichkeit am Zugang zu Wissen und Information und denen der Urheber an ausreichendem Schutz und Vergütung ihrer Tätigkeit.

Das war und ist genau der Kern der Kontroverse zwischen den Befürwortern eines möglichst weitgehenden und solchen eines sehr begrenzten Schutzes der Rechteinhaber. Die Zugangsinteressen der Öffentlichkeit werden insoweit 
berücksichtigt, als etwa die Patenterteilung die Offenlegung der Patentschrift verlangt und Nutzungen, die im öffentlichen Interesse (Rechtspflege, öffentliche Sicherheit und Berichterstattung durch die Presse sowie Zitatrecht) erfolgen, vom Schutz ausgeschlossen sind oder nur den Vergütungsanspruch belassen, also die Vervielfältigung zum privaten Gebrauch ermöglichen. In Deutschland und in etlichen anderen Staaten werden sie durch Pauschalabgaben entgolten.

Nach Ablauf der Schutzfrist (bei Patenten in der Regel 20 Jahre, bei literarischen Produkten 70 Jahre nach dem Tode des Urhebers) kann sich jeder die geschützte Erfindung oder das geschützte Werk aneignen, ohne dass er zuvor den Rechteinhaber um Erlaubnis fragen oder ihn finanziell entschädigen müsste. Diese Rechteinhaber können diese Rechte entweder selbst verwerten oder (und dies ist die Regel) Anderen eine Lizenz zur Verwertung ihrer Werke oder Erfindungen erteilen. Die daraus erzielten Gewinne sollen die Kosten für Erfindung oder Werkschöpfung zumindest kompensieren und damit Anreiz zu ihrer fortgesetzten Produktion bieten. Natürlich ließen sich solche Anreize auch auf andere Weise schaffen, etwa durch staatliche Alimentierung von Künstlern und Erfindern oder durch privates Mäzenatentum; beide Möglichkeiten wurden und werden erprobt, haben sich aber in der modernen Gesellschaft als unzureichend erwiesen.

Wer ohne Erlaubnis eine geschützte Leistung verwertet, kann vom Rechteinhaber auf Unterlassung verklagt werden und haftet für den Schaden, ohne dass ein Verschulden nachgewiesen werden muss. Da dieser Schaden nur selten genau beziffert werden kann, wird normalerweise der Betrag angesetzt, den ein ordnungsgemäßer Lizenznehmer hätte bezahlen müssen.

\subsubsection{Urheberechte und Copyright im digitalen Zeitalter}

Die Verfügung über und die Nutzung von Wissen war im analogen Zeitalter wenig kontrovers: Bücher konnten gelesen, Filme gesehen und Schallplatten gehört werden, ohne dass sich die Nutzer weiter um die Urheberrechte hätten kümmern müssen. Diese Praxis änderte sich bereits mit der Verbreitung von Fotokopiergeräten, Tonbändern und Videorekordern. Besonders gegen die Verbreitung von Tonbandgeräten wehrten sich die Verwertungsgesellschaften massiv, die deutsche GEMA (Gesellschaft für musikalische Aufführungs- und mechanische Vervielfältigungsrechte) wollte diese gar verbieten lassen. Der Bundesgerichtshof urteilte 1964, dass solche Geräte nur vertrieben werden dürften, wenn die Hersteller der Verwertungsgesellschaft eine Geräteabgabe zahlten, welche ihre Verluste aus Privatkopien kompensieren (Gehring 2007). 
Eine ganz neue Zeit brach mit der Digitalisierung der Produkte geistigen Eigentums an, vor allem für den normalen Konsum von Büchern, Schallplatten und Filmen durch den einzelnen Nutzer. Unter analogen Vorzeichen waren die Urheberechte durch entsprechende Vergütungen bzw. Pauschalabgaben geregelt. Inzwischen tangiert praktisch fast jede elektronische Kommunikation das Urheberrecht, alltägliches Verhalten - etwa das Herunterladen fremder Werke - hat damit rechtliche Relevanz bekommen (Kreutzer 2006). Früher war das Vervielfältigen von Büchern, Tonträgern und Filmen eine aufwändige und teure Angelegenheit, mittlerweile hat die Digitalisierung das beliebige Kopieren von Daten und deren Verbreitung zu einer nahezu kosten- und mühelosen Tätigkeit werden lassen, die auch ohne Qualitätsverlust der Daten von statten geht. Außerdem sind im Internet Tauschbörsen, Internet-Foren, Ebay-Auktionen und anderes entstanden, bei denen CDs und Filme getauscht, versteigert und gekauft werden können. Hier tummeln sich Tausende von mehr oder weniger professionellen und legalen Anbietern. Schließlich verwischen sich auch die einst klaren Grenzen zwischen den Medien und dem Charakter geistiger Werke: Ein ehedem abgeschlossenes, alleinstehendes Produkt mutiert zum Ausgangsmaterial für weitere Gestaltung. Durch diese Entwicklungen werden traditionelle Geschäftsmodelle der Verwerter geistigen Eigentums und deren rechtliche Regelung in Frage gestellt (Dreier und Nolte 2006; Hofmann und Katzenbach 2006).

Der Handel mit Büchern, Schallplatten und Filmen erhält massive Konkurrenz durch digitale Privatkopien oder das Online-Angebot entsprechender Produkte; daher sind die Umsätze konventioneller Geschäftsmodelle rückläufig. Sie sind bei der Musikindustrie - der Hauptbetroffenen von Urheberrechtsverletzungen - von 2001 bis 2010 um nahezu 40 Prozent zurückgegangen, parallel ist die Anzahl der illegalen Downloads zunächst kräftig gestiegen. Doch seit 2005 ist sie wieder deutlich rückläufig. Immer noch lediglich 44,2 Prozent der Nutzer beziehen ausschließlich legale Downloads, obwohl bekannt ist, dass das Anbieten oder Herunterladen von urheberrechtlich geschützten Inhalten nicht zulässig ist (Bundesverband Musikindustrie 2011, 2012). Eine Studie der OECD (2009) bestätigt diese Ergebnisse auch für die anderen Industriestaaten. Branchennahe Studien folgern für die gesamte Kreativwirtschaft einen beträchtlichen Verlust an Einkommen und Beschäftigung. Geschätzte 60 Prozent der Downloads von Büchern sind illegal, bei Filmen gar 83 Prozent (DIE ZEIT vom 15.3. 2012).

Ein Unrechtsbewusstsein der betreffenden Nutzer ist nach einer einschlägigen Untersuchung (Bundesverband Musikindustrie 2010) nur begrenzt auszumachen. Das erklärt sich auch dadurch, dass die Verletzung der Urheberrechte ja nicht aus Profitinteresse geschieht, sondern um Inhalte mit Freunden und Bekannten zu teilen. Viele im Internet auftretende Unternehmen haben diese Inhalte zunächst 
kostenfrei zur Verfügung gestellt, um hinterher (durch Werbung) Gewinne zu machen (WIPO 2002; EU 2009). Im Übrigen ist es wenig erfahrenen Nutzern nur schwer möglich, bei der Vielzahl der Informationsintermediäre zwischen legalem und illegalem Herunterladen von Information zu unterscheiden.

Unter dem Druck der Verwerter häufen sich seit Ende der 1990er Jahren Gesetzesinitiativen zum Schutz geistigen Eigentums, ebenso werden von Seiten der Anbieter Entwicklungen zum Kopierschutz (und gesetzliche Beschränkungen, diese zu umgehen) vorangetrieben sowie Prozesse gegen urheberrechtliche Verstöße geführt. Die Regierungen leiten international koordinierte oder harmonisierte Maßnahmen zur Anpassung der Eigentumsrechte im Internet ein. Die diese Maßnahmen empfehlenden und überwachenden internationalen Organisationen (wie die EU, die OECD und die WIPO) erweisen sich als besonders hartnäckige Verteidiger der Urheberrechte.

Die Diskussion um den Schutz geistigen Eigentums im digitalen Zeitalter ist heftig und kontrovers, nicht nur weil sich (a) die Interessen der Verwerter (indirekt auch der Urheber geistigen Eigentums) an möglichst weitgehender und vergüteter Nutzung von Informationen und (b) der Allgemeinheit an möglichst ungehindertem und kostenfreiem Zugang gegenüberstehen. Vielmehr ist Wissen heutzutage zu einem wichtigen, wenn nicht dem wichtigsten Produktionsfaktor geworden (Stichwort: Informationsgesellschaft [Kübler 2009]). Zugänge zu ihm gelten als wichtige Schlüssel für Wohlstand, gesellschaftliche Teilhabe und politischen Einfluss. Auch nur partieller Ausschluss firmiert als nicht unwesentliches Hindernis. Rechte an geistigem Eigentum und Zugangssperren zu den damit verbundenen Informationen haben also erhebliche Implikationen für die individuelle, aber auch gesamtgesellschaftliche Wohlfahrt.

Schließlich vermittelt das traditionelle Urheberrecht nur begrenzt Schutz wegen

(a) der zunehmenden Konvergenz der Medien (d. h. dem Zusammenwachsen und der Austauschbarkeit von Computern, Fernsehgeräten und Handys),

(b) der Verwischung der traditionellen Rollentrennung von Urhebern, Vermittlern, Vertreibenden und Archivaren,

(c) der Schwierigkeit, Verantwortlichkeit für Regelverstöße festzumachen (ist es der Nutzer, der Provider oder der Betreiber einer Tauschbörse?).

(d) der multifunktionalen Nutzung und Verwertung digitaler Werke, die zu neuen Produkten ergänzt und verändert werden können.

Diese Grenzverwischungen erschweren Gesetzgebung und Rechtsprechung erheblich. Das Urheberrecht ist auch deswegen nur eine begrenzte Hilfe für die 
Rechteinhaber, weil es trotz aller Harmonisierungsbemühungen - vor allem innerhalb der EU - noch weitgehend nationalen Charakter trägt. Zwar müssen ausländische Rechteinhaber von den Mitgliedern der Union und den Vertragsstaaten der Berner und Pariser Übereinkunft wie Inländer behandelt werden. Doch bestehen beträchtliche Unterschiede in den Rechtsordnungen der einzelnen Staaten - etwa in den Fragen, welche Tatbestände jeweils eine Verletzung des Urheberrechts darstellen, ob diese nach der Zivil- oder Strafprozessordnung zu behandeln sind, welches Gericht bei grenzüberschreitenden Sachverhalten zuständig ist und nach dem Recht welchen Staates Streitfälle zu verhandeln sind. Letzteres ist lediglich innerhalb der EU geklärt (EU 2009).

\subsubsection{Relevanz der Kultur- und Kreativwirtschaft für die gesamte Wirtschaftsleistung}

Um die Auseinandersetzungen um die Urheberrechte bzw. das Copyright zu verstehen, muss man sich zunächst die wirtschaftliche Bedeutung der sogenannten ,Kreativwirtschaft' vor Augen führen. Der Begriff Kreativwirtschaft bezeichnet jenen Teil der privaten Wirtschaft, der künstlerische und kulturelle Güter und Ideen schafft oder sie vertreibt; öffentlich geförderte Kultureinrichtungen zählen also nicht dazu. Der Begriff entstand in Großbritannien unter der Regierung von Tony Blair, der die Kulturwirtschaft als Zukunftsbranche der britischen Wirtschaft erkannte. Seine Regierung entwickelte entsprechende sektorspezifische Förderkonzepte. In Deutschland hat sich politisch damit zum ersten Mal die 2005 eingesetzte Enquetekommission des Deutschen Bundestages („Kultur in Deutschland') befasst (Deutscher Bundestag 2007) und ähnliche Förderanreize wie in Großbritannien gefordert. Auch die EU hat sich mit einer 2007 veranstalteten Konferenz zur Kultur- und Kreativwirtschaft dieses Themas angenommen. Die Kultur- und Kreativwirtschaft gliedert sich in elf Teilmärkte, darunter über die schon genannten hinaus in den Architektur-, Presse- und Werbemarkt und in die Designwirtschaft.

Der Anteil dieser Wirtschaftszweige am Bruttoinlandsprodukt betrug 2009 in Deutschland immerhin jeweils 2,6 Prozent (in der EU 2,4 Prozent), also vergleichbar mit dem des Automobilbaus, der chemischen Industrie und dem Maschinenbau. In der EU arbeiteten 2009 ca. 6,3 Millionen Beschäftigte in der Kreativwirtschaft, Deutschland belegte mit einer Million Beschäftigten die Spitze. Umsatzstärkste Einzelbereiche waren der Medienmarkt, die SoftwareIndustrie, der Werbemarkt und die Designwirtschaft. Der Umsatz der Kreativwirtschaft erhöht sich in schnellerem Tempo als der anderer Branchen, 
freilich nicht die Teilmärkte der Buch-, Film und Musikindustrie, also nicht zufällig jener Sektoren, die am meisten unter legalen oder illegalen Downloads leiden (Bundesministerium für Wirtschaft 2010). In der Kreativwirtschaft dominieren eher kleinere Betriebe. Kunst- und Kulturschaffende, ohne finanzielle Unterstützung durch einen Verwerter und meist auf sich gestellt, werden selten so erfolgreich, dass sie von ihren Einnahmen leben können. Sie brauchen also in der Regel die Mittel und das Know-how der Verwerter. Diese haben das Netz zunächst nicht als relevanten Absatzmarkt betrachtet, zumal anfangs die Möglichkeit fehlte, im Netz zu bezahlen. Daher stellte die Kreativwirtschaft Inhalte zunächst kostenfrei zur Verfügung und finanzierte sich weitgehend durch Werbung. Hinzu kam das Entstehen von Tauschbörsen, bei denen für die Nutzer kaum erkennbar war, ob das Kopieren der zur Verfügung gestellten Inhalte urheberrechtlich zulässig ist. Ein Unrechtsbewusstsein beim (an sich illegalen) Kopieren konnte sich nur schwer entwickeln. Auch waren legale, kommerzielle Downloadangebote zunächst wenig nutzerfreundlich. Dieser Nachteil hat sich mittlerweile aber geändert (Deutscher Bundestag 2011).

\subsubsection{Verschärfung der Urheberrechte}

Urheber und Rechteinhaber drängen die Gesetzgeber seit einigen Jahren, ihren durch die Verbreitung des Internets bewirkten Kontrollverlust durch Verschärfung des Urheberrechts abzuwehren, und sie hatten damit weitestgehend Erfolg. So berechtigt beispielsweise der Erwerb elektronischer Bücher nach heutiger Rechtslage nicht mehr automatisch dazu, diese auch anderen Lesern zur Verfügung zu stellen (wie beim herkömmlichen Buch); vielmehr muss dieses Recht erst erworben werden. Auch die oben genannten Schrankenbestimmungen des Urheberrechts (Nutzungen, die von der Zustimmung durch die Rechteinhaber befreit sind) werden neuerdings immer enger definiert. Ferner wurde der Schutz auf immer mehr Werkarten, etwa auf Computerprogramme und Datenbanken, ausgedehnt. Vorreiter dieser Reformen waren die WIPO mit ihrem 1996 verabschiedeten Copyright Treaty und dem gleichzeitigen Performances and Phonograms Treaty. Sie verpflichten alle Unterzeichner, ihr nationales Urheberrecht an die WIPO-Verträge anzupassen und Maßnahmen zur Umgehung technischer Schutzmaßnahmen zu ergreifen. Die einschlägige Richtlinie der EU, welche eine möglichst einheitliche Umsetzung der WIPOVerträge im europäischen Binnenmarkt schaffen sollte, ist eher noch restriktiver: Sie begrenzt die Breite nationaler Schrankenbestimmungen und erlaubt keine spätere Ausdehnung der einmal gewählten Ausnahmen (Kreuzer 2006). 
Die deutsche Gesetzgebung ist gehalten, sich an den Vorgaben der WIPO und der EU zu orientieren. Daher fanden die Stellungnahmen der Buch-, Musikund Filmindustrie bei der Novellierung des Urheberrechts von 2003 gebührend Gehör, entsprechend fiel der Gesetzestext aus. Er untersagt ebenfalls, von den Rechteinhabern installierte technische Kopierschutzmaßnahmen (Technical Data Management, TDM, und Digital Rights Management, DRM) zu umgehen. Problematisch an dieser Bestimmung ist, dass sie nicht nur die unbefugte Nutzung der Werke verbietet, sondern auch die ihr vorgelagerten Handlungen. Außerdem untersagt sie bei eingebauten Zugangssperren die nach dem traditionellen Urheberrecht mögliche „private“ Nutzung der Werke. Das Recht auf private Nutzung kann von den Rechteinhabern jeweils eingefordert werden, etwa dadurch dass Entschlüsselungsprogramme zur Verfügung gestellt werden. Ihm muss aber nicht zwingend stattgegeben werden. Ähnlich restriktiv wurde die Verwendung geschützter Werke durch Wissenschaft und Lehre geregelt.

Mit dem sogenannten „Zweiten Korb“ der Urheberrechtsform (von 2007) wurden die Rechte der Urheber nochmals über die Vorgaben der EU hinaus gestärkt. Die Bestimmungen schränken die Wiedergabe von elektronisch verfügbaren Werken durch Bibliotheken weiter ein: Eine Nutzung dieser Werke von außerhalb (nicht an eigenen elektronischen Leseplätzen) ist verboten, der Fernversand von Artikeln wird stark eingeschränkt. Auch der Tausch von urheberrechtlich geschützten Inhalten über Peer-to-Peer-Netzwerke oder Tauschbörsen ist untersagt, Privatkopien sind nicht von technischen Schutzmaßnahmen der Rechteinhaber ausgenommen, dürfen also nicht umgangen werden. Privatkopien von "offensichtlich rechtswidrig“ online gestellten Dateien sind nun ebenfalls unzulässig. Überdies wurde die ursprünglich geplante Bagatellklausel, welche die Vervielfältigung privater Kopien zum eigenen Gebrauch strafffrei gestellt hätte, gestrichen (Rehbinder 2010). Allerdings wurde das Recht auf Privatkopien nicht - wie vor allem von der Musikindustrie gefordert - gänzlich abgeschafft, hätte diese Regel doch für die Künstler erhebliche Einbußen gebracht, weil sie keine pauschalen Zuweisungen durch die GEMA oder die Verwertungsgemeinschaft Wort mehr erhalten hätten. Diese Pauschalgebühren werden nun aber nicht mehr vom Gesetzgeber festgelegt, sondern von den betroffenen Parteien (Gerätehersteller und Verwertungsgesellschaften) in einem festgelegten Verfahren ausgehandelt (Kreutzer 2007).

Ein noch im Verfahren befindlicher „Dritter Korb“ soll das Recht auf Privatkopien noch weiter einschränken und ein Leistungsschutzrecht für Presseverleger bringen (s.u.). Der Medienwirtschaft gehen selbst diese Änderungen noch nicht weit genug; der Interessenverband der Phonographischen Industrie fordert die generelle Abschaffung eines Rechts auf Privatkopien und die Verschärfung des Strafmaßes gegen Rechteverletzer. Der Börsenverein des Deutschen Buchhandels 
will das Lesen digitaler Kopien an elektronischen Leseplätzen weiter eingeschränkt wissen. Ganz offenkundig war die Bundesregierung bereit, dem Druck der Medienbranche auf Kosten der Nutzer nachzugeben.

\subsubsection{Technische Schutzmechanismen}

Technische Schutzmechanismen (Technical Protection Measures, TPM) zur Wahrnehmung der Rechte von Urhebern und Verwertern und digitales Rechtemanagment (Digital Rights Management, DRM) haben sich seit 1990 entwickelt; die erste größere Produktentwicklung war das pdf-Format, das durch seine Sicherheitseinstellungen erlaubt, den Druck und/oder die Speicherung eines Dokumentes, seine Veränderung und die Anbringung von Kommentaren zu verhindern. Analoge Schutzmechanismen wurden in den späteren 1990er Jahren für DVDs, noch später für Handys (Klingeltöne) und MP3-Player entwickelt. Das Problem dieser Mechanismen und der digitalen Aufzeichnung des Umfangs jeder einzelnen Werknutzung ist, dass sie die Nutzung der Werke verteuern, das Recht auf anonymen Medienkonsum aushöhlen und das im Urheberrecht noch zugestandene Recht auf Privatkopien zugunsten der Verwerter praktisch beseitigen. Nutzer, die sich den Zugang zu kostenpflichtigen Informationen nicht mehr leisten können, werden gewissermaßen weggeschlossen (Grassmuck 2006).

Abmahnungen wegen Verstöße gegen das Urheberrecht im Netz - also Hinweise der Rechteinhaber auf illegale Handlungen des Nutzers mit der Aufforderung, diese künftig zu unterlassen - sind $\mathrm{zu}$ einem Massenphänomen geworden. Es sind außergerichtliche Maßnahmen, die das deutsche Urheberrecht ausdrücklich vorsieht. Sie werden erleichtert durch die Pflicht der Informationsvermittler, die IP-Adressen (sowie Name und Anschrift des Besitzers) preiszugeben, von denen aus illegale Downloads erfolgen. Massenabmahnungen sind offenbar für viele Anwaltskanzleien zu einem lukrativen Geschäftsmodell geworden. Etliche Unternehmen verdienen ihr Geld allein damit, im Internetverkehr mittels automatischer Programmroboter Rechtsverstöße aufzuspüren. Es ist daher nicht verwunderlich, dass das Abmahninstrument bei den Internetnutzern stark in Verruf geraten ist. Auch schon erstmalige Abmahngebühren bei einfach gelagerten Rechtsverstößen sind nicht unbeträchtlich, sie belaufen sich zur Zeit auf ca. $500 €$. Hinzu kommen Ärger und Aufwand für die Beteiligten. Insgesamt ist die Rechtslage recht diffizil, und es ist immer noch wenig klar, was einfach gelagerte Fälle sind, wie Nutzer stets sicher sein können, dass sie keine fremden Rechte verletzen, wie weit die Verantwortung der Provider zur Unterbindung des illegalen Downloading reicht. Außerdem beschädigt jede Nachforschung nach Urheberrechtsverletzungen im Netz wiederum das Recht 
auf den Schutz persönlicher Daten, zumal die Zugänge für eine längere Zeit rückwirkend erfasst werden müssen. Schließlich - und das betrifft auch die anschließend zu behandelnden Verfahren zur Sanktionierung unrechtmäßiger Nutzung - werden manche Internet-Anschlüsse von mehr als einer Person genutzt, möglicherweise ohne Wissen des eigentlichen Besitzers (etwa durch Hacker). Mögliche Gegenmaßnahme ist dann nur die Verschlüsselung des Zugangs (Internet Society 2011).

\subsubsection{Sanktionen gegen Verstöße und Rechtsverletzer}

Um die Verfolgung und Ahndung von Urheberrechtsverstößen zu vereinfachen, werden in manchen Staaten neue Sanktionsverfahren geplant bzw. bereits umgesetzt, welche nach Warnungen an den Besitzer des Internetanschlusses diesen bei Wiederholung schlicht - jedenfalls für eine gewisse Zeit - sperren. In Frankreich wurde mit einem Gesetz von 2010 eine Behörde eingerichtet (Hadopi $=$ [Haute Autorité pour la diffusion des oeuvres et la protection des droits sur l'Internet]), die Warnungen an Rechtsverletzer ausspricht und nach zwei erfolglosen Warnungen sie vor Gericht bringt. Ihnen drohen Geldstrafen und die Unterbindung des Netzzuganges für bis zu einem Jahr. Ein ähnliches Gesetz existiert in Schweden und in Großbritannien. In Irland und Neuseeland stehen diese Vorhaben noch an oder harren der Umsetzung. Es ist keine Frage, dass diese sogenannten three strikeModelle einen beträchtlichen Eingriff in die Informationsfreiheit der Betroffenen darstellen, zudem ist auch ihre Wirkung umstritten. Die französische Behörde hat seit Inkrafttreten des Gesetzes täglich 25.000 Warnungen an Nutzer versendet, die angeblich ihr Verhalten dadurch stark verändert haben; in Schweden ist eine ähnliche Reaktion zu beobachten. Allerdings sind die Nutzer teilweise entweder auf andere Internetzugänge ausgewichen oder haben neue Kommunikationskanäle genutzt wie Streaming-Dienste oder One-Click-Sharehoster (Deutscher Bundestag 2011). Haben früher die Nutzer zumeist sogenannte Peer-to-Peer-Netzwerke verwendet, um Inhalte herunterzuladen - Daten, bei denen Rechner miteinander verbunden werden und die auszutauschenden Dateien direkt übertragen werden -, speichern sie heute die Daten nicht mehr auf dem Rechner, sondern beziehen sie aus Streaming-Netzwerken in Echtzeit oder zeitversetzt. Bekanntestes, einschlägiges Portal dafür ist YouTube. Die Musikindustrie fordert konsequenterweise ein Verbot der von diesen Portalen genutzten Aufnahmesoftware.

Neben der Sperrung des Internet-Zugangs sind andere Maßnahmen denkbar, um das illegale Herunterladen geschützter Daten $\mathrm{zu}$ verunmöglichen oder $\mathrm{zu}$ erschweren. So hat die britische Regierung 2009 vorgeschlagen, die Menge der herunterladbaren Daten zu limitieren, um insbesondere den Peer-to-Peer 
(P2P)-Datentausch, eine wesentliche Quelle für die Verletzung der Urheberrechte, zu behindern. Man könnte auch daran denken, die Übertragungsgeschwindigkeit solcher Datenübertragung künstlich zu reduzieren. Schwierig wäre es freilich, legale von illegaler Datenübertragung im P2P-Datentausch zu trennen, will man diese nicht für alle Nutzer erschweren. Mit ähnlichen Schwierigkeiten sind Problemlösungen behaftet, den Zugang zu bestimmten Internetadressen, bestimmten Protokollen (etwa P2P) oder spezifischen Websites zu blockieren (Internet Society 2011), ganz abgesehen von datenschutzrechtlichen Problemen.

Im Medium Internet schalten sich zwischen Inhalt und Endnutzern verschiedene Intermediäre (Access-Provider, Service-Provider). Diese können an sich am wirkungsvollsten illegales Herunterladen von Dateien verhindern. Access-Provider sind aber mit gutem Grund durch das bundesdeutsche Telemediengesetz davor geschützt, für die von ihnen transportierten Inhalte verantwortlich gemacht $\mathrm{zu}$ werden. Andernfalls müssten sie den Datenverkehr flächendeckend kontrollieren und auf seine rechtliche Zulässigkeit beurteilen. Bei Plattformbetreibern, die Dritten ermöglichen, Inhalte zu veröffentlichen (und davon profitieren), steht die urheberrechtliche Verantwortung zur Zeit noch zur Diskussion (Deutscher Bundestag 2011).

\subsubsection{Internationale Initiativen und Regelungen}

Bekanntlich ist das deutsche Urheberrecht in internationale Vereinbarungen eingebunden. Die wichtigsten sind das Agreement on Trade-Related Aspects of Intellectual Property Rights (TRIPS), das alle Mitglieder der Welthandelsorganisation (WTO) ratifizieren müssen. Es formuliert ein verbindliches und vergleichsweise hohes Schutzniveau für alle WTO-Mitglieder (also für fast alle Staaten der Erde). Insbesondere enthält es Regelungen zum Schutz der Urheber, zur Festlegung der Schutzdauer, zum Prinzip der Gleichstellung von in- und ausländischen Rechteinhabern. Verstöße gegen das Abkommen können durch Handelssanktionen geahndet werden. Im Gegensatz dazu sind die einschlägigen Verträge der WIPO vergleichsweise wirkungslos. Der einschlägige Copyright Treaty der WIPO wurde auf der Konferenz der WIPO-Mitgliedsstaaten im Jahr 1996 vereinbart; er ergänzt die Berner Übereinkunft und sollte diese an die Erfordernisse des digitalen Zeitalters anpassen. Er schließt erstmals den Schutz von Computerprogrammen und Datenbanken ein und verpflichtet die Vertragsstaaten, Maßnahmen gegen die Umgehung technischer Zugangssperren zu ergreifen (Internet Society 2011). International ist jedoch die Universalisierung des Urheberrechts durch TRIPS und die WIPO-Verträge keinesfalls unumstritten; die Entwicklungsländer sehen sich durch den ihrer Meinung nach exzessiven 
Schutz des geistigen Eigentums erheblich benachteiligt und in ihrer Entwicklung behindert. Daher dürfte eine oftmals angemahnte umfassende Reform dieser internationalen Verträge an den konfligierenden Interessen der beteiligten Staatengruppen scheitern.

Eine Initiative ohne die Entwicklungsländer, um das geistige Eigentum mit einem internationalen Standard zu schützen, ergriffen die USA und Japan mit dem sogenannte Anti-Counterfeiting Trade Agreement (ACTA). Ziel des Abkommen sollte es sein, die Standards des Urheber- und Markenrechts sowie zum gewerblichen Rechtsschutz zu vereinheitlichen, um so gemeinsam gegen Verletzungen dieser Rechte vorgehen zu können. Im Entwurf kam dem Internet ein wichtiger Stellenwert zu. Provider sollten zur Kooperation (offenkundig durch die Kontrolle der versendeten Datenpakete) verpflichtet werden, und illegales Herunterladen sollte strafrechtliche Konsequenzen nach sich ziehen. Diese Absicht sowie der damit verbundene Eingriff in die Grundrechte entfachten Anfang 2012 einen regelrechten Sturm der Entrüstung in interessierten Bevölkerungskreisen der europäischen Länder, dem sich auch viele Abgeordnete des Europäischen Parlaments anschlossen. Denn der geplante Schutz von Immaterialgütern wäre gegenüber den WIPO- und TRIPS-Verträgen massiv verschärft worden, ohne dass Vorgaben für den Schutz von Nutzerinteressen formuliert worden wären. Ohnedies waren die Verhandlungen hinter verschlossenen Türen geführt worden, so dass das Verfahren des Abkommens als recht geheim getadelt wurde. Kritiker fürchteten daher, dass mit ihm der freie Fluss von Informationen im Internet stark behindert und eine Zensurinfrastruktur geschaffen würde. Sie wäre zwar aus geschäftlichem Interesse eingerichtet worden, könnte aber auch politischen Zwecken dienen. Als Ergebnis dieser Proteste wurde das Vertragswerk von der deutschen Bundesregierung vorerst nicht unterzeichnet, vier andere europäische Staaten schlossen sich an. Auch das Europäische Parlament lehnte schließlich die Beschlussfassung ab (Süddeutsche Zeitung v. 11./12.2.2012).

\subsubsection{Neuere Entwicklungen und Ausblick}

Gegen die Ausweitung der Urheberrechte lassen sich offenbar nur Etappensiege erzielen: Im August 2012 wurde im Bundeskabinett das 7. Gesetz zur Änderung des Urheberrechtsgesetzes verabschiedet, das nun auch ein Leistungsschutzrecht für Presseverlage zum ersten Mal in der deutschen Geschichte einschließen soll. Suchmaschinenbetreiber wie Google und andere sollen danach künftig für ihren Zugriff auf journalistische Inhalte Gebühren bezahlen, wenn sie nicht nur einen Zeitungsartikel verlinken, sondern auch eine Artikelzusammenfassung oder 
einen teilweisen Abdruck im Netz bieten. Nicht vom Gesetz erfasst werden sollen andere Nutzer wie Blogger, Verbände und Privatunternehmen. Auch gegen diese Gesetzesinitiative brach ein Sturm der Entrüstung los, zumal Deutschland hier einen Alleingang vorlegt, der allerdings einen baldigen Nachahmer (Frankreich) gefunden hat. Gegner aus den Oppositionsparteien argumentieren, der Entwurf drohe hilfreiche Suchmaschinen und den legitimen Informationszugang der Bürger einzuschränken, Befürworter hingegen weisen darauf hin, dass etwa Google mit Inhalten Geld verdiene, die von Presseverlagen und Journalisten mit viel Aufwand produziert werden (Frankfurter Allgemeine Zeitung vom 1.12. und 4.12.2012). Google fordert in einer gegen diese Initiative gerichteten Kampagne seine Nutzer im Netz auf, dessen Freiheit und freiheitlichen Zugang zu verteidigen. Tatsächlich hat der Konzern sein Monopol und die daraus erzielbaren Einnahmen im Blick. Nicht nur ehrenwert ist auch die Argumentation der Presseverlagshäuser, die vor allem ihr überkommenes Geschäftsmodell retten wollen; es leidet bekanntlich unter rückläufigen Werbeeinnahmen. Denn sie wollen die Nutzung ihrer Inhalte durch Google \& Co. den eigenen Bedingungen (durch Indexierung) unterwerfen. Aber sie profitieren selbst davon, wenn ihre Inhalte von Suchmaschinen gefunden werden. Natürlich argumentieren beide Seiten mit dem gerne zitierten Allgemeinwohl für ihre je unterschiedlichen materiellen Interessen.

Der Deutsche Bundestag hat am 1. März 2013 gegen den vehementen Protest vieler Aktivisten den genannten Gesetzesvorschlag ohne größere Änderungen verabschiedet; eine kleinere Änderung betraf die Lizenzfreiheit „einzelner Wörter oder Textausschnitte", sehr zum Verdruss der Presseverlage, die sich schon aus der Nutzung von Überschriften und (Artikel-)Vorspännen durch Suchmaschinen erhebliche Einkünfte versprochen hatten. Wie aber legale, lizenzfreie ,Textausschnitte' zu definieren sind, dürfte erhebliche juristische Probleme bergen. Kritiker (aus Reihen der Grünen) meinten daher, einziger Profiteur der Reformen seien wohl die Rechtsanwälte, die Reform des Leistungsschutzrechts sei „der größte Schwachsinn aller Zeiten“, das Gesetz werde all die Apps und Dienste in Deutschland veröden lassen, die es für den Nutzer so einfach und spannend machten, Medien zu konsumieren (Frankfurter Allgemeine Zeitung vom 2.3.2013; Spiegel-online vom 1.3.2013). Wenig später passierte das Gesetz auch die Hürde des Bundesrats, trotz Drohung der Opposition mit Blockade.

Schlussendlich lässt sich das Urheberrecht im digitalen Zeitalter nur mit hohem Aufwand und ständigem rechtlichem Verfolgungsdruck retten. Seine Anpassung rennt zwangsläufig technischen Innovationen hinterher, die das illegale Herunterladen immer weniger zuordnungsfähig machen (Streaming, Cloud Computing). Zu Recht argumentiert ein Beitrag im SPIEGEL, dass die Einhegung dieser Entwicklungen Anstrengungen, Eingriffe und Überwachungsmaßnahmen 
erfordere, die irgendwann einmal auch die Idee des liberalen Rechtsstaates in Mitleidenschaft ziehen würden. So musste allein die Deutsche Telekom im Jahr 2010 2,4 Millionen Adressen zur Verfolgung von Urheberrechtsverletzungen preisgeben, die eine halbe Million Abmahnungen nach sich zogen (DER SPIEGEL vom 21.5.2012). Dieser ganze Aufwand nützt den eigentlichen Urhebern, die von den Verwertern immer gerne als Leidtragende zitiert werden, nur wenig.

Denn selbständige Künstler verdienen in Deutschland und andernorts im Durchschnitt bedrückend wenig: Schriftsteller laut einer einschlägigen Studie von 2007 gerade einmal $12.000 €$ im Jahr, in Deutschland noch weniger als in Großbritannien. Daher benötigen 60 Prozent der Schriftsteller einen Zweitjob, um zu überleben, und alle haben letztlich kaum oder keinen materiellen Gewinn durch die digitale Nutzung ihrer Werke (Kretschmer und Hardwick 2007). Um das Einkommen von bildenden Künstlern ist es noch schlechter bestellt (Kretschmer u. a. 2011). Für die meisten, weniger prominenten Künstler drücken nicht die Tauschbörsen ihr Einkommen, sondern die harte Marktkonkurrenz, das Fehlen jedweden tarifrechtlichen Schutzes sowie die Tatsache, dass sie sich in Vertragsverhandlungen mit den Medien und der Kreativindustrie in einer strukturell schwachen Position befinden. Begreiflicherweise hat diese an der Veröffentlichung solcher Informationen kein Interesse. Die Rede vom Schutz der kreativen Künstler durch das Urheberrecht oder das Copyright ist also oft nur ein Rauchvorhang vor den wirtschaftlichen Interessen der dominanten Verwerter.

Gibt es zu immer weiter getriebenen Ermittlungen gegen illegale Downloads die Musik- und Filmlobby drängt auf eine sogenannte "Deep-Packet-Inspection“ für professionelle Datenspeicher und die Meldung von Urheberechtsverletzungen durch die Provider - eine Alternative? Aus den USA kommt die Idee des „fair use", die Eingriffe in das Urheberrecht erlaubt, wenn kein wirtschaftlicher Schaden angerichtet oder das Verbot unverhältnismäßig wäre; es ist aber mit dem deutschen und europäischen Recht nur schwer vereinbar (Deutscher Bundestag 2011, 22). Leichter wäre es, Vergütungsregelungen für Kopien nach dem Muster der GEMA oder der VG Wort für alle Inhalte im Internet umzusetzen. So darf in Deutschland jeder ohne Erlaubnis Musik abspielen, wenn er dafür eine Gebühr an die GEMA entrichtet. Auch darf jeder Publikationen vervielfältigen, für welche der Copyshop oder der Gerätehändler per Abgabe eine Gebühr an die VG Wort entrichten. Die Probleme dieser pauschalen Erhebung (flat rate) sind, dass Gebühren auf jedes Gerät erhoben werden, gleichgültig, wie stark es zum Kopieren genutzt wird. Außerdem fließt ein erheblicher Teil der Gebühren ans Ausland ab, und diese Art der Gebührenerhebung macht dann keinen Sinn mehr, wenn die Verwerter mehrheitlich aufwändige Kopierschutzeinrichtungen installieren. 
Die Partei der Grünen arbeitet an dem Modell einer Internet-Flatrate für das private Herunterladen von Filmen und Musik, die an die Verwertungsgesellschaften abzuführen wäre. Dieses Modell wird meist als „Kultur-Flatrate“ tituliert, seinen Befürwortern gilt es als ein zeitgemäßes Modell, das sowohl die Interessen der Nutzer wie der Urheber wahre. Kritiker dieses Modells bemängeln die pauschale Erfassung des Wertes kulturellen Schaffens, die Kostenbelastung auch von Gerätebesitzern, welche die Inhalte gar nicht nutzen, und die Aushebelung des Marktes durch eine Behörde zur Festsetzung und Verteilung der Gebühren, welche erheblichen Einfluss auf das kulturelle Schaffen bekäme (Deutscher Bundestag 2011).

Nutzer sind nach Untersuchungen durchaus bereit, für komfortable, attraktive und qualitativ hochwertige Möglichkeiten zum Download geschützter Werke zu bezahlen; das zeigt der steigende Umsatz mit entsprechenden privatwirtschaftlichen Modellen. Um sie haben die Verwerter lange einen weiten Bogen gemacht (zur Freude von Google, YouTube \& Co.); diese Downloads könnten auch mit Werbung kombiniert werden, um weitere Einnahmen zu generieren. Es könnten auch einfachere und kostenfreie Dienste mit kostenpflichtigen Zusatzangeboten gekoppelt werden. Inzwischen haben sich auch Flatrateangebote als Alternativen etabliert. Sie ermöglichen gegen Zahlung einer monatlichen Gebühr unbeschränkten Zugriff auf definierte Inhalte. Kurzum, zur um sich greifenden Abmahnpraxis auf der Basis stets restriktiver gestalteter Urheberrechte gibt es offenkundige Alternativen.

In Teilbereichen kommt die Verbreitung von Kultur und Wissen mittlerweile auch ohne das Urheberrecht aus. Aus der Wissenschaft heraus entwickelt sich seit Jahren der sogenannte "Open Access“, der sich am Beispiel der OpenSource-Bewegung orientiert. Ziel des Open Access ist die bessere Versorgung von Wissenschaftlern mit kostenfreien, aktuellen Forschungsergebnissen. Die finanzielle Krise der meisten wissenschaftlichen Bibliotheken, bedingt auch durch die rasant steigenden Preise wissenschaftlicher Zeitschriften, war dabei ein wesentliches Beschleunigungselement. Viele Wissenschaftler schreiben zunehmend Aufsätze in Fachzeitschriften, welche die Bibliotheken aus Geldnot bereits abbestellt haben. Deshalb findet die Idee zunehmend Anklang, Artikel entweder nach kurzer Schutzfrist kostenlos im Internet zur Verfügung zu stellen oder gleich in reinen Internet-Zeitschriften zu veröffentlichen. Die Verlage stehen dieser Idee ablehnend gegenüber und starten Kampagnen, um gesetzliche Regeln gegen den Open Access durchzusetzen oder doch zumindest deren Förderung zu verhindern. In Deutschland haben sie damit begrenzten, in Großbritannien und den USA keinen Erfolg. Dort haben sich die Forschungsförderungsorganisationen dafür eingesetzt, die Vergabe von Fördermitteln an den offenen Zugang der Forschungsergebnisse zu binden (Gehring 2008). 
Die Ziele der Open-Content-Bewegung sind weiter gespannt. Sie will das kostenlose Kopieren, das Bearbeiten und die Verbreitung von urheberrechtlich geschütztem Material für nicht kommerzielle Zwecke fördern. Eine der prominentesten Organisationen in diesem Bereich ist Creative Commons (gegründet 2001). Sie bietet Standard-Lizenzverträge an, mit denen ein Urheber der Öffentlichkeit kostenfrei und auf einfache Weise unterschiedlich weit gehende Nutzungsrechte an seinem Werk einräumen kann, das Urheberrecht aber nicht aufgehoben wird. Diese Lizenzen bezogen sich zunächst auf das amerikanische Copyright, sind aber mittlerweile auch auf andere Rechtssysteme ausgedehnt. Eine solche Lizenz wird etwa von Wikipedia verwendet, genutzt werden solche Lizenzen aber auch vom NDR und der BBC (Filmarchiv). Eine ähnlich arbeitende Organisation ist die Open Content Alliance, ein Konsortium von Unternehmen, nicht gewinnorientierten und staatlichen Organisationen, welche das Ziel verfolgt, ein frei zugängliches Archiv von Texten und Multimediainhalten zu erstellen. Im Rahmen dieser Allianz hat das Projekt Open Library bereits über eine Million Bücher digital erfasst und ins Netz gestellt.

\subsection{Datenschutz und Persönlichkeitsrechte}

\subsubsection{Zu Aufgaben und Herausforderungen des Datenschutzes}

Datenschutz und Persönlichkeitsrechte sind wie kein anderes Politik- und Aktionsfeld mit dem Internet - inzwischen auch im alltäglichen Bewusstsein verknüpft (Schmidt und Weichert 2012): Das Internet und die mit ihnen möglichen Transaktionen fordern kontinuierlich dazu heraus, den Schutz der Persönlichkeitsrechte und der persönlichen Daten zu stärken und zu erweitern. Denn sie gelten primär als Instrumente und Risiken, die den Schutz persönlicher Daten gefährden oder zum Missbrauch für kommerzielle, politische, aber auch kriminelle Absichten anstiften. Dabei lässt sich eine signifikante Verlagerung der Beobachtungs- und Verdachtsfelder sowie der Stoßrichtungen des Schutzes registrieren: Galt früher der Staat und seine Instanzen, insbesondere seine geheimen Behörden und ihre Aktivitäten, als zentrale Objekte des Misstrauens und der Einschränkung, wie es hierzulande in den heftigen Protesten gegen die 1981 geplanten Volkszählung zum Ausdruck kam, die 1983 zu dem grundlegenden Urteil des Bundesverfassungsgerichts zur informationellen Selbstbestimmungen des einzelnen Bürgers führte, geraten mit der Verbreitung und intensiveren, vielfältigen Nutzung 
des Internets eher private und kommerzielle Profite des Datenmissbrauchs ins Visier kollektiven Argwohns und staatlich-juristischer Aufsicht. Mit diversen Gesetzen und zuständigen Instanzen des Datenschutzes - etwa die Beauftragten des Datenschutzes im Bund und in den Bundesländern - avancierte der Staat zum vorrangigen Beschützer und Verteidiger der persönlichen Daten, so dass die von ihm lancierten potentiellen Beeinträchtigungen oder Verletzungen weniger Beachtung finden. Sie werden zwar von den unabhängigen Datenschutzbeauftragten in öffentlichen Berichten ebenfalls regelmäßig moniert, aber erst wenn sie in der medialen Öffentlichkeit breit aufgegriffen und kritisiert werden, finden sie Eingang in öffentliche Diskurse.

Gleichwohl bleibt der Schutz persönlicher Daten die Basis für die Akzeptanz des Internet-Verkehrs. Ziel des Datenschutzrechts ist die informationelle Selbstbestimmung der Nutzer, also die Kontrolle über den Umgang mit Daten und Informationen, die den Nutzer selbst betreffen (Deutscher Bundestag 2012). Personenbezogene Daten werden nach dem deutschen Datenschutzgesetz definiert als „Einzelangaben über persönliche oder sachliche Verhältnisse einer bestimmten oder bestimmbaren natürlichen Person", mithin praktisch jede Information, die mit einer natürlichen Person in Verbindung gebracht werden kann. Als persönliche Merkmale zählen etwa Identifikationsmerkmale, äußere Merkmale, aber auch Meinungen, als sachliche werden Beziehungen zu Dritten und zur Umwelt (z. B. Besitz, Vertragsbeziehungen) erachtet. Die Regulierung dieser Daten umfasst nach geltendem Recht die Erhebung dieser Daten, ihre Verarbeitung im engeren Sinn (Speicherung, Übermittlung, Sperrung und Löschung personenbezogener Daten) und ihre Nutzung. Ein erhöhtes Schutzniveau genießen die so genannten sensiblen Daten wie rassische oder ethnische Zugehörigkeit, politische Meinungen, weltanschauliche Überzeugungen, die Zugehörigkeit zu bestimmten Verbänden und gesundheitsbezogene Daten (Absatz 9 Bundesdatenschutzgesetz).

Die früheren Menschenrechtspakte und -abkommen beinhalten kein eigenes Datenschutzgrundrecht, schützen aber das Privat- und Familienleben, die persönliche Kommunikation und die Privatwohnung, damit implizit auch die Kommunikation mittels Email oder Internettelefonie. Der Datenschutz wird mithin als ein Element der Privatsphäre betrachtet. In neueren Übereinkommen der Vereinten Nationen wird aber die informationelle Selbstbestimmung ausdrücklich thematisiert.

Der Schutz personenbezogener Daten vor unzulässiger Erhebung, Speicherung, Verarbeitung und Weitergabe an Dritte ist seit Beginn der Computernutzung von großem öffentlichem Interesse (Zürn und Mayer 2010). Er stellt ein größeres Problem als der Schutz anderweitiger gespeicherter Daten dar, weil erstens computergestützte Daten auch von unbedeutenden Akteuren gespeichert, miteinander abgeglichen und übertragen werden können. Zweitens kann daraus 
relativ einfach ein Profil individuellen Verhaltens, von Konsumgewohnheiten und Kreditwürdigkeit erstellt werden, das einen nicht unbeachtlichen kommerziellen Wert darstellt. Es kann von interessierten Unternehmen oder auch von staatlichen Instanzen (etwa zur steuerlichen Erfassung) genutzt werden kann. Drittens sind in einer Welt, die durch zunehmende Verflechtung der Märkte für Güter, Dienstleistungen und der damit einhergehenden Datenströme gekennzeichnet ist, nationale Datenschutzbestimmungen relativ wertlos, weil Daten durch Mausklick in eine andere nationale Jurisdiktion verschoben werden können (Gunasekura 2007). Nationale Datenschutzbestimmungen, sofern sie für die internetgestützte Datenübertragung überhaupt existieren - viele weniger entwickelte Staaten arbeiten allenfalls daran -, können dadurch ausgehöhlt werden.

Die einschlägigen Bestimmungen differieren nach Umfang, Regulierungsmodus (staatlich oder durch Selbstverpflichtung der beteiligten Firmen) sowie der Schärfe der zu erwartenden Sanktionen bei Regelverletzung recht deutlich. Es bietet sich daher für interessierte Firmen oder Sicherheitsapparate von Staaten an, Daten dort zu speichern oder abzufragen, wo der Datenschutz besonders niedrig ausfällt. Risiken für den Einzelnen sind die möglicherweise exzessive Datensammlung und Weitergabe durch staatliche Instanzen - zur Abwendung sicherheitsrelevanter Gefahren (z. B. internationaler Terrorismus) oder schlicht zur politischen Kontrolle ihrer Bürger und zum Verkauf oder Tausch persönlicher Daten zwischen Unternehmen zum Zwecke effizienterer Bewerbung der Klienten, zur Abschätzung ihrer Kreditwürdigkeit etc. $\mathrm{Da}$ aus der Fülle der Daten, die Einzelne im Netz zwangsläufig zur Verfügung stellen, durch Verkoppelung der Informationen relativ unaufwändig Profile ihrer Konsumgewohnheiten, Interessen, Beziehungen und Bewegungen im geografischen Raum zusammengestellt werden können, ist vielfach schon die Gefahr eines drohenden Orwellschen Überwachungsstaates, zumindest aber die Ausschlachtung persönlicher Daten zum Zwecke kommerzieller Nutzung an die Wand gemalt worden.

\subsubsection{Anforderungen an den Datenschutz}

Als notwendige Anforderungen an ein modernes Datenschutzrecht gelten:

(a) die klare Setzung eines Erlaubnisvorbehalts, d. h. der Umgang mit personenbezogenen Daten verlangt die (freiwillig erlangte und wirksame) Einwilligung des Betroffenen, es sei denn, die Erhebung und Weitergabe dieser Daten ist gesetzlich legitimiert. Verlangt ist auch die notwendige Information der Betroffenen über Sinn und Zweck der Erhebung und die Bedeutung der Datenfreigabe; 
(b) die Beschränkung der Datenabfrage und -weitergabe auf das zum Erreichen des Ziels notwendige Minimum;

(c) ein klar definierter Mindestschutz persönlicher Daten im Netz, der festlegt von wem, wann, welche Daten erhoben, gespeichert und übermittelt werden dürfen;

(d) eine internationale Angleichung diesbezüglicher Normen, um die Gefahr von Umgehung des Datenschutzes durch Auslagerung der Datensammlung und -übertragung in Jurisdiktionen mit niedrigem oder fehlendem Schutz zu umgehen, damit einhergehend

(e) strenge Auflagen für die grenzüberschreitende Weitergabe persönlicher Daten sowie möglicherweise

(f) eine Behinderung oder gar Unterbindung des „datamining" also der kommerziell motivierten Sammlung von Konsumenteninformationen durch spezialisierte Firmen und Agenturen und ihr Verkauf an interessierte Nutzer.

Diese Erfordernisse wurden schon früh erkannt; im nationalen Vergleich spielten Schweden, Deutschland, Frankreich und später die Vereinigten Staaten die Vorreiter eines effektiven Schutzes persönlicher Daten, eine hervorgehobene Pionierfunktion nahm in den letzten Jahren bei der Weiterentwicklung des Datenschutzes im Internetverkehr die Europäische Union ein.

\subsubsection{Datenschutz in der Bundesrepublik Deutschland}

Besonders weitgehend ist der Schutz persönlichkeitsbezogener Daten im deutschen Bundesdatenschutzgesetz geregelt, bedingt auch durch einschlägige Urteile des Bundesverfassungsgerichts, das diesen Schutz geradezu zum Verfassungsrang erhob und die „informationelle Selbstbestimmung“ schon im Urteil zur Volkszählung (1983) durch die Erstellung von Nutzerprofilen als gefährdet ansah. Das Bundesdatenschutzgesetz umfasst Grundsätze der Sparsamkeit der Datenerhebung und -verarbeitung (so wenig wie nötig), die gesetzliche oder persönliche Ermächtigung dieser Erhebung, die notwendige Information der Betroffenen über die Erhebung, der Identifikation des dabei handelnden Akteurs, des Nutzungszwecks und des Einverständnisses der Betroffenen. Unzulässig ist die Übermittlung der Daten an Instanzen und Staaten ohne ein ausreichendes Datenschutzniveau. Schließlich sind Verfahren automatisierter Verarbeitung vor Inbetriebnahme den zuständigen Aufsichtsbehörden zu melden (Der Bundesbeauftragte für den Datenschutz 2010). Natürlich räumt auch dieses Gesetz dem Bürger keine totale informationelle Selbstbestimmung, also die uneingeschränkte Herrschaft über seine Daten, ein. Aber es definiert recht klar und erkennbar den Umfang der Beschränkungen. 
Eine Besonderheit des deutschen Datenschutzrechts ist, dass es zwischen Datenschutz im öffentlichen und nicht-öffentlichen Bereich unterscheidet. Für die Datenverarbeitung im staatlichen Bereich sind engere Grenzen gesetzt als im privaten. Zudem spielt die föderale Ordnung der Bundesrepublik eine Rolle, es gibt Datenschutzbeauftragte auf der Ebene des Bundes und der Länder. Beide zusammen üben die Kontrolle über den staatlichen Bereich aus, für den privaten sind nur die Landesbeauftragten zuständig (Deutscher Bundestag 2012). Die besondere Stellung des Datenschutzes im öffentlichen Bereich ergibt sich vor allem aus dem Schutz der Grundrechte. Viele staatliche Stellen sammeln gleichwohl besonders sensible personenbezogene Daten; Eingriffe in die Persönlichkeitsrechte müssen stets gesetzlich legitimiert sein. Allerdings ermöglicht die wachsende informationstechnische Durchdringung der öffentlichen Verwaltung immer mehr die Erstellung umfassender Datenprofile der Bürger, die weder diesen noch den Gesetzgebern (Parlamenten) immer hinreichend bekannt und transparent sind (zu den Probleme und neueren Entwicklungen beim Datenschutz im privaten Bereich s.u.).

\subsubsection{Datenschutz in Europa und der OECD}

Die Harmonisierung der Datenschutzbestimmungen innerhalb der gesamten entwickelten Welt war bereits das Ziel der Guidelines on the Protection of Privacy and Trans-Border Flow of Personal Data (OECD 1980), die keine gesetzliche Regelung, sondern nur eine Empfehlung an die Mitgliedsstaaten war. Diese 1980 vereinbarten Richtlinien streben an, Datenschutz, den freien Fluss von Informationen und den freien Verkehr von Gütern und Dienstleistungen miteinander in Ausgleich zu bringen. Dabei verlangen sie - ähnlich wie die später verabschiedeten Gesetze der Mitgliedsländer - die Sparsamkeit und Zweckbindung der Daten, die Information der Betroffenen, den Schutz der erhobenen Daten gegen unerlaubten Zugang und Weitergabe, den Zugang der betroffenen Personen zu ihren Daten und das Recht auf Entfernung falscher Angaben. Außerdem werden die Mitgliedsstaaten zu einschlägiger und sanktionsbewehrter Gesetzgebung, zum Austausch untereinander über die jeweilige Umsetzung dieser Richtlinien sowie zur Ermittlung und Verfolgung von Verstößen aufgerufen. Die Leitlinien unterscheiden zwischen sensitiven und trivialen Angaben, von denen keine Gefahr ausgeht und die daher ausgenommen werden können. Auf unangemessen hohe Datenschutzregelungen, die den grenzüberschreitenden Datenverkehr behindern, soll verzichtet werden. Selbstregulierung statt staatlicher Regulierung wird ermutigt. Außerdem beabsichtigen diese Richtlinien nicht nur den Schutz der Persönlichkeit, sondern auch die Gewährleistung eines 
möglichst ungehinderten Informationsflusses zwischen den Mitgliedsstaaten. Dieser Anspruch wurde nur begrenzt erreicht: Die Grundsätze der einzelstaatlichen Datenschutzregelungen innerhalb der OECD-Welt orientierten sich zwar weitgehend an dieser (recht allgemeinen) Vorlage, bei der Umsetzung sind allerdings beachtliche Unterschiede festzustellen (Gunasekera 2007).

Im Gegensatz zu den OECD-Richtlinien verpflichtete die Datenschutzkonvention des Europarates von 1981 die Unterzeichnerstaaten, einen bestimmten Katalog von Grundsätzen einzuhalten. Persönliche Daten müssen nach Recht und Glauben und auf rechtmäßige Weise beschafft und verarbeitet werden. Die Speicherung und Verwendung ist nur für festgelegte Zwecke statthaft, ferner müssen die Daten nach der Zweckerfüllung anonymisiert werden. Schließlich muss für sensible Daten ein besonderes Schutzniveau erfüllt werden. Ein Zusatzprotokoll von 2001 verlangt die Einrichtung unabhängiger Kontrollstellen und beschränkt die Datenweitergabe an Nichtmitgliedsstaaten auf solche Länder, die über ein solch angemessenes Schutzniveau verfügen.

Ähnlich wie in Deutschland, aber durchaus doch unterscheidbar, wird der Datenschutz in nahezu allen Mitgliedsstaaten der Europäischen Union gehandhabt. Solche Differenzen bereiten bei zunehmendem transnationalem Datenverkehr allen Beteiligten durchaus Probleme; sie mindern bei den Bürgern das Vertrauen und erhöhen bei Unternehmen die Anpassungskosten. In Europa sind schon frühzeitig Bemühungen erkennbar, den Datenschutz in der Union zu harmonisieren bzw. zu vereinheitlichen. Einschlägig hierfür ist die Richtlinie des Europäischen Parlaments und des Rates zum Schutz personenbezogener Daten von 1995. Sie wurde mit besagtem unterschiedlichem Schutz in der Union begründet, der ein starkes Hindernis für die grenzüberschreitende Übermittlung von Daten und damit die weitere Entwicklung des europäischen Binnenmarktes darstellte. Verlangt wird daher ein gleichwertiges Schutzniveau innerhalb der EU. Die Richtlinie bestimmt, dass jede nationale Datenschutzbehörde Regelungshoheit über die Datenverarbeitung beanspruchen kann, die innerhalb ihres eigenen Territoriums durch ein einschlägiges, in diesem Staat niedergelassenes Unternehmen geschieht oder zur Bearbeitung Mittel benutzt, die sich dort befinden. Die Verarbeitung personenbezogener Daten hat dem angestrebten Zweck zu entsprechen und darf nicht darüber hinausgehen; sie darf nicht ohne Einwilligung der betroffenen Person erfolgen. Die Richtlinie definiert personenbezogene Daten (alle Informationen über eine Person) und Datenverarbeitung (jeden Vorgang der Erhebung und Speicherung personenbezogener Daten) sehr breit und zwingt die nationalen Behörden in der EU zur Zusammenarbeit, um die Mehrfachbehandlung strittiger Fälle zu unterbinden. Problematisch an dieser Regelung ist freilich, dass die Datenverarbeitung im Internet geografisch nur 
schwer zu lokalisieren ist, Verarbeitung und Nutzung getrennt werden und auswärtige Websites auch ohne Infrastruktur im Binnenmarkt verbreitet sein können. Artikel 25 der Richtlinie bestimmt weiterhin, dass der Transfer von Daten in Drittstaaten nur dann gestattet ist, wenn diese ausreichenden Datenschutz gewähren (sogenanntes „Safe Harbor-Prinzip“). Damit wird praktisch Druck auf diese Drittstatten ausgeübt, ihren Rechtsschutz entsprechend anzupassen (Europäische Gemeinschaft 1995; Kuner 2010a, b; Maier 2010).

Zudem wurde der Datenschutz bei gerichtlicher oder polizeilicher Zusammenarbeit in Strafsachen von diesen Regelungen ausgenommen - weil diese Bereiche vor dem Vertrag von Lissabon nur begrenzt vergemeinschaftet waren. Dennoch bekam mit diesem Vertrag der Datenschutz gleichsam Grundrechtscharakter innerhalb der EU, er ermächtigte auch das Europäische Parlament und den Rat der EU, Gesetze mit supranationaler Wirkung im Bereich des Datenschutzes zu beschließen.

\subsubsection{Unterschiedlicher Datenschutz in den USA und in Europa}

In den Vereinigten Staaten hat sich das Datenschutzrecht andersartig als etwa in Europa entwickelt. Dies betrifft vor allem die Regulierung des privatwirtschaftlichen Sektors, in dem Daten im Wesentlichen durch Selbstverpflichtungen der Unternehmen geschützt werden sollen. So entstand eine Art Flickenteppich einzelstaatlicher und bereichs- bzw. gruppenspezifischer Regelungen (Batnasan 2010; Busch 2012). Deshalb existiert keine nationale Datenschutzbehörde zur Untersuchung individueller Beschwerden wie praktisch überall sonst. Diese Unterschiede haben sich zu einem gravierenden Problem in den europäisch-amerikanischen Beziehungen, den beiden bislang weltweit wichtigsten Territorien im internationalen Datenverkehr, entwickelt. Denn mit zunehmendem Outsourcing ihrer Bearbeitung fließen persönliche Daten auch in Länder, die lange Zeit oder immer noch gesetzlich keinen zureichenden Schutz verankert haben. Immerhin haben sich mittlerweile einige größere Entwicklungsländer (z. B. Indien und Argentinien) entsprechende Gesetze gegeben, schon allein, um wirtschaftlich nicht abgehängt zu werden.

Im europäisch-amerikanischen Verhältnis entzündete sich zunächst am Verbot der Datenübertragung an Staaten mit nicht adäquatem Schutz ein lang anhaltender Konflikt. Die EU vertrat die Ansicht, dass nur formelle gesetzliche Regelungen und die Einrichtung einer entsprechenden Aufsichtsbehörde in den USA ein angemessenes Schutzniveau sicherstellen könnten. Die USA wollten weiterhin auf unabhängige Zertifizierungsstellen zum Schutz der Privatsphäre setzen. Allerdings unterwarfen sich nur wenige Unternehmen dieser Zertifizierung. 
Schließlich wurde ein Kompromiss insoweit gefunden, als sich amerikanische Unternehmen auf sieben durch das amerikanische Handelsministerium festgelegte und mit der EU vereinbarte Datenschutzprinzipien im Datenverkehr mit der EU verpflichten mussten und bei Nichteinhaltung rechtlicher Verfolgung ausgesetzt würden. Dieses sogenannte „Safe-Harbor-Abkommen“ von 2000 wurde als erfolgreiches Modell für die Lösung künftiger Konflikte angesehen, aber es wurde durch die nachfolgenden politischen Ereignisse überrollt.

In der Nachfolge der Terroranschläge vom 11. September 2001 beschloss die US-Regierung, elektronisch gespeicherte Flugpassagierdaten - welche auch Telefonnummern, Kreditkartendetails, Kontaktdaten für den Notfall etc. enthalten - für ihren Kampf gegen den internationalen Terrorismus zu nutzen. Falls der Zugang zu diesen Daten nicht gewährt würde, drohten die USA europäischen Fluggesellschaften mit dem Entzug der Landerechte. Die amerikanische Seite war in den Verhandlungen mit der EU bestrebt, relativ dauerhaften, vollständigen und unkontrollierten Zugang zu diesen Daten zu erhalten. Die Vertreter der EU lehnten dies als inakzeptabel ab, gaben aber später weitgehend nach. Gegen das entsprechende Abkommen von 2004 klagte daher das Europäische Parlament vor dem Europäischen Gerichtshof, der das Abkommen zwei Jahre später für nichtig erklärte.

Der nächste Konflikt folgte umgehend, als sich die amerikanische Regierung Zugriff zu den Daten über globale Finanztransaktionen durch eine Genossenschaft der Finanzindustrie (Society for Worldwide Interbank Financial Telecommunication, SWIFT) verschaffte - ebenfalls zum Zweck der Terrorismusbekämpfung und ohne dass SWIFT ihre Teilhaber über die Datenüberlassung informiert hätte (Kuner 2010b). Auch hier intervenierte das Europäische Parlament, verlangte vollständige Information über die Vorgänge und kritisierte die damit verbundene Aushöhlung des Schutzes personenbezogener Daten. Die europäisch-amerikanischen Konflikte um die Speicherung der Fluggastdaten und der Zugriff auf die Finanztransaktionen halten bis heute an. Ein neues, vorläufiges Abkommen über die erstgenannte Datengruppe kam den USA weit entgegen (in Bezug auf Speicherfrist und Zahl der zugriffsberechtigten amerikanischen Behörden), wurde aber vom Europäischen Parlament ebenso abgelehnt wie jenes über den Transfer der SWIFT-Daten. Die Nachbesserung nahm dann das Parlament vor. Die Kritik an der Umsetzung - insbesondere in Bezug auf die zu großzügige Überlassung von Daten an die amerikanische Seite - hält dagegen an, ein umfassendes transatlantisches Abkommen zum Datenschutz steht noch aus (Busch 2012).

Nicht nur in den USA - auch in europäischen Staaten gibt es ja durchaus Bestrebungen, die Vorratsdatenspeicherung zum Zwecke der Bekämpfung organisierter Kriminalität, politischen Extremismus und des Terrorismus voranzutreiben - zeigt sich eine Tendenz staatlicher Instanzen, den Schutz personenbezogener Daten aus sicherheitspolitischen Interessen auszuhebeln. In den 
USA gingen diese Bestrebungen aber besonders weit. So gab es zum Beispiel ein umfangreiches Projekt des Pentagon (namens Terrorism Information Awareness), das große, aus dem Privatsektor abgefragte Datenmassen zu einer Datenbasis zusammenführen sollte, um Vorhersagen über terroristische Aktivitäten treffen zu können. Die Finanzierung dieses Programms ist zwar mittlerweile eingestellt worden, einzelne Behörden setzen aber das "datamining" (Datenschürfen) durchaus fort (Gunasekera 2007). Der Patriot Act von 2001 senkte die Schwellen für den Datenzugang durch das FBI kräftig, öffnete den Zugang zu den Daten von einer großen Zahl privater Unternehmen und forderte Organisationen auf, verdächtige Aktivitäten zu melden. Das Gesetz bezog auch alle ausländischen Filialen amerikanischer Unternehmen ein. Ähnliche, freilich stärker garantiebewehrte Gesetze wurden in Kanada und Neuseeland erlassen (Ebd.).

\subsubsection{Jüngste Entwicklungen des Datenschutzes in Europa}

Im Jahr 2007 forderte die OECD in ihren Empfehlungen für eine bessere Zusammenarbeit beim grenzüberschreitenden Datenschutz ihre Mitgliedsstaaten erneut auf, die nationalen Vorkehrungen für den Schutz persönlicher Daten zu verbessern, Mechanismen für die internationale Durchsetzung des Datenschutzes $\mathrm{zu}$ entwickeln, einander dabei durch Information, Beschwerdeüberstellung und Ermittlungen zu unterstützen (OECD 2007). Unlängst hat sie geprüft, inwieweit diese Empfehlungen umgesetzt wurden. Das Ergebnis ist teilweise ernüchternd: Zwar wurde ein Netzwerk zur Einhaltung des Datenschutzes von 22 Behörden aus 16 Staaten und von Kontaktstellen zur Zusammenarbeit bei nahezu allen Mitgliedsländern eingerichtet und die Mitgliedsstaaten der Asia-Pacific Economic Cooperation (APEC), der die USA, die ost- und südostasiatischen Staaten, einige lateinamerikanische Länder und Russland angehören, schlossen sich diesem Verfahren 2009 an. In dem Prüfbericht der OECD wird aber auch festgehalten, dass etliche Datenschutzbehörden (z. B. in Kanada und den Niederlanden) noch immer keine Strafen für Datenschutzverletzungen verhängen können und dass die möglichen Höchststrafen für den Regelverstoß vergleichsweise niedrig bleiben. Generell hapert es wohl noch beträchtlich an der grenzüberschreitenden Zusammenarbeit bei der Durchsetzung des Datenschutzes, trotz einiger positiver Beispiele bilateraler Kooperation (etwa zwischen den USA und Kanada) (OECD 2011c).

Die Europäische Kommission hat 2012 eine umfassende Reform der Datenschutzbestimmungen von 1995 vorgeschlagen, weil der technische Fortschritt und die Globalisierung die Datenerhebung und -verwendung massiv erhöht und grundlegend verändert hat - gemeint sind vor allem digitale soziale Netzwerke, smart cards 
und "cloud computing" (die Speicherung von Daten auf entfernten Servern statt auf PCs) -, weil die Mitgliedsstaaten die Richtlinie von 1995 unterschiedlich umgesetzt haben und diese Divergenzen erhebliche Kosten für die Unternehmen verursachen. Denn alle gesetzlichen Datenschutzerfordernissen der Mitgliedsstaaten müssen eingehalten werden, in denen Geschäfte getätigt werden. Außerdem monierte die EU-Kommission, dass die Fragmentierung des Datenschutzes das Vertrauen der Konsumenten in den Online-Verkehr schmälere. Schließlich verstärke auch der Vertrag von Lissabon das Recht auf den Schutz persönlicher Daten und definiere diesen nun als Grundrecht (Europäische Kommission 2012a, b).

Eine neue Regelung soll einen gleichwertigen Datenschutz in allen Mitgliedsstaaten schaffen und damit den freien Fluss von Informationen im Binnenmarkt ermöglichen. Sie soll den Austausch von persönlichen Daten zwischen polizeilichen und gerichtlichen Instanzen in Europa fördern, den Verwaltungsaufwand für die am InternetVerkehr beteiligten Unternehmen durch die Eliminierung unnötiger Meldepflichten verringern und ihnen dadurch erhebliche Einsparungen ermöglichen. Der Vorstoß der Kommission sieht ein EU-weites Gesamtregelwerk vor, das die unverzügliche Meldung schwerer Datenschutzverletzungen an die nationalen Aufsichtsbehörden, den leichteren Zugriff der Bürger auf ihre eigenen Daten, die Einbeziehung aller außerhalb der EU erfolgende Bearbeitung von personenbezogenen Daten, stärkere Unabhängigkeit der Datenschutzbehörden und schärfere Strafen (bis zu 1 Mio. $€)$ gegen Verstöße beinhaltet. Klarer werden auch die Frage des anzuwendenden nationalen Rechts und damit die Verantwortlichkeit von Internetprovidern und Datenanbietern bzw. -verarbeitern geregelt. Denn an die Stelle des leicht umgehbaren Niederlassungsprinzips (des Anbieters) soll das Marktortprinzip treten, mithin soll das Recht jenes Staates gelten, in dem die wesentlichen Management-Aufgaben des Unternehmens stattfinden. Sofern der Datenanbieter und -verarbeiter nicht in der EU ansässig ist, aber Personen in der EU Produkte und Dienstleistungen offeriert, soll er ebenfalls den zitierten Auflagen unterliegen. Der Datenverarbeitung soll zudem von den Nutzern ausdrücklich zugestimmt werden müssen, statt diese Genehmigung nur vorauszusetzen. Alle Bürger sollen auch das Recht erhalten, ihre eigenen Daten löschen zu lassen, wenn keine legitimen Gründe für deren Vorhaltung bestehen. Profilbildung der Nutzer ist ausdrücklich untersagt (European Commission 2012b).

Der Vorstoß der Kommission unterscheidet überdies zwischen den Pflichten von Groß- und Kleinbetrieben, letztlich auch zwischen belangloser und unbedenklicher Datenverarbeitung. Warum sollte ein kleiner Handwerker, der Kundendaten verarbeitet, den gleichen Meldepflichten (und der Pflicht zur Einsetzung eines Beauftragten für den Datenschutz) unterliegen wie Internetportale, die jede Menge sensibler Nutzerdaten sammeln, verarbeiten und weiter geben? Fraglich ist natürlich auch, wie und wer harmlose Verarbeitungen von sensiblen unterscheiden soll und darf. 
Erstmals soll der europaweite Datenschutz auf die bisher ausgenommene Verarbeitung und grenzüberschreitende (nicht innerstaatliche) Übermittlung personenbezogener Angaben durch die Behörden bei der Verhütung, Aufdeckung und Verfolgung von Straftaten ausgedehnt werden, wobei die Rechte der Betroffenen hierbei stärkeren Einschränkungen unterliegen - insbesondere was die Auskunftsplichten der Daten erhebenden Behörden oder die Übermittlung der Daten an Staaten mit nicht gleichwertigem Schutzniveau anbetrifft (vgl. Europäische Kommission 2012b).

Dem neuen Vorstoß der EU-Kommission ging eine umfassende Prüfung der Wirkungen der Richtlinie von 1995 voraus. Dabei ergab sich, dass die unterschiedliche Umsetzung und Durchsetzung der Richtlinie von 1995 den beteiligten Unternehmen vermeidbare Kosten in Höhe von $3 \mathrm{Mrd}$. $€$ pro Jahr verursache und letztlich doch - wegen des stark angewachsenen transnationalen Datenverkehrs - den Schutz persönlicher Daten unterhöhle. Vor allem kleine Unternehmen haben Schwierigkeiten, mit den national differierenden Auflagen zum Datenschutz zurechtzukommen. Beträchtliche Unterschiede ermittelte die Überprüfungsstudie in der Auslegung der Zustimmung zur Erhebung und Bearbeitung persönlicher Daten, zur Definition besonders sensitiver Angaben (biometrischer Art, zur kriminellen Karriere, zur ethnischen Zugehörigkeit etc.), zum Erfordernis, die Methoden der Datenerhebung den Datenschutzbehörden zu melden (mit unterschiedlichen Ausnahmeregelungen), zur Weitergabe der Daten an Drittstaaten und zur Durchsetzung der Richtlinien. Etliche nationale Datenschutzagenturen seien finanziell und personell zu schwach ausgestattet, und sie verfügen über unterschiedliche Kompetenzen (etwa bei der Unterbindung nicht richtlinienkonformen Datentransfers). Zuletzt sei auch die Kooperation dieser Agenturen stark verbesserungsfähig (European Commission 2012a).

Viel hatten die Harmonisierungsbemühungen der EU bis zum erneuten Vorstoß im letzten Jahr also offensichtlich nicht erbracht. Auch beim Schutz personenbezogener Daten im Rahmen der polizeilichen und justiziellen Zusammenarbeit in Strafsachen war und ist das Schutzniveau innerhalb der EU noch recht unterschiedlich. In manchen Mitgliedsstaaten werden den Betroffenen gar keine Auskünfte erteilt, in manchen gibt es keine oder nur ungenügende Kontrollstellen für die Datenverarbeitung und -übermittlung (Europäische Kommission 2012c)

Gleichwohl ist das durch die neue EU-Initiative angezielte Schutzniveau weltweit fraglos ohne Beispiel, auch wenn man berücksichtigen muss, dass die Zielbestimmung ja nicht nur die Stärkung der Abwehrrechte des Einzelnen gegen informationelle Übergriffe des Staates und von Privatunternehmen ist. Sie zielt natürlich erstens darauf, den freien Fluss von Informationen, Dienstleistungen und Waren im europäischen Binnenmarkt zu erleichtern, soll also die Europäische Union in ihrer internationalen Konkurrenzfähigkeit stärken helfen. Die 
Kommission verfolgt mit dieser Initiative zweitens das Ziel, ihre Kompetenzen in diesem Bereich zu steigern, handelt also auch aus institutionellem Eigeninteresse. Freilich zeigt der Kommissionsvorschlag auch, dass die Mitgliedsländer der EUKommission dabei schon Zügel angelegt haben. Nicht umsonst unterscheidet der Vorschlag Datenschutz im öffentlichen und privaten Bereich: Die Mitgliedsstaaten verneinen nämlich einen noch stärkeren Harmonisierungsbedarf im öffentlichen Bereich, dort sei in vielen Bereichen (etwa im Polizei- oder im Steuerecht) der Datenschutz gar nicht mehr vom Fachrecht zu trennen, die Zusammenarbeit in Europa schon weit fortgeschritten (Rogall-Grothe 2012). Die Wirtschaft aber sei aus Gründen der Wettbewerbsgleichheit auf eine stärkere Harmonisierung des Datenschutzrechts angewiesen. Es geht - neben der möglichen sachlichen Richtigkeit dieser Argumente - natürlich auch darum, den Eingriff von Brüssel in besonders sensible Bereiche staatlicher Souveränität abzuwehren.

\subsubsection{Anhaltende Probleme und Desiderate des Datenschutzes}

Bleibt die Frage, ob selbst hohe gesetzliche Schutzbestrebungen für die Erfassung und die Verarbeitung personenbezogener Daten nicht zwangsläufig der technischen Entwicklung und ihrer staatlichen bzw. vor allem kommerzieller Nutzung hinterher laufen. Durch die zunehmende Vernetzung, die Möglichkeit der Verknüpfung von personenbezogenen Daten zu Persönlichkeitsprofilen und die Weiterentwicklung der Datenerfassungssysteme erhöht sich die Gefahr für die Persönlichkeitsrechte beständig. Dieses Risiko besteht nicht nur im Verhältnis des Bürgers zum Staat, sondern auch in seinem Verhältnis zu Mitbürgern oder zu Privatunternehmen. Der Erfolg von Google und einschlägigen sozialen Netzwerken beruht ja gerade darauf, dass diese gigantische informationelle Infrastrukturen bereithalten (Gurlitt 2010). Als problematisch erweisen sich im Verkehr des Bürgers mit dem Staat vor allem die informationstechnische Umstellung eines Großteils der öffentlichen Verwaltung, die zunehmende Umstellung des Schriftverkehrs der Bürger mit staatlichen Stellen auf elektronische Medien, die Zunahme zentraler, bereichsübergreifender Datenbestände verschiedener Behörden. Beides wird oft unter das Stichwort „E-Government“ subsummiert. Solche Tendenzen verschärfen sie noch mit der abzusehenden Auslagerung von Behördendaten auf zentrale Rechner (Cloud-Computing) (Deutscher Bundestag 2012).

Im Verhältnis von Bürgern zu privaten und/oder IT-Unternehmen werden zwangsläufig personenbezogene Daten gesammelt, die sich potentiell zu 
einem Gesamtbild des Nutzer- und Käuferverhaltens addieren lassen, das wiederum passgenaue Werbung ermöglicht und sich gewinnträchtig anbieten und vermarkten lässt. Der Nutzer wird damit zu einem Wirtschaftsgut, dessen digitales Spiegelbild kommerziellen Nutzen abwerfen kann. Viele Anbieter im Netz lassen sich ihre Dienste mit über sogenannte Cookies (beim Aufruf bestimmter Webseiten auf dem Computer des Nutzers gespeicherte Datenfolgen) gesammelte Informationen über ihre Nutzer bezahlen. Diese Daten haben durchaus ihren Marktwert und werden daher massenhaft weiter verkauft. Suchmaschinen können überdies ein umfangreiches Bewegungsprofil der Anwender bereitstellen, Nutzer von sozialen Netzwerken und anderen Plattformen geben viele, auch sensible Daten preis. Diese Praxis kann wohl auch unter die Rubriken „informationelle Selbstbestimmung“ und „Meinungsfreiheit" gefasst werden - vorausgesetzt die Nutzer wurden über die Verwendung ausreichend informiert, explizit um Einwilligung gebeten und die Vorgänge sind ausreichend transparent.

Problematisch wird es aber schon dann, wenn dies nicht oder nur begrenzt der Fall ist und nicht simple Tatbestände, sondern Meinungen, Einstellungen und Lebensstile abgefragt werden (Beispiele: Gefällt-mir-Button, politische Selbsteinschätzung). Am ergiebigsten sind diesbezüglich natürlich die sozialen Netzwerke, voran Facebook erlaubt es dem Nutzer, jederzeit über seinen Standort Bescheid zu geben. Handys geben ohnedies heutzutage immer den Standort des Nutzers an; konsequenterweise bietet eine ganze Reihe von Firmen ihre Ortung an (DER SPIEGEL 2/2011). Mittlerweile sind im Internet etliche mehr oder weniger honorige Firmen mit dem Zusammenkratzen (scraping) persönlicher Details aus Diskussionsforen beschäftigt, Spezialfirmen durchsuchen Emails und Telefonverbindungsdaten von Firmenmitarbeitern nach Anzeichen von Bestechlichkeit oder Verrat von Betriebsgeheimnissen. Die Liste ließe sich noch verlängern.

Für die Vertreter einschlägiger Plattformen stellt sich die Sache ganz einfach dar; mögliche Belästigungen durch das Ausspähen würden durch das einfache Drücken der Lösch-Taste vermieden. So ihre Verteidigung. Doch diese Option hindert freilich nicht daran, dass „Freunde“, die bisher mit persönlichen Daten versorgt wurden, diese auch danach noch verbreiten können. Bei der Einsicht in die gesammelten Daten geben die sozialen Plattformen wegen angeblicher Überlastung auch nur sehr zögerlich Antwort, die gesetzlich geforderte Transparenz ist daher kaum gegeben (DER SPIEGEL 43, 2011, 157). Schließlich sind die Regelungen anderer Staaten und von der europäischen Ebene wirkungslos, wenn die sozialen Netzwerke von nicht einbezogenem Ausland operieren.

So erklärt sich der genannte, erneute Vorstoß der Europäischen Kommission zum Datenschutz als weiterer Schritt der Harmonisierung im Binnenmarkt; er 
wird begleitet von einer geplanten "Grundrechte-Charta“ für den Datenschutz der US-amerikanischen Regierung. Sie räumt Internetnutzer mit einem Klick ein zu verhindern, dass Unternehmen ihre Spuren im Netz aufzeichnen und für personalisierte Werbung nutzen (DIE WELT vom 24.2.12). Letztlich wird der Anspruch auf volle Anonymität aber wohl auch in Zukunft nur einlösbar sein, wenn man auf einschlägige Netzdienste völlig verzichtet.

\subsection{E-Commerce und Online-Shopping}

\subsubsection{Begriffliche Einordnungen}

Unter den Begriff E-Commerce fallen Transaktionen, bei denen ein Wirtschaftsgut gegen Entgelt auf elektronischem Wege angeboten wird und der Bestellprozess und die Kundenbetreuung auf elektronischem Wege erfolgen (BITKOM 2009). Die erbrachten Leistungen können materieller oder immaterieller Natur (z. B. im Auftrag eines Kunden durchgeführte Arbeiten und Tätigkeiten, die Gewährleistung von Nutzungsrechten an Software und Inhalt) sein. Immateriellen Leistungen kommt im E-Commerce eine besondere Bedeutung zu, weil diese einfach und kostengünstig zu erbringen sind, oft nicht die Erzeugung und den Transport von Dokumenten erzwingen. Im Gegensatz zum klassischen Handel mit direktem Kontakt zwischen Händler und Kunden und der physischen Präsentation der Produkte oder - wie beim Versandhandel - in einem Katalog findet die Präsentation der Produkte und Leistungen auf einer Webseite statt ebenso wie der Bestelldialog. Kunden registrieren sich und pflegen ihre Daten selbst. Bezahlt wird überwiegend mit der Kreditkarte, seltener über PayPal oder Geldkarten.

Häufig ist es nötig, Mitglied auf einer Webseite zu werden, um etwas einkaufen zu können. Oft ist es auch möglich, den Artikel, den Versand, den Kontakt zum Verkäufer und den Verkauf an sich zu bewerten und zu kommentieren, viele Anbieter stellen diese Kundenbewertungen zur Verfügung. Dadurch werden die Nachteile, die daraus erwachsen, dass das Produkt nicht „angefasst“ werden kann, teilweise kompensiert. Das gilt auch für den zwangsläufig größeren Mangel an Vertrauen, den Kunden einem unpersönlichen Kaufvorgang entgegenbringen.

\subsubsection{Umfang und Probleme des E-Commerce}

Der E-Commerce befindet sich seit Jahren in einem raschen Aufstieg. Das hat vor allem mit der Zunahme der Internet-Nutzer und der Bequemlichkeit 
des Kaufvorganges zu tun. Die im Internet angebotenen Produkte und Dienstleistungen sind oft billiger, Preise der verschiedenen Anbieter können schnell miteinander verglichen werden, die gekauften Waren werden rasch geliefert und - noch bedeutsamer - mit der Ausdehnung des Internet-Nutzerkreises und der anbietenden Unternehmen hat sich das Angebot an Waren und Dienstleistungen nachhaltig verbreitert. Der Kunde hat letztlich Zugang auf Produkte weltweit.

So ist es kein Wunder, dass sich der elektronische Handel seit Jahren über Wachstumsraten im hohen, zweistelligen Bereich erfreut. Der Anteil der Kunden, die Käufe über das Internet getätigt haben, ist im Jahre 2008 in den westlichen Industrieländern auf 35 Prozent gestiegen, in der EU (2009/10) auf 37 Prozent (European Commission 2011c, 2012c; OECD 2009). Allerdings darf dabei nicht vergessen werden, dass sich erstens das Wachstum des E-Commerce international etwas abgeflacht hat (Bundesministerium für Wirtschaft und Technologie 2009), zweitens die Nutzung nach Ländern sehr unterschiedlich entwickelt und drittens der Anteil dieses Handels am Gesamtumsatz doch noch vergleichsweise bescheiden ausfällt. Haben in Norwegen und Schweden schon über 60 Prozent der Erwachsenen im Jahr 2008 Internetkäufe getätigt, so waren es in Deutschland über 50 Prozent, im EU-Durchschnitt aber nur etwas über 30 Prozent und in Italien, Portugal und Griechenland nur etwas über zehn Prozent (ebenda, vgl. Abb. 6.3).

Zudem stagniert dieser Anteil seit 2008 mehr oder weniger. Beim Umsatzanteil im Einzelhandel lag der E-Commerce aber selbst in den USA (als Marktführer) bei gerade einmal vier Prozent (in der EU im Durchschnitt 3,5 Prozent), während dort der Anteil beim elektronischen Handel zwischen Unternehmen immerhin auf 27 Prozent geklettert war. Auch ist die Nutzung nach sozialen und Altersgruppen sowie bestimmten Sektoren unterschiedlich: Die größte Erfahrung mit E-Commerce haben Angehörige der Altersgruppe von 20 bis 29 Jahren; für Ältere sinkt der Anteil drastisch (auf 20 Prozent für Kunden über 54 Jahren). Besser Gebildete sind deutlich aktiver (BITKOM 2009). Über das Internet werden hauptsächlich Bücher, Kleidung, Videos, DVDs, Spiele, Bahn- und Flugtickets sowie Elektronik geordert, viele andere Dinge also eher weniger (Bundesministerium für Wirtschaft und Technologie 2009). Auch die Bereitschaft der Konsumenten, grenzüberschreitend per Internet zu bestellen, hält sich in Grenzen. In der EU tätigten 2010 immerhin 37 Prozent der Konsumenten Internetkäufe, aber nur sieben Prozent von Verkäufern in anderen EU-Staaten (European Commission 2011c). Ausgeprägt ist dieses Missverhältnis vor allem bei den größeren Staaten der EU. Selbst von den europäischen Händlern verkauft nur etwas über ein Fünftel an Kunden außerhalb des Landes. Das alles muss Gründe haben. Einschlägige Internationale Organisationen wie die OECD und die Europäische Union haben 


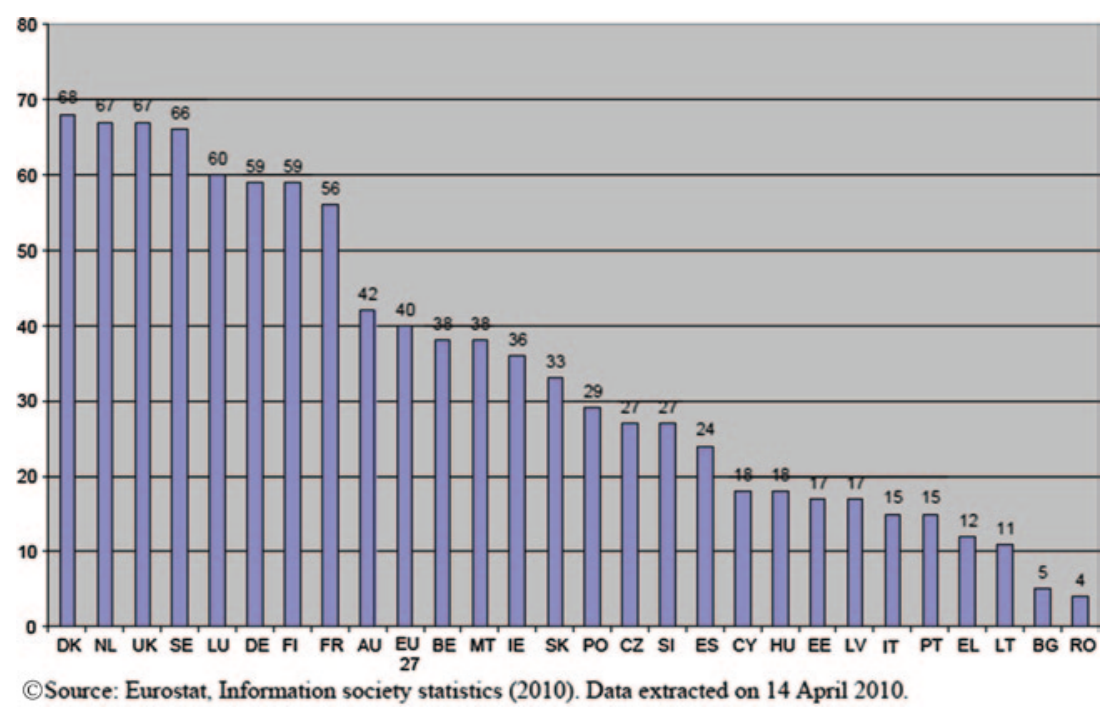

Abb. 6.3 Anteil der Personen, die Produkte oder Dienstleistungen im Internet für den privaten Gebrauch bestellt haben (2010)

diese Divergenzen schon seit längerem veranlasst, sich Sorgen um das unausgeschöpfte Potential dieses Handels zu machen (OECD 2003; EC 2004a). Vor allem die Europäische Union macht sich Sorgen um die Wachstumsverluste aus mangelnder Nutzung des E-Commerce und beziffert diese - unter der Voraussetzung einer möglichen Verdoppelung dieses Verkehrs - auf immerhin 1,7 Prozent des europäischen Bruttoinlandsprodukts (European Commission 2012c: 2) .

Hauptgrund für das unausgeschöpfte Potential war und ist mangelndes Vertrauen vieler Konsumenten in die Sicherheit entsprechender Käufe, also Zweifel an der Wirksamkeit des Konsumentenschutzes bei Internetgeschäften allgemein und vor allem bei Käufen aus dem Ausland. Ganz unbegründet ist dieses Misstrauen nicht, wie die tabellarische Übersicht (Abb. 6.4) über die bei Internetkäufen auftretenden Probleme demonstriert.

Nicht richtig begründet ist aber das größere Misstrauen gegenüber Käufen bei ausländischen im Verhältnis zu inländischen Anbietern im Internet (vgl. European Commission 2011c). Die Kunden sorgen sich hierbei noch stärker um die Sicherheit bei der Bezahlung der Waren und Dienstleistungen, in zweiter Linie um die Sicherheit bei der Belieferung, die Verlässlichkeit der Produktinformation, eventuelle Rückerstattungen und die Rücktrittsbedingungen bei Kaufverträgen (EC 
2004a). Bei Erhebungen in der EU gaben 59 Prozent der Befragten an, sich Sorgen über die Behandlung von Problemen und Beschwerden im/beim grenzüberschreitenden Internetkauf zu machen, ebenso viele fürchteten Opfer von Betrügereien $\mathrm{zu}$ werden und 47 Prozent fürchteten um die tatsächliche Auslieferung und Zustellung der Waren (European Commission 2011). Empirisch sind freilich die Beanstandungen beim transnationalen E-Commerce nicht häufiger als bei heimischen Internet-Käufen; die kritischere Sicht von Auslandskäufen ist also nicht berechtigt, ist eher ein Spiegel des generellen Misstrauens in solche Geschäfte, das mit der geografischen Distanz emotional zunimmt.

Immerhin 16 Prozent der Käufer hatten Probleme 2009/10 beim Internetkauf bei inländischen Anbietern (in Bulgarien 31 Prozent); der größere Teil von ihnen beschwerte sich beim Anbieter darüber, war aber zur Hälfte mit der Reaktion nicht oder gar nicht zufrieden, ein Anteil der sich gegenüber früher kaum verändert hat. Dieser Anteil war in den weniger entwickelten EU-Staaten (aber auch in Deutschland) besonders hoch. Die Hälfte der Käufer gab nach erfolgloser Beschwerde auf, nur circa sieben Prozent bemühten einen Rechtsanwalt (European Commission 2011c). Ein Sechstel der Kunden wurde nicht rechtzeitig beliefert, sechs Prozent überhaupt nicht, immerhin 61 Prozent der Konsumenten beklagten sich über unerwünschte oder

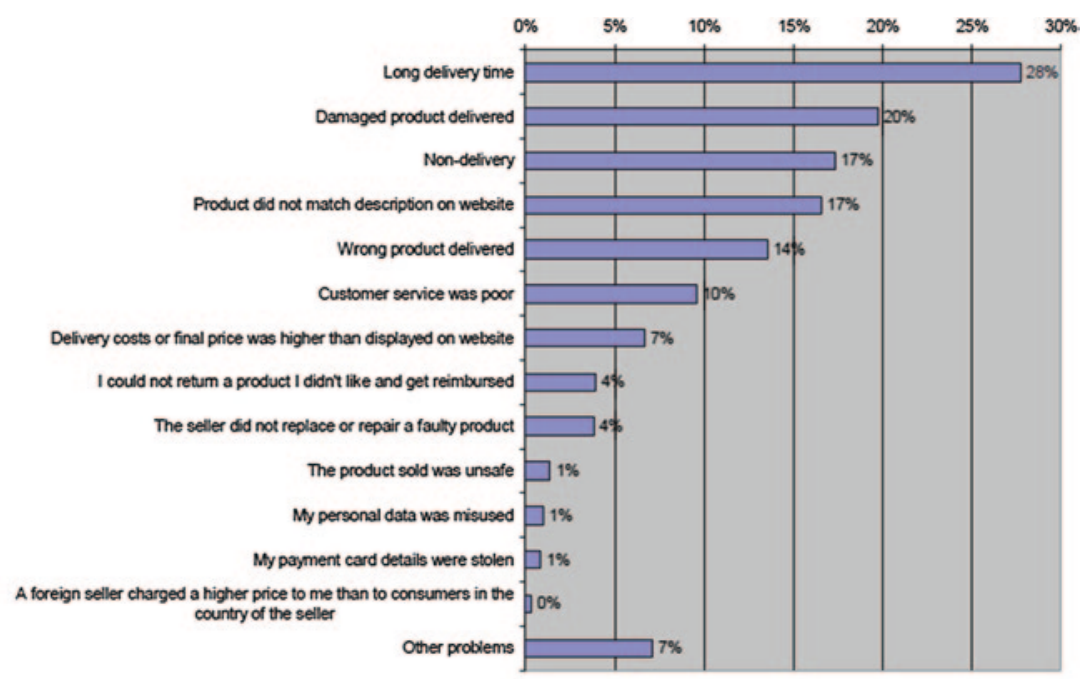

(C) Source: Civic Consulting (2011). "Consumer market study on the functioning of e-commerce".

Abb. 6.4 Aufgetretene Probleme beim Online-Kauf (2011) 
betrügerische Anzeigen und Angebote. Nicht unbeträchtlich war auch der Anteil der Kunden, der mit beschädigten oder nicht passenden Geräten beliefert wurden, wobei diese Probleme bei der Belieferung mit elektronischen Gütern am höchsten ausfiel. Groß war auch der Anteil der Bestellungen, die versteckte Kosten aufwiesen oder diese nicht korrekt auswiesen (The European Consumers Centre Network 2012). Da ist es allenfalls beruhigend, dass die große Mehrzahl der Konsumenten Vertrauen in die unabhängigen nationalen Verbraucherschutzbehörden zeigte und ein etwas geringerer Teil - mit national großer Varianz - den Verbraucherschutz für ausreichend hielt (European Commission 2011).

Probleme beim transnationalen Internethandel empfinden offenbar auch die Verkäufer/Unternehmen. Deutlich weniger als die gelisteten Firmen sind offenbar überhaupt bereit, sich auf entsprechenden Handel einzulassen, hauptsächlich wegen der schwierigen und international sehr unterschiedlichen Vertragsbedingungen und der Unkenntnis über die einschlägigen Regelungen in anderen Ländern (European Commission 2012d). Im übrigen befleißigte sich in der EU nur ein Teil der Verkäufer, ihre Verträge den Erfordernissen der EURegelungen anzupassen, informierten die Käufer nicht über ihr Rücktrittsrecht, die Regelungen im Streitfall oder z. T. nicht einmal über die Auftragsdetails (Ebd.). Nachdenklich muss auch stimmen, dass die Zahl der Konsumentenbeschwerden im Internethandel nicht abnimmt (OECD 2006), was natürlich auch damit zusammenhängt, dass die Anzahl der Käufer im Internet stetig zunimmt.

Das Misstrauen der Kunden beim Internetkauf ist also nicht ganz unberechtigt, auch wenn die Befürchtungen hierbei möglicherweise größer sind, als der Sachlage angemessen. Es kommt ja auch vor, dass bei normalen Käufen im Einzelhandel die Ware sich oft als schlechter herausstellt, als vom Verkäufer behauptet, Umtausch und Rückforderungen nicht immer leicht durchzusetzen sind. Man muss überdies sehen, dass die Möglichkeit im Internet einzukaufen, den Konsumenten andererseits ja zumindest partiell ermächtigt hat, ohne gleich in den Lobgesang des Bundesverbandes Informationswirtschaft, Telekommunikation und neue Medien (BITKOM) verfallen zu müssen, der aus der Digitalisierung der Kommunikation gleich eine Nivellierung der bisherigen Informationsasymmetrie zwischen Verbrauchern und Unternehmern und einen Machtzuwachs Ersterer gegeben sieht, die zu gestaltenden Akteuren des Wirtschaftsverkehrs würden (BITKOM oJ). Indizien dafür sind für den Bundesverband das Auftreten der Käufer auch als Anbieter (etwa bei ebay), die Möglichkeiten verschiedene Angebote online prüfen und vergleichen zu können, auch auf der Basis von Erfahrungsportalen, elektronischen Produktratgebern und Rating-Webseiten, kurzum: Dem mündigen Verbraucher erwachse aus der Nutzung des neuen Mediums „digital consumer power" (Ebd.). Konsequent setzt der Verband auch 
vornehmlich auf Verbraucherverantwortung und -Kompetenz, weniger auf seine „Bevormundung“ durch eine „unsachgemäße“ Fülle von gesetzlich geregelten Informationspflichten durch die Unternehmen, die zur Verteuerung von Produkten führten. Das zielt vor allem auf die Bemühungen der EU (s.u.), der unternehmensfeindliche Regelungswut unterstellt wird. Ohne dies weiter zu vertiefen, darf man die Ermächtigung des Konsumenten nicht übertreiben; nur ein Teil konsultiert die genannten Ratgeber und Rating-Webseiten, bevor sie Käufe tätigen (vgl. Civic Consulting 2011), die überdies oftmals ausländische Produkte nicht oder nur begrenzt berücksichtigen, nicht immer die billigsten Produkte zuerst nennen und nicht alle Endpreiskomponenten berücksichtigen (Ebd. und European Commission 2012b). Zwei weitere, ganz wesentliche Vorteile des Kaufs im Internet sollte man nicht verschweigen: Die Preise dort sind meist günstiger als im normalen Handel, durchschnittlich nach einer Schätzung der Europäischen Kommission um 6,7 Prozent (European Commission 2012c). Überdies ist natürlich auch das Angebot bei allen Produktkategorien - vor allem beim Einbezug ausländischer Anbieter - sehr viel größer als im stationären Einzelhandel.

\subsubsection{Ansätze zur Regulierung}

Tatsache bleibt aber, dass das Konsumentenvertrauen in Internet-Käufe nicht sonderlich hoch ist - in den letzten Jahren auch nicht signifikant zunahm - und es zudem faktische Probleme beim Kauf gibt und dass vor allem der grenzüberschreitende E-Commerce ein bislang recht kümmerliches Dasein fristet. Aus diesen Gründen sahen sich die einschlägigen Internationalen Organisationen schon recht frühzeitig aufgefordert, sich dieser Problemlage anzunehmen. Die OECD verabschiedete bereits auf ihrer Sitzung in Ottawa (1998) Kernprinzipien zum Konsumentenschutz beim Internethandel. Sie verlangen unter anderem faire Geschäfts-, Werbe- und Marketingpraktiken, die klare Information der Konsumenten über die Identität des anbietenden Unternehmens, die Produktqualität und die Kaufbedingungen, sichere Bezahlungswege, faire und rasche Konfliktschlichtung und den Schutz persönlicher Daten. Dazu kommen als öffentliche Aufgabe die Unterrichtung der Geschäftspartner, die Anpassung des Konsumentenschutzes an die Bedürfnisse des elektronischen Handels und die geforderte Zusammenarbeit bei der einschlägigen Rechtsdurchsetzung (OECD 1999). Später wurden weitere Richtlinien verabschiedet, 2003 jene zum Schutz der Konsumenten vor betrügerischen Praktiken im grenzüberschreitenden Handel (OECD 2003), eine Empfehlung zur Zusammenarbeit bei der Bekämpfung von Spam (2006) und eine Empfehlung zu Konsumentenbeschwerde und -entschädigung (2007). 
Die Erfolge dieser und weiterer Bemühungen fallen vergleichsweise gemischt aus; die OECD möchte diese natürlich im günstigen Licht darstellen. Es fällt aber auf, dass nicht alle OECD-Staaten den Konsumentenschutz an die Erfordernisse des E-Commerce angepasst haben (und sich dabei durchgängig an den OECD-Richtlinien orientieren), ganz zu schweigen von den Entwicklungsländern, die bislang meist nur über dürftigen Rechtsschutz verfügen. Die Zusammenarbeit der nationalen Behörden beim Verbraucherschutz hat sich moderat verbessert; es gibt Abkommen zur einschlägigen informationellen Zusammenarbeit zwischen den USA, Kanada und Australien, auch zwischen den USA und Mexiko und natürlich auch in der EU. Nahezu alle OECD-Staaten haben zumindest Kontaktstellen für Konsumentenbeschwerden mit transnationalem Charakter benannt. Schwachpunkte bei der Verfolgung von Verstößen bleiben die mangelnde internationale Kooperation der Ermittlungsbehörden und die Sanktionierung der Schädigung ausländischer Internet-Kunden durch inländische Stellen. Besser sieht es mit der Befolgung des Bildungsauftrages an Regierungen und Unternehmen hinsichtlich des Konsumentenschutzes im Internethandel aus; diese Aktionen sind allerdings politisch harmlos und kaum kontrovers (Übersicht in OECD 2006, 2009).

Natürlich sind auch andere internationale Organisationen aktiv geworden: Die EU-Kommission legte bereits 1998 einen Vorschlag für eine Richtlinie über bestimmte Aspekte des elektronischen Geschäftsverkehrs im Binnenmarkt vor, die im Jahr 2000 in Kraft trat. Ihr Ziel war es, die Errungenschaften des Verbraucherschutzes auch im E-Commerce zur vollen Anwendung zu bringen. Die wichtigsten Punkte betreffen die gegenseitige Anerkennung (in den Mitgliedsstaaten) der für Teledienste geltenden einzelstaatlichen Vorschriften, die uneingeschränkte Zulassungsfreiheit für Anbieter von Telediensten in der EU, bußgeldbewehrte Transparenzpflichten für die Anbieter zum Schutze der Verbraucher und die Verantwortlichkeit der Diensteanbieter für fremde Informationen im Internet. Die Richtlinie lässt den Mitgliedsstaaten freie Hand in der Ausgestaltung der Anforderungen an ihre inländischen Diensteanbieter, solange diese den Vorgaben der Richtlinie entsprechen. Misslich an dieser Richtlinie war (und ist weiterhin), dass sie keine spezifischen Regelungen für die Zuständigkeit nationaler Gerichte trifft, dies sich nach dem europäischen Handelsrecht richtet, der Kunde also eventuell im Niederlassungsstaat des ausländischen Anbieters klagen muss, was die Rechtsdurchsetzung erschwert und verteuert.

Kurz nach der Umsetzung dieser Richtlinie legte die Europäische Kommission ein Grünbuch vor, das die bestehenden Defizite im grenzüberschreitenden Verbraucherschutz beim E-Commerce darlegte. Dies fand ein gemischtes Echo; die meisten Mitgliedsstaaten befürworteten zwar eine weitere Harmonisierung der nationalen Bestimmungen, aber keine Vereinheitlichung. 
Hierfür sprachen sich im privaten Bereich vor allem die Verbraucherverbände aus, die Unternehmervereinigungen blieben naturgemäß zurückhaltender. Fortschritte wurden denn auch erst einmal nicht erzielt, auf dem Gebiet des Verbraucherschutzes allgemein ging es aber mit einer neuen Richtlinie von 2005 vorwärts. Auch dort werden im Vorspann die unterschiedlichen nationalen Regelungen als Problem und als Hemmnis für das ordnungsgemäße Funktionieren des europäischen Binnenmarktes hervorgehoben. Die neue Richtlinie will daher eine weitergehende Angleichung der nationalen Rechtsvorschriften über unlautere Geschäftspraktiken erreichen. Die Richtlinie legt eine Anzahl von Basisinformationen fest, die der Verbraucher benötigt, um eine informierte geschäftliche Entscheidung zu treffen. Den Mitgliedsstaaten ist es wiederum erlaubt, weitergehenden Schutz des Konsumenten zu verlangen, als es dieser Richtlinie entspricht. Sie untersagt unlautere Geschäftspraktiken, d. h. solche, die der beruflichen Sorgfaltspflicht widersprechen und das wirtschaftliche Verhalten der Konsumenten (durch Werbung) wesentlich beeinflusst. Untersagt sind auch Geschäftspraktiken, die irreführende oder falsche Angaben machen oder wichtige Informationen unterschlagen.

Eine neue Richtlinie der EU von 2011 verspricht jetzt die Vollharmonisierung der einzelstaatlichen Regelungen beim Online-Shopping. Zusätzlich räumt sie den Verbrauchern ein europaweit gleichwertiges 14-tägiges Widerrufsrecht beim Fernabsatz ein, fordert EU-einheitliche Informationspflichten für Unternehmen gegenüber den Kunden (v.a. Kontaktdaten), verbietet Voreinstellungen bei OnlineBestellungen (z. B. Häkchen, mit denen dem Verbraucher Zusatzleistungen untergeschoben werden) und verlangt die ausdrückliche Bestätigung des Endpreises durch den Verbraucher (European Union 2011).

In Deutschland wurden die EU-Bestimmungen zum E-Commerce in die Vorschriften zum Verbraucherschutz des Bürgerlichen Gesetzbuches integriert; die technische Seite des E-Commerce wird dagegen im Telekommunikationsgesetz (von 2007) geregelt. Bemerkenswert ist an diesem Gesetz vor allem, dass es bei Schutzrechtsverletzungen im Internet die Möglichkeit eröffnet, dass InternetDiensteanbieter von praktisch überall her verklagt werden können (Bundesministerium für Wirtschaft und Technologie 2007).

\subsubsection{Modelle der Selbstregulierung}

Zusätzlich zu staatlichen oder gemeinschaftlichen Regelungen gibt es Bemühungen der Unternehmen, den Konsumentenschutz durch Selbstregulierung zu verbessern. Die Europäische Union lancierte bereits im Jahr 2000 eine e-confidence-initiative, 
an der sich eine ganze Reihe von Unternehmen und Verbraucherverbänden beteiligte und die zur Schaffung von Vertrauenssigeln führen sollte; allerdings verlief sie weitgehend im Sande (European Commission 2004a). In den USA hat das Better Business Bureau einen Code of Online Business Practices erarbeitet und vergibt Sigel an die sich daran orientierenden Firmen; etwas Ähnliches wurde von der Werbewirtschaft für die Online-Werbung gestartet. Die Privatwirtschaft einiger anderer Industriestaaten zog nach. An regionalen Initiativen ist ein EU-Euro-Label Shop with Confidence hervorzuheben, welches das Vertrauen der Konsumenten in die Verlässlichkeit der im Internet gehandelten Produkte garantieren, redliche Produktpräsentation, Kostentransparenz, eine seriöse Rückabwicklungspraxis und die Einhaltung von Datenschutzbedingungen bieten soll. Gleiches gibt es mittlerweile auf globaler Ebene mit der Lancierung der Global Trustmark Alliance.

Die einschlägigen Wirtschaftsverbände favorisieren schon seit langem den stärkeren Verlass auf Selbstregulierung. Sie argumentieren, der zunehmende Wettbewerbsdruck im Internethandel werde schon für stärker kundenfreundliche Vertragsbedingungen sorgen, eine zu starke staatliche oder regionale/internationale Regulierung belaste vor allem die kleineren und mittleren Unternehmen, die ohnedies mit geringer Kapitaldecke und Gewinnmargen arbeiteten und übermäßige Regelung gefährde die Wettbewerbsfähigkeit von Standorten. Es soll nicht weiter thematisiert werden, inwieweit diese Behauptungen die üblichen, politisch wirksamen Argumente (Arbeitsplätze) auffahren, um die Interessen auch der Großen in der Branche zu vernebeln. Nicht plausibel erklärt werden kann aber, wie bei der Vielzahl der schon jetzt laufenden Unternehmensinitiativen mit unterschiedlich strikten und breiten Anforderungen der Verbraucher noch den Überblick behalten und verstärkt Vertrauen in den Internethandel entwickeln soll, zumal die Menge der Beschwerden gegen Firmen, die sich solchen Initiativen angeschlossen haben, (relativ) kaum geringer ausfällt als beim Rest (vgl. European Commission 2011c).

\subsubsection{Was bleibt zu tun?}

Irrtümlich wäre die Ansicht, der gesamte grenzüberschreitende Internethandel wäre schon zu allgemeiner Zufriedenheit geregelt. Dagegen sprechen schon die Differenzen der jeweiligen nationalen Regelungen, insbesondere bezüglich des Konsumentenschutzes. Manche Länder verfügen über einen spezifischen Schutz im Internethandel, andere verlassen sich auf generelle Regeln zum Schutz der Konsumenten. In Frankreich gibt es ein Spezialgesetz (Loi Chatel 2008), das den Anbieter zur Nennung seiner Kontaktdaten, zur Information über fehlende 
Widerrufsrechte und den Lieferzeitpunkt der Ware verpflichtet. In Norwegen hat der Consumer Ombudsman einen Standardvertrag entwickelt, an den sich alle OnlineHändler halten müssen. Nicht einmal innerhalb der EU, geschweige denn international, hat sich bislang eine befriedigende Harmonisierung des Verbraucherschutzes im E-Commerce durchsetzen lassen, der einschlägige Bericht der Kommission zeigt erhebliche Lücken bei der Umsetzung der europäischen Regelungen und Richtlinien, ein immer noch starkes Auseinanderdriften nationaler Regelungen (gefördert durch unterschiedliche aktive nationale Rechtsprechung) und eine mangelnde Befolgung selbst etablierter Regelungen durch die Anbieter (European Commission 2012d).

Ein nicht kleiner Anteil der Verkaufsplattformen wies nach einer europaweiten Umfrage Mängel bei der Information über die Konsumentenrechte, in Bezug auf die gesamten (Brutto-)Kosten der Ware sowie defizitäre Kontaktdaten auf (Rapid 2009; European Commission 2012d). Auch bei der Abwicklung der Zahlungsvorgänge gibt es offenbar noch erhebliche Mängel (OECD 2009). Beschwerden fallen immer wieder hinsichtlich so genannter individualisierter, also auf den individuellen Konsumenten maßgeschneiderter Werbung an. Einschlägige Daten werden aus früherem Kauf- und Suchverhalten gewonnen. Dadurch wird der persönliche Datenschutz tangiert, wenn nicht beeinträchtigt.

Größte Probleme des Internethandels ist die Furcht der Konsumenten, dass die Ware nicht rechtzeitig oder beschädigt ankommt und bei der Bezahlung der Ware oder Dienstleistung ihre Daten ausgespäht werden könnten - eine Furcht, die durch spektakuläre Hackerangriffe auf Kundenlisten von Online-Händlern nicht gerade gemindert wurde. In vielen Ländern begrenzen allerdings Gesetze und Verordnungen die Kundenverantwortung für nicht autorisierte Käufe, freilich in recht unterschiedlichem Maße und oft für grenzüberschreitende Transaktionen weniger als für solche im nationalen Rahmen. Was die Verlässlichkeit der Lieferung, ihre Qualität und eventuelle Rückerstattungen anbetrifft, waren nach einer Übersicht der EU die Probleme im Internethandel tatsächlich nicht gering, es gab aber keine signifikanten Unterschiede zwischen Lieferungen aus dem In- und solchen aus dem Ausland (European Commission 2012c).

Schließlich gibt es auch bei der Rechtsdurchsetzung gegenüber InternetGeschäftspartner im Ausland noch Probleme, schon allein deswegen, weil die Standorte der Internet-Verkäufer mitunter nur schwer lokalisiert werden können. Der diesbezügliche Informationsaustausch hat sich aber verbessert; dabei sind die Behörden der USA vorangeschritten. Sie treiben Entschädigungen mittlerweile auch für ausländische Konsumenten ein, die von einem US-Internetverkäufer materiell beeinträchtigt wurden. In der EU gibt es zwar ein System zur gegenseitigen Information, es leidet aber offenkundig unter zu schwacher personeller 
Ausstattung der Verfolgungsinstanzen (OECD 2009: 30). Seit Ende 2006 gibt es auch ein EU-Netzwerk zum Verbraucherschutz (unter Einschluss von Island, Liechtenstein und Norwegen), das regelwidriges Verhalten stoppen soll; es hat bislang 1800 Webseiten vor allem aus dem Bereich des Handels mit elektronischen Produkten und Dienstleistungen inspiziert und in den meisten (aber nicht allen) Fällen für Abhilfe gesorgt (European Commission 2012c).

Zuletzt muss bedacht werden, dass die Regelungen des E-Commerce eingebettet sind in nationale Vertragsrechte und Vertriebswege. Hier aber sind die Regelungen sehr unterschiedlich, selbst innerhalb der EU. Die Union konnte bisher nur bei der Bestimmung des jeweils anzuwendenden nationalen Rechts Fortschritte erzielen, nämlich bei der Harmonisierung der Informationspflichten, der Rücktrittsrechte und einigen Mindeststandards (etwa unfaire Geschäftspraktiken), nicht aber beim großen Rest. So ist der Verbraucherschutz insgesamt, wie die Kommission feststellt, immer noch ein Flickenteppich 27 verschiedener Regelwerke. Die oben geschilderte neue EU-Richtlinie von 2011 wird hier teilweise Abhilfe schaffen, muss aber erst Ende 2013 in nationales Recht umgesetzt werden. Bei einem für die Zukunft wichtiger werdenden Faktor, der elektronischen Ausweisung, Identifikation und Unterschrift, gibt es bislang keine Einigung, die Harmonisierung der Regeln für die Bezahlung per Internet und die Angleichung/Begrenzung der Gebühren hierfür befindet sich erst noch im Diskussionsstadium. Gleiches gilt für die Regelung der Probleme bei der Auslieferung durch die Post oder vergleichbare Dienste (European Commission 2012d). Es gibt also noch viel zu tun.

So wird zwar bei Internetkäufen generell und bei solchen aus dem Ausland empirisch kaum mehr Unheil angerichtet als bei simplen Käufen über den Ladentisch. Das muss aber nicht so bleiben, wenn der E-Commerce seine Aufwärtsbewegung fortsetzen sollte. Es ist außerdem verständlich, dass bei einem weitgehend anonymen Geschäft im Netz die Anforderungen an eine transparente und sichere Beziehung höher sind als beim Ladenkauf, wo die Ware zumindest angesehen, befühlt oder auch begrenzt getestet werden kann. Es ist aber nicht nur das mangelnde Verbrauchervertrauen, das den elektronischen Handel hemmt, sondern zumindest ebenso stark die Scheu der Verkäufer/Anbieter, sich darauf - vor allem grenzüberschreitend - einzulassen, weil die nationalen Unterschiede der Vertragsrechte, der Mehrwertsteuersätze und ihrer Erhebung sowie des CopyrightSchutzes ihnen diese Art der Geschäfte als zu mühselig erscheinen lassen. Der E-Commerce bleibt damit, was vor allem die EU und die OECD beklagen, deutlich unter seinem Potential, seine Chancen für die Steigerung von Wachstum und Wohlstand werden damit nur begrenzt ausgenutzt. 


\subsection{Inter- oder Cyber-Kriminalität}

\subsubsection{Kriminalität im nationalen und internationalen Kontext}

Kriminalität bezeichnet alle beabsichtigten oder schon durchgeführten Verstöße gegen eine bestehende Rechtsordnung. Ist sie hinreichend durch Verfassung und Gesetze legimitiert, besteht ein Rechtsstaat, falls nicht, handelt es sich um einen Unrechtstaat in autokratischen Regimen; dennoch ist die bestehende Rechtsordnung für den Einzelnen bindend und kann nur bei Gefahr für Leib und Leben bekämpft werden. Diese Verstöße werden durch das Strafrecht geahndet. Kriminalität definiert sich somit in einem durch bestimmte staatliche Konstituenten - z. B. Territorium, Staatsgebilde, Staatsvolk, Gesetzgeber - definierten Rechtsrahmen. Daher sind die Befugnisse des jeweiligen Staates, seine Rechtsordnung mittels Gesetze zu schützen und durch Polizei und Justiz Verstöße zu verfolgen, eindeutig und klar zugeordnet. Darüber definieren sich wesentlich die staatliche Souveränität und das Gewaltmonopol (Ostendorf 2010). Internationale Instanzen haben gemeinhin keine Exekutiv- und Sanktionsgewalt und bekommen nur in Ausnahmefällen Kompetenzen der Strafgerichtsbarkeit übertragen, soweit sie Straftaten zwischen bzw. gegen Staaten betreffen. Beispiele sind der Internationale Strafgerichtshof im holländischen Den Haag und der Internationale Seegerichtshof in Hamburg (Esser 2013).

1998 beschloss die UNO, einen Internationalen Strafgerichtshof einzurichten, der seit 1. Juli 2002 als eine unabhängige internationale Organisation arbeitet. Seine Hauptaufgabe ist die Verfolgung und Bestrafung von Verbrechen von internationaler Bedeutung. Im Unterschied zum Internationalen Gerichtshof, vor dem Konflikte zwischen verschiedenen Staaten verhandelt werden, wird vor dem Internationalen Strafgerichtshof gegen einzelne Verantwortliche für solche Verbrechen verhandelt und geurteilt. Dazu gehören Völkermord, Verbrechen gegen die Menschlichkeit und Kriegsverbrechen.

Ein internationales Gericht ist auch der Internationale Seegerichtshof (ISGH), der auf der Grundlage des Seerechtsübereinkommens der Vereinten Nationen von 1982 errichtet wurde. Seine Aufgabe ist die Verfolgung und Ahndung aller für die Seefahrt relevanten Verstöße; unter bestimmten Voraussetzungen kann er auch von Privatpersonen und internationalen Organisationen angerufen werden, nicht nur von den Vertragsparteien des Seerechtsübereinkommen. 


\subsubsection{Cyber-Kriminalität - traditionelle und neue Aktivitäten}

Aus philosophischer und kulturkritischer Sicht wird das Internet im Vergleich zur realen Wirklichkeit vielfach als parallele, virtuelle Welt oder auch als Cyberspace bezeichnet. Daraus folgen dann weitere Kombinationen wie Cyber-Kriminalität, Cyber Intelligence (Spionage) oder Cyber Security. Sachlicher dürfte der Terminus Internet-Kriminalität sein (Wernert 2011; Glenny 2012; Hilgedorf und Valerius 2012). Mit diesen Begriffsschöpfungen soll signalisiert werden, dass sich Strukturen, Situationen und Handlungen, wie sie in der realen Welt gegeben sind, auch in der digitalen Welt wiederfinden; aber auch, dass sich dort neue, spezielle Optionen herausbilden und möglichweise Probleme für das Zusammenleben und die Rechtsordnungen ergeben. Deshalb plädieren manche dafür, ein eigenes, vor allem vollständiges Internet-Recht für dieses Paralleluniversum zu entwickeln und nicht nur die bestehende Rechtskonstrukte der realen Welt bei Bedarf anzupassen, zumal die Internetwelt ja global und ohne konkrete Bezüge zu territorialen und kulturellen Eigenschaften der Nationalstaaten besteht. Allerdings fehlt dafür eine zuständige, vor allem anerkannte und durchsetzungsfähige Instanz, die nur auf der Ebene der UNO angesiedelt werden könnte.

Die Weiterentwicklungen rechtlicher Normen in verschiedenen Ländern führen zwangsläufig dazu, dass es keine Übereinstimmung in Bezeichnungen und Handlungsfelder für Internet-Kriminalität gibt. So bezeichnet die Cybercrime Convention des Europarats von 2002 Verbrechen wie Datenmissbrauch und Urheberrechtsverletzungen als "Cyberkriminalität" (Krone 2005). Seit März 2010 engagiert er sich mit einem Aktionsplan zur EU-weiten Bekämpfung von Cybercrime und treibt die Entwicklung eines Filters zur Sperrung von Webseiten voran. Sperrmaßnahmen sollen aber auch Glücksspielangebote, gewaltverherrlichende, rechtsextreme oder urheberrechtlich bedenkliche Webseiten und Filesharing-Netzwerke erfassen, wie dies Frankreich mit eigenen Spezialgesetzen bereits umsetzt. Andere Definitionen (Zeviar-Geese 1997-1998) sind umfassender und schließen Aktivitäten wie Betrug, unerlaubten Zugriff, Kinderpornografie und Online-Belästigung ein. Im Handbuch zur Vorbeugung und Kontrolle von Computerverbrechen der Vereinten Nationen vom März 2010 werden ebenfalls Betrug, Fälschungen und unerlaubten Zugriff unter Cyberkriminalität gefasst.

Ausreichend und vor allem vollständig sind solche Tatbestandsaufzählungen gewiss nicht. Eine umfassende, aber auch reichlich abstrakte Definition legt das internationale Sicherheitsunternehmen Symantec vor: Jedes Verbrechen, das mit Hilfe eines Computers, Netzwerks oder Hardware-Geräts begangen 
wird, kann Cybercrime genannt werden. Der Computer oder das Gerät kann dabei Agent, Vermittler oder Ziel des Verbrechens sein. Daher sei hier der analytische Versuch unternommen, drei Typen von Internet-kriminalität zu unterscheiden; sie sind heuristisch gemeint und können sich überschneiden (Symantec 2009):

1. Rechtsverstöße und Strafhandlungen, die in der realen Welt vorkommen und sich nun auch - mit der anhaltenden Verlagerung von Handlungen und sozialen, geschäftlichen Beziehungen ins Internet - in der digitalen Welt wiederfinden. Sie können analog zu ,realen' Vergehen geahndet werden und werden es auch bereits. Darunter sind etwa Täuschung, Fälschung, Betrug, Diebstahl, etc., wie sie vor allem im E-Commerce geschehen, zu fassen, aber auch (Kinder)Pornografie, illegales Glückspiel, Drogen- und Waffenhandel, Erpressung, Spionage sowie andere Strafrechtsverletzungen zu rechnen.

2. Rechtsverstöße und Strafhandlungen, die infolge der besonderen Bedingungen des Internets neu und speziell sind; sie lassen sich zwar aus analogen Vergehen in der realen Welt ableiten, doch erhalten sie mit den globalen und vernetzenden Potentialen des Internets neue Qualität. Dazu zählen alle Formen des Datenmissbrauches bis hin zu Datendiebstahl (E-MailAccounts und Onlinekonten), Adressen- und Profileverkauf sowie andere Datenschutzverletzungen; auch Urheberrechtsverletzungen, illegale Downloads von Software und Daten - Formen digitalen Diebstahls, geistigen Eigentums ${ }^{\mathbf{c}}$ haben mit den Scan- und Verbreitungskapazitäten des Internets an Macht und Schärfe zugenommen. Verbreitet sind auch, nicht zuletzt unter Kindern und Jugendlichen, öffentliche Anprangerungen, Beleidigungen, Belästigungen, falsche Beschuldigungen und generell Rufmord, als Cyber-Mobbing und -Stalking gebrandmarkt. Die Anonymität des Netzes verleitet oft auch zu sexuellen Übergriffen, zumal von sich tarnenden Erwachsenen gegenüber Kindern und Jugendlichen, Cyber-Grooming genannt. Besonders verlockend und lukrativ sind natürlich alle Online-Aktivitäten, bei denen die Daten für finanzielle Werte wie bei Online-Banking und Online-Finanztransfers firmieren.

3. Rechtsverstöße und Strafhandlungen, die sich besonders oder ausschließlich gegen das Internet als neuem Instrument der Kommunikation, des Datenverkehrs und Programmaustauschs, des virtuellen öffentlichen Raums, als Interaktionsforum, Geschäftsmodell und Publikationsplattform richten; sie zielen auf Manipulation, Störung oder Verhinderung der digitalen Kommunikation, beispielhaft durch Hacken und virtuelle Einbrüche in Intranets, der Infiltration von Virenprogrammen, Würmern und Trojanern. 


\subsubsection{Internetspezifische Vergehen}

Für die letztgenannte Kategorie von Verstößen seien exemplarisch aufgeführt (Gercke und Brunst 2009):

1. Am populärsten ist Hacken, nicht zuletzt durch eine öffentlich sehr verbreitete, von den Medien bisweilen sogar kultisch überhöhte Subkultur, die durch attraktive, gut vermarktbare Protagonisten wie etwa den Chaos Computer Club (CCC) in Hamburg verkörpert wird. Hacken bedeutet das (meist illegale, aber oft politisch legitimierte) Eindringen in Computersysteme über Netzwerke oder eben auch nur das ständige, zeitaufwändige Befassen mit Computerprogrammen und ihren Konstruktionen. Ein besonders prominentes Beispiel ist "WikiLeaks“ (vgl. Abschn. 6.5).

Beim Hacken werden sowohl gezielt mittels technischem Know-how oder auch ausdauerndem Experimentieren (,trial and error) Zugangscodes und Passwörter geknackt, mithin virtuelle Einbrüche verübt, um ein bislang geheimes Datenkontingent oder internes Netzwerk zu öffnen oder auch zu manipulieren. Die Schutzbehauptung von Hackern ist oft, man wolle Sicherheitslücken (etwa bei Kernkraftwerken, Banken und militärischen Einrichtungen) aufzeigen, sie beseitigen und die Cyber-Security steigern.

Häufig werden dabei auch störende oder schädliche Virenprogramme infiltriert, die Systeme manipulieren, verändern oder gar zerstören können. Werden sie getarnt und geheim implantiert und führen andere Funktionen aus, als die tatsächlich eingegebenen, ohne dass es die Nutzer merken, spricht man von einem „trojanisches Pferd“ oder auch kurz von einem „Trojaner“. Im Alltag werden sie häufig mit Computerviren gleichgesetzt sowie als Oberbegriff für Backdoors und Rootkits verwendet, sind aber von ihnen klar zu unterscheiden.

Denn ihre Kriminalitätsgrade sind unterschiedlich: Backdoors (auch Trapdoor oder Hintertür) sind nämlich (oft vom Autor eingebaute) Softwareteile, mit denen die Benutzer unter Umgehung der normalen Zugriffssicherung Zugang zum Computer oder einer sonst geschützten Funktion eines Computerprogramms erlangen. Weit verbreitet ist etwa das Knacken von Passwörtern, also das Aufdecken und illegale Benutzen einer persönlichen Codierung. Hingegen sind Rootkits (englisch etwa: „Administratorenbausatz"; root ist bei unixähnlichen Betriebssystemen der Benutzer mit Administratorrechten) Sammlungen von Softwarewerkzeugen, die nach dem Einbruch in ein Softwaresystem auf dem manipulierten System installiert werden, um zukünftige Anmeldevorgänge (logins) des Eindringlings zu verbergen und Prozesse und Dateien zu verstecken. 
Botnets sind Netzwerke, die aus vielen solch infizierter Privatcomputern bestehen; sie können von ihren Betreibern - großenteils von ferngesteuerten BotnetRechnern - mit Werbemails (Spams) vollgestopft werden; außerdem lassen sich damit auch Adressen und Webseiten lahmlegen, wenn unzählige Adressen gleichzeitig beschickt werden. So genannte Keylogger sind Spionageprogramme, die auf fremden Rechnern heimlich aus der Ferne installiert werden, um alles zu protokollieren, was ein Nutzer eintippt, zum Beispiel Passwörter oder Kreditkartenummern. Diese Daten im Hintergrund gehen an den Angreifer; das Opfer merkt diese Manipulation erst, wenn sich an seinen Daten nicht von ihm erwirkte Transfers manifestieren, beispielsweise automatische Abbuchungen.

2. Eine der häufigsten Formen von Kriminalität im Internet ist das so genannte Phishing. Dabei sucht man an persönliche Daten und Passwords eines InternetNutzers wie WWW-Adressen, Links in E-Mails oder Kurznachrichten heranzukommen, um seine Identität zu entschlüsseln, mithin arglistige Täuschung zu verüben. Nach dieser Decodierung lassen sich Daten umleiten, Konten plündern, Geschäftsgeheimnisse aufdecken und für eigene illegale Zwecke nutzen.

Nach den heute gebräuchlichen Varianten werden die Zugangsdaten von einer Schadsoftware im Hintergrund ohne eine Mitwirkungshandlung des Nutzers abgefangen (so genannter Trojaner). Denkbar ist aber auch, dass die Phisher die Internetknotenrechner scannen und von dort einen so genannten Man-in-theMiddle-Attac planen. Dabei wird besonders häufig und intensiv auf die vermeintliche persönliche Nähe sozialer Netzwerke gesetzt, eine Art social engineering praktiziert. Phisher geben sich als vertrauenswürdige Personen aus und versuchen, durch gefälschte elektronische Nachrichten an sensible Daten wie Benutzernamen und Passwörter für Online-Banking oder Kreditkarteninformationen zu gelangen. Phishing-Nachrichten werden meist per E-Mail oder Instant-Messaging versandt und fordern den Empfänger auf, auf einer präparierten Webseite oder am Telefon geheime Zugangsdaten preiszugeben. Versuche, der wachsenden Anzahl an Phishing-Attacken Herr zu werden, setzen unter anderem auf geänderte Rechtsprechung, Anwendertraining und technische Hilfsmittel.

3. Pharming (oder auch DNS-Spoofing) hat sich als Oberbegriff für verschiedene Arten von Angriffen auf das Domain Name-System (DNS) eingebürgert. Dabei geht es um die latente Manipulation von Verbindungen von einer Webseite auf die andere, ohne dass es der Nutzer merkt. Eine Methode ist etwa die lokale Manipulation der Host-Datei; mittels eines Trojaners oder eines Virus wird so gezielt manipuliert, dass gefälschte Websites angezeigt werden, obwohl die Adresse korrekt eingegeben wurde. Benutzer können so beispielsweise auf täuschend echt nachgebildete Seiten einer Bank geleitet werden. Durch aktuell gehaltene und richtig konfigurierte Sicherheitssoftware (aktive 
Hintergrundwächter, aktive Firewalls) lassen sich solche Manipulationen verhindern.

4. Als „Königsdisziplin“ (Rosenbach und Schmundt 2011, 34) in der angewandten Internet-Kriminalität gilt das Carding, der Kreditkartenklau, weil bei diesem Vergehen alle Techniken und Branchen der digitalen „Untergrundökonomie“ zusammenarbeiten: „Die komplizierte Transaktion beginnt mit einer Spam-Mail zum Beispiel aus Russland, die einem Empfänger in Deutschland vortäuscht, dass mit seiner Kreditkarten etwas nicht stimmt. Am Ende, nach Einsatz diverser Phishing- oder Keylogger-Instrumente, hat das Opfer oder das Geldinstitut oft viele tausend Euro verloren" (Ebd.).

\subsubsection{Empirische Ausmaße von Internet-Kriminalität}

Kriminelles Eindringen in und Manipulieren von Netzen ist deshalb besonders sensibel und risikoreich, da moderne Staaten, Unternehmen, Wissenschaft und Gesellschaft nicht mehr ohne digitalen Datenverkehr auskommen und daher extrem anfällig bzw. verletzbar sind. Entsprechend vermehren sich die Maßnahmen zur Sicherheitsvorkehrung - primär mittels Programme, aber auch mittels Hardware- und Systemkomponenten - und natürlich die Kosten.

In seinem Lagebericht Cybercrime 2010 rechnet das Bundeskriminalamt (BKA) mit rund 60.000 Internetstraftaten im engeren Sinne, zum Beispiel Passwortklau was ein Zuwachs von 19,1 Prozent im Vergleich zum Vorjahr bedeutet, auf 2011 sollen es acht Prozent gewesen sein. Insgesamt hat das BKA 2010 sogar 247.000 Fälle erfasst, in denen das Internet als Tatmittel eine Rolle spielt (Rosenbach und Schmundt 2011, 30). Allein in Nordrhein-Westfalen wurden im Jahr 2010 mehr als 48.000 Straftaten registriert, bei denen die Tat über das Internet begangen wurde (Neue Westfälische vom 27. Juli 2011). Allerdings schwanken die Angaben auch von offiziellen Stellen recht stark, je nach Definition und Einordnung der Vergehen. Mit über 180.000 Fällen machten 2010 Betrügereien im Internet den größten Anteil der Interkriminalität aus. Das Phishing - also das illegale Ausspähen von Daten - stieg mit 9.300 Fällen stark an. Die Verbreitung kinderpornografischer Fotos und Texte stellte prozentual einen eher kleinen Anteil dar (Hamburger Abendblatt vom 1. Juni 2011). Der finanzielle Schaden stieg in Deutschland zwischen 2009 und 2010 um zwei Drittel: auf 61,5 Millionen Euro (Rosenbach und Schmundt 2011, 37).

Deutschland ist bei den Cyber-Kriminellen, besonders bei den Botnet-Betreibern, sehr beliebt, weil das Netz hier leistungsstark ist und viele User mit ihren Flatrates oft und lange im Netz sind. So werden sie zu leichten Zielobjekten der Angriffe. Nach einer aktuellen Studie der internationalen Virenschutz-Firma Symantec 
nimmt Deutschland bei verseuchten Computern einen Spitzenrang ein: Denn rund 22 Prozent aller Internetnutzer hatten - laut der Erhebung des europäischen Statistikamtes (Eurostat) - binnen eines Jahres mit gefährlichen Computerinfektionen zu kämpfen. Nach einer Umfrage des Branchenverbandes BITKOM aus dem Jahr 2010 fühlten sich 85 Prozent der Deutschen von Internet-Kriminalität bedroht; bei sieben Millionen User wurden bereits Zugangsdaten etwa zu E-Mail-Diensten oder Bankkonten ausgespäht; das sind fast doppelt so viele wie 2009.

Aber nicht nur oft hilflose Privatnutzer werden zu Geschädigten; auch Weltkonzerne zumal aus der Elektronik- und Bankbranche sind vor Angriffe nicht gefeit: 2011 traf es zuerst den japanischen Elektronikriesen Sony, dem die Daten von über 100 Millionen Kunden gestohlen wurden, dann meldete die Citigroup mehr als 360.000 geklaute Datensätze, schließlich erwischte es Nintendo und Hotelketten. Auch Google wurde überfallen. Bislang nicht identifizierte Hacker knackten zum wiederholten Male den von Millionen Menschen genutzten E-MailDienst Gmail und drangen in die Konten von US-Regierungsbeamten und chinesischen Aktivisten ein (Ebd.). Spätestens seit der Computervirus Stuxnet 2010 das iranische Atomprogramm erfolgreich verzögerte, müssen auch Staaten mit virtuellen Angriffen auf ihre Infrastrukturen rechnen. Es geht um mächtige ökonomische Interessen, riesige Datentransfers bei Finanzen und sozialen Instanzen, militärische und politische Geheimnisse, nationale Sicherheit wie um die diverser Netze (etwa für Elektrizität, Verkehr). So warnte schon Anfang 2011 das amerikanische Verteidigungsministerium, dass Cyber-Attacken ab einer bestimmten Größenordnung und mit nationalen Folgen künftig als Kriegserklärung betrachtet und mit militärischen Mittel beantwortet würden (Cyberwar) (Abb. 6.5).

\subsubsection{Bekämpfung der Internet-Kriminalität}

Zur Bekämpfung der Internet-Kriminalität arbeiten in den USA Geheimdienste, Polizei, Hightech-Konzerne, Banken und Universitäten vornehmlich unter der Federführung des FBI eng zusammen. Schon 1997 wurde die National CyberForensics \& Training Alliance gegründet, heute ein Zusammenschluss von 15 Behörden und 40 Unternehmen. Potentielle Verbrechen und Kriminelle lassen sich mit wenigen Mausklicks identifizieren und registrieren, Unternehmen und Behörden tauschen schnell ihre Erkenntnisse, um virtuelle Spuren rasch $\mathrm{zu}$ verfolgen. Besonders das FBI greift auch zu unkonventionellen Methoden: Rund ein Viertel alle Hacker in den USA seien Informanten des FBI, vermutet das Szenemagazin 2600. Etliche Online-Schwarzmärkte seien von Special Agents unterwandert (Ebd.). 


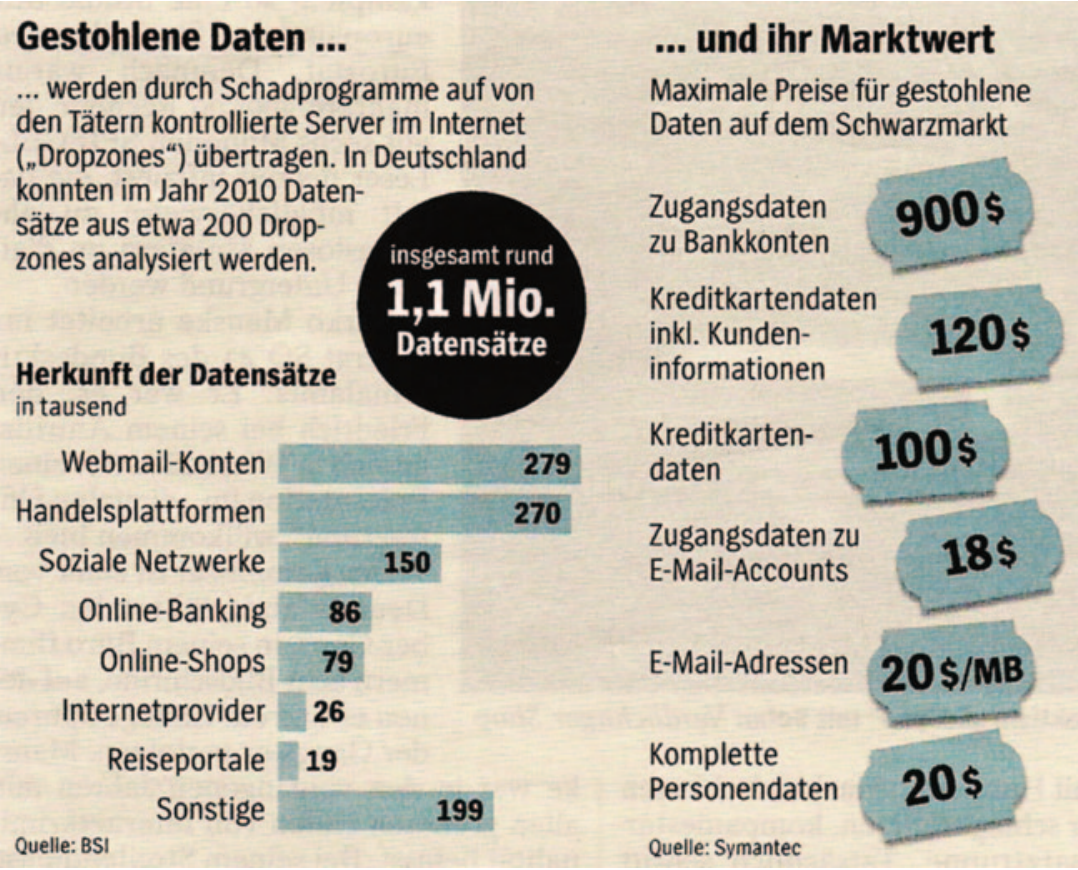

Abb. 6.5 C Cyber-Kriminalität 2010 (aus: Rosenbach und Schmundt 2011, 37)

In Deutschland wurden zentrale Maßnahmen zur Bekämpfung von InternetKriminalität erst kürzlich ergriffen. Im Juni 2011 wurde vom Bundesinnenministerium ein neues Nationales Cyber-Abwehrzentrum in Bonn mit noch wenigen Mitarbeitern eingesetzt. Es soll mögliche Angriffe auf staatliche Einrichtungen verhindern helfen, aber auch schwere Fälle von Internet-Kriminalität analysieren (Ebd.). Infolge ihrer Polizeihoheit verfolgen die Bundesländer eigene Strategien. So hat Nordrhein-Westfalen in seinem Landeskriminalamt (LKA) ein eigenes Cybercrime Zentrum etabliert. Rund hundert Polizisten, Wissenschaftler und ITTechniker sollen selbst gegen IT-Rechtsverstöße ermitteln oder Ermittler vor Ort unterstützen (Neue Westfälische vom 27.7. 2011).

Täter-Identifikation und Strafverfolgung gestalten sich enorm schwierig: Ständig liefern sich Cyber-Kriminelle und Verfolger einen Wettlauf um die modernste Technik, die neuesten raffiniertesten Programme und effizienteste Tarnung bzw. Aufdeckung. Und da die erforderlichen Ressourcen oft genug ungleich, zum Nachteil der öffentlichen, staatlichen Verfolger, verteilt sind, gewinnen sie meist 
nicht die Oberhand. Adressen und Daten lassen sich anonymisieren und laufen über Server auswärtiger Staaten, die oft keine Rechtsabkommen mit den westlichen Internet-Nationen haben, so dass die Identifikation von Tätern und die Lokalisierung ihrer Computer langwierig, oft genug aussichtslos verlaufen. Die Dunkelziffer ist daher extrem hoch. Vor allem Wirtschaftsunternehmen scheuen das Licht der Öffentlichkeit fast ebenso wie die Dunkelmänner im Netz - auch aus Imagegründen, wie die Sicherheitsbehörden immer wieder beklagen. Ohnehin können die Täter nur im geltenden nationalen Rechtsrahmen als persönlich Verantwortliche identifiziert und ihre Straftaten verfolgt werden. Meist gelingt dies nur, wenn der oder die Täter in die analoge, reale Welt ,zurückkehren' und dort die ,Früchte ihres Vergehens ernten wollen: meist in Form von finanziellen Leistungen.

Auf die Initiative der EU-Staaten und 20 weiteren Ländern, darunter den USA, Kambodscha, Thailand, Vietnam und den Philippinen, soll ein „weltweites Bündnis" gegen Kinderpornografie, unter der Schirmherrschaft der belgischen Königin Paola ins Leben gerufen werden. Die teilnehmenden Staaten wollen sich verpflichten, die Aufklärung der Verbrechen, die Verfolgung der Täter, den Schutz der Opfer und das Erschweren des Zugangs zu pornografischen Darstellungen im Netz voranzutreiben und zu koordinieren. Viele der Verbrechen werden in Asien begangen, und meist stehen die Server in den USA und in Ländern ohne rechtliche Abkommen. Schätzungen zufolge zirkulieren schon jetzt mehr als eine Million Bilder von sexuell missbrauchten Kindern im Internet. Jährlich kommen laut UNO rund 50.000 Fotos dazu (Neue Westfälische vom 5. Dezember 2012).

Die EU-Kommission beobachtet die Entwicklung der Cyber-Kriminalität, vor allem die in Milliardenhöhe steigenden Verluste für die europäische Wirtschaft mit großer Sorge und Aufmerksamkeit und fordert die Mitgliedsstaaten zu verstärkten Zusammenarbeit und Abwehr auf. Im Februar 2013 verabschiedete sie eine Mitteilung über Cyber-Sicherheitsstrategien und präzisierte ihre bereits 2010 vorgebrachten Richtlinien für Eine allgemeine Politik zur Bekämpfung der CyberKriminalität. Die erforderlichen Maßnahmen erstrecken sich auf verstärkte Zusammenarbeit bei der Strafverfolgung, Verschärfung der strafrechtlichen Sanktionen und öffentlich-private Partnerschaften.

Die wichtigste Neuerung des Vorschlags ist die Kriminalisierung des Einsatzes, der Produktion und des Verkaufs von Werkzeugen (Botnets genannt) zu Angriffen auf Informationssysteme. Der Vorschlag wird nun im Europäischen Parlament und im Europäischen Rat erörtert. Schon im März 2012 wurde innerhalb von Europol das europäische Cybercrime-Zentrum eingerichtet, das im Januar 2013 seinen Betrieb aufgenommen hat. Im Kern nimmt es vier Funktionen wahr:

1. Es dient als europäische Anlaufstelle für alle Informationen zu Cybercrime;

2. Es stellt einschlägige Expertise zur Unterstützung der Mitgliedstaaten bereit; 
3. Es unterstützt die Mitgliedsstaaten in ihrer Abwehr gegen Cyberkriminalität durch eigene Untersuchungen;

4. Es fungiert als kollektive Stimme der europäischen Cybercrime-Ermittler in der Strafverfolgung und der Justiz.

Die EU-Kommission will für diese konzertierte Abwehr auch mit dem privaten Sektor in Dialog treten und gemeinsame Strategien für die operative Zusammenarbeit entwickeln. Die European Network and Information Security Agency (ENISA) beteiligt sich an diesen Austauschprozessen zwischen und in den EU-Staaten (http://ec.europa.eu/dgs/home-affairs/what-we-do/policies/organizedcrime-and-human-trafficking/cybercrime/index_en.htm).

\subsection{Cyberwar und Internetkrieg}

\subsubsection{Neue Formen von Krieg}

Zwischen phantastischen Vorstellungen aus Science Fiction-Welten einerseits, wo Kriege der Sterne, automatische Kämpfe von Drohnen, Androiden und Computersystemen toben, und dem nüchternen Ermessen von Größenordnungen krimineller bzw. militärischer Attacken, das sich in einer zunehmend militanten Sprache ausdrückt, oszilliert der ebenfalls künstliche Begriff des Cyberwar (zu deutsch: Informations-, Internet- und/oder digitaler Datenkrieg). Nach dem Völkerrecht bezeichnet Krieg organisierte, militärische Konflikte zwischen Staaten, der so genannte Bürgerkrieg bezieht sich auf inländische Auseinandersetzungen in einer Nation. Werden sie von ungleichen Kontrahenten geführt, spricht man von asymmetrischer Kriegführung. Neuerdings kommen transnationale Konflikte wie die durch den internationalen Terrorismus hinzu (Jäger und Beckmann 2011).

Mit der Industrialisierung wurden technische Waffen (Panzer, Flugkörper und Raketen) entwickelt, die nicht nur die physische Eliminierung des feindlichen Heeres, der Soldaten, zum Ziel hatten, sondern die gegnerische Zivilbevölkerung und deren Wohnterritorien in die Kriegsführung einbezogen und einbeziehen. Ihre Verletzung bzw. Beschädigung und Zerstörung durch Bombardements und andere Fernangriffe wurden zunehmend zum Kern moderner Kriegsführung. Um sie zu steuern, bedarf es leistungsfähiger, flexibler Informations- und Kommunikationsinstrumente, weshalb die Erfindung und Entwicklung aller modernen Medien und Technologien durch militärische Impulse vorangetrieben 
wurden: Fernmeldetechnik/Telegrafie, Telefon, Radio, Fernsehen, Computer und endlich das Internet haben militärtechnische Ursprünge (Flichy 1994).

Spätestens seit dem Ersten Weltkrieg, in dem Telegrafie, Radio und Film schon einflussreiche Funktionen zur symbolischen, psychologischen Kriegsführung bei den Feinden, in der Weltöffentlichkeit, aber auch bei der eigenen Zivilbevölkerung und nicht zuletzt bei den eigenen Soldaten als Propaganda, Loyalitätsparolen und Durchhalteappelle übernommen haben, fungieren (Massen)Medien als immer wichtiger werdende Waffen (Paul 2004; Thiele 2009). Mit Fotografie und Film wurden Kriege und ihre Gräuel in immer eindrücklicheren, auch schockierenden Bildern dokumentiert und publiziert. In Deutschland erwuchs daraus die Gründung der damals größten Filmproduktionsgesellschaft, der UFA (Kreimeier 2002): Moderne Kriege werden mehr und mehr inszeniert, sie sind stets auch Medien- und Informationskriege, in denen - wie eine gebräuchliche Einsicht lautet - die Wahrheit zuerst stirbt. Sie müssen auch kommunikativ und symbolisch gewonnen werden, nicht nur auf den Schlachtfeldern.

Mit der anhaltenden Digitalisierung, die die Steuerung der zivilen wie militärischen Infrastruktur, der Datentransfers und Versorgungssysteme auf Computer und Internet verlagert, rückt ihre Beschädigung und Ausschaltung ins Zentrum der militärischen Strategien: Computer kämpfen gegen Computer (Wetzel 2012). Außerdem können mit elektronischer Ausspähung und Anpeilung Angriffe immer zielgenauer ausgerichtet werden, Flächenbombardements sind militärisch kaum mehr nötig. Manche sehen darin sogar die Chance, Kriege ,sanfter ${ }^{\text {' und ,humaner }}$ zu führen, da die Zivilbevölkerung und ihre physischen Schutzräume (wie Gebäude und Straßen) einigermaßen geschont werden könnten. Andere verweisen hingegen auf die enorme Schlagkraft solcher digitaler Angriffe, die nicht nur ganze Länder, sondern ganze Kontinente lahmlegen oder der Erpressung durch den Feind aussetzen können. Für die Kriegsführung selbst ergeben sich Potentiale der unbemannten Fernsteuerung, so dass eigene Soldaten im Kriegseinsatz geschont werden können, wie es die USA derzeit mit Drohnen in Pakistan und Afghanistan vorexerzieren. Computerspiele und digitale Kriegsführung nähern sich einander an und werden zum Training von Soldaten auch schon so eingesetzt. Werden noch biochemische Kampfstoffe zur Auslösung von Epidemien oder Gehirn-Manipulationen genutzt, erwachsen daraus Horrorvisionen.

Mit der digitalen Konvergenz (Verschmelzung) der traditionellen Massenmit den digitalen Medien übernehmen die neuen Systeme gewissermaßen beide Funktionen: die der Kriegsführung, aber auch die der positiven, propagandistischen Berichterstattung, auch direkt vom Kriegsgeschehen vor Ort, wie etwa die letzten Irak-Kriege seit 2003 gezeigt haben. Sowohl an die militärischen Steuerungszentrale 
wie - gezielt - an die Öffentlichkeit und Medien werden die ,Effizienz' und Treffgenauigkeit der Waffen rapportiert (Ulrich 2012).

\subsubsection{Digitaler Krieg: Cyberwar}

Cyberkrieg ist zum einen die kriegerische Auseinandersetzung im und um den virtuellen Raum, den Cyberspace, vorwiegend mit Mitteln der Informationstechnik. Die Kriegsführung kann sich sowohl gegen Staaten als auch gegen terroristische Gruppierungen richten. Zum anderen steht der Begriff generell für alle hochtechnisierten Formen des Krieges, die auf der Computerisierung, Elektronisierung und Vernetzung aller militärischer Bereiche und Belange basieren (Clarke 2011; Falkner 2011; Gaycken 2012).

Etwa seit Mitte der 1980er werden in den USA - nur dort öffentlich, nicht aber in der Sowjetunion und China - Konzepte ventiliert, die "den Wert und die systematische Nutzbarkeit von Daten und Informationen" in Konfliktfällen einbeziehen (Strategic Defense Initiative [http://de.wikipedia.org/wiki/Strategic_Defe nse_Initiative]). Die eingesetzten Waffen sind infiltrierte Computersoftware; sie greifen rechnergestützte Verbindungen an, um die Kommunikation des Feindes zu unterbinden. Komplexere Angriffe erobern die Kontrolle über die feindlichen Computersysteme. Umgekehrt muss jeder Gegner eigene Computersysteme haben und beschützen, um seine Kommunikations- und Kommandostrukturen aufrechtzuerhalten sowie die gegnerischen Angriffe auf sie abzuwehren. Dabei können auch physische Kampfmittel - etwa Strahlenemissionen - zum Einsatz kommen.

Übliche Strategien des Cyberkrieges sind:

- Spionage: also das Eindringen in fremde Computersysteme zum Zwecke der Informationsgewinnung;

- Defacement: also Veränderungen am Inhalt einer Website, um etwa Propaganda zu schalten;

- diverse Formen von Social Engineering;

- Einschleusen von kompromittierter Hardware, die bewusst fehlerhaft arbeitet oder Fremdsteuerung erlaubt;

- Denial-of-Service-Attacken, um feindliche Dienste zu stören oder vollständig zu unterdrücken;

- Materielle Angriffe (Zerstören, Sabotage, Ausschalten) von Hardware (z. B. Kabel-, Antennen- und Satellitenverbindungen)“ (Wikipedia [http://de.wikip edia.org/wiki/Cyberkrieg]). 
Seit den 1990er Jahren erfolgte zumindest in der USA der gezielte Auf- und Ausbau der Kapazitäten für digitale Kriegsführung: 1992 wurde die geheime Direktive TS-3600.1 des Pentagon zum Information Warfare erstellt. 1993 eröffnete die US-Luftwaffe in San Antonio (Texas) das Air Force Information Warfare Center mit damals bereits 1000 Mitarbeitern. 1994 wurde in Washington die School for Information Warfare and Strategy ins Leben gerufen. Ein Jahr später absolvierten die ersten Soldaten, die in Informationskriegsführung ausgebildet worden waren, an der National Defence University in Washington ihre Offizierslehrgänge. Im Januar 1995 entwickelte die US-Navy die Instruktion OPNAVINST 3430.26 zur Umsetzung des Informationskriegs. Ab demselben Jahr begannen die USMilitärs das Konzept des Network Centric Warfare zu entwickeln; dessen Ziel ist es, Dominanz in IT-Technik und Informationsmanagement unmittelbar in militärische Überlegenheit umzusetzen. Unter Federführung des FBI gründeten 1998 verschiedene US-Behörden das National Infrastructure Protection Center (NIPC), das mit Privatfirmen kooperiert und zur Aufgabe hat, den Schutz relevanter Infrastrukturen zu koordinieren und zu organisieren.

Ab 1999 baute das Pentagon unter der Leitung des damaligen USSTRATCOM ein Infowar-Team, das offensive Waffen für den Cyberkrieg konzipierte. 2002 ordnete der damalige US-Präsident George W. Bush in der National Security Presidential Directive 16 an, Strategien auszuarbeiten sowie Richtlinien für die Führung eines Cyberkriegs festzulegen. Im Juli 2002 wurde durch die BushRegierung das direkt dem Executive Office of the President im Weißen Haus unterstellte Office of Global Communications (OGC) ins Leben gerufen. Seine Aufgaben sind, „Botschaften für ein ausländisches Publikum zu formulieren und zu koordinieren“ sowie „die Darstellung der Außenpolitik der USA zu koordinieren und ihr Image im Ausland zu überwachen“.

Die National Cyber Security Division (NCSD), die ihre Arbeit am 6. Juni 2003 als eine Abteilung des Office of Cyber Security \& Communications aufnahm, koordinierte bereits seinerzeit mehrere Institutionen und war seitdem für die zivile Cyberverteidigung der Vereinigten Staaten zuständig. Bis zum Jahr 2005 wurde das Joint Functional Component Command for Network Warfare (JFCCNW) etabliert, das der National Security Agency zugeordnet ist. Für die Aufklärung und Informationsgewinnung ist hingegen das Joint Information Operations Warfare Command (JIOWC) verantwortlich. Am 31. Oktober 2010 nahm das United States Cyber Command seinen Dienst auf. Dieser neu geschaffene Teil des US-Militärs, der auch mit der National Security Agency (NSA), dem größten Geheimdienst der USA, assoziiert ist, setzt sich mit Strategien und Möglichkeiten des Cyberkriegs auseinander. Beide Behörden, der Cyber Command des Pentagons und die NSA 
arbeiten eng zusammen und haben derzeit denselben Chef (Wikipedia [http://de. wikipedia.org/wiki/Cyberkrieg]; Darnstädt u. a. 2013).

Noch im November 2012, vor seiner Wiederwahl, befasste sich US-Präsident Barack Obama mit der Computersicherheit der Vereinigten Staaten. Er unterzeichnete die geheime Presidential Policy Directive 20, die angeblich die bisher bestehenden Abwehrkapazitäten der US-Behörden im Kampf gegen Cyberkriminalität und -terrorismus erweitert. Während bislang die amerikanische Cyber-Abwehr primär das eigene Netzwerk, also etwa die technologisch gestützte Infrastruktur des Landes, schützen sollte, sollen nun auch Angriffe auf Netzwerke in anderen Ländern erlaubt sein. Denn die neue Direktive betont, dass auch offensive Aktionen der Abwehr dienen können und zulässig sind, sofern die digitale Sicherheit des Landes bedroht ist (SPIEGEL online vom 16. November 2012).

In den kommenden Jahren will das US-Pentagon die Zahl seiner Spezialisten für digitale Kriegsführung von jetzt 900 auf 4900 mehr als verfünffachen, berichten im Januar 2013 übereinstimmend die New York Times und die Washington Post (SPIEGEL online vom 20. Februar 2013). Anstoß für diese Entscheidung hätte die Netzattacke gegen das Netzwerk der Ölfirma Saudi Aramco im August 2012 gegeben, bei der 30.000 Computer der saudi-arabischen Firma mit einem Virus infiziert wurden. Die US-Militärs befürchten massive Bedrohungen durch iranische, russische und chinesische Netzangriffe sowie durch IT-ausgerüstete Extremistengruppen; sie können sich gegen US-Formen, staatliche Administrationen, Banken, Netzwerke und Versorgungssysteme richten.

Daher sollen im Cyber Command drei Typen von Netzkampfgruppen agieren:

- National Mission Forces: Sie sollen die Computer und Netzwerke schützen, von denen die nationale Infrastruktur der USA abhängt, also beispielsweise Stromnetze und Kraftwerke.

- Cyber Protection Forces: Diese Truppe dient dazu, die Netzwerke des Verteidigungsministeriums und der Streitkräfte zu schützen.

- Combat Mission Forces: Experten, die Streitkräften im Ausland bei der Planung und Durchführung von Angriffseinsätzen zur Seite stehen; mithin eine klar auf Offensivmaßnahmen spezialisierte Einheit (Ebd.).

Für die NATO wurde am 14. Mai 2008 das dem Verteidigungsbündnis zuarbeitende, aber nicht zu seiner formalen Organisation gehörende Cooperative Cyber Defence Centre of Excellence (CCD CoE) in Tallinn, Estland, gegründet. Am 28. Oktober 2008 wurde es als eines von nunmehr insgesamt zehn „Centers of Excellence" von der NATO offiziell akkreditiert. Das Personal umfasste anfangs 30 Personen (Stand: April 2009). Zu den Aufgaben des Kooperationszentrums für 
Cyberverteidigung zählen Erkenntnisse, Hilfestellungen und Fachinformationen zu alle Dimensionen der Thematik für die NATO bereitzustellen. Dazu gehören Konzeptionierung, Training und Übungen für einschlägige Strategien, die Publikation von Forschungsergebnissen sowie die Entwicklung eines rechtlichen Rahmens für die, wie es beim CCD CoE heißt, noch „unreife Disziplin“ Cyberverteidigung (Wikipedia http://de.wikipedia.org/wiki/Cyberkrieg).

Auf dem NATO-Gipfel in Bukarest im April 2008 wurde die Bereitschaft der Allianz unterstrichen, die „Fähigkeit zu bieten, Bündnismitglieder auf Verlangen bei der Abwehr eines Cyberangriffs zu unterstützen". Die erste CCD CoE Conference on Cyber Warfare fand vom 17. bis 19. Juni 2009 statt. Das CCD CoE will, wie es hieß, so rasch wie möglich auch ein Lexikon zum Cyber Warfare herausgeben. Vom 9. bis zum 11. September 2009 fand ebenfalls in Tallinn die Cyber Conflict Legal \& Policy Conference 2009 statt, gemeinsam veranstaltet vom George Mason University Center for Infrastructure Protection (CIP[26]) und dem CCD CoE.

Im März 2013 ist in Tallinn das Handbuch des internationalen Rechts für die Cyber-Kriegsführung erschienen, deshalb auch Tallin-Manual genannt. Führende Völkerrechtler unter dem Vorsitz eine Pentagon-nahen US-Militärjuristen haben Regeln für den digitalen Krieg der Zukunft in dem angeblich schmalen Brevier fixiert. NATO-Vertreter bezeichnen es als das „wichtigste rechtliche Dokument der Cyber-Ära“. Primär sei die Entscheidung, was als Angriff auf den Staat zu werten bzw. wann der Verteidigungsfall und das völkerrechtliche Prinzip der staatlichen Selbstverteidigung gegeben seien. Laut der neuen Doktrin sind „nur solche Angriffe [...] von völkerrechtlichem Gewicht, die an ihrem Ziel beim Gegner physische Schäden oder Personenschäden, aber nicht virtuelle Schäden auslösen. Der Ausfall eines Rechners oder der Verlust von Daten allein reicht nicht, von einem ,bewaffneten Angriff zu sprechen." Allerdings können Angriffe oder sogar präventive Erstschläge getätigt werden, wenn die potentiellen Schäden in Ökonomie und Infrastruktur als „katastrophal“ eingeschätzt werden. Letztlich entscheidet jeder Staat selbst darüber, ob, wie und wann solche Ausmaße eintreten können oder eingetreten sind - weshalb Kritiker diese Ermessensklausel als „Dammbruch“ für das völkerrechtliche Gewaltverbot bewerten und tadeln (Darnstädt u. a. 2013).

In Deutschland unterhält die Bundeswehr seit 2006 in der Tomburg-Kaserne in Rheinbach bei Bonn die Abteilung Informations- und Computernetzwerkoperationen, die zum Kommando Strategische Aufklärung zählt und mit ca. 7.000 Bediensteten das größte der Bundeswehr ist. Die Mitarbeiter der Computerabteilung rekrutieren sich in erster Linie aus Absolventen der Fachbereiche für Informatik an den Bundeswehruniversitäten. Das Kommando Strategische Aufklärung hatte im Dezember 2008 offiziell das satellitengestützte Spionagesystem SAR-Lupe in Dienst genommen. Mit fünf Satelliten kann die SAR-Lupe, die als eines der modernsten 
Systeme dieser Art gilt, unabhängig von Tageslicht und Wetter Bilder mit einer Auflösung von weniger als einem Meter liefern. Damit sei nahezu jeder beliebige Punkt auf der Erde „aufklärbar“, hieß es: „Es beschafft, sammelt und wertet Informationen über die militärpolitische Lage in einzelnen Ländern und Bündnissen des potentiellen oder tatsächlichen Gegners und über seine Streitkräfte aus“ (Ebd.). Das satellitengestützte Kommunikationssystem der Bundeswehr SATCOMBw nahm mit der Aussetzung des Satelliten COMSATBw-1 im Weltraum Anfang Oktober 2009 seinen Teilbetrieb auf. Der zweite Satellit, COMSATBw-2, wurde am 21. Mai 2010 ins All befördert und erreichte nach einer Woche seine vorhergesehene Position in der Erdumlaufbahn. Die Satelliten decken jeweils die östliche und die westliche Hemisphäre des Planeten ab. 2001 hatte die Bundeswehr in einem Planspiel, an dem sich auch das Bundesinnenministerium beteiligte, erstmals einen maßgeblich über das Internet geführten Krieg simuliert; am 1. April 2002 wurde das Bundesamt für Informationsmanagement und Informationstechnik (IT-AmtBw) gegründet.

Ebenfalls im Jahr 2001, als die Pläne der Militärs für künftige Kriege wie auch die Gefahren im Netz einer breiteren Öffentlichkeit bekannt wurden, forderten Die Grünen im Deutschen Bundestag vor dem Hintergrund der Furcht vor einem digitalen Wettrüsten eine „Cyber-Friedenspolitik“. In Berlin hatten sie im Juni ihre Initiative Für eine friedliche Nutzung des Cyberspace präsentiert (Ebd.). Die Bundeswehr wappnet sich weiterhin gegen Cyber-Attacken und verfügt seit Dezember 2011 über Experten, die selbst Angriffe im Internet starten können. Der Einsatz der Armee im Cyberspace unterliegt dabei den gleichen verfassungsrechtlichen Voraussetzungen wie jeder andere Streitkräfteeinsatz.

Im Oktober 2012 erklärte die Bundesregierung, sie behalte sich grundsätzlich das Recht vor, auf schwere Cyber-Attacken mit Waffengewalt zu reagieren. „Je nach Eigenart kann ein Cyber-Angriff im Einzelfall als bewaffneter Angriff auf einen Staat zu werten sein", zitiert die Nachrichtenagentur Reuters aus einem vertraulichen Bericht der Bundesregierung, der zwischen Innenministerium, Auswärtigem Amt, Bundeskanzleramt und Verteidigungsministerium abgestimmt ist. Staaten seien bei bestimmten Cyber-Angriffen berechtigt, „ihr naturgegebenes Recht auf individuelle oder kollektive Selbstverteidigung auszuüben“, heißt es in dem Bericht. Dies gelte insbesondere dann, wenn die Souveränität des angegriffenen Staates bedroht sei oder die Wirkung der Cyber-Attacke sich mit der Wirkung herkömmlicher Waffen vergleichen lasse. Das Verteidigungsministerium bestätigte auf Anfrage, dass ein entsprechender Bericht existiert. Er sei am 21. September 2012 den Mitgliedern des zuständigen Ausschusses des Bundestages zugegangen. Zum Inhalt äußerte sich das Ministerium unter Verweis auf die Geheimhaltungsstufe „VS - nur für den Dienstgebrauch“ nicht (SPIEGEL online vom 12. Oktober 2012). 
Grundsätzlich nehme die Bedrohung durch staatlich gesteuert Cyber-Attacken zu. Die Angriffe könnten auch über bewegliche Datenträger ausgeführt werden. „Damit sind selbst bislang vom (offenen) Internet als sicher abgetrennt vermutete IT-Systeme wie Industrieproduktionsstätten, kritische Infrastrukturen oder grundsätzlich auch militärische waffensystemspezifische Netze verwundbar", stellt der Bericht fest. Schädliche Software habe sich auch schon vor Jahrzehnten über Disketten verbreitet, daher sind Angriffe über „bewegliche Datenträger” nicht sonderlich neu. Allerdings haben die Attacken des Stuxnet-Wurms, den US Hightech-Krieger auf Anordnung des amerikanischen Präsidenten 2010 in iranische Atomanlagen einschmuggelten, gezeigt, dass Schadprogramme per USBStick erfolgreich in abgeschirmte Netze gebracht werden können.

„Dem Cyber-Raum wird somit zunehmend operative Bedeutung bei militärischen Auseinandersetzungen aller Art zukommen." Ausschließlicher Austragungsort eines Krieges werde das Internet auf absehbare Zeit allerdings nicht sein. Gleichwohl könnten Cyber-Angriffe in Kombination mit konventionellen Mitteln eine sehr hohe Bedrohung darstellen, auf die sich die Bundeswehr einstellen müsse. Die Armee nutze großenteils kommerziell verfügbare Systeme wie Microsoft, deren Schwachstellen ein Angreifer ausnutzen könne. Auch menschliches Fehlverhalten und extremistische Innentäter stellen eine Gefahr dar (Ebd.).

\subsubsection{Initiativen gegen Cyberwar}

Gegen solche Planungen und Abwehrmaßnahmen von Cyberwar argumentiert das Forum Informatiker und Informatikerinnen für Frieden und gesellschaftliche Verantwortung e. V. (FIfF) mit konsequenten Gegenvorschlägen:

„Für das potenzielle Schlachtfeld im Cyberspace wurde eine neue gefährliche Rüstungsspirale in Gang gesetzt. Sie zieht ihre Motivation aus dem Auf- und Ausbau von militärischen Cyberwar-Einheiten, der hohen Verletzlichkeit der digitalen Gesellschaften mit ihren global vernetzten IT-Systemen und dem vermeintlich geringen Risiko für den Angreifer, identifiziert und für sein Tun sanktioniert $\mathrm{zu}$ werden. Es ist höchste Zeit, dass die in Gang gesetzte Rüstungsmaschinerie wieder gestoppt wird. Das FIfF als Teil der Friedensbewegung ist in besonderer Weise gefordert, seine fachliche Expertise dafür zu nutzen. Die folgenden Forderungen sollen zu einer Deeskalation und Vermeidung von Cyber-Kriegen beitragen:

1. Verzicht auf Erstschlag und Offensive im Cyberspace: Staaten sollen öffentlich darauf verzichten, Cyber-Waffen präventiv oder zum Angriff einzusetzen. 
2. Reine defensive Sicherheitsstrategie: Staaten sollen sich verpflichten, keine Offensivwaffen für den Cyberwar zu entwickeln oder gar einzusetzen.

3. Digitale Genfer Konvention: Für die Zivilbevölkerung lebenswichtige Infrastrukturen wie Wasserversorgung, Gesundheitsversorgung etc. dürfen nicht angegriffen werden. Eine Verletzung dieses Grundsatzes soll als Kriegsverbrechen gelten.

4. Anerkennung eines Grundrechts auf zivilen Ungehorsam und OnlineProtestformen im Internet: Derartige Aktionen dürfen nicht kriminalisiert werden, geschweige denn als Kriegsgrund herhalten.

5. Wirtschaftliche Interessen, wie ein Verstoß gegen Intellectual Properties, sind kein legitimer Kriegsgrund.

6. Konventionelle Waffen dürfen nicht als Antwort auf eine Cyber-Attacke eingesetzt werden.

7. Staatliche Stellen müssen zur Offenlegung von Schwachstellen verpflichtet werden (ableitbar aus dem Grundrecht für Integrität, das der Staat schützen muss).

8. Betreiber kritischer Infrastrukturen müssen verpflichtet werden, sich selbst zu schützen, bzw. IT-Systeme sicher zu gestalten, zu implementieren und zu betreiben, anstatt nach dem Staat oder gar Militär zu rufen. Kompetente, transparente Prüfungen und Tests müssen Voraussetzung für eine Betriebserlaubnis sein. Wir fordern Entnetzung und Dezentralisierung kritischer Infrastrukturen (wie z. B. DE-CIX [heißt Deutscher Commercial Internet Exchange (Deutscher Commercial Internet Exchange), ein Internet Exchange Point in Frankfurt]).

9. Abrüstung der politischen Sprache: Klare Trennung von Cyberwar, Cyberterror, Cybercrime, Ethical Hacking, politischen Protestformen.

10. Demokratische Kontrolle, Gewaltenteilung, Parlamentsvorbehalt für CyberSicherheitsstrategien und deren Umsetzung.

11. Transparenz beim Aufbau jeglicher Cyber-Zentren.

12. Klare friedenspolitische Ausrichtung der Cyber-Zentren.

13. Die Trennung von Polizei und Geheimdiensten und Militär in CyberAbwehrzentren muss gewährleistet werden.

14. Cyberpeace-Initiative: Verpflichtung zur Förderung von Friedensforschung zur Entwicklung von Strategien zur Befriedung des Cyberspace" (FIfFKommunikation 1/12, 44ff.).

Solche Forderungen hören sich (noch) recht idealistisch an, wenn man sie mit den beschriebenen militärischen Vorbereitungen konfrontiert. Realisiert werden könnten sie ohnehin nur durch supranationale Vorgehensweisen, auf Druck zivilgesellschaftlicher Gruppierungen, zunächst wohl als kollektive Selbstverpflichtungen der Staaten und IT-Konzerne. Aber diese Forderungen illustrieren auch, dass isolierte, partielle Maßnahmen gegen die potentielle Universalität der digitalen Kriegsführung nicht ausreichen. 


\subsection{Digital Divide (Digitale Spaltung)}

\subsubsection{Ungleiche Diffusion}

An das und mit dem Internet sind seit seiner Entstehung, seiner rasanten Entwicklung und Diffusion, vor allem seit der Einführung des WWW seit Anfang der 1990er Jahres und damit seiner wachsenden, künftig noch stärker anhaltenden Kommerzialisierung und praktischen Gebrauchsfähigkeiten viele Erwartungen und Prognosen geknüpft. Sie richten sich auf die wirtschaftliche Wertschöpfung („new economy" Ende der 1990er Jahre, heute: digitale Wirtschaft), auf die Potentiale technischer und wissenschaftlicher Innovationen sowie auf politische Machtverteilung in der globalisierten Welt. Strategisch gemünzt heißt dies: Die so genannten Internet-Nationen - und das waren und sind vornehmlich die Industrienationen des Nordens - bauen mit dem Internet ihre wirtschaftlichen, technologisch-wissenschaftlichen und politischen Vorsprünge noch weiter aus, während die auch in der Internet-Diffusion nachhinkenden Regionen und Nationen des Südens - vor allem des afrikanischen Kontinents - zurückbleiben. Allerdings sind für manche Regionen wie Asien und Südamerika territoriale Differenzierungen angebracht; mindestens die boomenden Mega-Cities in den so genannten Schwellenländern dort weisen in ihren Dienstleistungszentren eine vergleichsweise entwickelte digitale Infrastruktur auf (Castells 2001, 2002, 2003) (Abb. 6.6).

Solche ungleiche Entwicklung und Verteilung des Internets sowie die damit verbundenen Folgen, Prognosen und Befürchtungen werden seit Mitte der 1990er Jahre mit dem pauschalen Schlagwort von digital divide (digitale Spaltung) oder digital gap (digitale Kluft) belegt. Seine Herkunft ist unklar oder lässt sich auf etliche Urheber und Quellen zurückführen (Marr 2005; Zillien 2009). Jedenfalls erreichte die dem US-Department of Commerce unterstellte National Telecommunications \& Information Administration (NTIA) mit ihren Berichten von 1998 und 1999, in dem sie "disparities in access to telephones, personal computers (PCs), and the Internet across certain demographic groups" pauschal als "digital divide" charakterisierte, eine beachtliche Resonanz und schuf ein diesbezügliches Problembewusstsein (zit. nach Marr und Zillien 2010, 262).

Auch die inhaltliche Dimensionierung des "digital divide“ ist recht unterschiedlich, wenn nicht willkürlich; sie ist natürlich auch davon abhängig, wie sich die einschlägigen Entwicklungen über die Zeit darstellen bzw. wie sie registriert werden und mit welchen Maßstäben sie gemessen werden:

1. Anfangs und vorrangig sind die technischen und infrastrukturellen Dimensionen (Konnektivität) gemeint: also die Verbreitung, die Verfügbarkeit und damit die Zugänglichkeit des Internets (Zugangsklüfte). Diese Konditionen 


\section{Internet users by region, March 2011}

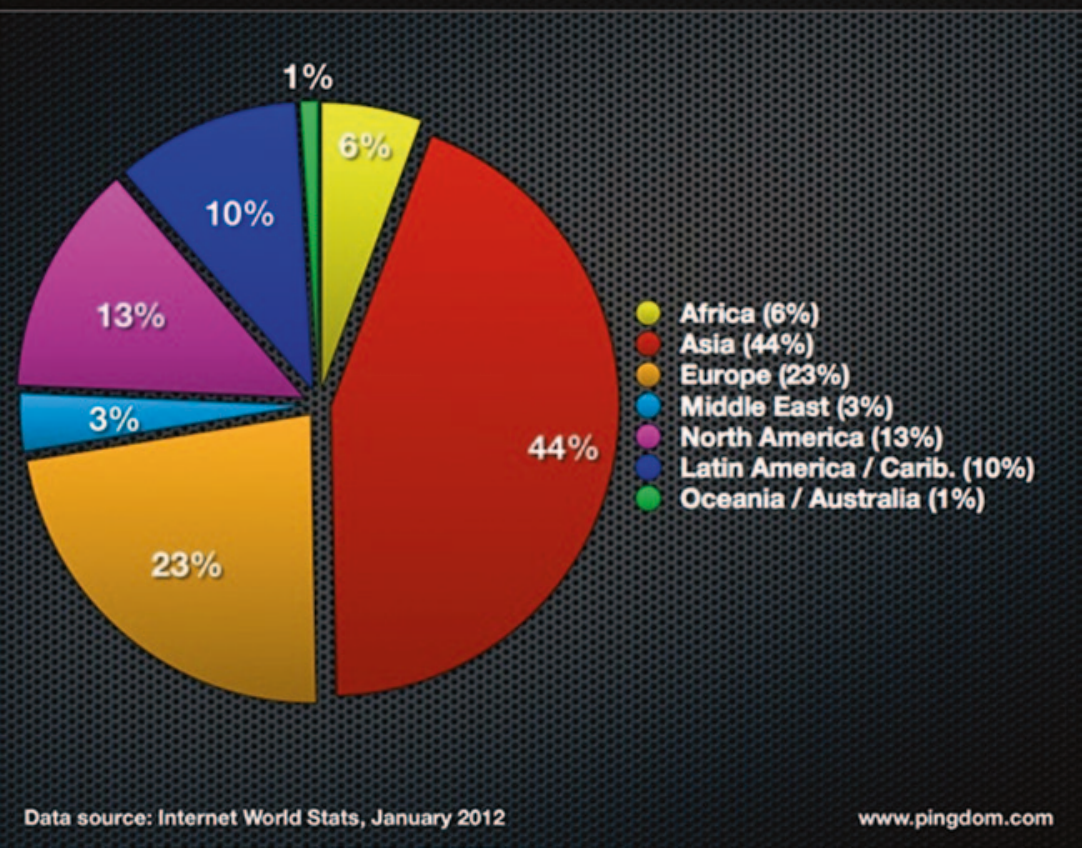

Abb. 6.6 (C) Internet-User in den Kontinenten Grafik (http://royal.pingdom.com/2012/01/ 17/internet-2011-in-numbers)

setzen die Existenz und Verfügbarkeit von stationären wie mobilen Netzen sowie Elektrizität voraus, was nicht überall - zumal nicht in weniger entwickelten Gebieten - gegeben ist. Mit den steigenden Übertragungsvolumina müssen die Kapazität und die Leistungsfähigkeit der Netze mitwachsen, so dass alle Nutzer die (multimedialen) Dienste in der vorhandenen Vielfalt, Vollständigkeit, Schnelligkeit, Qualität und Kostengröße nutzen können; ist dies nicht der Fall, wird über Priorisierungen und Kostenabstufungen debattiert (siehe Abschn. 6.2 Netzneutralität).

2. Davon ausgehend, lassen sich in subjektiver Hinsicht Unterschiede der InternetNutzung registrieren und deren Ursachen explizieren (Pohl 2007). Sie ergeben 
sich zum einen aus besagter verschiedenartiger Infra- und Angebotsstruktur, zum anderen aus den Nutzungsoptionen und -kompetenzen der Populationen (Nutzungsklüfte). Wie stark das Internet genutzt wird, wie Daten zur Nutzungshäufigkeit und -frequenz ausgewiesen werden, wird davon bestimmt, welche kommunikative und gesellschaftliche Relevanz und Funktionalität das Internet in der jeweiligen Gesellschaft hat, wie viele Ressourcen die Individuen zur Nutzung des Internets haben und welche Kompetenzen sie dafür vorweisen (können). Die viel beschworene Medien- und Internetkompetenz verkörpert also nicht ausschließlich subjektive Optionen, sondern wird auch von objektiven Bedingungen des Nutzungsbedarfs wie der Nutzungschancen konstituiert. Ihre jeweilige Ausgestaltung und damit Definition konkretisieren sich danach, wie die objektiven Gegebenheiten subjektiv effizient und ertragreich bearbeitet und angeeignet werden. Besonders den Generationen, die mit Computer und Internet aufgewachsen sind, wird die Selbstverständlichkeit und Umstandslosigkeit des Umgangs mit der digitalen Welt attestiert, die die analoge oder physische Welt mehr und mehr verdrängt, eingängig paradigmatisiert in der Bezeichnung als „digital natives“" (Kübler 2012).

3. Schließlich rechnen dazu auch inhaltliche Aspekte, wie sie in der internationalen bzw. transkulturellen Kommunikations- und Medienkomparatistik schon mindestens seit den 1970er Jahren thematisiert werden (MacBride-Bericht der UNESCO 1981): nämlich als Vorherrschaft des gemeinhin angloamerikanischen und westlichen Mainstreams in Content, Sprache, Kultur und der Benachteiligung, wenn nicht Unterdrückung weniger dominanter Kulturen und Sprachen (Inhaltsklüfte). Dass Computer und Internet Englisch zur globalen lingua franca befördert haben und mit ihr den American ,Way of life', lässt sich kaum leugnen - auch wenn sich zwischenzeitlich durch den raschen Auf- und Ausbau namentlich von Schwellenländern in Asien und Südamerika Relativierungen abzeichnen. So monierte 2003, auf dem Weltinformationsgipfel in Genf, der damalige UN-Generalsekretär Kofi Annan die inhaltliche Kluft (content divide): „Vieles im Netz geht an den wirklichen Bedürfnissen der Menschen vorbei. Und 70 Prozent der weltweiten Internetseiten sind auf Englisch und verdrängen die regionalen Stimmen und Sichtweisen“ (Wikipedia [http://de.wikipedia.org/wiki/Digitale_Kluft]).

Das Risiko der digitalen Spaltung und Wege zu ihrer Überwindung waren für die UNO und die UNESCO primär Anlass und Ziel, zwei spektakuläre UN-Weltgipfel zur Informationsgesellschaft (WSIS) 2003 in Genf und 2005 in Tunis abzuhalten. Diese Thematik fand bei den teilnehmenden Vertretern der Zivilgesellschaft breite 
Resonanz und beherrschte die offiziellen Dokumente. Dass diese Meetings globaler Internet Governance danach keine angemessene Fortsetzung fanden, vielmehr in weniger Aufsehen erregende Arbeitskreise (WSIS) verlagert wurden, wird unterschiedlich gedeutet: zum einen als allmähliche Nivellierung, mindestens wachsende, unübersichtlich werdende Ausdifferenzierung der technischen Komponenten, zum anderen als die Erfordernis, „digital divide“ breit und gründlich zu erkunden und ihre vielfältigen Ursachen aufzuspüren, und schließlich auch als anstehende (Re)Integration der Internet-Problematik in die Gesamtheit von sozialer Ungleichheit, Unterentwicklung und Benachteiligung. Denn wie bei allen anderen Kommunikations- und Medienfragen erweisen sich vermeintlich evidente, monokausale Kausalitätsannahmen als irreführend und falsch; sie müssen jeweils in der gesamte Interdependenz von Gesellschaft, Wirtschaft, Kultur, Bildung und subjektiver Lebensführung integriert werden (Zillien 2009; Marr und Zillien 2010).

\subsubsection{Wissensklüfte und Medienwirkungsforschung}

Inhaltliche Komponenten des "digital divide“ sind kommunikationswissenschaftlich bereits in den 1970er Jahren als so genannte Wissensklüfte (knowledge gaps) thematisiert worden; dabei sind erste empirische Erhebungen über ihre Ursachen durchgeführt worden. Heute werden sie auch als Vorläufer der breiter gefassten ,digital divide verstanden (Wikipedia [http://de.wikipedia.org/wiki/ Digitale_Kluft]).

In der Medienforschung wuchs spätestens seit den 1970er Jahren die analytische Erkenntnis, dass die vielfältig positiven Erwartungen, die man gemeinhin an demokratische Medien und an ihre digitalen Entwicklungen richtet, nicht unbedingt, jedenfalls nicht überall und bei allen eintreten, vielmehr sich auch unerwünschte, dysfunktionale Folgen zeigen. Denn die strukturellen Chancen wie die subjektiven Kompetenzen, in der steigenden Informationsflut die jeweils wichtigen und richtigen Informationen zu bekommen, sind im Publikum ungleich verteilt. Offenbar reproduzieren sich in der Informationsversorgung und -aufnahme die allgemeinen ungleichen und hierarchischen Verhältnisse einer Gesellschaft, insbesondere die unterschiedlichen Bildungsvoraussetzungen und -chancen. Diese (wohl nicht ganz neue) Einsicht diskutiert die Medienwirkungsforschung mittlerweile unter der anerkannte Hypothese von den wachsenden Wissensklüften (die im amerikanischen Original unterschiedlich als "differential growth of knowledge“, „information gaps“ oder „increasing knowledge gaps“ bezeichnet werden). In die deutschsprachige Forschung ist dieser Ansatz vor allem von den Zürcher 
Kommunikationswissenschaftlern Ulrich Saxer und Heinz Bonfadelli eingebracht worden (Bonfadelli 1994, 2002).

Erstmals 1970 haben die Kommunikationsforscher Philip J. Tichenor, George A. Donohue und Clarice N. Olien (1970) von der Minnesota-University die davor optimistische (oder auch naive) Annahme der Diffusionsforschung explizit dahingehend relativiert, dass die täglich verbreiteten Informationen der Medien nicht unbedingt und gleichmäßig zu einer allgemeinen Erhöhung des Wissensstandes der Menschen führen. Vielmehr haben sie und einige andere Forscher aufgezeigt, dass die Diffusion von Informationen unterschiedlich verläuft, und zwar entsprechend vielerlei Konditionen, die sowohl von den Modalitäten der Verbreitung (wie Art des Mediums, Thema bzw. Informationsobjekt, Zeitspanne) als auch von den subjektiven Dispositionen des Publikums (wie Medienkonsum, soziostrukturelle Faktoren, Interessen, Bildungsvoraussetzungen, Kognition und Motivation etc.) bedingt sind - im Grunde keine epochal neue Erkenntnis in der medialen Wirkungsforschung, deshalb auch schon als „nichtlinearer, selbstverstärkender“ „Matthäus-Effekt" apostrophiert (Merten 1994, 323). Diese Erkenntnisse haben die amerikanischen Forscher in folgender, hier auf deutsch wiedergegebenen Sentenz beispielhaft resümiert und damit besagte neue Forschungsperspektive begründet:

„Wenn der Informationszufluss von den Massenmedien in ein Sozialsystem wächst, tendieren die Bevölkerungssegmente mit höherem sozioökonomischem Status und/oder höherer formaler Bildung zu einer rascheren Aneignung dieser Information als die status- und bildungsniedrigeren Segmente, so dass die Wissenskluft zwischen diesen Segmenten tendenziell zu- statt abnimmt" (zit. nach Bonfadelli 2002, 567).

Im Kern spezifiziert diese Hypothese mithin allgemeine Erkenntnisse über Ungleichheiten und Benachteiligungen in modernen Gesellschaften für die Distribution und Diffusion von (über Medien vermittelter) Information und (medialem) Wissen, wie sie die Soziologie in ihren Status- und Schichtmodellen, die Erziehungswissenschaft als ungleiche Verteilung von Bildungschancen und die Linguistik als sprachliche Defizite oder Differenzen sprachlicher Kompetenzen thematisiert. Dementsprechend müssten sich Zusammenhänge oder gar Abhängigkeiten zwischen diesen verschiedenen Disparitäten, zwischen den „information haves" und den "information have nots“ (Schiller 1996), finden lassen, aber so gründlich und übergreifend sind die Studien bislang nicht vorgegangen. Nach fast dreißig Jahren empirischer Forschung (Bonfadelli 1994, 2002) weisen die meisten Studien Wissensklüfte nur bei relativ kurzfristigen, exakt begrenzbaren und gezielten ,Informations'-Kampagnen (z. B. bei Werbung, der Verbreitung eines bestimmten Sujets oder der Bekanntmachung einer Person) in einer - selten genügend 
repräsentativ gewählten - Population auf, wie auch eine amerikanische Übersicht nach 25 Jahren „Knowledge Gap Hypothesis“ bilanziert (Viswanath und Finnegan 1996).

Meist stellen sich die untersuchten Informationen als zeitversetzt und ungleich verteilt heraus, aber die vielfältigen Faktoren, die - außer den evidenten der Medien und der (vornehmlich politischen) Themen - dafür mutmaßlich auch verantwortlich sind, sind gemeinhin höchst unzureichend berücksichtigt worden, so dass bei vielen Studien erhebliche methodische Mängel zu monieren sind. Wie in der Medienwirkungsforschung üblich, neigen die meisten Studien zu singulären, linearen, wenn nicht monokausalen Faktoranalysen und damit zu ebensolcher Identifikation möglicher Ursachen. Nur wenige Untersuchungen sind langfristig, also über die einmalige Erhebung hinaus angelegt; doch auch sie zeitigen inkonsistente Resultate: Die eine Hälfte bestätigt, dass sich Wissensklüfte verstärken, die andere Hälfte stellt konstante oder gar rückläufige Wissensdisparitäten fest (Bonfadelli 1994, 223). Doch wie Wissen auf vielerlei Weise - und nicht nur über Medien - entsteht und fixiert wird, können auch diese Studien nicht hinreichend dokumentieren.

Besonders gravierend fällt ins Gewicht, dass die Wissenskluftforschung seit ihrem Bestehen auch keinen theoretisch begründeten und hinreichenden Wissensbegriff entwickelt hat. Vielmehr wird er lediglich in den empirischen Studien pragmatisch anhand diverser Indizes vorausgesetzt, bleibt also - wie sonst auch - vage, disparat und unbefriedigend (Bonfadelli 1994, 81; Wirth 1997, 94ff.). Zwar sind inzwischen einfache Dichotomien - wie etwa die übliche Unterscheidung in „knowledge about“ („Kenntnis von“) und „knowledge of" („Wissen über“) - weiter differenziert worden, und es werden Typen wie Themen- und Faktenwissen einerseits sowie Strukturund Hintergrundwissen andererseits unterschieden (Bonfadelli 2002), die von den Medien entsprechend unterschiedlich verbreitet werden - von den Printmedien etwa mehr Hintergrund und Struktur, vom Fernsehen mehr Fakten, Themen und assoziative Bilder. Um die Konzipierung eines ,integrierten“ Wissensbegriffs hat sich etwa der Kommunikationswissenschaftler W. Wirth (1997) bemüht, allerdings beschränkt er sich ebenfalls auf das durch die Medienrezeption erwerbbare politische Wissen. Wie aber Menschen generell diverse Wissensformen je unterschiedlich aufnehmen, behalten und artikulieren, welchen Einfluss ihr - wie immer erworbenes - ,Vorwissen' auf Lernen, Verstehen, Erinnern und Anwenden hat und welche Gründe und Motive dafür jeweils verantwortlich sind, dafür liefern die Studien der Wissenskluftforschung nur unzureichende Erklärungen. Mit den dafür zuständigen Forschungszweigen, der Kognitionswissenschaft und der Lernforschung, sind sie noch kaum abgeglichen. Außerdem gerät die Wissenskluftforschung wie alle empirische Forschung unweigerlich in das Dilemma kontingenter Relativierung bzw. nur 
noch kasueller Validität, wenn sie ihren Untersuchungsbereich weiter differenziert: Was in der einen Situation, mit dem einen Thema unter diesen Bedingungen mit der einen Population gilt, braucht noch lange nicht für die anderen Erhebungen mit differierenden Konditionen zu gelten (Kübler 2009, 118ff.).

Daher plädiert K. Merten (1990) dafür, diverse Vermittlungsprozesse nach funktionalen Gegebenheiten zu differenzieren und auf den Kommunikationszusammenhang hin zu relativieren: Denn „ein bestimmtes Wissen (Inhalt) kann nicht nur informieren, unterhalten oder meinungsbildend sein, sondern es kann im Prinzip unendlich viele Funktionen haben“ (Ebd., 31) - und dafür verantwortlich sind sowohl das Medium, das Thema, dessen soziale Relevanz für verschiedene Publikumsgruppen als auch die diversen Dispositionen und Attribute der Rezipienten, die Situation, die Dauer und Facettierung der Verbreitung etc. Folglich kann es keine unilineare, eindeutige Vermittlung geben, die vom Kommunikator stringent geplant ist und verursacht wird. Die "Wissensvermittlung" via Medien impliziert mithin alle Optionen und Nuancen, die auch sonst für die Wirkungsforschung virulent sind (Wirth 1997, 113ff.). Deshalb müssen, so Bonfadelli $(1994,231)$, die Studien weitere Kontextuierungen des Untersuchungsfeldes und langfristige methodische Perspektiven vornehmen, um sich überhaupt alltäglichen Prozessen analytisch anzunähern. Denn häufig seien die erfragten, über Medien verbreiteten Themen zumal für ohnehin sozial und bildungsmäßig unterprivilegierte Populationen von geringer sozialer Relevanz. Deshalb fordert Bonfadelli (1994) "ganzheitlich" ausgerichtete Studien, in denen außer der sozialen Relationierung und Relevanzprüfung des Wissens auch die Relativierung des Medienkonsums für den Wissenserwerb und die Wissensreproduktion berücksichtigt werden (auch Wirth 1997, 296ff.).

Sie konzentrieren sich zunehmend auf die Funktionalität und Nützlichkeit von Wissensrepertoires, mithin auf die "Lebensdienlichkeit des Wissens" (Bonfadelli 1994, 148). Dessen Verwendung und Brauchbarkeit ist kaum universell und statisch gegeben, sondern unterliegt situativen, motivationalen und subjektiven Gegebenheiten, die sich jeweils wandeln und neu konstituieren können. Der breit registrierte Defizitstatus wird mehr und mehr von verschiedenartigen Differenzbereichen abgelöst, die auch bei der Wahl von Medien von Belang sind. Ein wissenschaftliches oder auch nur ein Sach-Buch lässt nun einmal andere Wissensangebote und -aneignungsweisen erwarten als eine Unterhaltungsshow im Fernsehen. Allerdings dürfen die Differenzansätze nicht zur gänzlichen Nivellierung von Wissensbeständen führen; denn nach wie vor sorgen objektive, gesellschaftliche Wertungen für gewisse Kanonisierungen des Wissens und sie spiegeln auch soziale Ungleichheiten bzw. eingeschränkte Lernchancen wider; und 
auch die Medien folgen mehr oder weniger erkennbaren Gewichtungen - wiewohl sie etwa in ihren Ratenseiten und (Quiz)Shows abseitige, wenn nicht abstruse Wissensrepertoires - etwa dann als außergewöhnliche Hobbys stilisiert - hofieren.

Nach wie vor steht mithin die Erforschung von Zusammenhängen über Mediennutzung und ungleichen Wissenserwerb „erst am Anfang“, so ein Resümee der Wissenskluftforschung, die mittlerweile weniger intensiv betrieben wird (Bonfadelli 2002, 598). Erkennbar sei immerhin schon, „dass vor jeder Mediennutzung das soziale Umfeld bezüglich Pluralität oder Konflikt einerseits, andererseits das durch die Medien oder Informationskampagnen zugänglich gemachte Informationsangebot von Relevanz sind“ (Ebd.).

\subsubsection{Digitale Spaltungen}

Mit der Entwicklung und Verbreitung des Internets - vor allem seit der Jahrhundertwende - fokussierte sich die Debatte weitgehend auf das Internet zumal ihm zwischenzeitlich die am weitesten reichenden Wirkungspotentiale unterstellt werden. Unter dem Fokus des Zugangs (Marr und Zillien 2010, 264ff.) werden zunächst

- allgemeine Diffusionsraten und -tempi von Computern und Internet in territorialen, soziokulturellen Verteilungen registriert und nicht selten auch als gesamtgesellschaftliche Indikatoren für Innovation und Fortschrittlichkeit gewertet; sodann werden

- solche Daten für verschiedene Bevölkerungsgruppen gemessen, die nach den üblichen soziodemografischen Kriterien wie Alter, Geschlecht, Einkommen, Bildung, beruflichem Status unterschieden werden, und mit ihnen bekommt man Daten über ihre Netzaffinität, -interessen und -kompetenzen. Ihre Unterschiede bzw. Diversitäten lassen sich - zusammen mit allgemeinen Mediennutzungsdaten - zu diversen Medien(nutzungs)typologien clustern, ihre relativen Unterschiede als Grade ,digitaler Spaltung' bzw. Zugangsklüfte interpretieren; schließlich werden

- strukturelle und subjektive Ursachen für die Verteilung von Internetaffinitäten, krasser noch: für die Polarisierung von Onlinern und Offlinern erkundet und erörtert.

Überprüfen lassen sich etwa allgemeine Modelle der Innovationsforschung, etwa Dispositionen und Phasen der Adoption von Neuheiten und die unterschiedlich verteilte Bereitschaft, sie anzunehmen und zu forcieren. Sie lassen sich in 


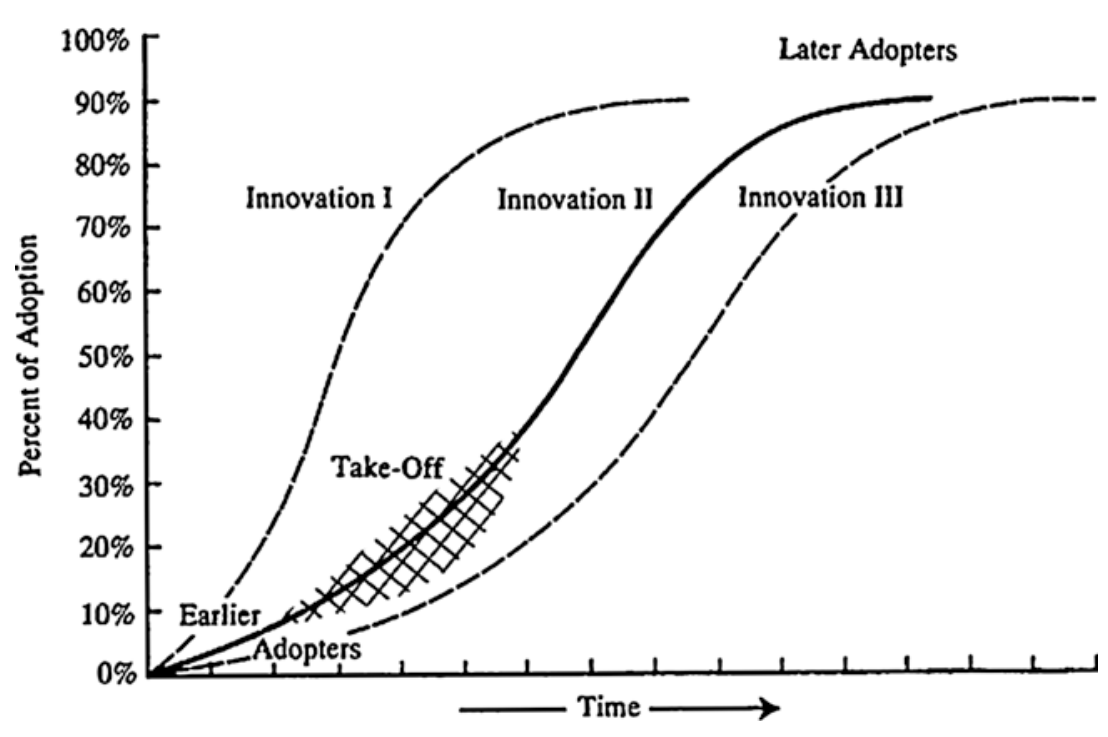

Abb.6.7 (C) Verlaufskurven der Medien-Diffusion (aus: Rogers 1983, 11 [hier: Bonfadelli 2004, 151])

Übernehmertypologien fassen, wovon die von Rogers (1983) die gängigste ist: Für Personen - mithin in subjektiver Hinsicht - lassen sich identifizieren a) die Innovatoren bzw. earlier adopters (5\%), b) die frühen Übernehmer, c) die frühe Mehrheit d) die späte Mehrheit e) die Nachzügler bzw. later adopters (Bonfadelli 2004, 151) (Abb. 6.7).

Nach den entwickelten Maßstäben muss eine Innovation nicht nur bekannt, akzeptiert und ausprobiert sein; vielmehr muss ihre Inanspruchnahme auch habitualisiert, wenn nicht routinisiert, d. h. in den alltäglichen Lebensvollzug gewohnheitsmäßig integriert sein und als weitgehende Selbstverständlichkeit ausgeführt werden.

Diese Kriterien scheinen vom Internet trotz vieler gegenteiliger Behauptungen längst noch nicht (bei allen) erreicht; hierbei unterscheiden sich kommunikationswissenschaftliche Studien (Marr und Zillien 2010, 265) von eher journalistischen oder kursorisch-deskriptiven (Beckedahl und Lüke 2012) deutlich, zumal die verfügbaren empirischen Daten infolge unterschiedlicher Erhebungsmethoden Unterschiedliches messen und zu unterschiedliche Größenordnungen anzeigen.

Als ,social divide' bezeichnete Norris (2001) im Unterscheid zum global divide strukturelle, soziale und auch individuelle Unterschiede des Internetzugangs und der 
Nutzung sowie ihre Gründe innerhalb der einzelnen Gesellschaften. Mitunter werden sie noch weiter in 'age divide' bzw. 'gaps', 'gender gaps' und 'status gaps' differenziert, je nachdem, welche Faktoren für die jeweiligen Unterschiedlichkeiten für maßgeblich gehalten werden. Generell lässt sich konstatieren, dass nach einer sprunghaften Verbreitung des Internets am Anfang keine vollständige Sättigung erreicht ist und nach wie vor gut ein Drittel der bundesdeutschen Bevölkerung offline bleibt - und dies obwohl viele Faktoren seine Diffusion nachhaltig begünstigt haben. Anführen lassen sich etwa sinkende Zugangskosten, wachsende Benutzerfreundlichkeit, hohe Prestigezuweisung, verbunden mit Prognosen und Versprechungen seiner Vorteile in Ausbildung, Beruf und Privatleben (bis hin zur Exklusion nicht online möglicher Dienste), mithin generell große öffentliche Aufmerksamkeit oder Zunahme massenattraktiver Webangebote (Marr und Zillien 2010, 265). Auch in anderen entwickelte Länder zeigen sich ähnliche Verhältnisse, selbst die USA mit einer Durchdringungsquote des Internets bei Dreiviertel der Bevölkerung. In den letzten Jahren hat sich ohnehin die weitere Verbreitung des Internets deutlich verlangsamt, so dass eine Vollzugänglichkeit noch länger auf sich warten lässt.

Von analytischem Belang ist, welche Gruppen welche Zugang und welche Nutzung des Internets aufweisen. In den Gründerjahren waren es die jungen, gebildeten, sozial aufstrebenden, technikaffinen Männer, die die Prototypen des Internethypes, die so genannten Onliners, verkörperten. Inzwischen haben sich die Proportionen weitgehend dem Bevölkerungsdurchschnitt angeglichen und werden es auch weiterhin tun, so dass eher die so genannten Offliners besonders markiert werden: Sie definieren sich vor allem durch ein höheres Alter, das weibliche Geschlecht, geringeren Bildungsgrad und einfache Berufstätigkeiten oder den Hausfrauenstatus (Ebd. 266; Kübler 2012). Neben solchen objektiven Faktoren der Erschwerung oder gar Behinderung des Internet-Zugangs ergeben sich bei intensiverer Betrachtung der Offliner auch Konstellationen der willentlichen Ablehnung - entweder im Vorfeld der Entscheidung oder aber auch nach zeitweiliger praktischer Nutzung und dann erfolgender Abkehr. Im Jahr 2006 (Riehm und Krings 2006) wurde etwa die Hälfte der aktuellen Onliner zu den so genannten Internet-Dropouts gezählt. Ihre Motive fallen ganz unterschiedlich aus: von finanziellen Einschränkungen über andere Kommunikationskonzepte bis hin zu nicht ersichtlichen Nützlichkeit des Internets, häufig auch im Vergleich zu den anderen Medien. Nach Zillien (2008) ergeben sich fünf wirksame Faktoren und Motive für die Nichtnutzung des Internets: „(1) materielle Barrieren (2) mangelnde Kompetenzen zur Nutzung des Internets, (3) Zweifel an der Zweckmäßigkeit der eigenen Internet-Nutzung, (4) fehlende Motivation und (5) explizite Ablehnung des Internets" (nach Marr und Zillien 2010, 267). 


\subsubsection{Global Digital Divide}

Ungleich disparater und auch unsicherer fallen Verbreitungs- und Zugangsraten von Internet im globalen Vergleich aus. Zwar gibt es umfangreiche und kontinuierliche Datensammlungen durch die Berichte der International Telecommunication Union, doch auf welche Art von nationalen Daten sie rekurrieren, lässt sich kaum verifizieren, zumal die Situation insbesondere in den Entwicklungsländern sehr unübersichtlich und unterschiedlich ist. Viele verfügen über keine nationalen Statistiken, sondern berufen sich auf Schätzungen. Daher ist die Datenlage am sichersten, je höher der Entwicklungsstand und damit auch der Grad der Computerverbreitung ist - wodurch sich freilich positive Überschätzungen ergeben können. Verbreitung und Nutzung von Telefonen, Computern und Internet-Zugängen werden von insgesamt 154 Staaten zu einem so genannten ICT Development Index (IDI) verdichtet; anschließend werden die Länder entsprechend dem Index-Maß in vier Gruppen eingeteilt.

Nach der Erhebung für 2007 können sich von 154 Ländern 66 zu den beiden Gruppen rechnen, die eine überdurchschnittliche ICT-Verbreitung haben. Sie repräsentieren allerdings nur 27 Prozent der Weltbevölkerung. Noch deutlicher wird die globale Spaltung, wenn man als einzelnen Indikator den Anteil der Haushalte mit Internet-Zugang herausgreift: Danach weisen nur 22 der 154 Länder mehr als 60 Prozent auf, wohingegen in 57 Länder weniger als fünf Prozent aller Haushalte ans Internet angeschlossen sind (Marr und Zillien 2010, 267). Für die Entwicklung signifikant ist, dass zwischen 2002 und 2007 die Proportionen in den extremen Gruppen sich kaum verändert haben, wenn auch leicht angestiegen sind; immerhin haben sich die Wachstumsraten in den mittleren Segmenten beschleunigt, so dass sich geringe Annäherungen nach oben abzeichnen.

Für die Identifikation und Erklärung der Ursachen dieser Entwicklungsdisparitäten wird primär der ökonomische Entwicklungsstand eines Landes angeführt. Dafür werden zusätzliche Indikatoren in makrotheoretischen Modellen aufgeführt, die verschiedene Erklärungskraft haben. Zusätzlich werden als Faktoren das Ausmaß der Deregulierung des Telekommunikationsmarktes und der dadurch ausgelöste Wettbewerb, die Investitionen eines Landes in den Bereichen Forschung und Entwicklung, die bestehende telekommunikative Infrastruktur und die kulturellen Werthaltung einer Nation angeführt (Ebd., 268). All diese Erklärungsversuche signalisieren, dass sich unterschiedliche Entwicklungstempi und -qualitäten gerade in den Bereichen Kommunikation und Medien nicht allein ökonomisch erklären lassen; sie zeigen mithin die beachtliche Bandbreite intervenierender Faktoren, aber auch die Anforderungen, potentiellen Wandel gründlicher anzugehen. 
Solche Differenzierungen sind besonders für die genauere Registrierung der Internet-Nutzung, mithin der Modalitäten und Motive verschiedener Usergruppen, angebracht; die simple Unterscheidung zwischen On- und Offlinern reicht dafür natürlich nicht aus, wie vielfach kritisiert wird. Allerdings dürften sich solche Differenzierungen kaum mehr unter die etwas grobschlächtige Dichotomie der digitalen Spaltung fassen lassen, wenngleich sich auch dafür noch strukturelle wie auch subjektive Faktoren anführen lassen und ihre ungleiche Verteilung auch schon als „second-level digital divide“ (Hargittai 2002) bezeichnet wurde. Für die Nutzung des Internets ist überhaupt maßgeblich, ob private Haushalte eine Internet-Ausstattung bzw. -zugänglichkeit haben und welche Qualität in technischer Hinsicht sie hat, auch für die einzelnen Familienmitglieder. Anderenfalls sind noch Nutzungsmöglichkeiten bei Freunden und in öffentlichen Einrichtungen (wie Internet-Cafés), in der Schule, Ausbildung und am Arbeitsplatz einzubeziehen. In entwickelten Nationen haben sich die Kosten der Nutzung durch Flatrates enorm minimalisiert, in Entwicklungsländern dürften sie nach wie vor Nutzungszeiten und -frequenzen bestimmen.

Zugänglichkeit und Nutzungshäufigkeit beeinflussen sicherlich auch die subjektive Qualität der Nutzung, sowohl hinsichtlich der technischen Kenntnisse über Computer, Internet, ebenso hinsichtlich der informatorischen über Datenbanken, Browser und Suchmaschinen als auch hinsichtlich der Vielfalt und Fähigkeiten des Umgangs - all diese Komponenten werden meist mit dem pauschalen Begriff der Kompetenz für Medien und Internet angesprochen, im Angelsächsischen mit dem der Media- oder Computer-Literacy (Deutscher Bundestag 2011a; Gapski und Tekster 2012). Von objektiver Seite sind ferner die Pluralität und das Niveau des Webangebots zu berücksichtigen. Solche Fähigkeitskonglomerate lassen sich beliebig unterteilen, womit nicht selten eine scheinbare Profilierung erreicht wird, die aber, recht besehen, nur künstlich ist. So werden aus der Allensbacher Computer- und Technikanalyse sekundäranalytisch folgende Komponenten für die digitale Kompetenz gewonnen:

(1) „Technische Bedienkompetenzen, die operationale Fertigkeiten von der Bedienung der Maus über das Abspeichern von Dateien bis hin zum Herstellen einer Internet-Verbindung umfassen,

(2) internetbezogenes Wissen zweiter Ordnung, das sich als Kombination aus Differenzierungs-, Selektions-, Orientierungs- und Evaluationskompetenz zusammenfassen lässt,

(3) Nutzungserfahrung, die als fortlaufende Anwendung von Computertechnologien den gängigsten Weg zum Erlernen relevanter Kenntnisse darstellt und sich aus der Dauer und dem Umfang der individuellen Computernutzung zusammensetzt und 
(4) Computeraffinität der sozialen Umgebung, die die Aus- und Weiterbildung digitaler Kompetenzen beispielsweise durch die konkrete Unterstützung im Anwendungsfall, den Vorbildcharakter, die Möglichkeit der informellen Nachfrage und den informellen technischen Support beeinflusst" (Zillien 2009; Marr und Zillien 2010, 270).

Rasch wird ersichtlich, dass etliche Wissens- und Fähigkeitsaspekte, die für den Umgang mit dem Internet unbedingt nötig sind - etwa Kenntnisse über Browser, Datenbank und Suchmaschinen - bei dieser Aufstellung nicht angesprochen sind; andere hingegen - (wie die unter (4)) - rechnen nicht zu den subjektiven Dispositionen des einzelnen User im engeren Sinne, sondern gehören zu den sozialen und situativen Voraussetzungen seiner Internetnutzung überhaupt.

Noch immer sind auch die soziodemografischen Indikatoren für das Ausmaß, Frequenz, Vielfalt und Qualität der Internetnutzung von Belang, wie sie von standardisierten Nutzungserhebungen ermittelt werden. Führend für die bundesdeutschen Verhältnisse ist die ARD/ZDF-Online-Studie, die seit 1997 jährlich durchgeführt wird und damit inzwischen mehr als ein Jahrzehnt Entwicklung und Modalitäten der Internet-Nutzung in Deutschland verzeichnen kann. Da sie nach wie vor in persönlichen, computergestützten Interviews ein umfangreiches Set an Handlungsweisen, Motiven, Themen und Bedingungen erhebt, liefert sie obendrein ein breit gefächertes Bild dieser Entwicklungen, wie es keine der anderen Studie tut (Klumpe 2011); zeitweilig parallel wurden auch die Gepflogenheiten der so genannten Offliner befragt, um so beide Seiten abzubilden. Diese Erhebung wurde 2009 eingestellt, da die Gruppen immer kleiner und weniger aussagekräftig wurden, so die Begründung.

Nach wie vor sind bei solchen Erhebungen Alter, Geschlecht, formale Bildung und sozialer Status maßgebliche Faktoren der Internetnutzung - auch wenn sie im Einzelnen immer weniger Gewicht haben. So ist der Anteil der über 60-jährigen unter den Internet-Nutzern in den letzten Jahren überproportional gewachsen, nur bei den über 80-jährigen bleibt die Zahl gering. Diese Entwicklung dürfte nicht zuletzt damit zusammenhängen, dass viele, die nun in Rente sind oder gehen, noch in ihren aktiven beruflichen Phase das Internet kennengelernt und genutzt haben und diese Gewohnheit in Ruhestand fortsetzen (Kübler 2012). Auch bei den Frauen jüngeren und mittleren Alters steigt der Anteil der Internet-Nutzerinnen; ebenso diskriminiert der Bildungsgrad immer weniger grundsätzlich, wohl aber hinsichtlich der Qualität der Nutzung. Es ist nun mal ein Niveau-Unterschied, ob man via Internet Computerspiele betreibt oder für eine anspruchsvolle wissenschaftliche Arbeit recherchiert. Aber solche Differenzierungen signalisieren auch, dass sich die Internetnutzung zunehmend in die Alltagsverrichtungen und Lebensvollzüge integriert und dann eben kaum mehr als etwas ganz Spezielles und Separates wahrgenommen wird. 
Schließlich bleibt zu berücksichtigen, dass der Begriff Internet ja recht pauschal für viele Anwendungen steht, die sich obendrein ständig wandeln. Die Dynamik dafür wird immer schneller und mannigfaltiger. Mit ihr müssen sich auch die Kompetenzen und Anwendungen der User fortwährend ändern, so dass alle Erhebungen nur Momentaufnahmen sind und rasch veralten. Stets wird behauptet, Innovationen machten die Handhabung einfacher und bequemer, zugleich aber auch vielfältiger - was oft genug die Komplexität erhöht und den Nutzern neue Anstrengungen abverlangt. Ziel ist es vorrangig, möglichste viele Dienstleistungen und Anwendungen auf einer Plattform anzubieten, um den Nutzer möglichst auf der eigenen Plattform zu halten und der Werbung zuzuführen. Gleichwohl sind Alltagsnähe und Nutzeraffinität vordringliche Ziele bei den Innovationen. So macht seit etwa 2006 das so genannte Web 2.0 mit seinen Mitmach-Funktionen (user generated content) und sozialen Netzwerken, Communities, Wikis, Weblogs und Twitter von sich reden. Aber etliche Plattformen und Netzwerke wie „Myspace“, „SchülerVZ“ und „StudieVZ“ sind bereits wieder in Nischen abgetaucht oder ganz verschwunden, da „Facebook“ alle Konkurrenten übertrumpft hat, aber auch der gegenwärtige Erfolg dieser sozialen Plattform wird schon mitunter relativiert und dürfte nicht für alle Zukunft anhalten.

\subsubsection{Zu potentiellen Wirkungen von ,Digital Divide'}

,Digital Divide ‘ wurde vor allem deshalb so massiv und lange apostrophiert, weil damit vielfältige Wirkungen verknüpft werden. Vielfach steht die Internetentwicklung für Wirtschafts- und Wohlstandswachstum, Innovationsfähigkeit, technischen Fortschritt und kulturelles Niveau. In allgemeinen Entwicklungskonzepten werden historische Abfolgen von Gesellschaftsformationen konstruiert, die etwa von der Industrie- über die Dienstleistungs- bis zur Informations- und Wissensgesellschaft gehen (Kübler 2009), und für sie werden eingeführte Indikatoren wie Umsatz-, Wertschöpfungs- und Arbeitsplatzraten für die jeweiligen Wirtschaftssektoren genutzt. Die Digitalisierung, also die Transformation möglichst vieler physischer, materieller Prozesse und Aktivitäten in virtuell-symbolische, wie sie mit Computer und Internet bewerkstelligt werden, wird als zentraler Motor und Anreiz für den Übergang zur Informations- und Wissensgesellschaft erachtet. Wo sie gegeben sind, werden positive Entwicklungen prognostiziert, wo nicht, eher stagnierende oder negative. Werden die Innovationen der Informationstechnologien mit anderen ebenso epochalen Welttendenzen wie der anhaltenden Globalisierung, dem demografischen Wandel (dem weltweiten Bevölkerungswachstum und der Überalterung in den Industrienationen), der weiteren Verwissenschaftlichung und Technisierung, der Mediatisierung bzw. Medialisierung, 
aber auch mit dem sich beschleunigenden Klimawandel, der fortschreitenden Umweltzerstörung und Ausbeutung der natürlichen Ressourcen, den Finanz- und Wirtschaftskrisen sowie den Kriegen um Rohstoffe, die sich vor allem in den ärmeren Regionen der Welt häufen, zusammen betrachtet, relativieren sich mindestens monokausale Wirkungsannahmen und eröffnen sich vielfältige, sehr komplexe Interdependenzkonstellationen (Hepp u. a. 2005; Kübler 2011).

Auf Analyseebenen geringer Reichweite werden Wirkungszusammenhänge unterschiedlicher Internetnutzung in empirischen Studien etwa hinsichtlich der Arbeitsmarktintegration, der politischen Information des bürgerschaftlichen Engagements und der politischen Partizipation sowie der Gesundheitskommunikation (Marr und Zillien 2010, 272ff.) untersucht. Auch bei solchen Dimensionen ergeben sich gemeinhin die bekannten Effekte, wonach sich die üblichen sozialen Ungleichheiten verstärken, die von Bildung, sozialem Status und Einkommen Begünstigten auch bei den Angeboten und Vorteilen der Informationstechnologien eher profitieren als die Benachteiligten. In der Medienforschung wird diese Disproportion als „Matthäus-Effekt“ („Wer hat, dem wird gegeben.“) bezeichnet (Merten 1990).

\subsubsection{Governance für ,Digital Divide'}

Überblickt man die unter, Digital Divide' angesprochene soziale Realität, stellt sich der Terminus eher als attraktives, kaum hinreichend differenziertes, aber politisch brauchbares Schlagwort heraus. Denn weder schafft die Diffusion und Zugänglichkeit des Internet gänzlich neue Ungleichheiten, noch lässt sich seine Existenz auf allein internettechnologische Ursachen reduzieren. Vielmehr fügen sich viele Aspekte in die strukturellen Kausalitäten von sozialer Ungleichheit ein; sie können sie allerdings verstärken oder pointieren sie zumeist in der einen oder anderen Richtung.

Entsprechend sind die zu ergreifenden Maßnahmen unterschiedlich: Sicherlich wären eine Hebung der allgemeinen Wirtschaftskraft und des allgemeinen Wohlstandes, der Ausbau der Infrastruktur und die Erhöhung der Bildungsniveaus in den benachteiligten Ländern die effektivsten Maßnahmen auch zur Beseitigung von digitaler Spaltung. Denn auch und gerade das Internet manifestiert und formt Kommunikation. Einzelne Maßnahmen können den Ausbau der Infrastruktur betreffen, technisch die Verfügbarkeit von Elektrizität, die Reichweite und das Vorhandensein von Netzen, von Servern und Providern. Um Verbreitung und Nutzungskompetenz zu erhöhen, sind etwa mehrere Konzepte entwickelt und Programme aufgelegt worden, um so genannte Einfach-Laptops zumal unter 
Jugendlichen breit zu streuen. Subjektiv müssen über Bildungsprogramme die Voraussetzungen für Media-Literacy und Medienkompetenz geschaffen werden. Oft genug beginnen sie mit grundlegenden Lese- und Schreib- sowie Sprachkenntnissen und reichen zu besagtem computer- und internetspezifischem Know-how. Vom Grad der Integration in eine Staatengemeinschaft und von der Verteilung öffentlicher Mittel hängt es ab, ob diese Aufgaben allein von einem Staat, von einer Staatengruppen oder von internationalen Organisationen unterstützt und finanziert werden.

\subsection{Jugendmedienschutz}

\subsubsection{Geschichte und Grundlagen des deutschen Jugendmedienschutzes}

Sorge um Kinder und Jugendliche und ihr Schutz vor physischen, vor allem sittlichen Gefährdungen - und zwar in der Öffentlichkeit, also durch staatliche und gesellschaftliche Instanzen, jenseits der anerkannten Privatheit der Familie - entwickeln sich erst mit der Anerkennung von Kindheit und Jugend als eigenständige Lebensphasen, mit der Erkenntnis und Respektierung von Kindern und Jugendlichen als besondere, noch nicht genügend resistente, damit gefährdete und schützenswerte Individuen; zuvor galten Kinder als kleine, noch nicht voll ausgereifte Erwachsene. Dem Kind wurde eher dieser biografische Sonderstatus eingeräumt, der ,Jugendliche folgte erst mit der Sozialgesetzgebung im frühen 20. Jahrhundert, zusammengefasst als, die Jugend'. Wegbereiter waren Humanismus und Aufklärung, die Erziehung und Pädagogik als soziale Flankierung bzw. Gestaltung des Schonraumes "Jugend" konstruierten, wie sie Jean-Jacques Rousseau (1712-1778) in seinem berühmten Erziehungsroman Emilie oder über die Erziehung (1762) exemplifizierte. Institutionelle Konsequenz war die Einführung der allgemeinen Schulpflicht: erstmals in einem Territorium der Welt (und damit auch Deutschlands) im Herzogtum Pfalz-Zweibrücken wurde sie 1592 eingeführt, Preußen folgte erst 1717.

Bezeichnenderweise wurden die ersten Schutzbestimmungen für Kinder und Jugendliche in Preußen 1839 erlassen. Mit ihnen sollte Kinderarbeit für die unter Neunjährigen verboten, für die Älteren zeitlich eingeschränkt werden, um die hohe Sterblichkeit, aber auch die wachsende Wehrdienst-Untauglichkeit der Heranwachsenden $\mathrm{zu}$ reduzieren. Um ihre Einhaltung musste mit den Unternehmern das gesamte Jahrhundert über gerungen werden. Hernach folgten Schutzbestimmungen gegen öffentliche Gefährdungen - wie Beschränkungen des 
Besuchs von Gaststätten, Spielhallen und anderen bedenklichen Etablissements, des Ausübens von Glück- und Automatenspielen, des Genusses von Alkohol, Nikotin und anderer Drogen sowie ganz generell des Aufenthalts im Freien -, wie es beispielsweise in der Bundesrepublik das Gesetz zum Schutz der Jugend in der Öffentlichkeit (JÖSchG) von 1951 vorsah; es wurde 2002 in das Jugendschutzgesetz (JuSchG) überführt.

Auch den Medien, zunächst den gedruckten, wurden seit ihrem Aufkommen Mitte des 15. Jahrhunderts Gefährdungen von Moral, Religion, der geltenden Ordnung und herrschenden Obrigkeiten vor allem von der katholischen Kirche, den feudalen Häuptern und ihren Administrationen zugschrieben. Deshalb wurden seit dem ersten päpstlichen Index von 1559 jeweils Listen verbotener oder zumindest verdächtiger Schriften, Bücher und Zeitschriften angefertigt, die für die gesamte Bevölkerung galten und deren Nichtachtung als Straftaten geahndet wurden - weshalb vielfach eine gemeinsame düstere Tradition von Zensur und Jugendmedienschutz unterstellt wird (Dickfeldt 1979; Kommer 1979; Breuer 1990). Dieser Zusammenhang ist indes zumindest formal in Demokratien mit ihrer verfassungsrechtlich garantierten Meinungs-, Medien- und Pressefreiheit und dem Verbot von Zensur - gemeint ist die Vorzensur von Staats wegen - nicht gegeben. Denn der Jugendmedienschutz blockiert und selegiert nicht Medien, bevor sie auf den Markt kommen, sondern schränkt nur ihre Zugänglichkeit für junge, noch nicht volljährige Altersgruppen ein. Allerdings haben sich die dafür angeführten Begründungen und damit die daraus folgenden Maßnahmen im Laufe der Zeit immer wieder geändert, sie sind jeweils recht willkürlich, vage, zeitabhängig und damit weitgehend beliebig ausgefallen, so dass Eindrücke von sittlich-moralischer Überbehütung, wenn nicht gar Heuchelei oft nicht von der Hand zu weisen sind.

Mit der Entwicklung und Verbreitung neuer Massenmedien, zuerst des Films und seiner Abspielstätten (anfangs Jahrmärkte, Läden, Kneipen), rückten die Gefährdungen der Medien ins Visier der Beschützer und begründeten allmählich einen eigenen Jugendmedienschutz. Diskutiert wurde etwa zu Beginn des 20. Jahrhunderts, ob und wie minderwertige Bücher und Filme - damals als „Schmutz und Schund“ diffamiert - die allerorten steigende Jugendkriminalität beförderten. Nach etlichen vergeblichen Anläufen, die nicht zuletzt an den anderen Notwendigkeiten des Ersten Weltkrieges scheiterten, wurde in der Weimarer Verfassung von 1919 im Art 118 Abs. 2 die verfassungsrechtlichen Voraussetzungen „zur Bekämpfung der Schund- und Schmutzliteratur sowie zum Schutze der Jugend bei öffentlichen Schaustellungen und Darbietungen " geschaffen und dafür gesetzliche Maßnahmen für zulässig erklärt (Dickfeldt 1979, 34). Prompt folgte am 29. Mai 1920 das so genannte Reichslichtspielgesetz, eine Sonderregelung für den Film, obwohl die Zensur gemeinhin von der Weimarer Verfassung verboten worden war. 
Das Gesetz richtete sich vor allem gegen Sitten- und Aufklärungsfilme, die seit 1918 produziert worden waren; aber auch politisch verdächtigte Filme wie etwa Sergej Eisensteins Panzerkreuzer Potemkin (1925) konnten zumindest zeitweise verboten oder mit Auflagen versehen werden. In Berlin und München wurden Prüfstellen eingerichtet; von ihnen musste jeder Film, der öffentlich vorgeführt werden sollte oder zu diesem Zweck in den Verkehr gebracht wurde, zugelassen werden. Gründe für das Verbot eines Films oder die Herausnahme einzelner Szenen waren die „Gefährdung der öffentlichen Ordnung und Sicherheit", die „Verletzung des religiösen Empfindens“, die „entsittlichende und verrohende Wirkung" auf das Publikum oder die Gefährdung des deutschen Ansehens im Ausland. Die exekutive Einhaltung des Gesetzes oblag der Polizei (Ebd. 46ff.).

Außerdem verabschiedete der Reichstag am 18. Dezember 1926 das spezielle Gesetz zur Bewahrung der Jugend vor Schund- und Schmutzschriften gewissermaßen als erste Maßnahme des Jugendmedienschutzes. Eine Schrift, die von den Prüfstellen als „Schund und Schmutz" klassifiziert wurde, unterlag einem Herstellungs- und Verbreitungsverbot. Allerdings enthielt das Gesetz keine Definition, was "Schmutz und Schund“ sei, so dass die Spruchpraxis der Prüfstellen hierzu allmählich Leitsätze entwickelte: Schriften mit erotischem Charakter („gemeine geschlechtliche Lüsternheit") sowie mit kriminalistischen Inhalten wurden fast unausweichlich indiziert, da sie (bzw. ihre "verwerfliche' Wertlosigkeit") als "jugendgefährdend“ galten oder ihnen die mögliche Verursachung von Jugendkriminalität unterstellt werden konnte (Ebd.).

Mit dem Erlass der Verordnung des Reichspräsidenten zum Schutze des Deutschen Volkes vom 4. Februar 1933, nach deren $\$ 7$ Druckschriften, „deren Inhalt geeignet ist, die öffentliche Sicherheit und Ordnung zu gefährden“, von der Polizei beschlagnahmt und eingezogen werden konnten, verloren die Bestimmungen des "Schund- und Schmutzgesetzes" faktisch ihre Bedeutung. Formal wurden sie erst durch das Reichsgesetz vom 10. April 1935 mit der Begründung außer Kraft gesetzt, dass die Gesetzgebung zur Reichskulturkammer bereits vom September 1933 die Jugend besser, umfassender und wirksamer schütze. Schon 1934 wurde das Reichslichtspielgesetz von 1920 durch eine nationalsozialistische Fassung abgelöst, mit der Film und Kino gänzlich kontrolliert und in den NS-Propaganda-Apparat eingefügt wurden.

In der Bundesrepublik wurde dem JÖSchG nach dem Weimarer Vorbild bereits 1953 das Gesetz über die Verbreitung jugendgefährdender Schriften (GjS) hinzugesellt, wie es Art 5 Abs. 3 GG als Einschränkung der Meinungs- und Pressefreiheit („gesetzliche Bestimmungen zum Schutz der Jugend“) vorsieht (Ebd., 144ff.). Das GjS enthielt neben der Generalklausel, nach der "Schriften, die geeignet sind, Jugendliche zu gefährden“, in eine öffentliche Liste aufzunehmen sind, u. a. dazu Ausführungs- und 
Verfahrensbestimmungen, Regelungen für die Bundesprüfstelle sowie Strafvorschriften gegen zuwider handelnde Gewerbetreibende. Beauftragt mit der Durchführung wurde die 1954 eingerichtete Bundesprüfstelle für jugendgefährdende Schriften (heute Medien) als Bundesbehörde, die zunächst dem Innenministerium, heute dem Ministerium für Familien, Senioren, Frauen und Jugend unterstellt ist. Ihre Prüforgane beurteilen auf Antrag, ob ein Werk „jugendgefährdend“, d. h. „desorientierend“ und „die Entwicklung von Kindern und Jugendlichen beeinträchtigend“, oder „schwer jugendgefährdend“ (und damit auch strafrechtlich relevant) ist. Bezeichnenderweise waren die ersten beiden Werke, die von der Bundesprüfstelle indiziert wurden, die Comics Der kleine Sheriff und Jezab, der Seefahrer, und auch in den folgenden Jahren waren Comics die am häufigsten indizierte Gattung - weshalb man sie auch als Instrument für die verbreitete Anti-Comic-Einstellung beargwöhnte. Als Begründung für die erste Indizierung wurde angeführt, die Bildstreifen würden auf Jugendliche „nervenaufpeitschend und verrohend wirken“ und sie ,in eine unwirkliche Lügenwelt versetzen“. Derartige Darstellungen seien „das Ergebnis einer entarteten Fantasie“ (Dolle-Weinkauff 1990, 99ff.).

Der Jugendschutz für Film und Kino wurde mit einer Zugangskontrolle zum Kino bzw. einer Altersfreigabe von Filmen geregelt, die der Staat schon 1949 an die Freiwilligen Selbstkontrolle der Filmwirtschaft (FSK), eine Einrichtung, die von der Spitzenorganisation der Filmwirtschaft (SPIO) in Wiesbaden getragen wird, delegierte. Dafür verpflichtete sich die SPIO, nur Filme öffentlich aufzuführen, die von der FSK geprüft sind. Ihre Gremien, in der auch Vertreter der staatlichen Jugendhilfe mitarbeiten, versehen jeden Film mit einem Prüfsiegel (FSK) und einer Freigabe oder Alterskennzeichnung. Gesetzliche Grundlage dafür war das JÖSchG $\$ 6$ Abs. 3. Beide Gesetze wurden im Laufe der Zeit modifiziert bzw. novelliert, je nach den medialen Gegebenheiten. So geriet etwa in den 60er Jahren die Jugendpostille Bravo mit ihren Rubriken und Bildgeschichten zur Sexualaufklärung mehrfach auf den Index (Knoll und Stefen 1978). Mit der Verbreitung von fragwürdigen, als jugendgefährdend erachteten Videofilmen und Computerspielen wurde die (freiwillige) Verpflichtung zur Altersfreigabe 1985 auf „Videofilme und vergleichbare Bildträger“ ausgeweitet, um auch diesen Markt zu beobachten und zu kontrollieren. Dafür schloss sich Bundesverband Video e.V. der FSK an und übertrug ihr die Aufgabe der Alterskennzeichnung. Ebenso wurden im selben Jahr die Altersfreigaben zum Schutz der Jugend erstmals gesetzlich vorgeschrieben.

Auch auf das Fernsehen wurden diese Altersfreigaben übertragen; dort werden sie als Einschränkungen der Sendezeit definiert (was angesichts des meist recht unkontrollierten Fernsehkonsums von Kindern und Jugendlichen und diverser Aufzeichnungsoptionen allenfalls nur noch als deklamatorisch bewertet werden kann; aber andere Möglichkeiten schließt die Meinungs- und Medienfreiheit aus): 
Sendungen und Filme mit einer Freigabe bis zwölf Jahren können zu jeder Tagesund Nachtzeit ausgestrahlt werden; dabei soll allerdings ,dem Wohl jüngerer Kinder Rechnung getragen werden" (Jugendmedienschutz-Staatsvertrag $\$ 5$ Abs. 4 S. 3). Die Altersfreigabe der FSK ab 16 Jahre verlangt eine Sendezeit ab 22 Uhr sowie einen Warnhinweis, die ab 18 Jahre eine Sendezeit ab 23 Uhr. Die Sender können jeweils einen Ausnahmenantrag stellen, um die Bindung an die FSK-Freigaben zu lösen (Seufert und Gundlach 2012, 249). Üblicher sind bei anstößigen Szenen Schnitte, die von Gutachtergremien empfohlen werden, um bessere, sprich: breitere FSK-Kennzeichnungen zu bekommen. Während die öffentlich-rechtlichen Rundfunkanstalten die Beachtung des Jugendmedienschutzes durch ihre Gremien und ihre Jugendschutzbeauftragten als gegeben ansehen, haben sich die privatkommerziellen Fernsehbetreiber - 2011 sind es 28 Veranstalter (Ebd.) - 1993 zur Freiwilligen Selbstkontrolle Fernsehen e.V. (FSF), einem gemeinnützigen Verein, zusammengeschlossen, um die Richtlinien des Jugendmedienschutzes nach der jeweiligen Fassung des Jugendmedienschutzstaatsvertrags in ihren Programmen einzuhalten. Dafür werden die Programme von beauftragten Gremien aus Wissenschaft, Kultur und Medienpädagogik einer Vorkontrolle unterzogen, Sendezeiten festgelegt oder Empfehlungen für Schnitte ausgesprochen. Im Jahr 2003 wurde die FSF von der Kommission für Jugendmedienschutz der Landesmedienanstalten (KJM), die seit 2003 laut dem Staatsvertrag über den Schutz der Medienwürde und den Jugendschutz in Rundfunk und Telemedien (JMStV) verantwortlich ist und sich dazu auch der Einrichtungen der Freiwilligen Medienselbstkontrolle bedient, mit der Auflage anerkannt, dass sich ihre Gremien an den gemeinsamen Jugendschutz-Regelungen orientieren (Ebd., 248f.).

1994 folgte als weitere Einrichtung der Medienselbstkontrolle die UnterhaltungsSoftware-Selbstkontrolle (USK) für Video- und Computerspiele. Sie wird getragen von Unternehmen und Verbänden zur Entwicklung, Produktion und zum Vertrieb solcher Spiele, besonders vom Bundesverband Interaktive Unterhaltungssoftware (BIU) und dem Bundesverband der Entwickler von Computerspielen (G.A.M.E). Ihre Prüfverfahren vergeben Altersfreigaben analog denen der FSK sowie gemäß den rechtlichen Bestimmungen von JuSchG und JMStV, wobei die Kriterien den medienspezifischen Besonderheiten der Computerspiele angepasst sind. Auf Antrag der KJM werden auch Online-Spiele geprüft.

Schließlich kam 1997 die Freiwillige Selbstkontrolle Multimedia-Diensteanbieter e.V. (FSM) hinzu, die die Einhaltung der Jugendschutzrichtlinien in OnlineDiensten beobachtet und die dortige Verbreitung rechtswidriger und jugendgefährdender Inhalte verhindern soll. Dazu hat sie in Anlehnung an den JMStV einen Verhaltenskodex entwickelt, in dem strafrechtliche und auf den Jugendschutz bezogene Vorschriften sowie die anerkannten journalistischen Grundsätze enthalten sind. 
$\mathrm{Zu}$ deren Einhaltung (selbst)verpflichtet sich jedes Mitglied, also vor allem Server, Provider und Plattformen. Auch sie ist von der KJM als Selbstkontrolleinrichtung anerkannt (Ebd., 303). Allerdings endet die operative Wirkungsweise an den deutschen Grenzen. Werden unzulässige Inhalte aus dem Ausland angeboten, kann die FSM die Beschwerde nun an die jeweils zuständige Organisation weiterleiten.

Die zwischenzeitlich erreichte Vielzahl von (Selbstkontroll-)Gremien und Zuständigkeiten ist wenig überschaubar und letztlich auch nicht sehr effizient. Sie folgt zum einen dem verfassungsrechtlichen Gebot der Meinungs- und Medienfreiheit, das direkte staatliche Eingriffe (Zensur) ausschließt, sowie der föderalen Struktur der Bundesrepublik, die die Medienpolitik weitgehend noch als Kompetenz der Länder bestimmt. Zum anderen trägt sie den differenzierten Strukturen, Aktivitäten und Geschäftsmodellen in der Medienbranche Rechnung, die noch nicht völlig konzentriert ist - wiewohl sich allenthalben größere Oligopole zeigen. Und sie bietet damit den Jugendschutzverantwortlichen, vor allem der KJM, Optionen, um die Einhaltung des Jugendmedienschutzes nicht zuletzt über die Maximen des Wettbewerbs und der Imagepflege, also eher informell und lautlos, zu erreichen. Eine brauchbare, grafische Übersicht sieht aktuell so aus (Abb. 6.8).

Um der wachsenden Vernetzung und Konvergenz der Medien durch das Internet, die zumal zwischen den Rechtsträgern Bund und Bundesländer immer wieder Kompetenzrangeleien hervorrufen - der Bund war ursprünglich gemäß der weiteren technischen Auslegung seiner ausschließlichen Gesetzgebungskompetenz für die Post und das Fernmeldewesen (Art 73, S. 7 GG) für die so genannten (Online)-Telemedien zuständig, die Bundesländer nach wie vor für den Rundfunk (Hörfunk und Fernsehen) samt seinen fortschreitenden digitalen Erweiterungen -, aber auch um der aufgeregten öffentlichen Diskussion nach dem Amoklauf eines Jugendlichen in Erfurt, dessen Motivierung nicht zuletzt durch den exzessiven Konsum von gewalthaltigen Computerspielen vermutet wurde, Rechnung zu tragen, wurden 2002/03 die Jugendschutzbestimmungen, die früher im Rundfunkstaatsvertrag und im Staatsvertrag über Mediendienste enthalten waren, zusammengefasst und einer gemeinsamen Aufsicht unterstellt. Die neue Systematik übertrug den Ländern mehr Kompetenzen: Im Juli 2002 wurde das neue Jugendschutzgesetz mit Wirkung zum 1. April 2003 verabschiedet, gleichzeitig trat der Staatsvertrag über den Schutz der Medienwürde und den Jugendschutz in Rundfunk und Telemedien (JMStV) zwischen allen Bundesländern in Kraft. In beide Regelwerke sind die früheren Bestimmungen zu den traditionellen Medien eingearbeitet und mithin auf das Hypermedium Internet übertragen.

Das JuSchG regelt vor allem den Jugendschutz in der Öffentlichkeit und bestimmt die Zugangs- und Verbreitungsbeschränkungen von jugendgefährdenden 


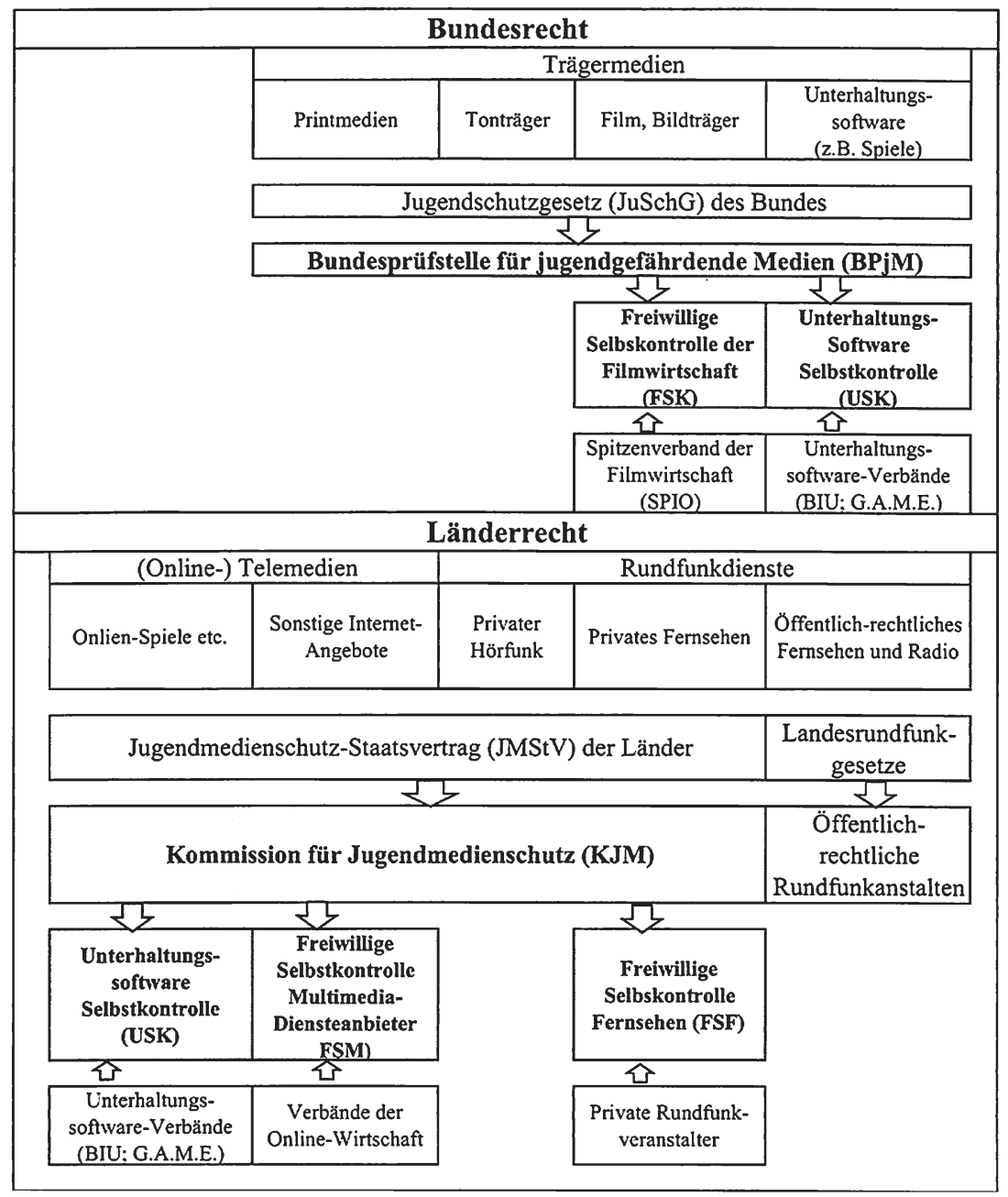

Abb.6.8 () Kompetenzen, Akteure und Rechtsfelder des Jugendmedienschutzes (Seufert und Gundlach 2012, 196)

Trägermedien (Printmedien, Videos, CD-ROMs, DVDs usw.). In seiner Neufassung sind die verstreuten Vorschriften, die sich bislang im Rundfunkstaatsvertrag (RStV) und Mediendienstestaatsvertrag (MDStV) fanden, gebündelt. Insbesondere ging dabei auch der Regelungsgehalt des „Gesetzes über die Verbreitung 
jugendgefährdender Schriften und Medieninhalte (GjSM)“, zuletzt bekanntgemacht am 12. Juli 1985 (Bundes-Gesetz-Blatt I, 1502ff.), im Jugendschutzgesetz auf.

Gemäß der Rundfunkhoheit der Bundesländer enthält der JMStV die Bestimmungen zu Rundfunk und den so genannten Telemedien. Um die Menschenwürde und strafrechtlich geschützte Rechtsgüter zu schützen, geht der JMStV deutlich über den Jugendschutz hinaus. Dabei rekurriert er auf die Selbstkontrolle der Medien; er ist vorrangig an deutsche Betreiber von Internetseiten - etwa zehn Prozent der in Deutschland verfügbaren Seiten - adressiert und belegt unfreiwillig die Grenzen des nationalen Jugendmedienschutzes.

Die Einhaltung des JMStV wird durch die zuständige Landesmedienanstalt bzw. durch die gemeinsame, von allen Landesmedienanstalten getragene Kommission für Jugendmedienschutz (KJM) überprüft (vgl. $\$ \$ 14 \mathrm{ff}$. JMStV). Dabei wird sie durch das Unternehmen jugendschutz.net unterstützt (vgl. \$18 JMStV). Zusätzlich überwachen Einrichtungen der Freien Selbstkontrolle (z. B. die FSM) die Einhaltung der staatsvertraglichen Bestimmungen (vgl. $\$ 19 \mathrm{JMStV}$ ). Anlässlich der geplanten Neufassung des Rundfunkstaatsvertrages als so genannte 14. Änderung beschlossen die Ministerpräsidenten der Länder am 10. Juni 2010 auch eine Novellierung des JMStV. Das Änderungsgesetz, das zum 1. Januar 2011 in Kraft treten sollte, wurde kontrovers diskutiert, vor allem hinsichtlich der Einführung einer Alterskennzeichnung auch von Inhalten im Internet, analog den anderen Medien; doch sie wurde von Kritikern für nicht praktikabel und für wenig rechtssicher gehalten. Die Befürworter sahen hingegen in der Alterskennzeichnung eine willkommene Stärkung der Selbstregulierung durch Selbstklassifizierung und einen für Online-Anbieter geeigneteren Mechanismus als die Sendezeitbeschränkungen und Jugendschutzprogramme. Am 16. Dezember 2010 lehnte der nordrhein-westfälische Landtag einstimmig die Novellierung des JMStV ab; sie ist damit gegenstandslos und muss neu verhandelt werden. Bis zur Neuregelung bleibt der seit 2003 bestehende Jugendmedienschutz-Staatsvertrag weiterhin in Kraft. Auch nach ihm müssen alle Betreiber von Websites ihre Inhalte einschätzen und gegebenenfalls die in $₫ 5$ Abs. 3 in Verbindung mit $\$ 11 \mathrm{JMStV}$ genannten Maßnahmen ergreifen. Die Alterskennzeichnung wäre hier nur ein zusätzliches Mittel gewesen.

Eine weitere Neuerung ist, dass in beiden Gesetzen bestimmte Inhalte benannt werden, die auch ohne Indizierung oder Altersfreigabebeschränkung nicht verbreitet werden dürfen. Allerdings gelten sie für Telemedien in einem anderen Ausmaß als für Trägermedien, auch sind die Folgen bei Verstößen unterschiedlich. Diese Inhalte sind „den Krieg verherrlichende Trägermedien“ ( $\$ 15$ Absatz 2 Nr. 2 JuSchG), ferner Medien, die „Kinder und Jugendliche in unnatürlich geschlechtsbetonter Körperhaltung darstellen“ ( $\$ 15$ Absatz 2 Nr. 4 JuSchG), sowie Medieninhalte, die „Menschen, die sterben oder schweren seelischen Leiden ausgesetzt sind oder waren, 
in einer die Menschenwürde verletzenden Weise darstellen und ein tatsächliches Geschehen wiedergeben, ohne dass ein überwiegendes berechtigtes Interesse gerade an dieser Form der Berichterstattung vorliegt" ( $\$ 15$ Abs. 2 Nr. 3 JuSchG und $\S 4$ Abs. 1 S. 1 Nr. 8 JMStV). Außerdem regelt das JuSchG den Vertrieb von Computerund Videospielen schärfer; sie müssen, wenn sie an Minderjährige verkauft werden sollen, der USK vorgelegt werden. Die von ihr festgelegten Alterskennzeichnungen müssen deutlich auf dem Produkt angebracht werden.

Nach längerer Debatte wurde mit Wirkung zum 1. Juli 2008 die Kennzeichnung von Trägermedien weiter verschärft und ein so genanntes Killerspielverbot eingeführt: Medien, die „besonders realistische, grausame und reißerische Darstellungen selbstzweckbehafteter Gewalt beinhalten, die das Geschehen beherrschen" ( $\$ 15$ Abs. 2 Nr. 3a), gelten nach der neuen Gesetzeslage automatisch (d. h. auch ohne ein Tätigwerden der BPjM) als „schwer jugendgefährdend“, mit der Folge, dass sie unter anderem nicht an allgemein zugänglichen Verkaufsstellen oder im Versandhandel angeboten und nicht öffentlich beworben werden dürfen. Ferner wurde die BPjM ermächtigt, in die Liste jugendgefährdender Medien auch solche Medien (mit den gleichen genannten Rechtsfolgen) aufzunehmen, die ( $\$ 18$ Abs. 1 Nr. 1)

- Gewalthandlungen wie Mord- und Metzelszenen selbstzweckhaft und detailliert darstellen oder

- Selbstjustiz als einzig bewährtes Mittel zur Durchsetzung der vermeintlichen Gerechtigkeit nahelegen.

All diese gesetzlichen Bestimmungen und Maßnahmen zielen darauf ab, den Medienmarkt um des Schutzes von Kindern und Jugendlichen willen zu beschränken und ihnen Medien, die sie desorientieren und zum antisozialen Verhalten verleiten, die ihre Entwicklung beeinträchtigen oder gar schädigen, vorzuenthalten. Dazu gehört auch ein Werbe- und Zur-Schau-Stellungsverbot. Da viele Medien dadurch in einem auf öffentliche Aufmerksamkeit, ungehinderten Zugang oder sogar auf lautstarke Promotion angelegten Markt ihre Absatzchancen und damit die erwünschten Umsätze einbüßen, sind die Betreiber und Vermarkter daran interessiert, möglichst nicht unter die Restriktionen des Jugendmedienschutzes zu fallen und nehmen lieber inhaltliche Auflagen in Kauf.

Dieser auf Markt und Produzenten gerichtete Jugendschutz wird vielfach auch als repressiver, polizeilicher oder zumindest restriktiver Jugendschutz bezeichnet, weil er primär das Versteck, die Ausschließung, Sanktionierung oder gar das Verbot von Medien intendiert. Doch mit der Vervielfältigung, gar der Privatisierung und Anonymisierung von Vertriebswegen wird diese Rechtskonstruktion ständig poröser und unglaubwürdiger; sie entspricht auch nicht mehr dem aktuellen Verständnis der 
ebenfalls tangierten Kinder- und Jugendhilfe, deren wichtigste Aufgabe ist, Kinder und Jugendliche in ihrer Entwicklung zu eigenverantwortlichen und gemeinschaftsfähigen Persönlichkeiten zu fördern und ihre Rechte in Familie und Gesellschaft zu garantieren. Hinsichtlich der Medien hat sich eingebürgert, diese Aufgaben als Förderung und Weiterentwicklung einer vielschichtigen und weit reichenden Medienkompetenz zu sehen, damit Kinder und Jugendliche mit den Medien konstruktiv und kreativ umgehen lernen und sie für ihre kommunikativen Bedürfnisse und Belange effektiv nutzen können. Diese Intentionen werden inzwischen als präventiver oder erzieherischer Jugendschutz bezeichnet und sie sollen aus der Sicht vieler Jugendschutzvertreter gleich-, wenn nicht sogar vorrangig zu den Sanktionen des Jugendmedienschutzes treten. Entsprechende Formulierungen finden sich in etlichen Zielkonzepten und Ausführungsbestimmungen. In der Praxis treffen sich diese Intentionen mit den Maßnahmen und Projekte von Medienpädagogik - sie können sich unmittelbar an jugendliche Adressaten, aber auch an pädagogische Multiplikatoren und Eltern richten -, wobei sich der präventive Jugendmedienschutz vorzugsweise auf die außerschulische oder freie Kinder- und Jugendarbeit konzentriert. Häufig lässt sich auch beobachten, dass sich dieser Jugendschutz eher in der allgemeinen Orientierung und Beratung, in der Koordination oder gar Finanzierung von größeren Maßnahmen engagiert, weniger in der praktischen Arbeit vor Ort. Dazu zählen hinsichtlich des Internets auch Ratgeber-Plattformen wie klicksafe.de (im Auftrag der Europäischen Kommission), watch your web (von der Bundesregierung zusammen mit Facebook, Schuelervz.net, Lokalisten.de, Viva und t-online), internet $a b c$ (von den Landesmedienanstalten der Evangelischen Kirche, der Initiative D 21, Stiftung Digitale Chancen und dem Deutschen Kinderschutzbund e.V.), internauten (vom Deutschen Kinderhilfswerk e.V., der Freiwilligen Selbstkontrolle Multimedia-Anbieter e.V. und von Microsoft Deutschland), juuuport (von der Niedersächsischen Landesmedienanstalt) und netzdurchblick (von der Medienanstalt Hamburg Schleswig-Holstein) (Kübler 2011a; Krause 2012). Allerdings lassen etliche Plattformen die funktionale, mitunter auch strukturelle Nähe zur Medienbranche erkennen, die bei engagierten Pädagogen auf Misstrauen stößt.

\subsubsection{Jugendmedienschutz in anderen europäischen Ländern - eine kursorische Übersicht}

Kaum ein Jugendmedienschutz in anderen Ländern dürfte so kompliziert und komplex sein wie der in Deutschland, so dass ihn nur noch Fachjuristen beherrschen (Bellut 2012). Darin drückt sich zum einen der deutsche Hang zur juristischen Überregulierung aus, zum anderen aber auch die verbreitete 
Skepsis gegenüber Medien und reichlich überzogene Ängste über ihre möglichen Wirkungen. Schließlich gilt es auch, die unterschiedlichen gesetzlichen Kompetenzzuschreibungen in einem förderalen Staat zu berücksichtigen.

Ein Vergleich mit anderen europäischen Ländern zeigt deutlich andere gesetzliche Bestimmungen, unterschiedliche Aufgabenkonzepte und mediale Tatbestände welche Kinder und Jugendliche sind vor welchen Inhalten in welchen Medien wie zu schützen? - und erst recht andere operative Maßnahmen und Instanzen (von Gottberg 2011). Zwar werden Medienangebote und -vernetzungen ständig inter- und transnationaler, wenn nicht global, so dass nationale Besonderheiten nur noch in wenigen Segmenten, meist in Nischen zu unterscheiden sind, aber für die Jugendschutzbestimmungen ist eine hinreichende Harmonisierung noch weit entfernt.

Weitgehende Übereinstimmung scheint in Europa zu bestehen, dass Darstellungen physischer Gewalt in den Medien von Kindern und Jugendlichen fernzuhalten sind (Ebd., 23). Doch kontrovers werden schon die Beurteilungskriterien und damit die Vorgehensweisen betrachtet: Während die einen Kinder und Jugendliche generell vor mutmaßlich aggressions- und gewaltsteigernden Themen und Darstellungen schützen wollen, neigen andere zu Abschreckungskonzepten und wollen Gewalt und ihre Folgen möglichst wirklichkeitsecht und detailliert zeigen. Kritiker halten solche Strategien für makabre,schwarze Pädagogik', wenn sozial erwünschtes Verhalten durch Angstmache erreicht werden soll. In allen europäischen Ländern beziehen sich Jugendschutzmaßnahmen zunächst auf Kinofilme, die unter der Prämisse der Öffentlichkeit stehen, die Rezeption von DVDs und Fernsehen wird vielfach als privat erachtet und unterliegt damit nicht der Zuständigkeit des Staates. Allerdings variieren die Altersbeschränkungen in den einzelnen Ländern erheblich: Weder gibt es übereinstimmende Kriterien für bestimmte Perioden des Heranwachsens (Kleinkind, Kind, Jugendlicher, junge Erwachsener) noch werden sie beim jeweiligen Medienprodukt (Film) identisch angewendet.

Solche Divergenzen durchziehen sämtliche gesetzliche Bestimmungen, ihre Begründung und legitimatorische Ableitung, wie ein kursorischer Überblick über die Jugendschutzbestimmungen in Europa belegt (Ebd., 20ff.):

- Frankreich: Die Vorführung eines Kinofilms ist nur gestattet, wenn er über eine Freigabe der staatlichen Commission de Classification des Oeuvres Cinémategraphiques verfügt. Die Freigabepraxis ist allerdings äußerst liberal: Filme gelten als Fiktion und Kunst und sind grundsätzlich frei. Über 90 Prozent alle Filme werden ohne Altersbeschränkung zugelassen. Schon eine Freigabe ab 12 Jahren wird als Einschränkung erachtet, eine ab 16 Jahren fast als Zensur. Die Freigabe ab 18 Jahren steht zwar noch im Gesetz, ist aber in 
den letzten Jahren nur einmal ausgesprochen worden. Bei dargestellter Gewalt reagiert man auf zwei Themen, die die französischen Gesellschaft aufrütteln, besonders sensibel: bei der Darstellung von Selbstmorden von Jugendlichen und von Jugendbanden im Umfeld der Großstädte. Für die DVDs müssen die Alterskennzeichnungen der Filme übernommen werden, eine gesetzliche Regelung existiert aber nicht. Das Fernsehen beaufsichtigt der Conseil supérieur de l'audiovisuel (CSA), der auch für den Jugendschutz zuständig ist. Er setzt vornehmlich auf Zuschauerinformation, die im Programm eingeblendet werden; da es keine gesetzliche Regelung gibt, beruht diese Praxis auf Vereinbarungen des CSA mit den Sendern. Zwar wären besagte Alterskennzeichnungen auch als Beschränkung möglicher Sendezeiten umzusetzen, aber da sie für Spielfilme kaum getroffen werden, sind sie auch für die Sendepraxis unerheblich.

- Großbritannien: Filme werden durch das British Board of Film Classification (BBFC) geprüft; es ist eine Art gemeinnützige $\mathrm{GmbH}$, die von angesehenen Personen getragen wird. Finanziert wird sie von Gebühren für die Filmvorführung. Für Kinofilme gibt es kein gültiges Gesetz, zuständig sind grundsätzlich die Kommunen im Rahmen der Aufrechterhaltung der öffentlichen Ordnung und Sicherheit. In Europa vergibt das BBFC die strengsten Altersbeschränkungen, knapp dahinter folgt die deutsche FSK. Um zu verhindern, dass die Freigaben in den Kommunen und Regionen unterschiedlich ausfallen, sind die Filmverleiher an nationalen Vorgaben interessiert, die von den Kommunen übernommen werden sollen.

DVDs unterliegen einer gesetzlichen Prüfpflicht, die aufgrund einer Vereinbarung mit dem Innenministerium ebenfalls vom BBFC durchgeführt wird. Oftmals werden Kinofilme weniger streng eingestuft als Videofilme, da - so die kaum haltbare Begründung - diese mehrfach angeschaut werden können. Die relativ hohe Jugendkriminalität in Großbritannien wird nicht zuletzt von der Darstellung der Planung und Durchführung von Verbrechen in den Videofilmen stark beeinflusst gesehen, sie wird mithin als Nachahmung gewertet. Besonders sensibel reagiert man auch auf eine vulgäre Sprache, da sie als Herabwürdigung von Menschen klassifiziert wird.

- Niederlande: Die Freigaben von Filmen sind weitgehend den Anbietern übertragen; dementsprechend soll die Medienindustrie auch bald die Kosten für die Kennzeichnung tragen. Den vom Nederlands Instituut vor de Classificatie van Audiovisuelle Media (NICAM) entwickelten Fragebogen füllen speziell geschulte Mitarbeiter der Anbieter selbst aus und senden ihn online an das NICAM, das aus den Angaben mit einem computergesteuerten Verfahren die Freigabe errechnet. Das NICAM ist für die Einhaltung der gesetzlichen Jugendschutzbestimmungen zuständig, die für Kinofilme, DVDs und 
Fernsehen gelten; über eine Erweiterung auf das Internet wird nachgedacht. Zur Orientierung der Eltern werden die Trägermedien mit kleinen Piktogrammen versehen, die aufzeigen, wo mögliche Probleme des Films liegen könnten.

- Österreich: Jedes Bundesland hat ein eigenes Jugendschutzgesetz, das die Altersstufen teils unterschiedlich festschreibt. Da es in den Bundesländern indes oft keine eigene Institution gibt, die die Altersstufen fixiert, übernehmen die meisten Freigaben die in Wien ansässige Bundesfilmkommission. Diese Kommission beschließt nicht nur Freigaben, sie veröffentlicht auch Altersempfehlungen.

- Die Schweiz: Auch dort ist der Jugendschutz Sache der Kantone, die über jeweils unterschiedliche Bestimmungen verfügen.

- Schweden: 2011 wurde eine neue gesetzliche Grundlage geschaffen: Die bislang vom Staat (Kulturministerium) vergebene Freigabe (Höchststufe: frei ab 15 Jahre) wurde an eine neu zu gründende Kommission übergeben, um damit den Verdacht einer möglichen Zensur vorzubeugen.

- Spanien: Altersfreigaben werden von einer Kommission des Kulturministeriums vergeben, aber sie gelten nur als Empfehlung.

- Portugal: Kinder, deren Alter eine Stufe unter der Freigabe liegt, können den Film besuchen, wenn ihre Eltern dabei sind - eine Regelung, die auch in Dänemark und mittlerweile auch in Deutschland gilt.

- Norwegen: Gehalthaltige Filme werden sehr scharf geprüft; auch wenn sie sie ironisch oder lustig darstellen - was andere Länder als Distanzierungsoption werten -, erfolgt eine strenge Sanktion.

\subsubsection{Kindersicherungen für den PC als mechanischer Jugendmedienschutz}

Über die Landesgrenzen hinaus werden von interessierter Seite - etwa von der schon 1999 von Microsoft, AOL-Europe, T-Online und Bertelsmann gegründete Vereinigung Internet Content Rating Association [ICRA]), die auf Selbstregulation des Anbieters basiert, von EU-Geldern unterstützt und im deutschsprachigen Raum von der Bertelsmann-Stiftung vertreten wird - Sicherungssysteme für den häuslichen PC und Internetzugang angepriesen. Solche Programme ermöglichen die Festlegung von Zeitlimits für die Nutzung und die Steuerung des Zugriffs auf Webinhalte, Programme oder Systemeinstellungen. Die Zeitlimits lassen sich für jeden Wochentag einzeln festlegen. Sperrzeiten sorgen dafür, dass der PC oder das Internet zum Beispiel erst nach den Hausaufgaben genutzt werden können. Auch Pausenzeiten können für einzelne Programme erzwungen werden. Sind die 
Limits erreicht, wird der Rechner nach entsprechender Vorwarnung heruntergefahren oder in den Standby-Modus geschickt. Auch Belohnungen (Gutscheincodes [TANs]) können eingebaut werden, wenn Kinder nur bestimmte Programme nutzen oder die fixierten Nutzungszeiten unterschreiten. Eltern ersparen diese Maßnahmen nervige Diskussionen, so die einschlägige Werbung.

Mit der Internetsteuerung können bestimmte Homepages und Webseiten gesperrt werden, die bedenkliche Schlüsselwörter wie „Sex und Pornografie“ oder „Alkohol, Drogen“ enthalten. Auch andere anstößige Seiten wie „Chat-Dating“ können ausgeschlossen werden. Ferner greifen die Systeme in Deutschland auf den Filter der Bundesprüfstelle für jugendgefährdende Medien (BPjM) zu. Noch zuverlässigeren Schutz bietet eine Positivliste („Whitelist“), mit der Kinder ausschließlich auf Internetseiten surfen können, die als unbedenklich eingestuft wurden. Eine solche Liste bezieht das Programm automatisch, beispielsweise von der Brancheninitiative FragFinn.de.

Außerdem kann der Start von Filesharing-Software komplett verhindert werden. Ebenso lassen sich manuell eingetragene Programme und der Zugriff auf Systemeinstellungen untersagen oder einfach alle Downloads unterbinden. All diese Steuerungen können entsprechend den Benutzern in der Familie individuell getrennt für (fast) alle Zugriffe detailliert geregelt und ständig mittels automatisch erzeugter Listen überprüft werden. Dass damit auch mögliche finanzielle Risiken durch teure Downloads verhindert werden, versteht sich. Pädagogen warnen hingegen davor, dass solche Maßnahmen bei Kindern und Jugendlichen Misstrauen und das Gefühl permanenter Überwachung hervorrufen, wodurch ein vertrauensvoller und offener Umgang mit den IT-Geräten in den Familien beeinträchtigt, wenn nicht unterminiert wird und ihr Wunsch nach selbst verfügbarer Gerätschaft wächst.

\subsubsection{Jugendmedienschutz der Europäischen Union}

Seit Ende der achtziger Jahre ist der Jugendmedienschutz als grundsätzliches politisches Ziel in der Europäischen Gemeinschaft (EG) bzw. Europäischen Union (EU) anerkannt. Allerdings handelt es sich vorwiegend um Verlautbarungen appellativen Charakters, da Medien- und Jugendpolitik hauptsächlich in die Kompetenz der Mitgliedsländer fällt. Zunächst sind Regelwerke zu europäischen Standards für Fernsehen und Videospiele entstanden.

1989 verabschiedete die EG die Fernsehrichtlinie (Television without frontiers), die seit 2007 in einer dritten überarbeiteten Fassung vorliegt. Ihr Ziel ist unter anderem die Durchsetzung von Mindeststandards, die für nationale Jugendschutzmaßnahmen verbindlich sein sollen. Die knapp formulierten Auflagen 
untersagen die Ausstrahlung von Programmen, „die die körperliche, geistige und sittliche Entwicklung von Minderjährigen ernsthaft beeinträchtigen können, insbesondere solche, die Pornographie oder grundlose Gewalttätigkeiten zeigen “ (Richtlinie 2007/65/EG Art. 22 (1)). Derartige Inhalte dürfen nur zu Sendezeiten ausgestrahlt werden, zu denen keine Minderjährigen vor dem Fernseher zu erwarten sind, sie müssen durch akustische Zeichen angekündigt oder durch optische Mittel während der gesamten Sendung kenntlich gemacht werden. Ersatzweise können technische Sperren eingesetzt werden. Diese Grundsätze sollen grenzüberschreitende Rundfunkausstrahlungen ermöglichen, da ihre Unterbindung für jedes Land erhebliche technische und finanzielle Probleme bergen würde (Kückner 2006, 12ff.).

2003 wurde das so genannte Pan European Game Information System (PEGI) eingeführt. Da mit ihm erstmals eine europaweite Standardisierung erreicht wurde, kommt ihm eine Vorreiterstellung im europäischen Jugendmedienschutz zu. Das System wurde vom holländischen NICAM entwickelt und operiert nach denselben Prinzipien wie die niederländische Film- und Fernsehklassifizierung. Die Software-Anbieter selbst kennzeichnen ihre Produkte nach den Alters- und Inhaltskategorien für diesen Medientyp. In Portugal und Großbritannien mussten kleine Anpassungen an das nationale Recht vorgenommen werden, doch wird das System ansonsten europaweit einheitlich genutzt. Die einzige Ausnahme ist Deutschland. Hier findet die Prüfung von Video- und Computerspielen durch die Freiwillige Selbstkontrolle Unterhaltungssoftware (USK) statt.

Über die einzelnen Medien hinaus liegen von der EG bzw. EU Empfehlungen vor, die Grundsätze zur Darstellung von Gewalt und Diskriminierungen enthalten, ähnlich denen der Fernsehrichtlinie (vgl. Empfehlung Nr. R (97) 19, 20, 21). Sie gelten für audiovisuelle Mediendienste und enthalten spezielle Bestimmungen zum Schutz von Minderjährigen. Ergänzt werden sie durch Empfehlungen aus den Jahren 1998 und 2006 über den Jugendschutz und den Schutz der Menschenwürde. Ferner fördert das Safer Internet Programme die sichere Nutzung des Internets und neuer Online-Technologien, vor allem durch Kinder. Seit 2004 existiert dafür die Plattform klick-safe.de; sie gibt dafür konkrete Ratschläge, lädt zu Erprobungen und Spielen ein, fördert die Medienund Internetkompetenz und informiert über alle aktuelle Entwicklungen. In Deutschland wird das Safer Internet Programme durch den Verbund Saferinternet $D E$ umgesetzt. Diesem gehören neben dem Awareness Centre klicksafe die Internet-Hotlines internet-beschwerdestelle.de (durchgeführt von eco [Verband der deutschen Internetwirtschaft e.V] und FSM) und jugendschutz.net sowie das Kinder- und Jugendtelefon von Nummer gegen Kummer (Helpline) an. klicksafe" ist von der Europäischen Kommission 2004 angestoßen worden, wird seither finanziert und in Deutschland als gemeinsames Projekt der Landeszentrale 
für Medien und Kommunikation (LMK) Rheinland-Pfalz (Projektkoordination) sowie der Landesanstalt für Medien Nordrhein-Westfalen (LfM) getragen.

Mit der von Olsberg u. a. (2003) durchgeführten Studie strebte die Europäische Kommission erstmals an, Grundlagen zur Harmonisierung des Jugendmedienschutzes für Kino, Fernsehen und Video zu erreichen. Verglichen wurden die zuständigen Institutionen, Vertreter der Filmindustrie sowie Verbraucherschützer wurden befragt. Als künftige Option des Jugendmedienschutzes schälte sich heraus, traditionelle Restriktionen wie Indizierungen und Schnitte zugunsten präventiver wie beratender Funktionen der Jugendschutzinstitutionen zu reduzieren. Dafür müssten Selbstregulierungen der Medienbetreiber verstärkt werden, um dem wachsenden Medienmarkt mit seinen vielen medialen Varianten besser Rechnung zu tragen. Neben den Niederlanden gehen auch Dänemark, Finnland und Portugal in diese Richtung. Außerdem helfen dabei die schon entwickelten Alterskennzeichnungen, deren verschiedene nationale Versionen aneinander angeglichen werden müssten nicht zuletzt um Kosten zu sparen (zit. nach Kückner 2006, 35ff.).

Im April 2009 wurden innerhalb des Safer Internet Aktionsplans (Safer Internet Programme) der Europäischen Kommission auf einem Treffen des Runden Tisches acht Leitsätze zur Verbesserung des Jugendmedienschutzes und ein unverbindliches Toolkit (oder auch Toolbox, das ist eine Sammlung für Hilfsmittel zum Programmieren) veröffentlicht. Damit sollte eine gemeinsame Sprache zwischen den Generationen, Wohlfahrtsarbeitern und Technikern angestrebt werden. Jährlich wird jeweils in der ersten Februar-Woche der Safer Internet Day mit zahlreichen Veranstaltungen, Aktionen und Initiativen von vielen beteiligten Instanzen und Grupperungen begangen. In Deutschland initiiert und koordiniert klicksafe die nationalen Aktivitäten mit dem Ziel, möglichst viele Akteure und Institutionen für eine Beteiligung in eigener Regie zu gewinnen.

Am 28. September 2009 empfahl die Parlamentarische Versammlung des Europarates (PACE) ihren Mitgliedsstaaten in einer Resolution, sich für ein kinderfreundliches, die bestehenden sozialen und kulturellen Grenzen überwindendes Internet einzusetzen und für Minderjährige angemessene Internet- und Online-Medien-Dienste anzubieten. Deshalb sollten die Inhalteanbieter mehr rechtliche Verantwortung für illegale Inhalte übernehmen, die in einem weiteren Zusatzprotokoll der Konvention zu Cyber-Verbrechen (Convention on Cybercrime) genauer definiert sind. Außerdem sollten sichere und beschränkte Intranets (so genannte "Gated Communities") entwickelt werden. Insgesamt sollten diese Ziele vom Internet Governance Forum (IGF) und vom Europäischen Dialog zur Internet Governance unterstützt werden. 